\title{
Effectiveness of zinc fortified drinking water on zinc intake, status and morbidity of rural Kenyan pre-school children
}

Prosper Kujinga-Chopera 


\section{Thesis committee}

\section{Promotor}

Prof. Dr M.B. Zimmermann

Professor of Micronutrients and International Health, Wageningen University

Professor of Human Nutrition, Swiss Federal Institute of Technology (ETH) Zurich,

Switzerland

\section{Co-promotors}

Dr I.D. Brouwer

Associate professor, Division of Human Nutrition

Wageningen University

Dr D. Moretti

Senior Scientist

Swiss Federal Institute of Technology (ETH) Zurich, Switzerland

\section{Other members}

Prof. Dr E. Kampman, Wageningen University

Dr G. Ferrero, UNESCO-IHE Institute for Water Education, The Hague

Dr S. Osendarp, The Micronutrient Initiative, Ottawa, Canada

Dr J.C.M. Verhoef, Wageningen University/London School of Tropical Hygiene and Medicine

This research was conducted under the auspices of the Graduate School VLAG (Advanced studies in Food Technology, Agrobiotechnology, Nutrition and Health Sciences). 


\title{
Effectiveness of zinc fortified drinking water on zinc intake, status and morbidity of rural Kenyan pre-school children
}

\section{Prosper Kujinga-Chopera}

\author{
Thesis \\ submitted in fulfilment of the requirements for the degree of doctor \\ at Wageningen University \\ by the authority of the Rector Magnificus \\ Prof. Dr A.P.J. Mol, \\ in the presence of the
}

Thesis Committee appointed by the Academic Board

to be defended in public

on Tuesday 17 May 2016

at 4 p.m. in the Aula. 
Prosper Kujinga-Chopera

Effectiveness of zinc fortified drinking water on zinc intake, status and morbidity of rural Kenyan pre-school children,

138 pages.

PhD thesis, Wageningen University, Wageningen, NL (2016)

With references, with summary in English

ISBN 978-94-6257-757-2 
To the memory of my father (Mr Kudakwashe Kujinga), my mother (Sithembile Sibanda-Kujinga) and sister (Norma Kujinga). 


\section{ABSTRACT}

Background: Zinc deficiency is considered a significant public health problem in preschool children in Africa together with infections such as diarrhea, which further deplete the body of zinc. Young children are more vulnerable to zinc deficiency due to increased requirements and frequent infections. Zinc fortified water is one way of improving zinc intake and reducing diarrheal infections in such vulnerable groups. Vestergaard Frandsen has developed a point-ofuse device capable of purifying and concomitantly fortifying water with zinc at concentration ranges of $\approx 1-4 \mathrm{mg} / \mathrm{L}$. This filter is meant for households in areas of poor socioeconomic status with limited access to improved water sources. The overall aim of this thesis is to assess the contribution that zinc fortified water can make to zinc intake and bioavailability in children aged 2-6 years old from rural Western Kenya.

Methods: The investigations in this thesis comprise a cross sectional and effectiveness study conducted in rural Western Kenya and a stable isotope study conducted in Switzerland. Firstly we assessed the baseline prevalence of zinc, iron and vitamin A deficiency in 461 children aged between 2-6 years in rural Western Kenya in a cross sectional study. We conducted a stable isotope study in Swiss adults to determine bioavailability of zinc from zinc fortified water produced by a household water purification and fortification device - the Lifestraw Family filter (LSF filter). Furthermore we conducted laboratory trials to investigate effect of usage pattern and idle time on zinc elution levels. Next we investigated the effectiveness of daily consumption of zinc fortified water on zinc intake, zinc status and morbidity in rural Kenyan children 2-6 years old $(n=184)$. Lastly we used dietary intake data of the children involved in the effectiveness trial to develop food based recommendations that should accompany the introduction of zinc fortified water to ensure overall nutrient adequacy.

Results: The results indicated that zinc and iron deficiency were highly prevalent and affected $74 \%$ and $61 \%$ respectively of the children. Vitamin A deficiency affected $34 \%$ of the children. Inflammation was high in this population and applying published approaches to correct nutrient biomarker for inflammation led to varying estimates of deficiency. Percent decrease in zinc and vitamin A deficiency ranged from 2-19\%, and 43-78\% respectively, with iron deficiency (definition inclusive of soluble transferrin receptor) decreasing by $10 \%$ using exclusion method and increasing by range $0.6-3.6 \%$ by all other approaches. The stable isotope study showed that geometric mean $(-\mathrm{SD},+\mathrm{SD})$ fractional absorption was $65.9 \%(42.2,102.4)$ from fortified water, higher $(\mathrm{p}<0.01)$ than $9.8 \%(5.7,16.7)$ and $9.1 \%(6.0,13.7)$ when either water was fortified and consumed with maize or when maize was fortified and consumed with water, respectively $(p<0.01)$. Zinc elution was higher in filters used to treat $2 \mathrm{~L} /$ day $(4.7 \pm 1.6 \mathrm{mg} / \mathrm{L})$ than $10 \mathrm{~L} / \mathrm{d}(1.7 \pm 0.9)$ and $20 \mathrm{~L} / \mathrm{d}(1.3 \pm 0.7 \mathrm{mg} / \mathrm{L})(\mathrm{p}<0.05)$. Percent increase in zinc eluted after 1 week storage was $23.4 \%(2 \mathrm{~L} / \mathrm{d}), 82.4 \%(10 \mathrm{~L} / \mathrm{d})$ and $43.1 \%(20 \mathrm{~L} / \mathrm{d})$. After the second week of storage, zinc elution further increased by $56.9 \%(2 \mathrm{~L} / \mathrm{d}), 12.9 \%(10 \mathrm{~L} / \mathrm{d})$ and $7.5 \%(20 \mathrm{~L} / \mathrm{d})$, compared to previous week of continuous usage. Daily consumption of zinc fortified water at the rate $\approx 461 \mathrm{ml} / \mathrm{d}$ per child, contributed $42 \%$ and $36 \%$ of daily requirements for absorbable zinc in children 2-3 and 4-6 years respectively. Zinc fortified water decreased overall morbidity (RR=0.91; 95\%CI: $0.87,0.96)$, morbidity due to colds (RR=0.91; 95\%CI: 0.83, 0.99 ) and stomach pain ( $\mathrm{RR}=0.70 ; 95 \% \mathrm{CI}:=0.56,0.89)$ and a significant reduction for diarrhea in the per protocol analysis, $(\mathrm{RR}=0.72 ; 95 \% \mathrm{CI}:=0.53,0.96)$. There was no treatment effect on plasma zinc concentration and stunting. The final set of FBRs developed comprised unfortified 
whole grain products (14 serves per week), unfortified fluid or powdered milk ( 7 serves per week), nuts and seeds (4 serves per week), vitamin A rich vegetables ( 7 serves per week), other starchy plants ( 7 serves per week), vitamin $C$ rich vegetables ( 7 serves per week) and small whole fish with bones ( 7 serves per week). These FBRs achieved nutrient adequacy for all nutrients except for vitamin A (25\%RNI) and folate (68\%RNI).

Conclusion: We have shown that in areas at elevated risk of zinc deficiency and with limited access to improved water sources, daily consumption of zinc fortified water contributes substantially to daily zinc intake and is effective in reducing prevalence of common infectious morbidity in children. A single nutrient intervention such as zinc fortified water must be accompanied by food based recommendations in order to fulfill nutrient gaps as these communities often suffer from multi micronutrient deficiencies. In areas with high prevalence of deficiencies, correcting nutritional biomarker for inflammation does not change the conclusion that deficiency levels are of public health relevance. 


\section{TABLE OF CONTENTS}

Chapter 1

1

General introduction

Chapter 2

Assessing micronutrient status in the presence of inflammation: comparing approaches in children aged 2-6 years from rural Western Kenya

Chapter 3

Zinc bioavailability and elution rate from zinc fortified water produced by the Lifestraw® Family Filter

\section{Chapter 4}

Daily consumption of zinc fortified water increases daily zinc intake and improves overall morbidity from common childhood infections in rural Kenyan children: a randomized, controlled effectiveness trial

\section{Chapter 5}

Food-based dietary recommendations combined with zinc fortified drinking water ensure nutrient adequacy among 4-6 year old Kenyan children

Chapter 6

General discussion

Summary

Acknowledgements

About the author

List of publications 


\section{Chapter 1}

General introduction 


\section{INTRODUCTION}

Zinc deficiency is considered a significant public health problem in Africa, and is likely to be highly prevalent particularly among pre-school children in rural areas. These children mainly subsist on cereal based foods low in zinc content and high in inhibitors of zinc absorption. They are also frequently exposed to infections such as diarrhea that is known to deplete the body of zinc [1]. Foods with high amounts of zinc or high in bioavailable zinc are often unavailable and/or unaffordable in such areas. Providing additional dietary zinc to such age groups is difficult because often they cannot consume large enough amounts to supply requirements. Due to high prevalence of zinc deficiency concurrently with high prevalence of diarrhea, approaches to addressing these two issues separately may tend to be ineffective [2]. Measures to control prevalence of diarrhea may be more effective when combined with measures to reduce prevalence of zinc deficiency. Introduction of zinc fortified drink water through LSF (Lifestraw Family filter) strategy offers two benefits: purifying drinking water and secondly improving zinc intake and status, however direct evidence on the public health potential of this approach is lacking [2].

To assess this, we conducted a cross sectional study to assess prevalence of zinc deficiency; an elution and bioavailability study to assess the potential of this method to deliver safe, adequate amounts of bioavailable zinc; and an effectiveness trial. The trial assessed the extent to which daily consumption of zinc fortified water in households contributed to dietary zinc intake and subsequently to zinc status and morbidity of preschool children living in diarrhea endemic parts of rural western Kenya. Lastly we developed food based recommendations to accompany this single nutrient intervention for overall nutrient adequacy.

\section{BACKGROUND}

\section{Zinc, metabolism and function in the human body}

Zinc is an essential trace element highly necessary in all bodily systems. In its physiological state it almost always exists in the divalent form $\left(\mathrm{Zn}^{2+}\right)$ and does not participate in redox reactions. The biochemical role of zinc in the body can be divided into: catalytic, structural and regulatory roles [3]. In its catalytic and structural role zinc acts as a cofactor on metallo-enzyme active sites, either participating in biochemical reactions, or stabilising the tertiary structure of the enzyme [4]. Removal of the zinc ion from metallo-enzymes leads to loss of enzymatic activity. An example is carbonic anhydrase, responsible for catalysing the reversible reaction between $\mathrm{CO}_{2}$ and bicarbonate ions to enable transport of $\mathrm{CO}_{2}$ from tissues to the lungs for exhalation [5]. A classic example where zinc performs purely a structural role is in the zinc finger motifs [6]. Zinc fingers play roles in cell adhesion, DNA transcription, cellular differentiation and proliferation [6]. In its regulatory function, zinc is responsible for stimulating transacting factors responsible for regulating gene expression. As a result of its numerous biologic functions, a deficiency state will affect a number of biochemical pathways thus disrupting multiple functions in the body [7]. Infants, pre-schoolers, pregnant and lactating women are considered high risk groups for zinc deficiency due to their higher requirements to support growth and development of new tissues. 
The human body has a zinc content of approximately 1.5-2.5g [7]. Males have higher average zinc content than females due to higher tissue concentrations. Most (>95\%) of the zinc in the body is located intracellularly. It is present in all organs, tissues, fluids and secretions, and serum zinc represents only about $0.1 \%$ of total body zinc. When a meal containing zinc is ingested, absorption of free zinc ions begins in the small intestine primarily the distal duodenum and proximal jejunum [8,9]. There is no consensus as to which anatomical region in the gastro intestinal tract (GIT) is responsible for most of the absorption, however studies have shown that most absorption occurs between the mid distal duodenum and proximal jejunum [8]. The efficiency of zinc absorption depends on many factors including the deficiency state of the individual, the amount of zinc consumed, and the presence of inhibitors in food such as phytates $[10,11]$. Active transport of zinc is thought to dominate at low or normal intake whilst zinc is passively transported at high intakes [8]. Twenty four distinct zinc transporters have been identified with various roles in the body [12]. The first class is the Zinc Transporter Protein (ZIP) family of transporters responsible for increasing intracellular zinc levels and the second class is the Zinc Transporter (ZnT) family responsible for decreasing intracellular zinc levels. Zinc transporter proteins such as Zinc Transporter Protein 1 (ZnTP-1) are responsible for facilitating the passage of zinc across the basolateral membranes of enterocytes into the portal circulation [12]. From the portal system zinc is carried directly to the liver. In the liver it is taken up rapidly and released into the systemic circulation for delivery to other tissues.

Some zinc is secreted into the intestine from the pancreas after each meal and also from the gall bladder. Intestinal secretions also contain some amount of zinc. The total amount of endogenous zinc secreted exceeds the amount consumed in the diet however most of the zinc is subsequently re-absorbed. This excretion and reabsorption process is essential in regulating total body zinc. Faecal zinc losses composed of endogenous secretions and unabsorbed zinc ranges from $1 \mathrm{mg} / \mathrm{d}$ in zinc restricted diets to greater than $5 \mathrm{mg} / \mathrm{d}$ in zinc rich diets [13]. Faecal excretion of zinc decreases when dietary zinc is decreased or when zinc needs are increased due to growth or lactation [9]. Additionally, urinary zinc losses and losses from skin surface range between $0.5-0.7 \mathrm{mg} / \mathrm{d}$ [14]. Some amount of zinc is also lost through semen $\approx 0.1 \mathrm{mg} / \mathrm{d}$ [7] and menstrual blood 0.1-5mg [15].

Up to 12 plasma proteins bind to zinc in vitro, however two such proteins (albumin $70 \%$ and alpha macroglobulin 20-40\%) contain most of the plasma zinc [16]. Any conditions that alter serum albumin concentration also affect serum zinc levels. Pregnancy, for example, due to hemo dilution causes a decline in serum zinc concentration. Protein energy malnutrition which leads to hypoalbuminemia also causes a decrease in serum zinc concentration. Serum zinc levels rise during fasting due to release from muscle catabolism and the levels decline after meal consumption. Infections, trauma and other stress cause a decline in serum zinc levels [7].

\section{Etiology of zinc deficiency and prevalence}

Inadequate dietary intake appears to be the most important cause for zinc deficiency. Important food sources of zinc are animal source foods such as organ meats or flesh foods. Zinc content is also relatively high in nuts, seeds, legumes and whole grain cereals however these also contain high amounts of phytic acid, a potent inhibitor of zinc absorption $[17,18]$ rendering them poor sources of absorbable zinc. Even though some zinc may be present in water, drinking water itself is usually a poor contributor to zinc intake [19]. Increased requirements such as during 
growth, pregnancy and lactation are important factors in the etiology of zinc deficiency. Disease states that cause malabsorption, excessive loss (diarrhea and vomiting) or impaired utilisation may also lead to zinc deficiency [20].

Exact data on prevalence of zinc deficiency are unavailable mostly due to lack of a specific and sensitive biomarker. Depending on the indicator used and method of calculation, prevalence estimates of zinc deficiency vary globally. Estimates are currently based on proxy indicators such as prevalence of inadequate dietary zinc intake and prevalence of stunting. Zinc deficiency worldwide is estimated to be at $17,3 \%$ based on estimates of absorbable zinc content of national food supplies derived from national food balance sheets of the FAO [21]. Using this method, Sub Saharan Africa is the second highest with an estimated prevalence of $26 \%$ after South Asia (30\%), see Figure 1. Recently some experts have used the EAR cutpoint method on data derived from food balance sheets and food composition tables and using this indicator zinc deficiency is believed to be highest in Africa at 40\% [22].

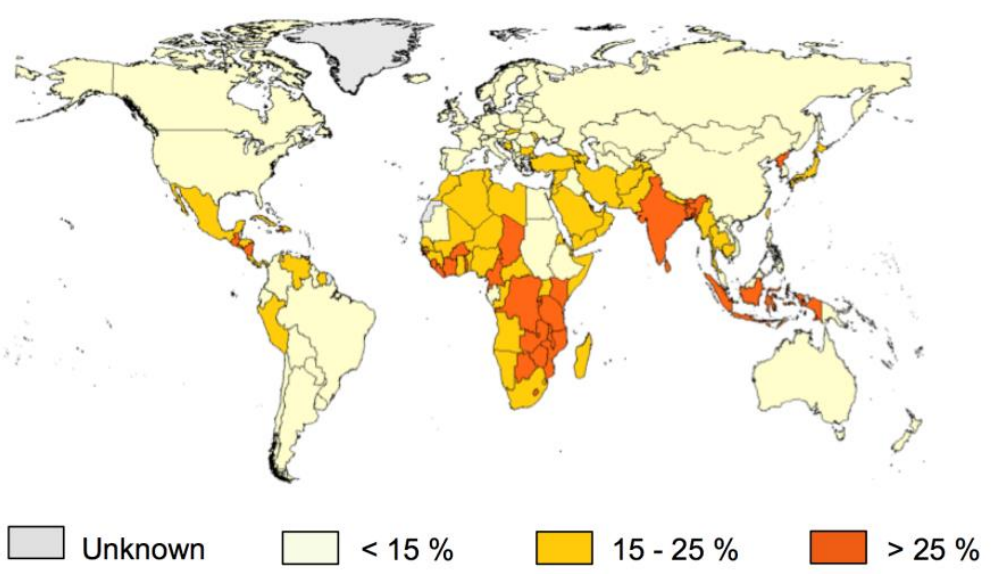

Figure 1: Estimated country-specific prevalence of inadequate dietary zinc availability based on FAO's food balance sheets [21]

\section{Prevalence of infections related to zinc deficiency}

It has been observed that a high prevalence of zinc deficiency and diarrhea are found in conjunction in low socio-economic settings in developing countries [23]. Globally it is estimated that almost two million deaths in under-fives are due to diarrheal disease with about $40 \%$ of these being in Africa [24]. Diarrhea is a symptom characterised by stools of decreased consistency and increased number. The WHO defines diarrhea as the passage of 3 or more liquid or watery stools per day [25]. Diarrhea is not a disease in itself but is often a sign of an infection in the gastro-intestinal system by bacteria, viruses or parasites. In most developing countries diarrhea is more often linked to lack of safe drinking water, good hygiene and poor basic sanitation [26]. A wide variety of bacterial, viral, and protozoan pathogens excreted in the faeces of humans and animals are known to cause diarrhea. Among the most important of these are Escherichia coli, Salmonella sp., Shigella sp., Campylobacter jejuni, Vibrio cholerae, and rotavirus [27]. Many of these diarrhogenic agents are potentially waterborne [27]. Severe diarrhea leads to dehydration and may be life threatening especially to young children. Various methods have been proposed to reduce exposure to diarrhogenic agents and these incorporate safer sanitation techniques that include improved household/personal hygiene and water 
purification techniques [26]. Diarrhea still remains a leading cause of childhood mortality in poor countries [28].

\section{Dietary zinc requirements for children}

Human zinc requirements have been determined by estimating the average physiologic zinc requirements by expert committees composed of the IOM, WHO, IAEA and IZINCG. Physiologic zinc requirements are defined as "the amount of zinc that must be absorbed to offset the amount of endogenous zinc lost from both intestinal and non-intestinal sites"(3). There is no consensus on which requirement levels to use. Table 1 shows the physiological requirements in absorbed zinc, EARs and RDAs for children between the ages of 1-8years as set by WHO and IZINCG.

Table 1: Estimated physiological requirements, EARs and RDAs as set by WHO and revised by IZINCG [7, 29]

\begin{tabular}{|c|c|c|c|c|c|c|c|}
\hline \multicolumn{4}{|l|}{ WHO } & \multicolumn{4}{|l|}{ IZiNCG } \\
\hline $\begin{array}{l}\text { Age } \\
\text { group } \\
\text { (years) }\end{array}$ & $\begin{array}{l}\text { Physiological } \\
\text { requirements } \\
\text { (mg/d) }\end{array}$ & $\begin{array}{l}\text { EAR } \\
(\mathrm{mg} / \mathrm{d})\end{array}$ & $\begin{array}{l}\text { RDA } \\
(\mathrm{mg} / \mathrm{d})\end{array}$ & $\begin{array}{l}\text { Age group } \\
\text { (years) }\end{array}$ & $\begin{array}{l}\text { Physiological } \\
\text { requirements } \\
\text { (mg/d) }\end{array}$ & $\begin{array}{l}\text { EAR } \\
(\mathrm{mg} / \mathrm{d})\end{array}$ & $\begin{array}{l}\text { RDA } \\
(\mathrm{mg} / \mathrm{d})\end{array}$ \\
\hline $1-3$ & 0.83 & 3.0 & 6.9 & $1-3$ & 0.53 & 2.0 & 3.0 \\
\hline $3-6$ & 0.97 & 5.0 & 8.0 & $4-8$ & 0.83 & 4.0 & 5.0 \\
\hline
\end{tabular}

\section{OUTSTANDING ISSUES}

\section{Prevalence of nutrient deficiencies in the presence of inflammation}

Malnutrition is considered to be high in developing countries, with main nutritional deficiencies of public health significance being that of zinc, iron and vitamin A [30,31]. There is also a high prevalence of infectious diseases such as diarrhea, ARI and malaria [32]. The consequence is that individuals in these regions are often malnourished and simultaneously affected by underlying infections [33]. Children particularly present this conundrum because of their vulnerability to deficiency and susceptibility to disease due to their immature immune system. The relationship between infection and malnutrition can therefore be a vicious cycle in such individuals with one exacerbating the other [34]. The immune response itself also causes a rapid redistribution of nutrients which only goes back to normal when infection subsides. Due to this intimate relationship most biomarkers of nutrition are not reliable during infection [35]. However, it is more the direct effect of inflammation on the biomarker itself that makes assessment of nutrition status during inflammation difficult.

One of the recommended indicators to assess individuals at risk of zinc deficiency at population level is plasma (PZn) or serum zinc (SZn) concentration [36]. This indicator is however not very reliable for two reasons: 1) concentrations of plasma zinc are strictly maintained and therefore not sensitive to diet intake changes [18] and 2) in the presence of inflammation concentrations are known to be reduced due to release of calprotectin from damaged neutrophils during inflammation. This is seen as a defense mechanism similar to iron to reduce amount of zinc present for microbial metabolism [37, 38]. 
Zinc is not the only nutrient affected by immune response. Low serum ferritin (SF) concentrations are considered to be sensitive indicators of iron deficiency [39]. However ferritin is also an acute phase protein, and its concentrations rise during the acute phase reaction because it is responsible for iron sequestration [40] masking iron deficiency status. Retinol binding protein (RBP), a biomarker of vitamin A status, has been observed to fall during acute phase reaction due to compartmentalization of vitamin A which is known to negatively regulate natural killer (NK) cell function [41]. These changes hamper the correct estimation of those at risk of deficiency.

To estimate the impact of inflammation on nutritional biomarkers, it is therefore recommended to measure acute phase proteins in nutrition surveys in developing countries [42]. Different approaches have been proposed to correct nutritional biomarker data for the effects of inflammation [33, 43-45]. The correct estimation of individuals at risk of deficiency would be important to assess the need for an intervention, to evaluate success of an intervention and to allow for quality control and accountability in public health programs and initiatives. There is however no consensus on which method to use to correct nutritional biomarker for inflammation and a limited number of studies which compare the different approaches are available $[46,47]$.

\section{Measures to reduce zinc deficiency}

Despite numerous measures available to combat zinc deficiency like fortification, dietary diversity, bio-fortification and supplementation, the risk of deficiency remains high in most poor countries. Fortification, the process of adding nutrients to food vehicles at amounts higher than those normally found in the food, is currently the most desirable and sustainable way for improving zinc intake [29]. The most common food vehicles used to deliver zinc are cereals such as wheat and maize. Though many fortification programmes have been implemented at both targeted and nationwide scale, the efficacy of this approach on child growth still remains unclear [48-50]. A recently published review of 11 trials on effect of zinc fortification on zinc status of pregnant women and children found that zinc fortification was associated with significant improvement in serum zinc status and weak but significant improvement in height velocity in new-borns with very low birthweight in a subgroup analysis. The authors concluded that the overall effectiveness of this approach is limited. A possible reason has been attributed to the fortification vehicles used [51]. As cereal foods contain phytic acid, the zinc absorption inhibition may persist in fortified cereals affecting bioavailability of native and fortificant zinc [52]. A possible alternative would be to fortify vehicles such as water that are devoid of inhibitors.

\section{Water Fortification}

Water's most important function is the maintenance of fluid and electrolyte homeostasis. Even though its potential as a fortification vehicle has not been fully explored, water fortification defined as the act of adding nutrients to drinking water is not a completely new concept. The following nutrients have been added to water in the past and their efficacy and effectiveness tested in the following studies; iodine has been added for the eradication of iodine deficiency disorders [53-55], flouride to prevent dental flourosis [56] and iron to improve iron status in preschool children $[57,58]$. Mineral water fortified with vitamins $\mathrm{B}_{6}, \mathrm{~B}_{12}$, and $\mathrm{D}$ and calcium has been effective in improving folate status and decreasing plasma homocysteine in men and 
women [59]. Water as a vehicle for zinc fortification deserves more research attention due to its numerous advantages such as long shelf life, its stability and high bioavailability of the fortificant due to absence of the food matrix [60].

\section{Lifestraw Family filtering device}

Verstergaard Frandsen S.A. (Lausanne, Switzerland) has developed a point-of-use water treatment system called LifeStraw ${ }^{\circledR}$ Family 1.0 (LSF) intended for daily use in households from low-income settings (Figure 2). The device can filter up to $18^{\prime} 000$ liters, which is estimated to be enough to supply a family of five with microbiologically clean drinking water for up to three years, assuming that per person three liters of water are used daily for drinking. The device is built as a 3-tier water purification system with the following stages (Figure 2); 1) source water is introduced into an upper bucket which has a capacity of $2.5 \mathrm{~L}$ and consisting of a $80 \mu \mathrm{m}$ prefilter for gross particles removal; 2) immediately below the upper bucket is a chamber that contains a chlorine tablet.This tablet releases each time a small amount of chlorine to prevent biofilm forming on the ultrafiltration membranes described below. The water runs down a 1 metre plastic pipe forming enough pressure in 3) the ultrafiltration chamber to force the water through the membranes. This is the final purification step that occurs in the light blue compartment which consists of membranes with a pore size of $20 \mathrm{~nm}$. These membranes have the ability to remove all of remaining solid particles $(<0.5$ NTU turbidity reduction), bacteria ( $>\log 6$ reduction), viruses ( $>\log 4$ reduction) and cysts ( $>\log 3$ reduction) [61]. The device assures a $20 \mathrm{l}$ /hour flow rate which decreases to $10 \mathrm{l} /$ hour towards end of filter life (i.e. approximately three years) (Vestergaard Frandsen, personal communication). Previous laboratory tests have demonstrated that the LSF meets the microbiological performance specifications by United States Environment Protect Agency (US EPA) and WHO [62]. This device treats water in the household right before use and thus falls under the category of pointof-use water treatment systems. Point-of-use water treatment systems can be effective in delivering safe drinking water and therefore preventing waterborne diseases in low-income settings [63] and are recommended by UNICEF as the preferred water treatment method [64].

The Lifestraw family filter with zinc is an adaptation to the Lifestraw Family 1.0 described above (Figure 3). A nutrient chamber containing two soluble zinc based glass plates has been placed adjacent to the ultrafiltration chamber. The zinc support matrix consists of sodiumphosphate glass plate(s) with embedded zinc oxide. The purified water runs through the zinc chamber where zinc is continuously released from two phosphate based glass plates. Filtered water produced contains phosphate, sodium and zinc ions with the following approximate concentrations: Zn 1-5mg/L; P $1.85 \mathrm{mg} / \mathrm{L} ; \mathrm{Na} 0.62 \mathrm{mg} / \mathrm{L}$ (Vestergaard Frandsen, personal communication). Bioavailability of zinc from water fortified using this device has not been described before as well as its performance under varying usage conditions. 


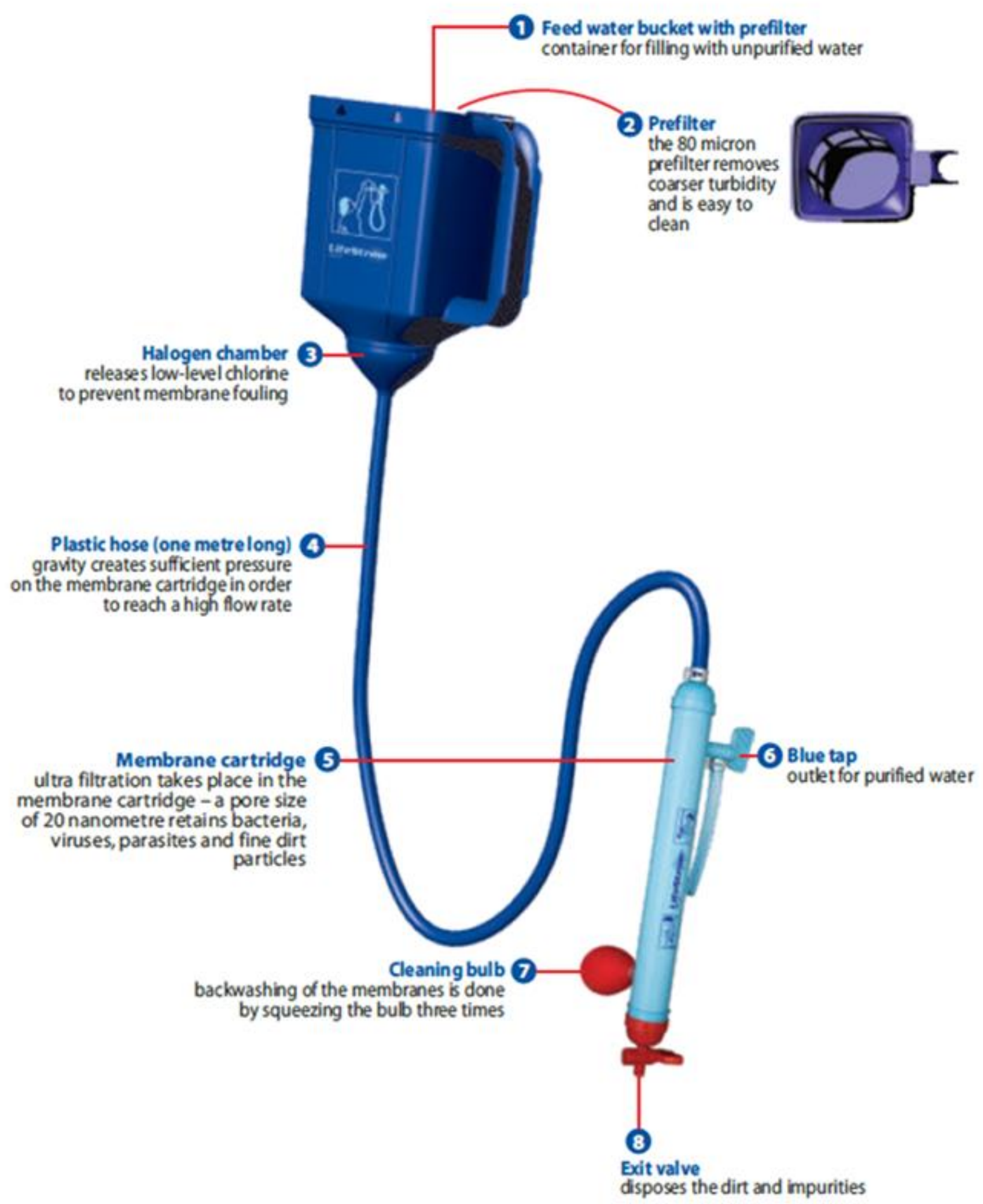

Figure 2: The Lifestraw Family Filter 1.0, a point of use water filter by Vestergaard Frandsen 

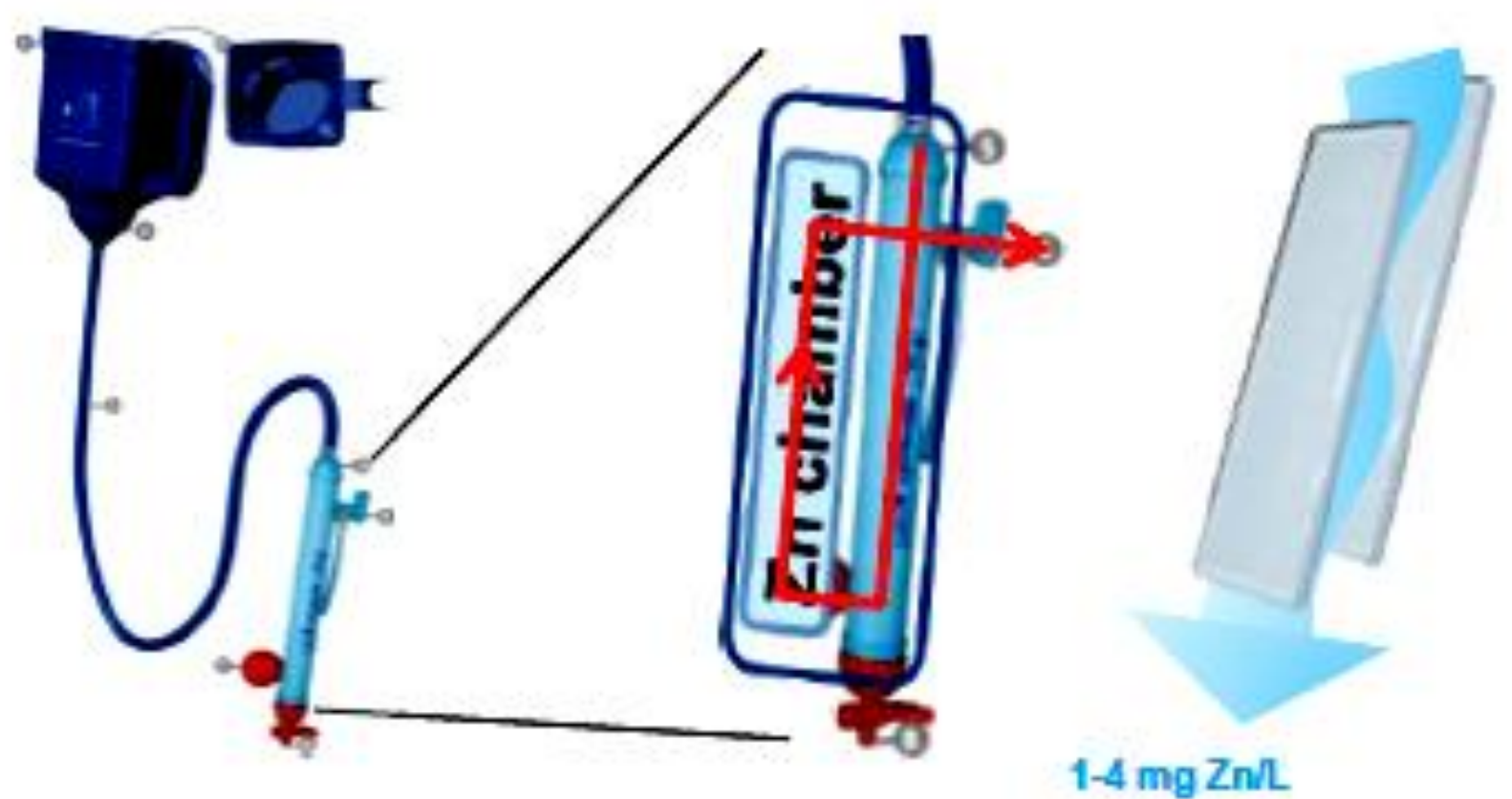

Figure 3: Ultrafiltration and fortification with zinc in one device (Illustration from Galetti et al)[65]

\section{Efficacy of zinc fortified water}

Zinc fortified drinking water may make a significant contribution to dietary zinc intake in areas that subsist on cereal based diets and this may translate to improved zinc status in vulnerable groups. However the effectiveness of this approach in resource poor countries still needs to be confirmed. In a recent efficacy trial investigating the effect of zinc fortified water on zinc status and diarrhea morbidity, a small but significant effect of the zinc fortified water was demonstrated on plasma zinc concentration but no effect on diarrhea prevalence [66]. This was a 20 week duration school based study conducted in rural Benin. It recruited school children between the ages of 6-10 years and the daily dosage of zinc delivered was $2.6-4.6 \mathrm{mg}$ in $300 \mathrm{ml}$ of drinking water. Even though compliance in this controlled study was high at $87 \%$, factors such as a strong seasonal influence and possible presence of tropical enteropathy may have precluded a larger effect on plasma zinc. The trial was however able to demonstrate proof of concept and provided first evidence that zinc fortified water when consumed daily can maintain higher plasma zinc levels compared to non-fortified water. It is not known what contribution daily consumption of zinc fortified water by a free living population would have on dietary zinc intake, and its subsequent effects on zinc status biomarkers and morbidity.

\section{The need for food based recommendations in conjunction with single nutrient intervention}

A single nutrient intervention may need to be accompanied by additional food based recommendations for overall improvement of nutrition status as children from resource poor countries often suffer from multiple micronutrient deficiencies. Linear programming, a mathematical modeling approach, offers the possibility to arrive at the best possible diet whilst taking into consideration constraints such as the energy content of the diet and cost of local 
food [67]. This mathematical modeling approach has been used successfully in analysis such as, designing optimal food based recommendations in young children and adults [68-70] , studying the impact of cost constraint on food choices [71] and assessing economic value when introducing fortified foods and food aid [72-74]. This method offers the advantages that it is an objective approach and as it is based on local foods and current dietary patterns the food based guidelines are likely to be adhered to $[68,75]$. The ability to model the contribution that zinc fortified water together with additional recommendations can make to the diet to ensure overall nutrient adequacy could help to improve the overall effect on micronutrient status when combining the two.

\section{RATIONALE OF STUDY AND OBJECTIVES OF THESIS}

Zinc deficiency is considered a major public health problem in developing countries especially among young children. The high growth rate, intake of weaning foods low in zinc and high in inhibitors as well as frequent diarrheal infections makes this group very vulnerable to zinc deficiency. Prolonged deficiency ultimately may lead to stunting, which later in life causes reduced physical work capacity and impacts on economic development. Efforts to reduce or prevent diarrhea (clean water, improved hygiene) and improve zinc intake may be cost effective to reduce the zinc deficiency burden. Fortification of clean drinking water with zinc may be a possible option to improve zinc intake and status among vulnerable groups whilst also protecting these groups from diarrheal infections. The Lifestraw Family filter is a device capable of purifying drinking water and concomitantly fortifying the water with zinc (approx. 1-4mg/L). This device is meant for use in low socioeconomic areas using drinking water from unimproved sources. The efficacy of this intervention has been shown before; however the effectiveness of this intervention has not been proven.

The evaluation of such an intervention and similar ones is dependent upon accurate determination of prevalence of nutrient deficiency. This is usually hampered by the fact that most micronutrient biomarkers are affected by inflammation. Various approaches have been proposed in literature to correct for inflammation and these will be compared in this thesis. In order to instruct the participants on how to use the device at household level for optimum zinc delivery, it is necessary to conduct elution trials under varying conditions of use. Finally as intervention with zinc fortified water constitutes a single nutrient intervention, it is important to develop dietary recommendations to accompany the introduction of zinc fortified water to achieve overall nutrient adequacy. 


\section{AIM AND OUTLINE OF THIS THESIS}

The overall aim of this research is to assess the contribution that zinc fortified water can make to zinc intake and bioavailability in children aged 2-6 years old from rural Kenya. To achieve this aim, the following objectives were formulated:

Primary objective

1. To assess effectiveness of a household water filtration device capable of purifying and fortifying water with zinc (Lifestraw Family filter) in increasing zinc intake and subsequent status and morbidity in children aged 2-6 years from rural Western Kenya

Secondary objectives are:

1. To compare approaches for assessing prevalence of micronutrient deficiency in the presence of inflammation in children aged 2-6 years from rural Western Kenya

2. To assess bioavailability of zinc from zinc enriched Lifestraw Family filter water, as well as effect of volume filtered and idle time on zinc elution from the device.

3. To determine food-based dietary recommendations that should accompany the introduction of daily consumption of zinc fortified drinking water in children between 4 and 6 years old to optimize nutrient adequacy.

\section{OUTLINE OF THESIS}

This thesis is based on a baseline cross sectional study, a bioavailability study and an effectiveness trial (Figure 4).

Chapter 2 which is based on a cross sectional study conducted in 2011 and 2014 describes the prevalence of zinc and other nutrient deficiencies in pre-school children in the study area and compares approaches that have been proposed in literature to control for the effect of inflammation on nutrition status biomarkers. A water ultra-purification device capable of fortifying water with zinc is evaluated in an isotope study described in chapter $\mathbf{3}$ to determine its potential to deliver bioavailable zinc. In a laboratory based trial, the effect of different usage patterns and storage on zinc elution from this device is also investigated. Chapter $\mathbf{4}$ is based on the effectiveness trial to determine whether purified water with low dose zinc fortification can effectively improve zinc intake and subsequently status and morbidity in pre-school children. Dietary intake data from children in the effectiveness study was used in chapter $\mathbf{5}$ to propose food based recommendations that should accompany the introduction of zinc fortified water to fulfill nutrient adequacy. Firstly we assess the extent to which daily inclusion of zinc fortified water in their dietary patterns can theoretically improve fulfillment of the zinc intake gap, and then we assess the extent to which different combinations of local foods can be used to improve the overall nutrient adequacy of the diets of these young children. Finally chapter 6 discusses the main findings of this thesis, internal and external validity, public health implications as well as direction for future research. 


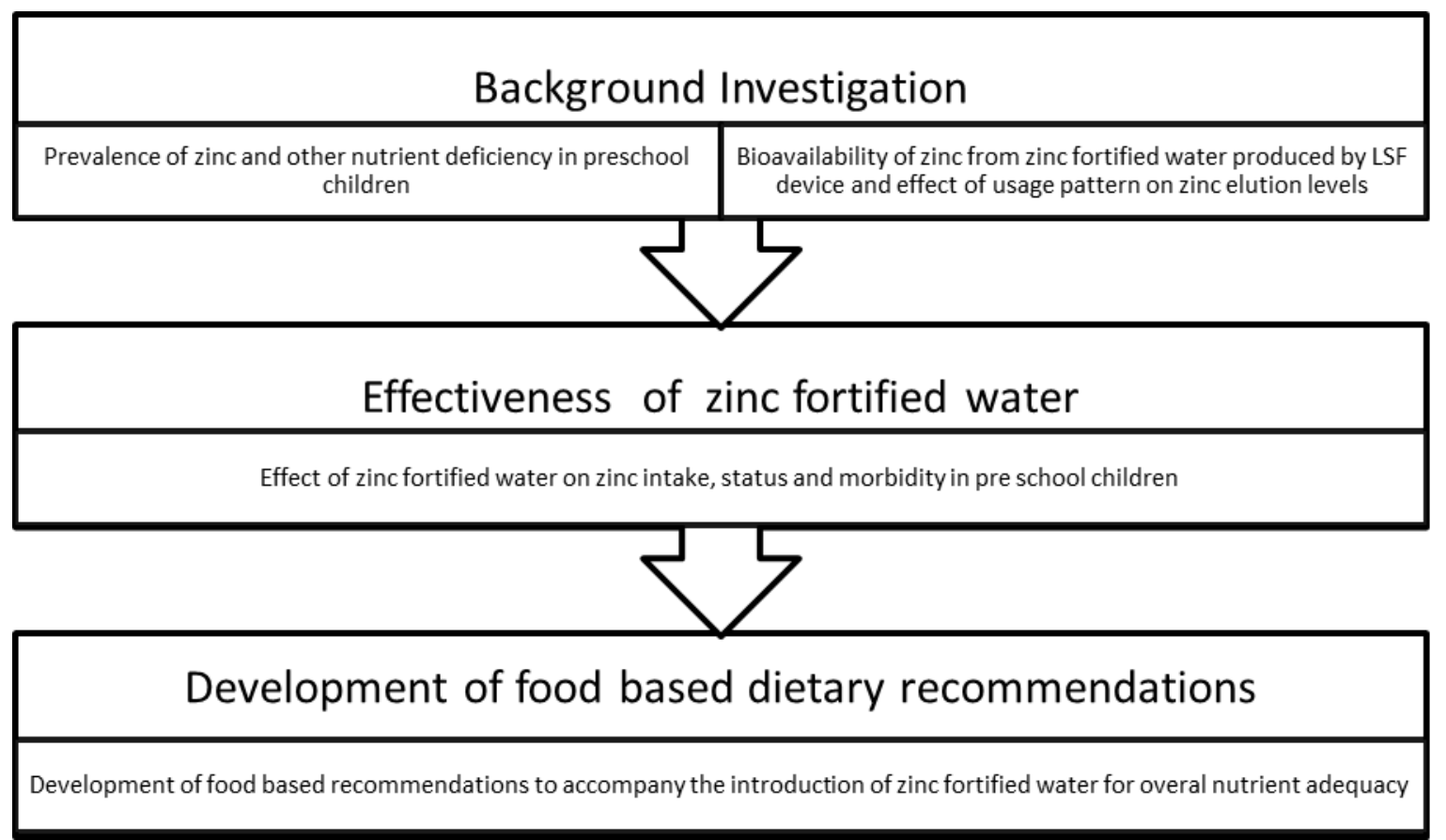

Figure 4: Framework of the temporary linkages in studying the contribution that zinc fortified water makes to zinc intake and status of preschool children.

\section{STUDY SITE SELECTION}

We selected the study area based on the following criteria: expected high prevalence of low serum zinc status in preschool children, high rates of contaminated surface water usage for domestic purposes and high prevalence of diarrhea in under five year olds. Based on these selection criteria we conducted our study in Western Kenya, rural Kisumu (Figure 5). Western Kenya has a tropical climate which is warm and humid throughout the year, with 2 rainy seasons, the long rains from March to May and the short rains from October to December. The study area Kajulu Koker consists of 15 villages which lie along the shores of Lake Victoria and about $25 \mathrm{Km}$ from Kisumu city. This rural population lacks access to many basic healthcare services and poverty is high. The study population relies on water from Lake Victoria or rain water for domestic purposes, with main economic activities being small scale farming and fishing restricted to parts bordering Lake Victoria. The bioavailability study in chapter 3 was conducted at The Clinical Trials Center (CTC) of the University Hospital of Zurich, Switzerland largely because adequate resources were not available in the research area for such a study and establishing them during the time frame was beyond the capacity of the project. 


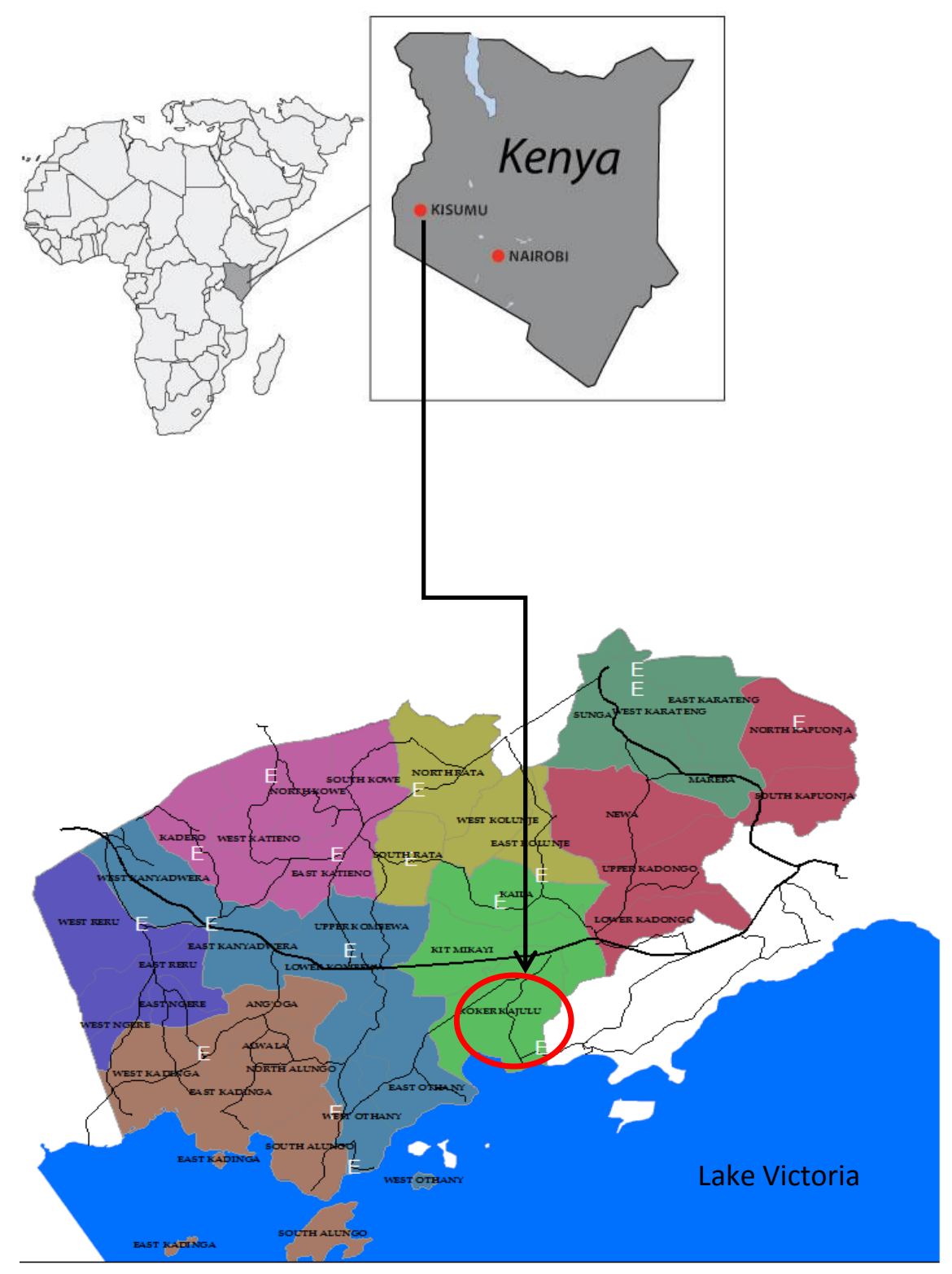

Figure 5. Map of Kenya showing Kisumu and the study site (rural Kisumu) encircled in red 


\section{REFERENCES}

1. Hambidge KM: Zinc and diarrhoea. Acta Paediatr Suppl 1992, 381:82-86.

2. Young GP, Mortimer EK, Gopalsamy GL, Alpers DH, Binder HJ, Manary MJ, Ramakrishna BS, Brown IL, Brewer TG: Zinc deficiency in children with environmental enteropathydevelopment of new strategies: report from an expert workshop. Am J Clin Nutr 2014, 100:1198-1207.

3. Dibley MJ: Present Knowledge in Nutrition 8th Edition. Washington: ILSI Press; 2001.

4. McCall KA, Huang C, Fierke CA: Function and Mechanism of Zinc Metalloenzymes. J Nutr 2000, 130 (5 ):1437S-1446S.

5. Berg JM, Tymoczko JL, Stryer L: Making a Fast Reaction Faster: Carbonic Anhydrases. 2002.

6. Cousins RJ, McMahon RJ: Integrative aspects of zinc transporters. J Nutr 2000, 130(5S Suppl):1384S-7S.

7. Brown KH, Rivera JA, Bhutta Z, Gibson RS, King JC, Lonnerdal B, Ruel MT, Sandtrom B, Wasantwisut E, Hotz C: International Zinc Nutrition Consultative Group (IZiNCG) technical document \#1. Assessment of the risk of zinc deficiency in populations and options for its control. Food Nutr Bull 2004, 25(1 Suppl 2):S99-203.

8. Lee H, Prasad AS, Brewer GJ, Owyang C: Zinc absorption in the small intestine. Am J Physiol 1989, 256:G87-91.

9. Krebs NF: Overview of zinc absorption and excretion in the human gastrointestinal tract. J Nutr 2000, 130(5S Suppl):1374S-7S.

10. Lonnerdal B: Dietary Factors Influencing Zinc Absorption. J Nutr 2000, 130:1378S-1383.

11. Sandström B, Lönnerdal B: Promoters and Antagonists of Zinc Absorption. Devon, UK: Springer-Verlag; 1989.

12. Huang L, Tepaamorndech S: The SLC30 family of zinc transporters - a review of current understanding of their biological and pathophysiological roles. Mol Aspects Med 2013, 34:548-60.

13. IOM, FNB: Dietary Reference Intakes for Vitamin A, Vitamin K, Arsenic, Boron, Chromium, Copper, Iodine, Iron, Manganese, Molybdenum, Nickel, Silicon, Vanadium, and Zinc. 2nd edition. Washington D C, USA: National Academy Press; 2001.

14. King J, Turnlund J: Human Zinc Requirements. In Zinc in Human Biology SE - 21. Edited by Mills C. Springer London; 1989:335-350. [ILSI Human Nutrition Reviews]

15. Hess FM, King JC, Margen S: Zinc excretion in young women on low zinc intakes and oral contraceptive agents. J Nutr 1977, 107:1610-20.

16. Chesters JK, Will M: Zinc transport proteins in plasma. Br J Nutr 1981, 46:111-118. 
17. Lonnerdal B: Dietary Factors Influencing Zinc Absorption. J Nutr 2000, 130:1378S-1383.

18. Hambidge KM, Miller L V, Westcott JE, Sheng X, Krebs NF: Zinc bioavailability and homeostasis. Am J Clin Nutr 2010, 91:1478S-1483S.

19. Deveau M: Contribution of drinking water to dietary requirements of essential metals. J Toxicol Environ Health A 2010, 73:235-41.

20. Gibson R: Zinc deficiency and human health: etiology, health consequences, and future solutions. Plant Soil 2012, 361:291-299.

21. Wessels RK, Singh MG, Brown KH: Estimating the Global Prevalence of Inadequate Zinc Intake from national Food Balance Sheets: Effects of Methodological Assumptions. PLoS One 2012.

22. Joy EJM, Ander EL, Young SD, Black CR, Watts MJ, Chilimba ADC, Chilima B, Siyame EWP, Kalimbira AA, Hurst R, Fairweather-Tait SJ, Stein AJ, Gibson RS, White PJ, Broadley MR: Dietary mineral supplies in Africa. Physiol Plant 2014, 151:208-229.

23. Haider BA, Bhutta ZA: The effect of therapeutic zinc supplementation among young children with selected infections: a review of the evidence. Food Nutr Bull 2009, 30(1 Suppl):S41-59.

24. Boschi-Pinto C, Velebit L, Shibuya K: WHO | Estimating child mortality due to diarrhoea in developing countries. .

25. WHO/UNICEF: Joint Statement on Clinical Management of Acute Diarrhoea . 2004.

26. Keusch G, Fontaine O, Bhargava A: Diarrheal Diseases. In Disease Control Priorities in Developing Countries 2nd. Edited by Jamison D, Breman J, Measham A. Washington DC: World Bank; 2006.

27. Ashbolt NJ: Microbial contamination of drinking water and disease outcomes in developing regions. Toxicology 2004, 198:229-38.

28. UNICEF/WHO: Diarrhoea: why children are still dying and what can be done. 2009.

29. Allen L, de Benoist B, Dary O, Hurrell RF (Eds): WHO / Guidelines on Food Fortification with Micronutrients. World Health Organization; 2006.

30. Black RE, Allen LH, Bhutta ZA, Caulfield LE, de Onis M, Ezzati M, Mathers C, Rivera J: Maternal and child undernutrition: global and regional exposures and health consequences. Lancet 2008, 371:243-60.

31. Ramakrishnan U: Prevalence of Micronutrient Malnutrition Worldwide. Nutr Rev 2002, 60:S46-S52.

32. Jamison DT, Breman JG, Measham AR, Alleyne G, Claeson M, Evans DB, Jha P, Mills A, Musgrove P: Disease Control Priorities in Developing Countries. 2006.

33. Thurnham DI, Mburu ASW, Mwaniki DL, Wagt A De: Micronutrients in childhood and the influence of subclinical inflammation. Proc Nutr Soc 2005, 64:502-509. 
34. Katona P, Katona-Apte J: The Interaction between Nutrition and Infection. Clin Infect Dis 2008, 46 (10):1582-1588.

35. Thurnham DI: Inflammation and Biomarkers of Nutrition. Sight Life Mag 2015, 2:51-57.

36. Gibson RS, Hess SY, Hotz C, Brown KH: Indicators of zinc status at the population level: a review of the evidence. BrJ Nutr 2008, 99(Supplement S3):S14-S23.

37. Isaksen B, Fagerhol MK: Calprotectin inhibits matrix metalloproteinases by sequestration of zinc. Mol Pathol 2001, 54 (5 ):289-292.

38. Haraguchi Y, Sakurai H, Hussain S, Anner BM, Hoshino H: Inhibition of HIV-1 infection by zinc group metal compounds. Antiviral Res 1999, 43:123-133.

39. WHO/CDC: Assessing the Iron Status of Populations: A Report of a Joint World Health Organisation/Centers for Disease Control and Prevention Technical Consultation on the Assessment of Iron Status at the Population Level. Geneva; 2005.

40. Drakesmith H, Prentice AM: Hepcidin and the iron-infection axis. Science 2012, 338:76872.

41. Austenaa LM, Carlsen H, Hollung K, Blomhoff HK, Blomhoff R: Retinoic acid dampens LPSinduced NF-kappaB activity: results from human monoblasts and in vivo imaging of NFkappaB reporter mice. J Nutr Biochem 2009, 20:726-34.

42. WHO/CDC: Assessing the Iron Status of Populations. Geneva, Switzerland; 2007.

43. Mburu ASW, Thurnham DI, Mwaniki DL, Muniu EM, Alumasa F, de Wagt A: The Influence and Benefits of Controlling for Inflammation on Plasma Ferritin and Hemoglobin Responses following a Multi-Micronutrient Supplement in Apparently Healthy, HIV+ Kenyan Adults. J Nutr 2008, 138 (3 ):613-619.

44. Grant FKE, Suchdev PS, Flores-Ayala R, Cole CR, Ramakrishnan U, Ruth LJ, Martorell R: Correcting for Inflammation Changes Estimates of Iron Deficiency among Rural Kenyan Preschool Children. J Nutr 2012, 142 (1 ):105-111.

45. Thurnham DI, McCabe LD, Haldar S, Wieringa FT, Northrop-Clewes CA, McCabe GP: Adjusting plasma ferritin concentrations to remove the effects of subclinical inflammation in the assessment of iron deficiency: a meta-analysis. Am J Clin Nutr 2010, 92:546-55.

46. Larson L, Addo OY, Sandalinas F, Baawo K, Faigao K, Kupka R, Flores-Ayala R, Suchdev P: Accounting for the Influence of Inflammation on Retinol Binding Protein in a Population Survey of Liberian Preschool-Aged Children. FASEB J 2015, 29 (1 Supplement ).

47. Raiten DJ, Ashour FAS, Ross AC, Meydani SN, Dawson HD, Stephensen CB, Brabin BJ, Suchdev PS, van Ommen B: Inflammation and Nutritional Science for Programs/Policies and Interpretation of Research Evidence (INSPIRE). J Nutr 2015, 145:1039S-108S.

48. Gibson RS: Zinc: the missing link in combating micronutrient malnutrition in developing countries. Proc Nutr Soc 2006, 65:51-60. 
49. Abrams SA, Mushi A, Hilmers DC, Griffin IJ, Davila P, Allen L: A multinutrient-fortified beverage enhances the nutritional status of children in Botswana. J Nutr 2003, 133:18341840 .

50. Ash DM, Tatala SR, Frongillo EAJ, Ndossi GD, Latham MC: Randomized efficacy trial of a micronutrient-fortified beverage in primary school children in Tanzania. Am J Clin Nutr 2003, 77:891-898.

51. Das J, Kumar R, Bhutta Z, Salam R: Systematic Review of Zinc Fortification Trials. Ann Nutr Metab 2013, 62(suppl 1):44-56.

52. Brown K, Hambidge M, Ranum P, Zinc Fortification working group: Zinc fortification of cereal flours: Current recommendations and research needs. Food Nutr Bull 2010, 31(1 (Supplement)).

53. Maberly GF, Eastman CJ, Corcoran JM: Effect of iodination of a village water-supply on goitre size and thyroid function. Lancet 1981, 318:1270-1272.

54. Elnagar B, Eltom M, Karlsson FA, Bourdoux PP, Gebre-Medhin M: Control of Iodine Deficiency Using Iodination of Water in a Goitre Endemic Area. 2009.

55. Lim K, Siti Rohana D, Zawiah A, Wan Nazaimoon W: An evaluation of the effectiveness of water iodinator system to supply iodine to selected schools in Terengganu, Malaysia. Trop Biomed 2006, 23:172-178.

56. McDonagh MS, Whiting PF, Wilson PM, Sutton AJ, Chestnutt I, Cooper J, Misso K, Bradley M, Treasure E, Kleijnen J: Systematic review of water fluoridation. BMJ 2000, 321:855-859.

57. Rocha D, Capanema F, Netto M, de Almeida C, Franceschini S, Lamounier J: Effectiveness of fortification of drinking water with iron and vitamin $C$ in the reduction of anemia and improvement of nutritional status in children attending day-care centers in Belo Horizonte, Brazil. Food Nutr Bull 2011, 32:340-346.

58. Arcanjo F, Amancio O, Braga A, Pinto V: Randomised controlled trial of iron fortified drinking water in pre-school children. J Am Coll Nutr 2013, 29:122-129.

59. Tapola NS, Karvonen HM, Niskanen LK, Sarkkinen ES: Mineral water fortified with folic acid, vitamins B6, B12, D and calcium improves folate status and decreases plasma homocysteine concentration in men and women. Eur J Clin Nutr , 58:376-385.

60. Polaki H, Yarla N: Water as a New Vehicle for Nutrition.J Nutr Food Sci 2014, 4.

61. Clasen T, Naranjo J, Frauchiger D, Gerba C: Laboratory Assessment of a Gravity-Fed Ultrafiltration Water Treatment Device Designed for Household Use in Low-Income Settings. Am J Trop Med Hyg 2009, 80:819-823.

62. USEPA: Guide Standard and Protocol for Testing Microbiological Water Purifiers. Washington DC; 1987.

63. Clasen T, Roberts I, Rabie T, Schmidt W, Cairncross S: Interventions to improve water quality for preventing diarrhoea. Cochrane Database Syst Rev 2006. 
64. UNICEF: Promotion of Household Water Treatment and Safe Storage in UNICEF WASH Programmes. 2008.

65. Galetti V: Combining water treatment and zinc fortification against zinc deficiency and diarrhea in low-income settings. Ph.D. thesis. ETH Zurich; 2014.

66. Galetti V, Kujinga P, Mitchikpè CES, Zeder C, Tay F, Tossou F, Hounhouigan JD, Zimmermann MB, Moretti D: Efficacy of highly bioavailable zinc from fortified water: a randomized controlled trial in rural Beninese children. Am J Clin Nutr 2015, 102:1238-48.

67. Ferguson E, Darmon N, Fahmida U: Formulate and evaluate population-specific complementary feeding recommendations using linear programming. Sight Life Mag 2008:13-18.

68. Briend A, Darmon N, Ferguson E, JG E: Linear programming: a mathematical tool for analyzing and optimizing children's diets during the complementary feeding period. $J$ Pediatr Gastroenterol Nutr 2003, 36:12-22.

69. Ferguson EL, Darmon N, Fahmida U, Fitriyanti S, Harper TB, Premachandra IM: Design of Optimal Food-Based Complementary Feeding Recommendations and Identification of Key “Problem Nutrients” Using Goal Programming. J Nutr 2006, 136:2399-2404.

70. Maillot M, Vieux F, Ferguson EF, Volatier J-L, Amiot MJ, Darmon N: To meet nutrient recommendations, most French adults need to expand their habitual food repertoire. $J$ Nutr 2009, 139:1721-7.

71. Darmon N, Ferguson EL, Briend A: Impact of a cost constraint on nutritionally adequate food choices for French women: an analysis by linear programming. $J$ Nutr Educ Behav 2006, 38:82-90.

72. Briend A, Ferguson E, Darmon N: Local food price analysis by linear programming: A new approach to assess the economic value of fortified food supplements. Food Nutr Bull 2001, 22:184-189.

73. Rambeloson Z, Darmon N, EL F: Linear programming can help identify practical solutions to improve the nutritional quality of food aid. Public Heal Nutr 2008, 11:395-404.

74. Frega R, Lanfranco J, De Greve S, Bernardini S, Geniez P, Grede N, Bloem M, de Pee S: What linear programming contributes: world food programme experience with the "cost of the diet" tool. Food Nutr Bull 2012, 33(3 Suppl):S228-34.

75. Ferguson EL, Darmon N, Briend A, Premachandra IM: Food-Based Dietary Guidelines Can Be Developed and Tested Using Linear Programming Analysis. J Nutr 2004, 134:951-957. 


\section{Chapter 2}

Assessing micronutrient status in the presence of inflammation: comparing approaches in children aged 2-6 years from rural Western Kenya

Prosper Kujinga, Valeria Galetti, Elizabeth Opiyo Anyango, Pauline Andang'o, Peter Sifuna, Inge

D. Brouwer, Michael B. Zimmerman and Diego Moretti 


\section{ABSTRACT}

Introduction: Malnutrition and Inflammation are highly and concurrently prevalent in preschool children in rural Western Kenya, making estimation of those at risk of deficiency difficult. Different approaches have been proposed to correct nutritional biomarker data for the effects of inflammation.

Objectives: (1) to assess the impact on population prevalence estimates of zinc, iron and vitamin A deficiencies of different recently proposed approaches to correct for inflammation and (2) to investigate the determinants of zinc, iron and vitamin A status in children 2-6 years old living in rural Western Kenya.

Methods: Iron deficiency was defined as plasma ferritin concentration $<12 \mu \mathrm{g} / \mathrm{L}$ and/or soluble transferrin receptor concentration > 8.3mg; zinc deficiency as plasma zinc less than 65 and 57 $\mu \mathrm{g} / \mathrm{dl}$ (collection morning and afternoon, respectively) and vitamin A deficiency as retinol binding protein levels $>0.75 \mu \mathrm{mol} / \mathrm{l}$. Inflammation was defined as C-reactive protein $>5 \mathrm{mg} / \mathrm{l}$ and alpha 1 acid glycoprotein $>1 \mathrm{~g} / \mathrm{l}$. Five approaches to correct nutritional biomarkers for inflammation were compared (a) ignoring inflammation, therefore assessing nutritional deficiency prevalence without taking into account acute phase proteins, (b) exclusion of inflamed individuals from the survey, (c) change of nutrient biomarker cut off values for those with and without elevated APP, (d) four level inflammation correction factors and (e) regression modelling. Linear regression was used to assess determinants of zinc, iron and vitamin A status.

Results: Zinc deficiency prevalence was 74\%, vitamin A deficiency, 34\% and iron deficiency $61 \%$. Acute phase proteins were elevated in $53 \%$ and $37 \%$ of the children (AGP and CRP respectively). Prevalence estimates varied for all nutrient biomarkers depending on approach used to correct for inflammation: percent decrease range for zinc and vitamin A deficiency was $2 \%-19 \%$ and $43-78 \%$ respectively. Iron deficiency prevalence increased by range $0.6-3.6 \%$ by all other approaches except exclusion where it decreased by $10 \%$. Fasting status, household size, alpha 1 acid glycoprotein, hemoglobin, and retinol binding protein concentration were significant predictors of PZn status. The age of child, C-reactive protein and alpha 1 acid glycoprotein concentration were significant predictors for plasma ferritin levels. Whilst plasma zinc, hemoglobin and $\mathrm{C}$ reactive protein concentrations were significant predictors of retinol binding protein levels.

Conclusions: Zinc, iron and vitamin A deficiencies as well as inflammation were high in the Kenyan preschool children assessed. Regardless of the approach used in this population, for high prevalences above global thresholds there was no substantial difference in Fe and $\mathrm{Zn}$ deficiency prevalence hence correction is not required in such instances to determine the public health relevance of a nutritional deficiency problem. 


\section{INTRODUCTION}

Micronutrient deficiencies, especially zinc, iron and vitamin A deficiency, are major public health concerns in developing countries affected by inadequate dietary intake, frequent infections or both [1]. Whilst a deficiency state deprives the body of important nutrients required to mount an effective immune response, infections may cause nutritional deficiency through mechanisms such as reduced appetite, malabsorption, metabolic losses and increased requirements $[2,3]$. The relationship between infection and nutrition has therefore been described before as an intimate one [4] and that between infection and malnutrition as a "vicious cycle"[5].

The assessment of nutritional status is complicated by the fact that many biochemical markers of nutrition status are not reliable during infection [5], leading to an apparent increase or decrease in the estimated prevalence of nutrient deficiencies. The estimation of those at risk of deficiency is important for many reasons namely, assessing the need for an intervention, targeting of resources, investigating the etiology of a nutritional problem, evaluation of success [6], and to allow quality control and accountability in public health programs and initiatives. Plasma zinc (PZn), and retinol binding protein (RBP), are known to decrease during inflammation while plasma ferritin (PF), increases. This may lead to masking true deficiency status, resulting in a possible overestimation of zinc and vitamin A deficiency and to an underestimation of iron deficiency, respectively.

For this reason, the measurement of acute phase proteins (APP) in nutrition surveys has been recommended in communities where nutritional deficiencies and infections and inflammation coexist [6,7]. Different approaches to correct nutrition status biomarkers for inflammation have been proposed [6,8-11] and a recent comprehensive review on the complex interrelation between nutrition and infection and inflammation [6] has identified five main approaches to account for the effect of inflammation on markers of nutritional status: (a) ignoring inflammation, therefore assessing nutritional deficiency prevalence without taking into account APP, (b) exclusion of inflamed individuals from the survey, (c) change of nutrient biomarker cut off values for those with and without elevated APP, (d) four level inflammation correction factors (CFs) and (e) regression modelling [6]. While the choice for any of the approaches above may be context specific, there is no consensus on the best approach to account for inflammation in prevalence studies [6].

In a cross sectional study of preschool children living in rural Western Kenya, we aimed to: (1) compare prevalence estimates of zinc, iron and vitamin A deficiencies corrected for infection/inflammation using various recently proposed approaches [6] and (2) investigate the determinants of zinc, iron and vitamin A status.

\section{METHODS}

Cross-sectional biochemical and anthropometric data were collected in September 2011 and February 2014 in rural Western Kenya, Kisumu West District from children between the ages of 2-6 years. The research site and subjects were chosen based on eligibility for conducting an 
effectiveness study with a water purification device that fortifies water with zinc in communities with coexisting zinc deficiency and high prevalence of diarrhea.

Data was used from 2 data bases, a baseline conducted in 2011 and one conducted in 2014. The methodology was the same in both studies. In total 487 children were recruited from rural western Kisumu through a household demographic and health surveillance system (HDSS) established by United States Army Medical Research Unit-Kenya (USAMRU-K) and the Kenya Medical Research Institute (KEMRI) [12]. Trained field assistants collected socio economic status data through household visits, using pretested questionnaires in the local language Luo.

Height and weight were measured in duplicate with the child wearing light clothing and no shoes. Standing height was measured to the nearest $0.1 \mathrm{~cm}$ using a UNICEF wooden measuring board with a sliding foot or head piece. Weight was measured to the nearest $0.1 \mathrm{~kg}$ using an electronic scale (Ashton Meyers, England, United Kingdom), which was calibrated daily. Blood samples were collected between 0800 and 1300 from fasting and non-fasting subjects and handled according to standardized protocols by IZINCG [13]. Hemoglobin (Hb) was analyzed in the field on the spot using a Hemocue photometer (Hemocue HB 201, Angelholm, Sweden). We analyzed PZn by flame atomic absorption spectrometry (FAAS) (AA240FS, Varian Inc., Australia) at the Laboratory of Human Nutrition, ETH Zurich, Switzerland. Plasma ferritin (PF), soluble transferrin receptor (sTfR), alpha-1-acid glycoprotein (AGP), C-reactive protein (CRP), and retinol binding protein (RBP) were analyzed at a private laboratory in Freiburg, Germany, with previously published sandwich ELISA technique [14]. All samples were measured in duplicate. For evaluating the prevalence of zinc deficiency among the study population, two cutoffs were used: PZn $<65 \mu \mathrm{g} / \mathrm{dl}$ for blood samples collected during the morning, and PZn $<57$ $\mu \mathrm{g} / \mathrm{dl}$ for the afternoon samples [15]. The thresholds for defining abnormal values for biochemical indicators assessed were as follows: CRP $>5 \mathrm{mg} / \mathrm{L}$ and AGP $>1.0 \mathrm{~g} / \mathrm{L}$ for presence of inflammation, PF $<12 \mu \mathrm{g} / \mathrm{L}$ for low iron stores, sTfR $>8.3 \mathrm{mg} / \mathrm{L}$ for iron deficiency, and RBP $<0.75 \mu \mathrm{mol} / \mathrm{L}$ for vitamin A deficiency [11]. Anemia was defined according to the WHO threshold as $\mathrm{Hb}<110 \mathrm{~g} / \mathrm{L}$ for children $0.5-4.99$ years and $\mathrm{Hb}<115 \mathrm{~g} / \mathrm{L}$ for children $>5 y e a r s$ [16].

The study protocols were approved by the Ethical Review Committees of Kenyatta National Hospital/Nairobi University (KNH-ERC/A/197, and KNH-ERC/A/335), Wageningen University Ethical Committee (WUR 10/20) and ETH Zurich Ethical review committee (EK 2010-N-34, and EK 2013-N-31). The study was presented to local leaders and they gave their approval for its conduction. Written informed consent was obtained from the caregivers on behalf of their children before the study commenced. These trials were registered at www.clinicaltrials.gov; NCT01481181 and NCT02162238.

\section{Data Analysis}

Body iron stores (BIS) in $\mathrm{mg} / \mathrm{kg}$ body weight were calculated using the Cook method [17]. Prevalence of children below respective cutoff for each nutritional status biomarker (PZn, PF, and RBP) were computed using the 5 methods as follows:

(a) Ignoring inflammation: uncorrected prevalence were computed using the following cutoffs; PZn $<65 \mu \mathrm{g} / \mathrm{dl}$ for blood samples collected during the morning, and PZn $<57$ 
$\mu \mathrm{g} / \mathrm{dl}$ for the afternoon samples; PF $<12 \mu \mathrm{g} / \mathrm{L}$ for low iron stores or (inclusive) serum transferrin receptor $>8.3 \mathrm{mg} / \mathrm{l}$; RBP $<0.75 \mu \mathrm{mol} / \mathrm{L}$ for vitamin A deficiency.

(b) Exclusion: prevalence based on individuals without elevated APP was computed (reference group)

(c) Change of nutrient biomarker cutoff: a higher cutoff for inflamed individuals only is applied. For PF a higher cutoff of $30 \mu \mathrm{g} / \mathrm{dl}$ has been proposed. This has not been suggested for PZn and RBP.

(d) Four level inflammation correction factor approach: data was corrected using the Thurnham adjustment method [10] based on

(i) study specific CFs, according to whether participants belong to reference group (plasma CRP concentration was $\leq 5 \mathrm{mg} / \mathrm{L}$ and/or plasma AGP was $\leq 1.0 \mathrm{~g} / \mathrm{l}$ ), to the CRP elevated group (infection incubation), to both CRP and AGP elevated (early convalescence from infection) or to AGP elevated only group (late convalescence) respectively.

(ii) CFs from literature when available.

CFs were determined as ratios of mean or median concentration of biomarker in inflamed group relative to the reference group. To obtain corrected biomarker concentration we multiplied individual values by group specific CF's.

(e) Regression modelling: to correct by regression, specific regression models were computed to assess the effect of inflammation on the markers, with the outcome variable being the respective biomarker and the predictor variable being CRP for the group with raised CRP, CRP and AGP for the group with both raised APP and AGP for the group with elevated AGP only. To calculate the corrected biomarker, the slope was used in each case for example corrected PZn for CRP raised only group =PZn-(CRP $\mathrm{x}$ slope).

We analysed data using IBM SPSS software (version 22.0). Normality of distributions was tested visually using QQ plots. Non normal data was log transformed when necessary. Statistical significance was set at $\mathrm{p}<0.05$. ANOVA followed by posthoc Bonferroni or Kruskal Wallis was used to compare mean or median values across subgroups grouped by inflammation status. The percent change in prevalence was calculated as $(A-B / A) * 100$ whereby $A$ is prevalence before correcting and B is prevalence after correcting.

To assess a linear relationship between nutritional status indicators, anthropometry and APPs we used Spearmen correlation coefficients with uncorrected biomarkers. A backward stepwise regression analysis was used to achieve the best fit model as determined by $\mathrm{R}^{2}$. 


\section{RESULTS}

\section{General characteristics}

In total 487 children were recruited (September 2011, n=303; February 2014, n=184 children). Data on APP was available for 461 children. The median $\left[25^{\text {th }}, 75^{\text {th }}\right.$ percentile] age of the children was $48[36,56]$ months and $48 \%$ were males. Stunting prevalence was $22 \%$, and $11 \%$ of the children were underweight. The mean value for PZn was $58 \pm 12 \mu \mathrm{g} / \mathrm{dl}$ and the median $\left[25^{\text {th }}, 75^{\text {th }}\right.$ percentile] for iron status indicators was as follows; $\mathrm{Hb}=107 \mathrm{~g} / \mathrm{L}[96,116], \mathrm{PF}=55.9$ $\mu \mathrm{g} / \mathrm{L}[24,102] ; \mathrm{sTfR}=9.1 \mathrm{mg} / \mathrm{L}[7.2,13]$ and BIS= $4.9 \mathrm{mg} / \mathrm{kg}[2,7]$. A high proportion were zinc deficient (74.4\% had low uncorrected PZn status), 10.2\% and 15\% had low iron PF and BIS, $61 \%$ high transferrin receptor and $62.6 \%$ had anemia. Over a third of the children (34\%) had a low vitamin A status. Thirty-seven percent of the children had more than 1 deficiency. A high proportion of the children had elevated CRP (37\%) and AGP concentrations (53\%) indicating a high degree of infection/inflammation within this study population (Table 1).

\section{Effect of inflammation on nutritional biomarkers}

When individuals were grouped according to APP status, PZn concentration was below the cutoff $(65 \mu \mathrm{g} / \mathrm{dl})$ in all the groups even in the group without inflammation. RBP concentrations were above the cutoff $0.75 \mu \mathrm{mol} / \mathrm{l}$ in all groups except for high CRP and high AGP $(0.7 \mu \mathrm{mol} / \mathrm{l})$. Plasma ferritin was higher than $12 \mu \mathrm{g} / \mathrm{l}$ in all the groups particularly in the early convalescence group (with both CRP and AGP elevated). Generally, there was a significant difference in biomarker concentration between groups of participants grouped by APP status for all biomarkers $(\mathrm{p}<0.001)$ (Table 2). Biomarker concentration did not differ substantially between reference and incubation group for all biomarkers except for RBP. When both APPs were raised, the concentration of PF was significantly higher, and PZn and RBP significantly lower compared to reference group. When only AGP was raised, PZn remained significantly lower and PF remained significantly higher compared to reference group. However, RBP concentration was the same in this stage of inflammation as in the reference group. 
Table 1: Anthropometry and biochemical characteristics of children 2-6 years old from rural Western Kenya $(\mathrm{n}=461)^{1,2}$

\begin{tabular}{|c|c|}
\hline Characteristic & \\
\hline Age (months)* & $48[36,56]$ \\
\hline Males \%(n) & $48(220)$ \\
\hline HAZ & $-0.9 \pm 1.7$ \\
\hline Less than -2SD, \% & 22.5 \\
\hline WAZ & $-0.6 \pm 1.1$ \\
\hline Less than $-2 \mathrm{SD}, \%$ & 10.9 \\
\hline BAZ & $-0.2 \pm 0.9$ \\
\hline Less than $-2 \mathrm{SD}, \%$ & 2.5 \\
\hline $\mathrm{PZn} \mu \mathrm{g} / \mathrm{dl}$ & $58 \pm 12$ \\
\hline Zinc deficient $3 \%$ & 74.4 \\
\hline Hemoglobin concentration $\mathrm{g} / \mathrm{L}$ & $107[96,116]$ \\
\hline Anemia ${ }^{4} \%$ & 62.6 \\
\hline Ferritin,ug/L & $55.9[24,102]$ \\
\hline Low ferritin $5 \%$ & 10.2 \\
\hline Transferrin receptor mg/L & $9.1[7.2,13]$ \\
\hline Iron deficient $5 \%$ & 61 \\
\hline Body iron stores $\mathrm{mg} / \mathrm{kg}$ & $4.9[2,7]$ \\
\hline Low BIS $\%$ & 15 \\
\hline Retinol binding protein $\mu \mathrm{mol} / \mathrm{L}$ & $0.8[0.6,1]$ \\
\hline Vitamin A deficient $6 \%$ & 34 \\
\hline CRPmg/L & $2.4[0.7,13]$ \\
\hline High CRP7 \% & 37 \\
\hline AGPg/L & $1.0[0.7,1.5]$ \\
\hline High AGP7 \% & 53 \\
\hline
\end{tabular}

${ }^{1}$ Values are mean \pm SD and median $\left[25^{\text {th }}, 75^{\text {th }}\right.$ percentiles $]$ unless stated otherwise

*Age determined for $\mathrm{n}=449$ children

${ }^{2} \mathrm{n}=461$ except for HAZ and WAZ where $\mathrm{n}=432$ and BAZ $\mathrm{n}=433$

${ }^{3}$ values less than 65 and $57 \mu \mathrm{g} / \mathrm{dl}$ were considered low for samples collected in the morning and afternoon respectively

${ }^{4} \mathrm{Anaemia}$ is defined as $\mathrm{Hb}<110 \mathrm{~g} / \mathrm{L}$ for children below the age of 59 months and $\mathrm{Hb}<115 \mathrm{~g} / \mathrm{L}$ for children $5-11$ years

${ }^{5}$ For iron status indicators the following cutoffs were used: less than $12 \mathrm{ug} / \mathrm{l}$ was considered low for ferritin, $>8.3 \mathrm{mg} / \mathrm{l}$ low for transferrin receptor, and $<0 \mathrm{mg} / \mathrm{kg}$ low for body iron stores

${ }^{6}$ Values less than 0.75umol/l were considered vitamin A deficient

${ }^{7}$ Children with serum $\mathrm{C}$ reactive protein $>5 \mathrm{mg} / \mathrm{L}$ and $\mathrm{AGP}>1 \mathrm{~g} / \mathrm{l}$ were considered inflamed

HAZ-height for age z scores, WAZ-weight for age z scores, BAZ-BMI for age z scores, CRP-C reactive protein, AGP-alpha 1 acid glycoprotein, BIS Body iron stores 
Table 2: Concentration of biomarker by inflammation status in children 2-6 years old from rural Western Kenya $(\mathrm{n}=461)^{1}$

\begin{tabular}{|c|c|c|c|c|c|}
\hline \multirow[t]{2}{*}{ Biomarker } & Non inflamed & $\begin{array}{l}\text { High CRP } \\
\text { (Incubation) }\end{array}$ & $\begin{array}{l}\text { High CRP and High } \\
\text { AGP } \\
\text { (Early }\end{array}$ & $\begin{array}{l}\text { High AGP } \\
\text { (Late } \\
\text { convalescence) }\end{array}$ & \\
\hline & $n=199$ & $n=20$ & $\mathrm{n}=150$ & $\mathrm{n}=92$ & $\mathrm{p}$-value \\
\hline PZn $(\mu \mathrm{g} / \mathrm{dl})$ & $61.2 \pm 11.0^{\mathrm{a}}$ & $61.8 \pm 12.5^{\mathrm{a}, \mathrm{b}}$ & $54.9 \pm 12.6^{b}$ & $55.7 \pm 12.7 \mathrm{~b}$ & $\mathrm{p}<0.001$ \\
\hline $\mathrm{RBP}(\mu \mathrm{mol} / \mathrm{l})$ & $0.9 \pm 0.2^{\mathrm{a}}$ & $0.8 \pm 0.1^{b}$ & $0.7 \pm 0.2^{\mathrm{b}, \mathrm{d}}$ & $0.9 \pm 0.2^{\mathrm{a}}$ & $\mathrm{p}<0.001$ \\
\hline Ferritin $(\mu \mathrm{g} / \mathrm{l})$ & $32[14,54]^{\mathrm{a}}$ & $55[21,91]^{a, c}$ & $105[63,166]^{\mathrm{b}}$ & $60[31,92]^{\mathrm{c}}$ & $\mathrm{p}<0.001$ \\
\hline
\end{tabular}

Prevalence of micronutrient deficiency depending on the correction approach for inflammation The prevalence of micronutrient deficiency differed depending on which method was used to correct for inflammation (Table 3). Correction by all applicable methods in comparison to uncorrected prevalence had the effect of decreasing estimated prevalence of zinc and vitamin $\mathrm{A}$ deficiencies whilst increasing iron deficiency (except for exclusion method) albeit to different degrees.

When ignoring inflammation the prevalence of zinc, iron and vitamin A deficiency was $74.4 \%$, $63.9 \%$ and $36.7 \%$ respectively. Analysis of the reference group resulted in lower prevalence for zinc, iron and vitamin A deficiency of $66.8 \%, 57.3 \%$ and $18.6 \%$ respectively representing a reduction in prevalence of $10 \%, 10 \%$ and $49 \%$ respectively. However, when iron deficiency was defined by PF only, not taking into account elevated sTfR, ignoring inflammation increased prevalence of iron deficiency by $82.3 \%$, resulting in an estimated prevalence of $18.2 \%$.

The study specific four level inflammation CFs for PZn were 0.96, 1.09 and 1.07 for incubation, early and late convalescence respectively. The resulting prevalence of zinc deficiency using study specific CFs was $67.2 \%$, a decrease of $9.7 \%$ from uncorrected prevalence. The prevalence of iron deficiency after correcting using study specific CFs $[0.6,0.3$ and 0.5 for incubation, early and late convalescence respectively) was $65.5 \%$ representing an increase of $2.5 \%$ from the uncorrected prevalence. When using PF only to estimate iron deficiency, prevalence changed by $38.2 \%$ from the uncorrected prevalence. The prevalence of vitamin A deficiency was $21 \%$ after using the following study specific CFs to correct for inflammation $(1.27,1.43$, and 1.09). This represented a $43 \%$ decrease from the uncorrected prevalence.

Meta-analysis CFs were not available for PZn but published CFs [10] resulted in a prevalence of zinc deficiency of $60.1 \%$, a reduction of $19 \%$ from uncorrected prevalence. Meta-analysis CFs for $\mathrm{PF}$ gave a prevalence of iron deficiency of $64.3 \%$, an increase of $0.6 \%$ from uncorrected prevalence. When only PF was used to define iron deficiency there was a $16.6 \%$ increase in iron deficiency prevalence. A higher cutoff has been proposed for PF only. Use of $30 \mu \mathrm{g} / \mathrm{l}$ instead of $12 \mu \mathrm{g} / \mathrm{l}$ for PF on inflamed individuals increased prevalence of iron deficiency to $66.2 \%$ (an increase of 3.6\%) when both PF and sTfR was used to define iron deficiency. When only PF was used, there was a $194.1 \%$ increase in prevalence of iron deficiency. 
The prevalence of zinc, iron and vitamin A deficiency after using regression modelling was $72.9 \%, 65.1 \%$ and $8.0 \%$ respectively representing a decrease of $2 \%$ and $78 \%$ for the zinc and vitamin A deficiency prevalence and an increase of $1.9 \%$ for iron deficiency prevalence. Using PF only, iron deficiency prevalence increased by $54.9 \%$

\section{Determinants for zinc, vitamin A and iron status}

\section{Zinc status}

PZn was negatively correlated with fasting status $(\mathrm{r}=-0.230 ; \mathrm{p}<0.01)$, size of household $(\mathrm{r}=-$ 0.117; $\mathrm{p}<0.05), \mathrm{PF}(\mathrm{r}=-0.115 ; \mathrm{p}<0.05)$, CRP $(\mathrm{r}=-0.214 ; \mathrm{p}<0.01)$, AGP $(\mathrm{r}=-0.287 ; \mathrm{p}<0.01)$ and was positively correlated with $\mathrm{Hb}(\mathrm{r}=0.258 ; \mathrm{p}<0.01)$ and $\mathrm{RBP}(\mathrm{r}=0.299 ; \mathrm{p}<0.01)$ (Table 4). In linear regression analysis with $\mathrm{PZn}$ as dependent variable, fasting status $(\beta=-0.218)$, family size $(\beta=-$ $0.127)$, AGP $(\beta=-0.149)$ were significant negative predictors, whilst $\mathrm{Hb}(\beta=0.115)$ and $\mathrm{RBP}$ $(\beta=0.219)$ were significant positive predictors of plasma zinc $(p<0.05)$. In total these variables explained $19 \%$ of the variability in plasma zinc.

Stunting (HAZ) was positively correlated with size of household ( $\mathrm{r}=0.095 ; \mathrm{p}<0.05)$, age of child $(\mathrm{r}=0.138 ; \mathrm{p}<0.01), \mathrm{Hb}(\mathrm{r}=0.150 ; \mathrm{p}<0.01)$, BIS $(\mathrm{r}=0.107 ; \mathrm{p}<0.05)$ and negatively correlated with serum transferrin receptor $(\mathrm{r}=-0.173 ; \mathrm{p}<0.01)$ and AGP $(\mathrm{r}=-0.140 ; \mathrm{p}<0.01)$ (Table 4). Explanatory power was detected for AGP $(\beta=-0.209)$ and BIS $(\beta=0.187)$ only. The regression model explained $5 \%$ of the variability. 
Table 3: Comparison of effect on prevalence estimates of approaches proposed in literature on data from children aged 2-6 years from rural Western Kenya ${ }^{1,2}$

\begin{tabular}{|c|c|c|c|c|c|c|}
\hline & $\begin{array}{l}\text { Ignore } \\
\text { Inflammation }\end{array}$ & Exclusion & $\begin{array}{l}\text { Four-level } \\
\text { inflammation CFs }\end{array}$ & $\begin{array}{l}\text { Meta analysis } \\
\text { CFs }\end{array}$ & $\begin{array}{l}\text { Change } \\
\text { nutrient } \\
\text { biomarker } \\
\text { cutoff }\end{array}$ & $\begin{array}{l}\text { Regression } \\
\text { modelling }\end{array}$ \\
\hline Mean PZn concentration $(\mu \mathrm{g} / \mathrm{dl})$ & $58.0 \pm 12$ & $61.2 \pm 11$ & $60.3 \pm 12.5$ & $62.0 \pm 13$ & & $58.9 \pm 12$ \\
\hline Low PZn (\%) & 74.4 & 66.8 & 67.2 & $60.1^{3}$ & NA & 72.9 \\
\hline $\begin{array}{l}\text { Magnitude of change in } \\
\text { prevalence PZn (\%) }\end{array}$ & & 10.2 & 9.7 & 19.2 & & 2.0 \\
\hline Median PF concentration $(\mu \mathrm{g} / \mathrm{L})$ & $55.9[24,102]$ & $31.5[14.5,54.5]$ & $31.3[16.1,50.7]$ & $43.0[20.5,71.1]$ & & $45.8[17.8,82.3]$ \\
\hline Iron deficiency (\%) ${ }^{4}$ & 63.9 & 57.3 & 65.5 & $64.3^{5}$ & 66.2 & 65.1 \\
\hline $\begin{array}{l}\text { Magnitude of change in iron } \\
\text { deficiency prevalence (\%) }\end{array}$ & & 10.3 & -2.5 & -0.6 & -3.6 & -1.9 \\
\hline Iron deficiency $(\%)^{6}$ & 10.2 & 18.6 & 16.5 & $11.9^{5}$ & 30 & 15.8 \\
\hline $\begin{array}{l}\text { Magnitude of change in iron } \\
\text { deficiency based on PF only (\%) }\end{array}$ & & 82.3 & 38.2 & 16.6 & 194.1 & 54.9 \\
\hline $\begin{array}{l}\text { Median RBP concentration } \\
(\mu \mathrm{mol} / \mathrm{L})\end{array}$ & $0.8[0.6,1]$ & $0.93[0.77,1.2]$ & $0.93[0.77,1.12]$ & & & $1.3[1.0,5.0]$ \\
\hline $\begin{array}{l}\text { Low RBP }(\%)^{7} \\
\text { Magnitude of change in vitamin A } \\
\text { deficiency prevalence (\%) }\end{array}$ & 36.7 & 18.6 & 21.0 & NA & NA & 8.0 \\
\hline
\end{tabular}

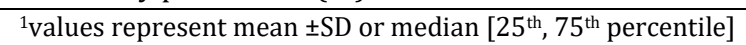

${ }^{2} \mathrm{~N}=461$ expect for exclusion where $\mathrm{n}=199$

${ }^{3}$ Meta analysis CF not available, CFs used refer to Thurnham et al 2005 [10]

${ }^{4}$ as defined by PF concentration $<12 \mu \mathrm{g} / \mathrm{L}$ and/or soluble transferrin receptor concentration $>8.3 \mathrm{mg} / \mathrm{l}$ except in method 4 where a cutoff $\mathrm{PF}<30 \mu \mathrm{g} / \mathrm{l}$ was used

${ }^{5}$ refers to Thurnham et al 2010[11]

${ }^{6}$ as defined by $\mathrm{PF}$ concentration $<12 \mu \mathrm{g} / \mathrm{L}$ except where a higher cutoff $<30 \mu \mathrm{g} / \mathrm{l}$ was used

${ }^{7}$ Values less than $0.75 \mathrm{umol} / \mathrm{l}$ were considered Vitamin A deficient

${ }^{8}$ The slope from the regression model was used in each case to correct; CRP only for group with raised CRP only, CRP and AGP for group with both raised APP and AGP for group with raised AGP only

PZn-plasma zinc, PF, plasma ferritin, RBP-retinol binding protein, NA-not applicable 


\section{Vitamin A status}

RBP was positively correlated with PZn ( $\mathrm{r}=0.299$; $\mathrm{p}<0.01), \mathrm{Hb}(\mathrm{r}=0.302 ; \mathrm{p}<0.01)$, and negatively correlated with PF $(\mathrm{r}=-0.228 ; \mathrm{p}<0.01)$, transferrin receptor $(\mathrm{r}=-0.149 ; \mathrm{p}<0.01)$, BIS $(\mathrm{r}=-0.150$; $\mathrm{p}<0.01)$, CRP $(\mathrm{r}=-0.529 ; \mathrm{p}<0.01)$ and AGP $(\mathrm{r}=-0.420 ; \mathrm{p}<0.01)$ (Table 4). In the regression model PZn $(\beta=0.220)$ and $\mathrm{Hb}(\beta=0.122)$ were significant positive predictors of RBP whilst CRP ( $\beta=-$ 0.335 ) was a significant negative predictor. Together they explained $24 \%$ of the variability in the model.

\section{Iron status}

$\mathrm{Hb}$ was positively correlated with HAZ $(\mathrm{r}=0.150 ; \mathrm{p}<0.01)$, $\mathrm{PZn}(\mathrm{r}=0.258 ; \mathrm{p}<0.01)$, age ( $\mathrm{r}=0.196$; $\mathrm{p}<0.01)$, RBP ( $\mathrm{r}=0.302 ; \mathrm{p}<0.01)$, and negatively correlated with $\mathrm{PF}(\mathrm{r}=-0.185 ; \mathrm{p}<0.01)$, sTfR $(\mathrm{r}=-$ 0.586; $\mathrm{p}<0.01)$, CRP $(\mathrm{r}=-0.415 ; \mathrm{p}<0.01)$ and AGP $(\mathrm{r}=-0.422 ; \mathrm{p}<0.01)$ (Table 4). Significant negative predictors of $\mathrm{Hb}$ in the regression model were $\mathrm{PF}(\beta=-0.108)$, transferrin receptor $(\beta=-$ 0.602 , and AGP $(\beta=-0.107)$. PZn $(\beta=0.112)$ and RBP $(\beta=0.111)$ were positive significant predictors of $\mathrm{Hb}$. In total these variables explained $51 \%$ of the variability in $\mathrm{Hb}$.

Log PF was negatively correlated with PZn $(\mathrm{r}=-0.115 ; \mathrm{p}<0.05)$, age of child $(\mathrm{r}=-0.133 ; \mathrm{p}<0.01)$, $\mathrm{Hb}(\mathrm{r}=-0.185 ; \mathrm{p}<0.01)$, BIS $(\mathrm{r}=-0.912 ; \mathrm{p}<0.01)$, RBP $(\mathrm{r}=-0.228 ; \mathrm{p}<0.01)$ and positively correlated with CRP $(\mathrm{r}=0.556 ; \mathrm{p}<0.01)$ and AGP $(\mathrm{r}=0.541 ; \mathrm{p}<0.01)$. In regression analysis significant positive predictors were age of child $(\beta=0.232)$, CRP $(\beta=0.226)$ and AGP $(\beta=0.368)$. Together they explained $31 \%$ of the variability in PF.

Log sTfR was negatively correlated with HAZ ( $\mathrm{r}=-0.173 ; \mathrm{p}<0.01)$, age of child ( $\mathrm{r}=-0.172 ; \mathrm{p}<0.01)$, $\mathrm{Hb}(\mathrm{r}=-0.586 ; \mathrm{p}<0.01)$ BIS $(\mathrm{r}=-0.343 ; \mathrm{p}<0.01)$, RBP $(\mathrm{r}=-0.149 ; \mathrm{p}<0.01)$ and positively correlated with CRP $(\mathrm{r}=0.191 ; \mathrm{p}<0.01)$ and AGP $(\mathrm{r}=0.290 ; \mathrm{p}<0.05)$. Significant negative predictors in the regression model were $\mathrm{Hb}(\beta=-0.358)$ and AGP was a significant positive predictor $(\beta=0.127)$. These variables explained $18 \%$ of the variability in the model.

\section{DISCUSSION}

Our results show that deficiencies in zinc, iron and vitamin A are high and occur concurrently in a third of the children. Inflammation affects at least half of the population and correcting for inflammation results in prevalence estimates that do not substantially differ from uncorrected prevalence except for vitamin A and depending on the indicator used to define the deficiency. Interventions to reduce zinc, iron and vitamin A deficiency are required in this population.

The prevalence of low serum zinc (74.4\%) and stunting $(22.5 \%)$ was above the $20 \%$ cutoff suggested by IZINCG which are indications of a population at an elevated risk of zinc deficiency [18]. This confirms evidence from previous trials that zinc deficiency is present and of public health concern among Kenyan children particularly from Western Kenya [19-21]. Anemia was high in this population (62\%) and also an almost equally high percentage of the children (63.9\%) suffered from iron deficiency. The prevalence of anemia is comparable with that assessed in similar studies conducted in the same area $[19,22,23]$ confirming that this population suffers from chronic malnutrition, zinc deficiency and anemia. 
Table 4: Spearmen correlation coefficients (Rho) for demographic, nutritional status and inflammation markers of the study children aged 2-6 years old from rural Western Kenya

\begin{tabular}{|c|c|c|c|c|c|c|c|c|c|c|c|c|}
\hline & HAZ & PZn & $\begin{array}{l}\text { fasting } \\
\text { status }\end{array}$ & $\begin{array}{l}\text { family } \\
\text { size }\end{array}$ & $\begin{array}{l}\text { age } \\
\text { (mths) }\end{array}$ & $\mathrm{Hb}$ & $\mathrm{PF}$ & STFR & BIS & RBP & CRP & AGP \\
\hline Gender & 0.000 & 0.014 & 0.03 & -0.088 & -0.066 & -0.007 & -0.017 & 0.057 & -0.034 & 0.002 & -0.05 & 0.038 \\
\hline HAZ & & 0.045 & 0.021 & $.095^{*}$ & $.138^{* *}$ & $.150^{* *}$ & 0.052 & $-.173^{* *}$ & $.107^{*}$ & 0.032 & -0.027 & $-.140^{* *}$ \\
\hline PZn & & & $-.230^{* *}$ & $-.117^{*}$ & 0.055 & $.258^{* *}$ & $-.115^{*}$ & -0.08 & -0.078 & $.299 * *$ & $-.214^{* *}$ & $-.287^{* *}$ \\
\hline fasting status & & & & -0.004 & -0.037 & -0.075 & 0.005 & -0.003 & 0.013 & -0.064 & -0.009 & -0.036 \\
\hline family size & & & & & 0.043 & -0.013 & 0.004 & -0.088 & 0.038 & 0.004 & -0.031 & -0.049 \\
\hline age (mths) & & & & & & $.196^{* *}$ & $.133^{* *}$ & $-.172^{* *}$ & $.195^{* *}$ & 0.01 & -0.013 & $-.168^{* *}$ \\
\hline $\mathrm{Hb}$ & & & & & & & $-.185^{* *}$ & $-.586^{* *}$ & 0.039 & $.302^{* *}$ & $-.415^{* *}$ & $-.422^{* *}$ \\
\hline $\mathrm{PF}$ & & & & & & & & 0.03 & $.912^{* *}$ & $-.228^{* *}$ & $.556^{* *}$ & $.541^{* *}$ \\
\hline sTfR & & & & & & & & & $-.343^{* *}$ & $-.149^{* *}$ & $.191^{* *}$ & $.290 * *$ \\
\hline BIS & & & & & & & & & & $-.150^{* *}$ & $.438^{* *}$ & $.383^{* *}$ \\
\hline RBP & & & & & & & & & & & $-.529 * *$ & $-.420^{* *}$ \\
\hline CRP & & & & & & & & & & & & $.717^{* *}$ \\
\hline
\end{tabular}

${ }^{*}$ Correlation is significant at the 0.05 level

**Correlation is significant at the 0.01 level

HAZ-height for age z scores, PZn-plasma zinc, Hb-hemoglobin, PF-plasma ferritin, sTfR soluble transferrin receptor, BIS-body iron stores, RBP-retinol binding protein, CRP-c reactive protein 
We used CRP and AGP to define acute and chronic phases of the acute phase response and also for purposes of comparing across studies. Over a third and about half of the children had elevated acute and chronic acute-phase markers respectively. Similar proportions were obtained by Grant et al (2012) in their study in Western Kenya [9]. When the data was grouped by inflammation status, the proportion of children in the incubation group was low and this is comparable to other similar studies $[9,10,24]$ although in a study in Indonesian infants, lower proportions were found in the early convalescence group [25]. Lower numbers in the incubation group (high CRP only) is expected as the incubation period is very short as compared to the early and late convalescence phase and few individuals will be in that phase at any given time. The fact that prevalence of elevated AGP, linked to a higher number in the early or late convalescence period indicates that in this population there are repeated inflammation events which occur before full recovery from the previous event.

\section{Zinc deficiency prevalence estimates}

We aimed at comparing the impact on estimated deficiency prevalence of different recently suggested approaches to correct nutritional biomarkers for inflammation. A quantitative insight into the magnitude of change in the prevalence estimates is essential to compare the different approaches for correcting for the effects of inflammation. Inflammation had the effect of decreasing PZn concentration thereby overestimating prevalence of zinc deficiency by between $2-10.2 \%$ when excluding published CF approach as these were from a single study. On a population basis the method of correction did not fundamentally change the nutritional assessment for this population. The observed decrease of PZn with infection has been observed previously, and has been ascribed to the fact that zinc moves from the bone marrow to the liver during the acute phase and this results in a decrease in PZn concentration. This decrease in PZn concentration has been observed in some studies [25-27] but not in a recent study conducted in 6-11 year old children from Guatemala [28]. The latter study was conducted in older apparently healthy children whilst the former studies were conducted in younger children and immune compromised adults. This difference in age and physiological status may have affected the way PZn responded to inflammation leading to a non-response in the 'healthier' older children.

\section{Iron deficiency prevalence estimates}

In our results, PF was elevated in the inflamed groups leading to an underestimation of prevalence of iron deficiency. The magnitude of prevalence increased when using PF only to define iron deficiency ranging from 16.6\% (meta analysis CFs) to 194\% (use of higher biomarker cutoff). When the definition of iron deficiency was inclusive of sTfR, the magnitude of prevalence increase was much lower and ranged from $0.6-3.6 \%$ by all other approaches except exclusion where it decreased by $10 \%$. This almost constant prevalence for iron deficiency is likely due to the fact that STfR is generally less affected by inflammation/infection than PF [29, 30]. $\mathrm{PF}$ is a positive acute phase protein and concentrations rise during the acute phase reaction while it is unclear whether PF plays a role in iron sequestration or is a secondary signal following the infection induced increase in hepcidin [31, 32].

\section{Vitamin A deficiency prevalence estimates}

Consistent with our results, RBP concentrations have been observed to fall during acute phase leading to overestimation of vitamin A deficiency $[33,34]$. The change in prevalence from $36.7 \%$ (ignoring inflammation) to $18.6 \%$ (reference group only) and to $21 \%$ using study specific CFs may indicate that deficiency levels have shifted from 'high' to 'moderate', however in the absence of global cutoffs for RBP [35] the prevalence changes remain difficult to interpret. In 
this case ignoring inflammation misclassifies individuals by between $42.8-78 \%$. We used RBP a surrogate biomarker of vitamin A status known to overestimate vitamin A deficiency in malnourished individuals due to excess unbound RBP in the circulation released from the liver. Serum retinol is the biomarker commonly used to evaluate vitamin A deficiency [36], however it is also known to decrease during inflammation due to reduced hepatic synthesis of RBP and secretion of the retinol-RBP complex [37,38]. Serum retinol as a biomarker of vitamin A status thus too misclassifies individuals during periods of inflammation [39].

\section{Public health and policy impacts of change in prevalence}

In summary, our prevalence estimates differed depending on the approach used for correction. However the magnitude of difference, for iron and zinc deficiency was small and produced a change in estimated prevalence of $10 \%$ for both nutrients. This data suggest that if a survey is conducted with the solely aim of estimating nutritional deficiency prevalence, the choice of the correction methods may not greatly affect the overall estimate of a deficiency. This may have programmatic implication and our data if confirmed in larger studies in other population groups, suggest that assessing the public health importance of a nutritional deficiency is not greatly affected by the approach used. It is however likely that for lower prevalence and in smaller surveys the approach used to correct for inflammation will be critical. In contrast to the findings in minerals, for vitamin A deficiency, prevalence estimates changed from high to moderate to being not judged a problem of public health significance depending on the approach used. From a public health perspective the choice of approach used can therefore have extensive consequences on resource allocation when it comes to programme planning and management.

Concerning for example iron deficiency, for case finding, the consequences would vary greatly depending on the definition used. For the definition inclusive of sTfR which is the recommended definition [40] the approach used to correct for inflammation did not change the prevalence substantially. However when based on PF only there can be extensive misclassification of individuals. There was a high prevalence of seemingly false negatives when ignoring inflammation. Using this latter approach would have a negative bearing on evaluating overall effectiveness of targeted interventions to reduce deficiency.

\section{Rationale for correcting}

Correcting biomarker concentration for inflammation is based on the assumption that diet is the only responsible factor for the concentration of nutrient biomarker, therefore removing the effects of inflammation would imply that what remains is the 'true' concentration of biomarker. This assumption may not be true especially for individuals exposed to chronic inflammation being the cause for the poor nutritional status and not a confounder. There is evidence that in areas where parasitic infections are high and endemic, repeated infections may lead to chronic inflammation [41] with observations that the condition itself often leads to undernutrition and stunted growth in children $[42,43]$. Infections such as HIV, highly prevalent in developing countries can cause metabolic disturbances leading to altered micronutrient levels [44]. Low grade chronic inflammation has been shown to cause poor nutrition status in infants [45]. In such situations correcting for inflammation when inflammation is the cause of malnutrition may not be justified. Distinguishing these scenarios will be dependent on a functioning health care system and local judgement.

To strengthen estimates of deficiency and for more complete assessment it is often advised to combine biomarker concentrations with dietary intake data [18]. In a dietary survey conducted 
in a subsample of the children aged 4-6 years in the same area $(n=60)$ in 2014 (chapter 5), 85\% were below the WHO EAR for zinc intake, $55 \%$ for vitamin A, and $0 \%$ for iron. Those at risk of zinc deficiency were high in this population and this prevalence is consistent with the uncorrected prevalence obtained from PZn. Risk of vitamin A deficiency from dietary intake was also high. However for iron, despite high prevalence of iron deficiency and anemia, no children in this subsample were below the EAR for inadequate iron intake. This may indicate the negative iron balance in this population, highlighted by the high prevalence of iron deficiency and anemia, due to other reason than insufficient intakes. One possible explanation is the low mineral bioavailability from the diet in this population relying mostly on whole maize, cereals with limited intake of iron absorption enhancers. An additional possible etiological factor for the high prevalence is the likely high prevalence of parasitic infections, which are highly prevalent in Western Kenya [46-49]. The dietary survey however was conducted in a small sample and in one season and therefore cannot be fully compared with the results obtained from the biochemical markers in these children. In the case that there is high prevalence below the EAR correlating with low biomarker concentrations, correcting for inflammation may not be required.

\section{Determinants for low plasma zinc, anemia, stunting and vitamin A status}

The regression model predicted $\approx 20 \%$ of the variability in zinc status. Whilst some studies have found an association between PZn and stunting [50, 51], we found no such association and therefore height for age z scores were not included in the modeling. Family size was associated with both PZn as well as with stunting, suggesting that in this population, poverty may be a determinant of low nutritional status in children. $\mathrm{PZn}$ and $\mathrm{Hb}$ were significant positive predictors of RBP. The nutrient-nutrient interactions between zinc, iron and vitamin A have long been established [52]. Conversion of retinol to retinal requires a zinc dependent retinol dehydrogenase enzyme [53], zinc regulates transport of vitamin A through protein synthesis $[54,55]$ and erythropoiesis is known to be modulated by vitamin A [56] hence the metabolism of vitamin $A$ is dependent on adequate supply of zinc and iron and vice versa. The regression model for $\mathrm{Hb}$ had high predictive power (51\%) possibly due to the presence of $\mathrm{PF}$ and transferrin receptor in the model. We decided to maintain these predictors as we did not detect any collinearity in the diagnostics procedure.

In conclusion, the difference in estimated prevalence suggest that inflammation is only marginally affecting the estimated prevalence of nutritional deficiency in this population. In view of the different approaches available for correcting for inflammation and until a consensus is reached, we suggest that with elevated uncorrected prevalence (above the respective threshold), the choice of approach may not be important to decide if a problem is of public health significance or not. At lower prevalence, to correct for inflammation in programme planning and evaluation, we propose the following hierarchy of decision making. First, in cross sectional studies with adequate sample size, prevalence should be estimated from uninflamed population only (exclusion). A second choice would be correction by study specific correction factors as these gave similar prevalence to restrictive analysis. Finally, if the survey has not collected APP status biomarkers then the application of correction factors from meta analysis should be explored if the population and study setting are comparable. More research is required to establish the possibility of using a higher cutoff for other biomarkers in times of inflammation. As different approaches had varying effects on each biomarker there should be consideration for the decision making process to be biomarker specific. 


\section{REFERENCES}

1. Caulfield LE, Richard SA, Rivera JA, Musgrove P, Black RE: Stunting, Wasting, and Micronutrient Deficiency Disorders. In Disease Control Priorities in Developing Countries. 2nd ed. Edited by Jamison D, Breman J, Measham A, Alleyne G, Claeson M, Evans DB, Jha P, Mills A, Musgrove P. Washington (DC): World Bank; 2006.

2. Scrimshaw N, Taylor C, Gordon J: Interactions of Nutrition and Infection. Monograph Series No. 37. Geneva, Switzerland; 1968.

3. Scrimshaw N: Effect of Infection on Nutritional Status. In Proceedings of the National Science Council, ROC. Volume 16; 1992:46-64.

4. Thurnham DI: Inflammation and Biomarkers of Nutrition. Sight Life Mag 2015, 2:51-57.

5. Katona P, Katona-Apte J: The Interaction between Nutrition and Infection. Clin Infect Dis 2008, 46 (10):1582-1588.

6. Raiten DJ, Ashour FAS, Ross AC, Meydani SN, Dawson HD, Stephensen CB, Brabin BJ, Suchdev PS, van Ommen B: Inflammation and Nutritional Science for Programs/Policies and Interpretation of Research Evidence (INSPIRE). J Nutr 2015, 145:1039S-108S.

7. WHO/CDC: Assessing the Iron Status of Populations. Geneva, Switzerland; 2007.

8. Mburu ASW, Thurnham DI, Mwaniki DL, Muniu EM, Alumasa F, de Wagt A: The Influence and Benefits of Controlling for Inflammation on Plasma Ferritin and Hemoglobin Responses following a Multi-Micronutrient Supplement in Apparently Healthy, HIV+ Kenyan Adults. J Nutr 2008, 138 (3 ):613-619.

9. Grant FKE, Suchdev PS, Flores-Ayala R, Cole CR, Ramakrishnan U, Ruth LJ, Martorell R: Correcting for Inflammation Changes Estimates of Iron Deficiency among Rural Kenyan Preschool Children. J Nutr 2012, 142 (1):105-111.

10. Thurnham DI, Mburu ASW, Mwaniki DL, Wagt A De: Micronutrients in childhood and the influence of subclinical inflammation. Proc Nutr Soc 2005, 64:502-509.

11. Thurnham DI, McCabe LD, Haldar S, Wieringa FT, Northrop-Clewes CA, McCabe GP: Adjusting plasma ferritin concentrations to remove the effects of subclinical inflammation in the assessment of iron deficiency: a meta-analysis. Am J Clin Nutr 2010, 92:546-55.

12. Sifuna P, Oyugi M, Ogutu B, Andagalu B, Otieno A, Owira V, Otsyula N, Oyieko J, Cowden J, Otieno L, Otieno W: Health \& Demographic Surveillance System Profile: The Kombewa Health and Demographic Surveillance System (Kombewa HDSS). Int J Epidemiol 2014, 43:1097-1104.

13. IZINCG: Collecting Blood in the Field for Assessment of Plasma Zinc Concentration. Practical Tips. 2012.

14. Erhardt JG, Estes JE, Pfeiffer CM, Biesalski HK, Craft NE: Combined Measurement of Ferritin, Soluble Transferrin Receptor, Retinol Binding Protein, and C-Reactive Protein by an Inexpensive, Sensitive, and Simple Sandwich Enzyme-Linked Immunosorbent Assay Technique. J Nutr 2004, 134 (11):3127-3132.

15. Hotz C, Peerson JM, Brown KH: Suggested lower cutoffs of serum zinc concentrations for assessing zinc status: reanalysis of the second National Health and Nutrition Examination Survey data (1976-1980). Am J Clin Nutr 2003, 78:756-64.

16. McLean E, Cogswell M, Egli I, Wojdyla D, de Benoist B: Worldwide prevalence of anaemia, WHO Vitamin and Mineral Nutrition Information System, 1993-2005. Public Health Nutr 2009, 12:444-54.

17. Cook JD, Flowers CH, Skikne BS: The quantitative assessment of body iron. Blood 2003, 101:3359-3363.

18. Brown KH, Rivera JA, Bhutta Z, Gibson RS, King JC, Lonnerdal B, Ruel MT, Sandtrom B, Wasantwisut E, Hotz C: International Zinc Nutrition Consultative Group (IZiNCG) technical document \#1. Assessment of the risk of zinc deficiency in populations and options for its control. Food Nutr Bull 2004, 25(1 Suppl 2):S99-203.

19. GOK\&UNICEF: Anaemia and the Status of Iron, Vitamin A and Zinc in Kenya. The 1999 Micronutrient Survey Report. Nairobi; 2002. 
20. Feikin DR, Bigogo G, Audi A, Pals SL, Aol G, Mbakaya C, Williamson J, Breiman RF, Larson CP: Village-randomized clinical trial of home distribution of zinc for treatment of childhood diarrhea in rural Western kenya. PLoS One 2014, 9:e94436.

21. Siekmann JH, Allen LH, Bwibo NO, Demment MW, Murphy SP, Neumann CG: Kenyan School Children Have Multiple Micronutrient Deficiencies, but Increased Plasma Vitamin B12 Is the Only Detectable Micronutrient Response to Meat or Milk Supplementation.J Nutr 2003, 133 (11):3972S-3980S.

22. Foote EM, Sullivan KM, Ruth LJ, Oremo J, Sadumah I, Williams TN, Suchdev PS: Determinants of Anemia among Preschool Children in Rural, Western Kenya. Am J Trop Med Hyg 2013, 88 (4 ):757-764.

23. Grant FKE, Martorell R, Flores-Ayala R, Cole CR, Ruth LJ, Ramakrishnan U, Suchdev PS: Comparison of indicators of iron deficiency in Kenyan children. Am J Clin Nutr 2012, 95 (5):1231-1237.

24. Paracha PI, Jamil A, Northrop-Clewes CA, Thurnham DI: Interpretation of vitamin A status in apparently healthy Pakistani children by using markers of subclinical infection. $\mathrm{Am}$ J Clin Nutr 2000, 72 (5):1164-1169.

25. Wieringa FT, Dijkhuizen MA, West CE, Northrop-Clewes CA, Muhilal: Estimation of the Effect of the Acute Phase Response on Indicators of Micronutrient Status in Indonesian Infants. J Nutr 2002, 132 (10):3061-3066.

26. Mburu ASW, Thurnham DI, Mwaniki DL, Muniu EM, Alumasa FM: The influence of inflammation on plasma zinc concentration in apparently healthy, HIV+ Kenyan adults and zinc responses after a multi-micronutrient supplement. Eur J Clin Nutr 2010, 64:510-517.

27. Duggan C, MacLeod WB, Krebs NF, Westcott JL, Fawzi WW, Premji ZG, Mwanakasale V, Simon JL, Yeboah-Antwi K, Hamer DH, Group the ZAPS: Plasma Zinc Concentrations Are Depressed during the Acute Phase Response in Children with Falciparum Malaria. $J$ Nutr 2005, 135 (4):802-807.

28. Bui V, Stein A, DiGirolamo A, Ramakrishnan U, Flores-Ayala R, Ramirez-Zea M, Grant F, Villalpando S, Martorell R: Associations between Serum C-reactive Protein and Serum Zinc, Ferritin, and Copper in Guatemalan School Children. Biol Trace Elem Res 2012, 148:154-160.

29. Beguin Y: Soluble transferrin receptor for the evaluation of erythropoiesis and iron status. Clin Chim Acta 2003, 329:9-22.

30. World Health Organisation, Centers for Disease Control and Prevention: WHO / Assessing the Iron Status of Populations. Geneva, Switzerland: World Health Organization; 2007.

31. Drakesmith H, Prentice AM: Hepcidin and the iron-infection axis. Science 2012, 338:76872.

32. Cohen LA, Gutierrez L, Weiss A, Leichtmann-Bardoogo Y, Zhang D, Crooks DR, Sougrat R, Morgenstern A, Galy B, Hentze MW, Lazaro FJ, Rouault TA, Meyron-Holtz EG: Serum ferritin is derived primarily from macrophages through a nonclassical secretory pathway. Blood 2010, 116:1574-84.

33. Smith FR, Goodman DS, Zaklama MS, Gabr MK, El Maraghy S, Patwardhan VN: Serum vitamin A, retinol-binding protein, and prealbumin concentrations in protein-calorie malnutrition: I. A functional defect in hepatic retinol release . Am J Clin Nutr 1973, 26 (9):973-981.

34. Ramsden DB, Princé HP, Burr WA, Bradwell AR, Black EG, Evans AE, Hoffenberg R: The inter-relationship of thyroid hormones, vitamin $A$ and their binding proteins following acute stress. Clin Endocrinol (Oxf) 1978, 8:109-22.

35. Whitehead R, Perrine C, Mebrahtu S, Dahal P, Subedi GR, Jefferds ME: Defining a vitamin A deficiency cut-off for retinol binding protein in Nepal children 6-23 mo of age. FASEBJ 2015, 29(1 Supplement).

36. Tanumihardjo SA: Vitamin A: biomarkers of nutrition for development. Am J Clin Nutr 2011, $94(2): 658 S-665 S$. 
37. Rosales FJ, Ritter SJ, Zolfaghari R, Smith JE, Ross AC: Effects of acute inflammation on plasma retinol, retinol-binding protein, and its mRNA in the liver and kidneys of vitamin A-sufficient rats. J Lipid Res 1996, 37 (5 ):962-971.

38. Stephensen $C B$, Gildengorin G: Serum retinol, the acute phase response, and the apparent misclassification of vitamin $A$ status in the third National Health and Nutrition Examination Survey. Am J Clin Nutr 2000, 72 (5):1170-1178.

39. Thurnham DI, McCabe GP, Northrop-Clewes CA, Nestel P: Effects of subclinical infection on plasma retinol concentrations and assessment of prevalence of vitamin A deficiency: meta-analysis. Lancet (London, England) 2003, 362:2052-8.

40. WHO/UNICEF/UNU: Iron Deficiency Anemia: Assessment, Prevention and Control. A Guide for Programme Managers. WHO/NHD/01.3. Geneva, Switzerland; 2001.

41. King $\mathrm{CH}$, Dangerfield-Cha M: The unacknowledged impact of chronic schistosomiasis. Chronic Illn 2008, 4 (1):65-79.

42. Friedman JF, Kanzaria HK, Acosta LP, Langdon GC, Manalo DL, Wu H, Olveda RM, McGarvey ST, Kurtis JD: Relationship between Schistosoma japonicum and nutritional status among children and young adults in Leyte, the Philippines. Am J Trop Med Hyg 2005, 72:527-33.

43. Zhou H, Ohtsuka R, He Y, Yuan L, Yamauchi T, Sleigh AC: Impact of parasitic infections and dietary intake on child growth in the schistosomiasis-endemic Dongting Lake Region, China. Am J Trop Med Hyg 2005, 72:534-9.

44. Friis H, Michaelsen KF: Micronutrients and HIV infection: a review. Eur J Clin Nutr 1998, 52:157-63.

45. Prendergast AJ, Rukobo S, Chasekwa B, Mutasa K, Ntozini R, Mbuya MNN, Jones A, Moulton LH, Stoltzfus RJ, Humphrey JH: Stunting is characterized by chronic inflammation in Zimbabwean infants. PLoS One 2014, 9:e86928.

46. Brooker S, Miguel E, Moulin S, Luoba A, Bundy D, Kremer M: Epidemiology of single and multiple species helminth infections among schoolchildren in Busia district, Kenya. East Afr Med J 2000:279-282.

47. WHO: WHO | World Malaria Report 2014. 2014.

48. Brooker S, Akhwale W, Pullan R, Estambale B, Clarke SE, Snow RW, Hotez PJ: Epidemiology of Plasmodium-Helminth Co-Infection in Africa: Populations at Risk, Potential Impact on Anemia, and Prospects for Combining Control. Am J Trop Med Hyg 2007, 77 (6 Suppl ):88-98.

49. Koukounari A, Estambale BBA, Njagi JK, Cundill B, Ajanga A, Crudder C, Otido J, Jukes MCH, Clarke SE, Brooker S: Relationships between anaemia and parasitic infections in Kenyan schoolchildren: a Bayesian hierarchical modelling approach. Int J Parasitol 2008, 38:1663-71.

50. Golden BE, Golden MH: Plasma zinc and the clinical features of malnutrition. Am J Clin Nutr 1979, 32 (12):2490-2494.

51. Galetti V, Mitchikpè CES, Kujinga $P$, Tossou F, Hounhouigan DJ, Zimmermann MB, Moretti D: Rural Beninese Children Are at Risk of Zinc Deficiency According to Stunting Prevalence and Plasma Zinc Concentration but Not Dietary Zinc Intakes. J Nutr 2016 Jan 1;146 (1):114-23.

52. Christian P, West KP: Interactions between zinc and vitamin A: an update. Am J Clin Nutr 1998, 68 (2):435S-441S.

53. Terhune MW, Sandstead HH: Decreased RNA polymerase activity in mammalian zinc deficiency. Science 1972, 177:68-9.

54. Huber AM, Gershoff SN: Effects of zinc deficiency on the oxidation of retinol and ethanol in rats. $J$ Nutr 1975, 105:1486-90.

55. Sundaresan PR, Cope FO, Smith JC: Influence of zinc deficiency on retinal reductase and oxidase activities in rat liver and testes. $J$ Nutr 1977, 107:2189-97.

56. Da Cunha MSB, Siqueira EMA, Trindade LS, Arruda SF: Vitamin A deficiency modulates iron metabolism via ineffective erythropoiesis. J Nutr Biochem 2015, 25:1035-1044. 


\section{Chapter 3}

\section{Zinc bioavailability and elution rate from zinc fortified water produced by the Lifestraw ${ }^{\circledR}$ Family Filter}

Prosper Kujinga, Valeria Galetti, Elizabeth Opiyo Anyango, Diego Moretti, Christophe Zeder, Adam Krzystek, Fabian Tay, Pauline Andang'o, Inge D Brouwer, Michael B. Zimmermann.

Based on: Valeria Galetti, Prosper Kujinga, Comlan Evariste S Mitchikpe', Christophe Zeder, Fabian Tay, Félicien Tossou, Joseph D Hounhouigan, Michael B Zimmermann, and Diego Moretti. Efficacy of highly bioavailable zinc from fortified water: a randomized controlled trial in rural Beninese children, American Journal of Clinical Nutrition 2015 Nov;102(5):1238-48 


\section{ABSTRACT}

Introduction: Zinc deficiency is a major public health problem in many developing countries. Zn fortification of foods may have limited impact because $\mathrm{Zn}$ bioavailability from staple foods is generally low. Fortification of drinking water with a stable, predictable concentration of fortificant at safe but adequate levels may be an alternative approach.

Objectives (a) to compare bioavailability of zinc from fortified water consumed with or without zinc fortified maize in healthy adults (b) to investigate the effect of 3 simulated usage patterns and storage on zinc eluted into purified drinking water and (c) to compare expected enrichment levels with physiological requirements in children aged 1-6 years.

Methods: Fractional Zn absorption (FAZ) was assessed in human subjects using the double isotopic zinc urinary monitoring method. The study had a single blind three way cross over design comparing bioavailability from fortified water consumed with $(\mathrm{M}+\mathrm{FW})$ and without $(\mathrm{FW})$ maize porridge compared to $\mathrm{Zn}$-fortified maize porridge alone $(\mathrm{FM}+\mathrm{W})$. Lifestraw family filters, a point-of-use water ultrafiltration device fitted with zinc glass plates were used to filter daily 2L, 10L and 20L for 6 weeks. The filters were kept idle on week 7 and 9 and the entire trial lasted 10 weeks. Zinc concentration in water was measured daily with a rapid zinc test method. Expected fortification and consumption levels were compared to physiological requirements in children aged 2-6 years.

Results: Geometric mean (-SD, +SD) FAZ was significantly higher from FW $(65.9 \%(42.2,102.4))$ than from M+FW $(9.8 \%(5.7,16.7))$ or from $\mathrm{FM}+\mathrm{W}(9.1 \%(6.0,13.7))(p<0.01)$. Zinc elution was significantly higher in filters used to treat $2 \mathrm{~L} /$ day $(4.7 \pm 1.6 \mathrm{mg} / \mathrm{L})$ than $10 \mathrm{~L} / \mathrm{d}(1.7 \pm 0.9)$ and $20 \mathrm{~L} / \mathrm{d}(1.3 \pm 0.7 \mathrm{mg} / \mathrm{L})(\mathrm{p}<0.05)$. Percent increase in zinc eluted after 1 week storage was $23.4 \%$ $(2 \mathrm{~L} / \mathrm{d}), 82.4 \%(10 \mathrm{~L} / \mathrm{d})$ and $43.1 \%(20 \mathrm{~L} / \mathrm{d})$. After second week of storage zinc elution further increased by $56.9 \%(2 \mathrm{~L} / \mathrm{d}), 12.9 \%(10 \mathrm{~L} / \mathrm{d})$ and $7.5 \%(20 \mathrm{~L} / \mathrm{d})$, compared to the last week of filtering. Fortified water from high and medium usage can provide adequate coverage of physiologic requirements (30-120\%) in children aged between 2-6 years without reaching upper limits.

Conclusions: Zinc fortified water should be consumed away from meals for high bioavailability. Regular filter usage with higher quantities of water leads to decreased, adequate and safe zinc concentrations in drinking water. The device is more resilient to increased zinc elution caused by idle time at high usage patterns. 


\section{INTRODUCTION}

Zinc deficiency is particularly common among young children in developing countries [1] mainly due to high estimated physiological requirements [2], cereal based weaning foods low in zinc [3, 4] and rich in zinc absorption inhibitors such as phytate [5-9]. Provision of zinc through drinking water, could prove useful in the global effort to control zinc deficiency.

Verstergaard Frandsen S.A. (Lausanne, Switzerland) has developed a point-of-use water treatment system called LifeStraw ${ }^{\circledR}$ Family (LSF) intended for daily use in households from lowincome settings. The device is capable of removing solid particles $(<0.5$ NTU turbidity reduction), bacteria ( $>\log 6$ reduction), viruses $(>\log 4$ reduction) and spores $(>\log 3$ reduction)[10] by means of a hollow fibre filtration cartridge. Lower incidence of diarrhea in groups using the LSF filter compared to controls has been reported in a community based field trial [11] and a prospective cohort study [12].

A new configuration of the LSF with soluble zinc based glass plates housed in a post-filtration cartridge can slowly elute zinc into the purified water (Figure 1). The zinc support matrix consists of sodium-phosphate glass plate(s) with embedded zinc oxide. Filtered water produced contains phosphate, sodium and zinc ions with the following approximate concentrations $\mathrm{Zn} 1$ mg/L: P 1.85 mg/L: Na $0.62 \mathrm{mg} / \mathrm{L}$ (personal communication, Daniel Frauchiger, Vestergaard Frandsen). Bioavailability of this novel zinc containing water has never been described.

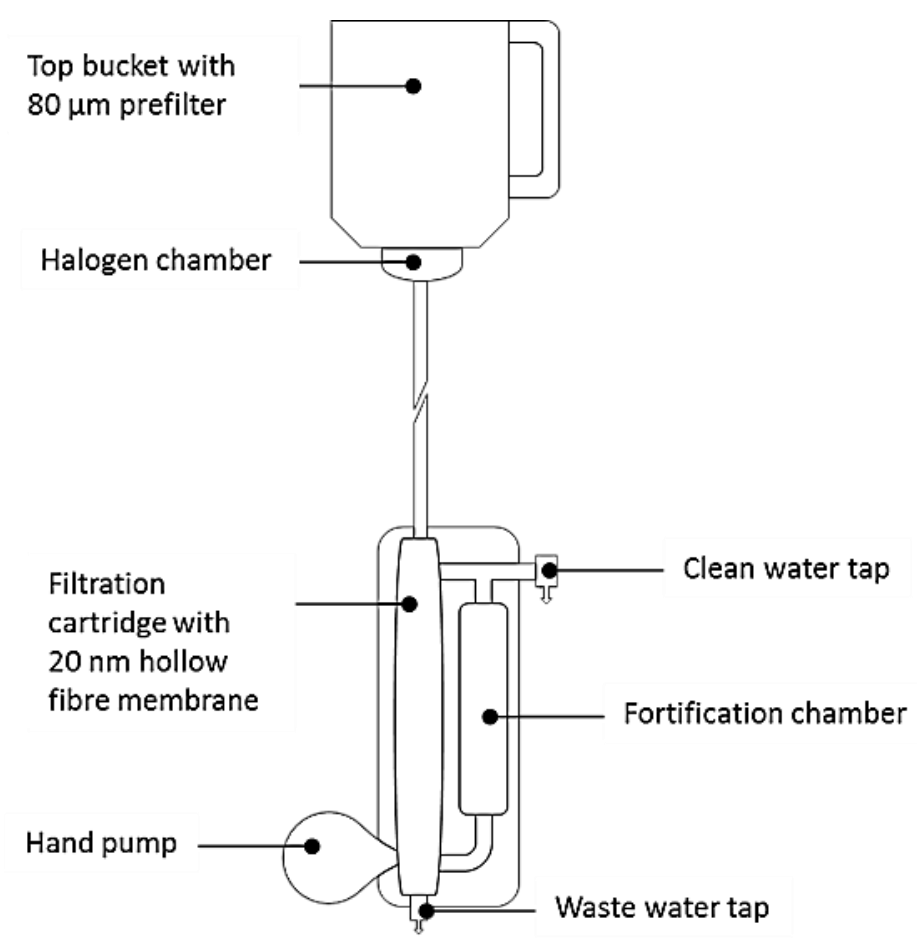

Figure 1: Schematic of LSF filter with integrated Zn fortification cartridge

Bioavailability of zinc from water has been described before in studies investigating different dosages or the effect of a meal $[13,14]$, the influence of iron, tin, copper, and ascorbic acid on zinc absorption [15-17], and comparing absorption of zinc from supplements administered in water [18]. To our knowledge our study is the first that seeks to test bioavailability of zinc added 
by an ultrafiltration device to water using a unique matrix containing phosphorus and sodium. It is also important to know if the final zinc containing water solution results in a bioavailability comparable to that from previous studies.

Furthermore not much is known about the zinc delivery from this new configuration under different usage patterns. Knowledge about the zinc delivery in addition to bioavailability will provide information concerning the potential effectiveness of this novel approach in improving nutrition. Secondly it will provide indirect information about possible compliance and safety. High $\mathrm{Zn}$ concentrations in eluted water would be of great concern because zinc imparts an astringent taste to water at concentrations higher than $\approx 4 \mathrm{mg} / \mathrm{L}$ [19]. IZINCG has set revised tolerable upper intake levels (UL) for zinc intake in children aged between 2-3 and 4-6 years the ULs at 8 and 14mg/d respectively [1]. Higher concentrations may not only be unsafe but may affect compliance and yet maximal compliance would be important in achieving public health impact. It is hence necessary to test this novel strategy targeted towards populations at risk of zinc deficiency in areas with unimproved water sources.

The aims of this study were therefore to: a) measure fractional zinc absorption using stable isotopes from the LSF-fortified water consumed with and without maize porridge and compare it to Zn-fortified maize porridge alone and b) investigate the effect of 3 simulated distinct usage patterns and storage time on zinc enrichment of water by the LSF filter fitted with zinc glass plates and c) to compare expected enrichment levels with physiological requirements in children aged 1-6 years.

\section{MATERIALS AND METHODS}

\section{Zn absorption study}

We performed the Zn absorption study between June and August 2012 at the Clinical Trials Center (CTC) of the University Hospital of Zurich, Switzerland as well as at the laboratory of Human Nutrition, ETH Zürich. We recruited potential subjects from the student and staff population of ETH Zürich; we screened 25 individuals to determine their eligibility for the trial. We assessed medical history and dietary patterns by using a short questionnaire and measured height and weight. We applied the following inclusion criteria: 18 to 45 years of age, body mass index (BMI) 19 to $25 \mathrm{~kg} / \mathrm{m}^{2}$, no mineral or vitamin supplementation for at least two weeks prior to start and during the whole duration of the study, no major chronic diseases or long-term medication (except for oral contraceptives), no vegan diet, non-smokers, not pregnant and not lactating, no participation in any other clinical study within the preceding 30 days, no earlier participation in a study using Zn stable isotopes. We invited 18 subjects to participate in the study; all gave informed written consent. The Cantonal Ethics Commission of the Canton of Zurich approved the research protocol (KEK-ZH-No. 2012-0168). We registered the study at www.clinicaltrials.gov (NCT01636583).

The study was a single-blind, three-way crossover trial to quantify fractional zinc absorption (FAZ) from three Zn-fortified test meals and/or water each containing a total of $2 \mathrm{mg} \mathrm{Zn}$. These were: 1) a Zn-fortified maize porridge consumed with ultrapure water $(18.2 \mathrm{M} \Omega)(\mathrm{FM}+\mathrm{W}) ; 2)$ the same maize porridge but unfortified consumed with Zn-fortified LSF-water (M+FW); and 3) Zn-fortified LSF-water alone (FW). We randomly assigned 18 subjects, each of whom had to consume all three test meals, to one of six possible meal administration sequences. To allow for 
isotope washout, we administered the test meals $>24$ days apart. The evening before the meal administration, subjects consumed no food after $8.00 \mathrm{pm}$ and had no beverages after midnight. Following meal administration, the subjects remained fasted for at least 3 hours. Thereafter, each of the subjects resumed their usual dietary habits until the evening before the next test meal administration. We determined FAZ after oral and intravenous administration of the stable isotopes using the measured isotopic enrichment in urine samples collected before and after the test meal according to the dual isotope tracer ratio (DITR) technique, as previously described [20-22].

We prepared the porridge in bulk by cooking on a stovetop for 30 minutes. To account for water loss during cooking, we added ultrapure water $(18.2 \mathrm{M} \Omega$ ) back to the cooked porridge after cooling to room temperature. Each serving consisted of $5 \mathrm{~g}$ sugar, $170 \mathrm{~g}$ ultrapure water and $50 \mathrm{~g}$ maize flour. We prepared servings of $225 \mathrm{~g}$ wet weight maize porridge in pre-coded plastic bowls that were frozen to $-20^{\circ} \mathrm{C}$ until the evening before feeding day. We designed the three test meals/drinks to each deliver $2 \mathrm{mg}$ total $\mathrm{Zn}$ per serving. $\mathrm{FM}+\mathrm{W}$ meal consisted of a serving of maize porridge containing $0.56 \mathrm{mg}$ native $\mathrm{Zn}, 0.44 \mathrm{mg}$ added $\mathrm{Zn}$ as $\mathrm{ZnSO}_{4}$ and labelled with $1.00 \mathrm{mg}{ }^{67 \mathrm{Zn}}$ as $\mathrm{ZnSO}_{4}$. We served this meal with $300 \mathrm{ml}$ of ultrapure water. The M+FW meal was composed of the same porridge $(0.56 \mathrm{mg}$ native $\mathrm{Zn})$ but unfortified, and was served with $300 \mathrm{ml}$ LSF-water containing $0.44 \mathrm{mg} \mathrm{Zn}$ as LSF-Zn and labelled with $1.00 \mathrm{mg}{ }^{67 \mathrm{Zn}}$ as $\mathrm{ZnSO}_{4}$. The FW drink was composed of $300 \mathrm{ml}$ LSF-water containing $1.00 \mathrm{mg} \mathrm{Zn}$ as LSF-Zn and labelled with $1.00 \mathrm{mg}{ }^{67 \mathrm{Zn}}$ as $\mathrm{ZnSO}_{4}$. We prepared the $\mathrm{Zn}$-fortified water at a specified concentration by diluting $\mathrm{Zn}$ concentrated water produced with the LSF filter with ultrapure water. Fortification concentrations for the maize flour and the LSF-water were of 28.8 and $6.7 \mathrm{ppm}$, respectively. The $\mathrm{FM}+\mathrm{W}$ and $\mathrm{M}+\mathrm{FW}$ meals had a phytic acid (PA) to $\mathrm{Zn}$ molar ratio of 16.4:1. On administration day, we heated the defrosted porridge in the microwave for 2 minutes. We quantitatively added the ${ }^{67} \mathrm{Zn}$ tracer to either the porridge or the LSF-water, out of the subject's sight. The subjects consumed the test meals under supervision and the serving bowls were weighed before and after feeding. Immediately after feeding, we injected intravenously $0.2 \mathrm{mg}{ }^{70} \mathrm{Zn}$ in $9 \mathrm{ml}$ saline over a period of 5 minutes to each subject; we weighed the syringe before and after injection and flushed the injection system (catheter and needle) with $10 \mathrm{ml}$ physiological saline to ensure quantitative isotope administration.

We purchased isotopically-labelled $\mathrm{Zn}$ oxide powders (67ZnO and ${ }^{70} \mathrm{ZnO}$ ) from Chemgas (Boulogne, France). Powders were stored in a glass vial as provided by the supplier at room temperature prior to preparation. For the test meal label, we prepared isotopically-labelled $\mathrm{Zn}$

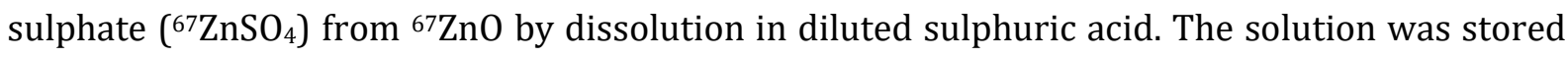
at room temperature until use. For the preparation of the intravenous dose, we converted ${ }^{70} \mathrm{ZnO}$ to ${ }^{70} \mathrm{ZnCl}$ with $\mathrm{HCl}$, adjusted to $\mathrm{pH} 6$ by adding $\mathrm{NaHCO}_{3}$ and diluted by physiological saline. The Cantonal Pharmacy of the University Hospital Zurich prepared the individual intravenous doses of $9.5 \mathrm{~g}$ solution by transferring to septum sealed glass vials where they were sterilised and checked for sterility and pyrogens. Doses were stored at $4{ }^{\circ} \mathrm{C}$ until use. We used inductively coupled plasma mass spectrometry (ICP-MS) to determine the concentration of the administered isotopic labels in solution and in the administered $\mathrm{Zn}$ fortificant.

We drew a $7.5 \mathrm{ml}$ fasting blood sample from each study participant into a trace element free tube (Monovette Li-He, Sarstedt, Nümbrecht, Germany) in the morning of study day 1 for baseline biochemical analyses (plasma zinc, PZn; C-reactive protein, CRP) prior to the first meal and intravenous dose. Since raised intravascular pressure causes the outward movement of fluid 
into the interstitial space, thereby increasing the concentration of serum proteins and $\mathrm{Zn}$, the subject remained laying for the blood-drawing procedure and the tourniquet was placed for a standardized length of time (less than 1 minute) [23]. The blood samples were refrigerated at $4{ }^{\circ} \mathrm{C}$ immediately after collection, centrifuged within 1 hour ( $3000 \mathrm{xg}$ for 10 minutes), aliquoted into acid washed plastic vials (Eppendorf AG, Hamburg, Germany) and frozen at $-25^{\circ} \mathrm{C}$ for later analysis of PZn and CRP. We measured PZn by flame atomic absorption spectrometer (AAS) (AA240FS, Varian Inc., Australia) using standard addition technique to minimize matrix effects, a commercial aqueous standard (Titrisol 1.009953.0001, Merck, Germany) for external calibration and Seronorm ${ }^{\mathrm{TM}}$ Trace Elements Serum L-2 (lot 0903107, ref 203105, Sero AS, Norway) as reference material. Instrumental parameters were set at $213.9 \mathrm{~nm}$ for wavelength, $1 \mathrm{~cm}$ for slit width and no background correction. We measured acute response indicator CRP using an automated chemiluminescent immunoassay system (IMMULITE®, Diagnostic Products Corporation, Los Angeles, USA) according to manufacturer's instructions. This analysis defined CRP $>3.0 \mathrm{mg} / \mathrm{L}$ as the cutoff for high CRP [24]. We compared mean PZn concentration (from duplicate analysis) to the suggested sex-specific lower cutoff indicating Zn deficiency in populations, which for morning fasting blood samples in adults was defined as $74 \mu \mathrm{g} \mathrm{Zn} / \mathrm{dl}$ and $70 \mu \mathrm{g} \mathrm{Zn/dl} \mathrm{for} \mathrm{males} \mathrm{and} \mathrm{non-pregnant} \mathrm{females,} \mathrm{respectively} \mathrm{[1].}$

Before and $96 \pm 3$ hours after each meal administration, we collected a morning urine sample to assess baseline and enriched isotopic composition. All urine samples were collected into prelabelled Zn-free (acid washed) PE-containers and kept at $4{ }^{\circ} \mathrm{C}$ until delivery to ETH, where they were stored at $-25^{\circ} \mathrm{C}$ until analysis. We applied an hCG marker test for pregnancy to each baseline urine sample from female participants. After freeze-drying, we mineralized urine samples using an $\mathrm{HNO}_{3} / \mathrm{H}_{2} \mathrm{O}_{2}$ mixture and microwave digestion followed by separation of the sample $\mathrm{Zn}$ matrix by anion-exchange chromatography. We performed the isotopic analyses by ICP-MS using a high resolution double focusing magnetic sector field multi-collector mass spectrometer (Neptune, Thermo Scientific), in duplicate and under chemical blank monitoring.

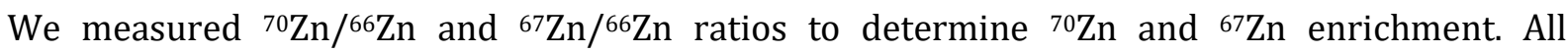
laboratory analyses were performed at the Laboratory of Human Nutrition at ETH.

\section{Zinc elution study}

The zinc elution study was performed between April and May 2012 in a controlled environment in Kisumu, Kenya. The following three usage patterns obtained from preliminary data on usage of the filter in the study area, were assessed: Low usage- 2 litres of water; medium usage-10 litres of water; high usage pattern-20 litres of water. Influent water used was tap water with the following characteristics; temperature $23^{\circ} \mathrm{C}, \mathrm{pH} 6.6$, conductivity $210 \mu \mathrm{S} / \mathrm{cm}$. Each usage pattern was assessed in duplicate $(n=2)$ in a laboratory set up in Kisumu, Kenya.

We filtered the respective amounts into 20L jerricans every day once a day except on Saturdays and Sundays for 6 weeks. At week 7, the filters were kept without usage for one week to simulate a prolonged nonuse of the filter. Filtering of the respective amounts resumed throughout week 8 . In the following week 9, the filters were again stored without usage for 1 week. Filtering and testing resumed in week 10. To standardize, each filter was flushed with 1 litre of water which was discarded before use each time. Water samples were collected from each filled jerrican into $50 \mathrm{ml}$ polypropylene bottles and tested for zinc immediately at the spot using the Rapid Zinc test kit (Aquaquant, Merck 1.14412.0001 Darmstadt, Germany). 
The rapid zinc test was previously validated in a series of experiments conducted at the Institute of Food, Nutrition and Health, ETH Zurich [25]. Validation was carried out by repeated measurements of standard zinc samples of different concentrations, all of them verified by flame atomic absorption spectrometry (FAAS). The kit was found to be most sensitive at the range between 0 and $1.0 \mathrm{mg} / \mathrm{l}$. All samples with concentrations above $1 \mathrm{mg} / \mathrm{l}$ were therefore reanalysed after a x10 dilution. The measurement value was multiplied with the dilution factor to arrive at the final concentration.

\section{Statistical methods}

We conducted data analysis with Excel (Microsoft Office, Seattle WA, USA), SPSS version 19; (IBM, Chicago IL, USA) and R statistical programming environment (version 3.0.3) [26]. When data were not normally distributed, values were logarithmically transformed before statistical analysis. Characteristics of participants of the absorption study (age, BMI, PZn, CRP) are presented as mean $( \pm S D)$ or median (min, max) and FAZ as geometric mean $( \pm S D)$. Zinc concentrations per usage pattern are presented as mean $( \pm S D)$. Percentage increase in zinc concentration after storage was determined as the zinc concentration of current week (a) minus mean zinc concentration of preceding week before storage (b) divided by (b) times hundred.

For the comparison of FAZ between different test meals in the absorption study, and zinc concentrations in eluted water per usage pattern in the elution study we used repeated measures ANOVA with posthoc tests corrected for multiple comparison (Bonferroni). We required 18 eligible subjects in order to detect a FAZ difference of $40 \%$ between test meals, with $80 \%$ power at a 0.05 significance level by taking into account a $20 \%$ dropout rate. We based sample size calculation on the pooled results of 5 previous $\mathrm{Zn}$ absorption studies we performed at ETH (SD of the log-transformed differences between pairs, 0.20).

To investigate a time effect on the level of zinc eluted, linear regression was used with zinc concentration as dependent variable and time as independent variable. Significance was set at $(\mathrm{p}<0.05)$.

We compared expected enrichment levels with physiological requirements for zinc in our target group, assuming the bioavailability obtained from this study and $25^{\text {th }}, 50^{\text {th }}$ and $75^{\text {th }}$ percentile drinking water intake data obtained from an unpublished study conducted in the same study area [27].

\section{RESULTS}

\section{Zn absorption study}

The content of PA and $\mathrm{Zn}$ in each maize meal serving was $330 \mathrm{mg}$ and $0.56 \mathrm{mg}$. Sixteen out of 18 subjects successfully completed the study. Two subjects dropped out on study day 1 and one was replaced. Another subject developed a cystitis that was judged unrelated to study participation and withdrew from the study on day 58. Thus, we administered 50 meals and intravenous doses $(n(\mathrm{FM}+\mathrm{W})=16, n(\mathrm{M}+\mathrm{FW})=17$ and $n(\mathrm{FW})=17)$ and collected 50 pairs of baseline and enriched urines. Baseline characteristics (age, BMI, PZn and CRP concentrations) are shown in (Table 1). In 3 subjects, we measured an elevated CRP value $(10.2,5.1$ and 
$15.6 \mathrm{mg} / \mathrm{L}$ ) [24], but we found no correlation between PZn and CRP and therefore we did not correct the PZn values of subjects with elevated CRP.

Table 1: Baseline characteristics of the Swiss subjects in the absorption study, by sex ${ }^{1}$

\begin{tabular}{llll}
\hline & All & Males & Females \\
\hline$N$ & 18 & 7 & 11 \\
Age $(\mathrm{y})$ & $24.0 \pm 1.7$ & $25.4 \pm 1.7{ }^{a}$ & $23.2 \pm 1.1$ \\
$\mathrm{BMI}\left(\mathrm{kg} / \mathrm{m}^{2}\right)$ & $21.5 \pm 1.6$ & $22.3 \pm 1.7$ & $21.0 \pm 1.4$ \\
Plasma Zn $(\mu \mathrm{g} / \mathrm{dl})$ & $76.0 \pm 11.1$ & $80.3 \pm 10.0$ & $73.2 \pm 11.4$ \\
Plasma CRP $(\mathrm{mg} / \mathrm{L})$ & $0.2(0.2-15.6)$ & $0.2(0.2-10.2)$ & $0.2(0.2-15.6)$ \\
\hline${ }^{1}$ Values are mean \pm SD or median (min-max). CRP, C-reactive protein; Zn, zinc. \\
${ }^{a}$ Different from females, $p<0.005$ (independent samples t-test).
\end{tabular}

Geometric mean (-SD, +SD) FAZ was 65.9\% $(42.2,102.4)$ from FW, 9.8\% from M+FW and 9.1\% from $\mathrm{FM}+\mathrm{W}$ (Table 2 and Figure 2). In post-hoc comparisons, meals containing maize (FM+W and $\mathrm{M}+\mathrm{FW}$ ) showed significantly lower FAZ than FW $(p<0.01)$, but FAZ did not significantly differ in FM+W versus M+FW. We found no significant correlation between PZn and FAZ.

Table 2: Composition of the test meals containing a total of $2 \mathrm{mg} \mathrm{Zn}$, and fractional and total absorption of Zn in young Swiss adults ${ }^{1}$

\begin{tabular}{llll}
\hline & $\mathrm{FM}+\mathrm{W}^{2}$ & $\mathrm{M}+\mathrm{FW}^{3}$ & $\mathrm{FW}^{4}$ \\
\hline Maize porridge, $g$ & 225 & 225 & - \\
Ultrapure water, $m l$ & 300 & 300 & 300 \\
PA:Zn molar ratio & $16.4: 1$ & $16.4: 1$ & - \\
$\mathrm{FAZ}^{5}, \%$ & $9.1(6.0,13.7)^{a}$ & $9.8(5.7,16.7)^{a}$ & $65.9(42.4,102.4)$ \\
$\mathrm{TAZ}^{5}, m g$ & $0.18(0.12,0.27)^{a}$ & $0.20(0.11,0.33)^{a}$ & $1.32(0.85,2.05)$ \\
\hline
\end{tabular}

${ }^{1}$ FAZ, fractional absorption of Zn; TAZ, total absorption of Zn; FM+W, fortified maize porridge and ultrapure water (18.2 M $\Omega$ ); $\mathrm{M}+\mathrm{FW}$, maize porridge and Zn-fortified water; FW, Zn-fortified water; PA, phytic acid; Zn, zinc.

${ }^{2}$ Composition per maize porridge serving: native $\mathrm{Zn}$ content, $0.56 \mathrm{mg}$; added $\mathrm{Zn}$ of normal isotopic composition as $\mathrm{ZnSO}_{4}, 0.44 \mathrm{mg}$; added ${ }^{67} \mathrm{Zn}$ as $\mathrm{ZnSO}_{4}, 1.00 \mathrm{mg}$; native phytic acid content, $330.5 \pm 11 \mathrm{mg}$.

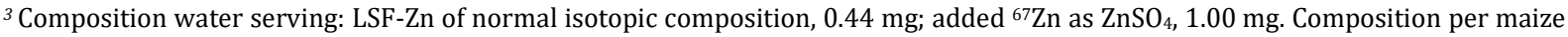
porridge serving: native $\mathrm{Zn}$ content, $0.56 \mathrm{mg}$.

${ }^{4}$ Composition per water serving: $\mathrm{LSF}-\mathrm{Zn}$ of normal isotopic composition, $1.00 \mathrm{mg}$; added ${ }^{67} \mathrm{Zn}$ as $\mathrm{ZnSO}_{4}, 1.00 \mathrm{mg}$.

${ }^{5}$ Values are geometric means $(-\mathrm{SD},+\mathrm{SD})$.

${ }^{a}$ Treatment effect based on repeated measures ANOVA (Bonferroni test for multiple comparisons), $p<0.01$. 


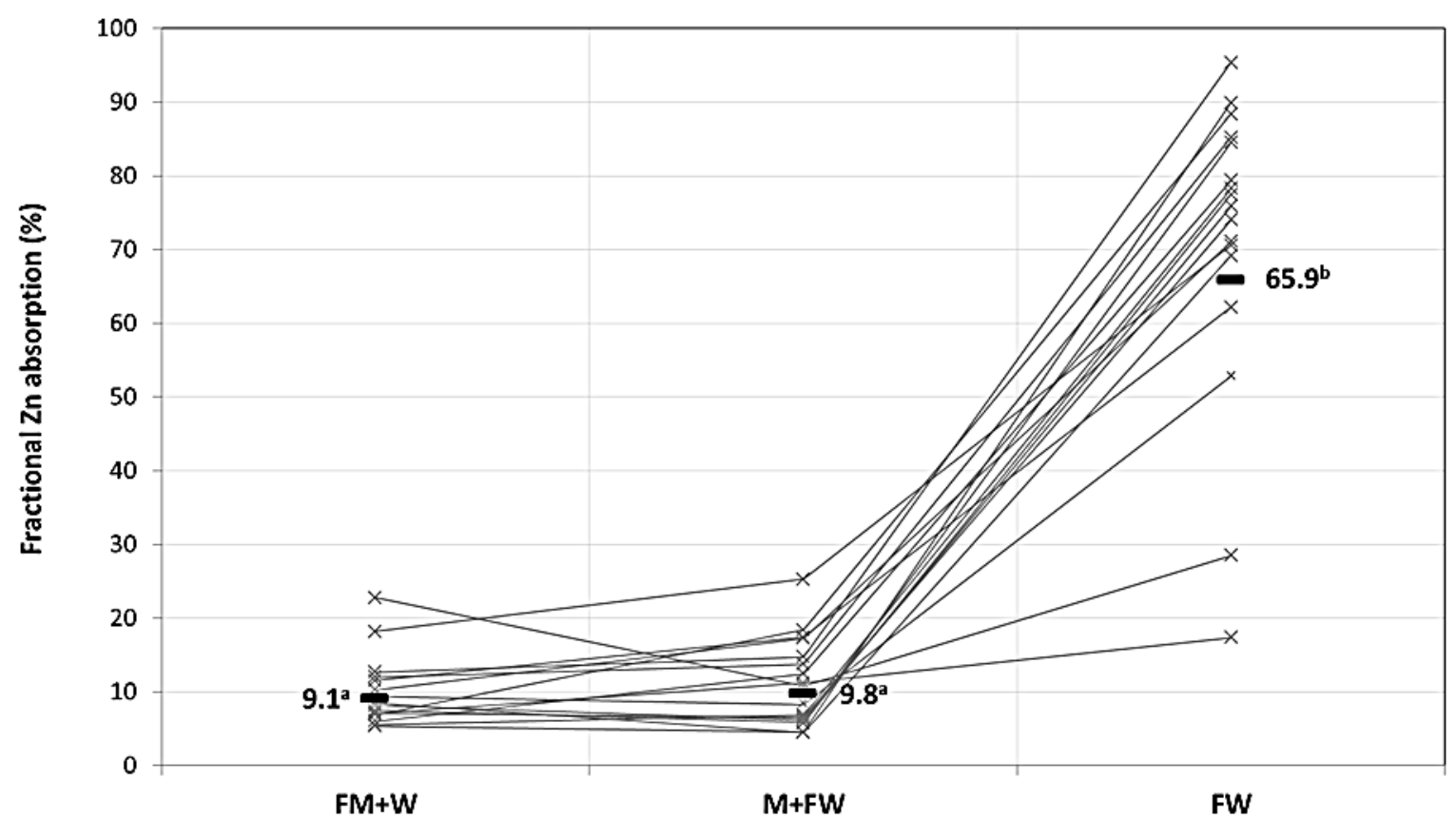

Figure 2: Fractional absorption of $\mathrm{Zn}(\mathrm{FAZ})$ from fortified maize porridge and ultrapure water (FM+W), maize porridge and fortified water $(\mathrm{M}+\mathrm{FW})$ and fortified water (FW) containing a total of $2 \mathrm{mg} \mathrm{Zn}$ in young Swiss adults. Lines represent individual FAZ and dashes represent geometric means. Labelled geometric means without a common letter differ, $p<0.001^{1}$

\section{Zinc elution trial}

Water was filtered and tested for 39 days excluding weekends and the 2 storage weeks. With regular usage the $2 \mathrm{~L} /$ day pattern led to significantly higher zinc elution $(4.7 \pm 1.6 \mathrm{mg} / \mathrm{L})(\mathrm{p}<0.05)$ than the $10 \mathrm{~L} / \mathrm{d}$ and $20 \mathrm{~L} / \mathrm{d}$ pattern $(1.7 \pm 0.9$ and $1.3 \pm 0.7 \mathrm{mg} / \mathrm{L}$ respectively) (Table 3$)$. There was no significant difference in zinc elution between the $10 \mathrm{~L} / \mathrm{d}$ and $20 \mathrm{~L} / \mathrm{d}$ usage pattern $(\mathrm{p}=0.67)$.

Table 3: Zinc concentration (mg/L) in eluates of the 6 LSF filter units before and after storage ${ }^{1}$

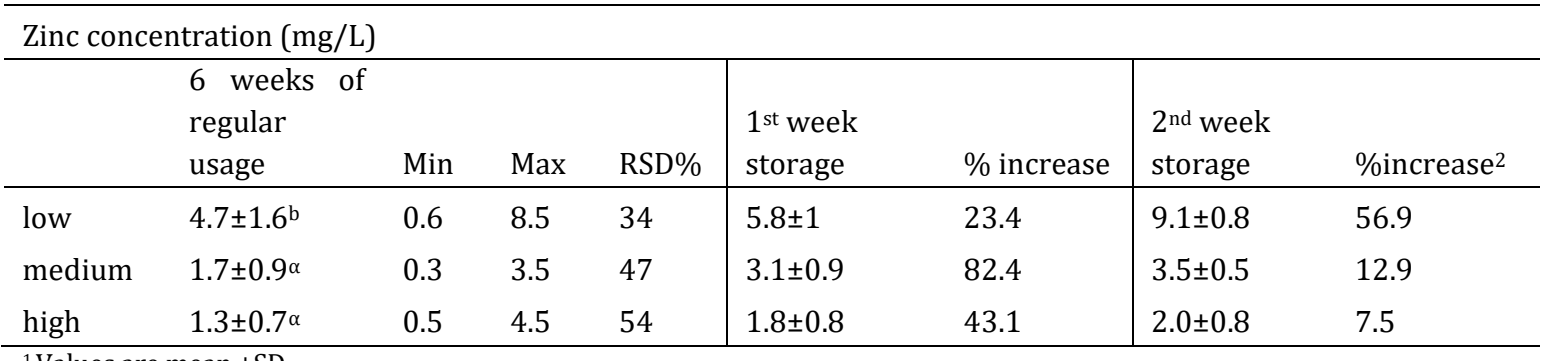

1 Values are mean \pm SD

2as compared to last filtering week

RSD-relative standard deviation

Time had no significant effect on zinc concentration for the 2 and 10L/d patterns. The trendlines for the $2 \mathrm{~L} / \mathrm{d}$ pattern and $10 \mathrm{~L} / \mathrm{d}$ pattern over time of regular usage gave $\mathrm{R}$ square values of $R^{2}=0.06$ and 0.01 respectively. Both trendlines did not significantly fit the data $(\beta=0.05 p=0.20$ and $\beta=-0.01 p=0.66$ ) respectively. For the $20 \mathrm{~L} / \mathrm{d}$ pattern time had a significant reducing effect on zinc concentration. The trendline only poorly but significantly fit with, $R^{2}=0.21(\beta=-0.02 p=0.01)$ (Figure 3). 


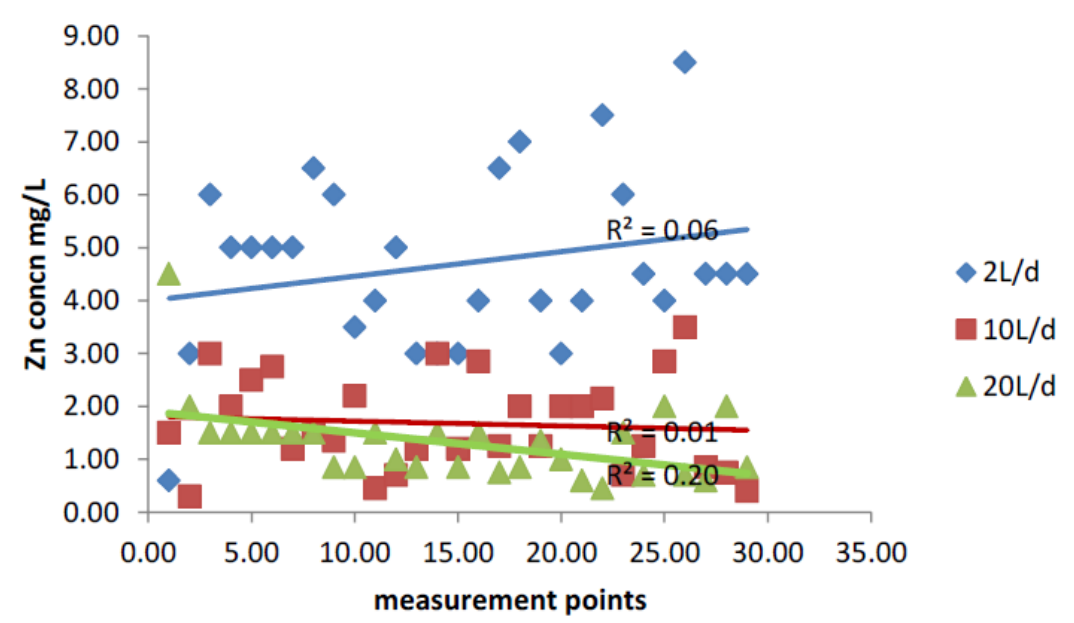

Figure 3: Trends per filtering pattern over 6 weeks of regular usage

\section{Effect of storage}

The mean zinc concentration before storage was compared to week 8 after storage for a week. There was a marked increase in zinc concentration across all usage patterns. Percentage increase were $23.4 \%$ (2L/d), 82.4\% 10L/d and 43.1\% (20L/d). Storage for another week led to a higher percentage increase in the low pattern $56.9 \%(2 \mathrm{~L} / \mathrm{d})$. The increase was less in the other 2 patterns studied $12.9 \%$ (10L/d) and 7.5\% (20L/d) (Table 3 and Figure 4).

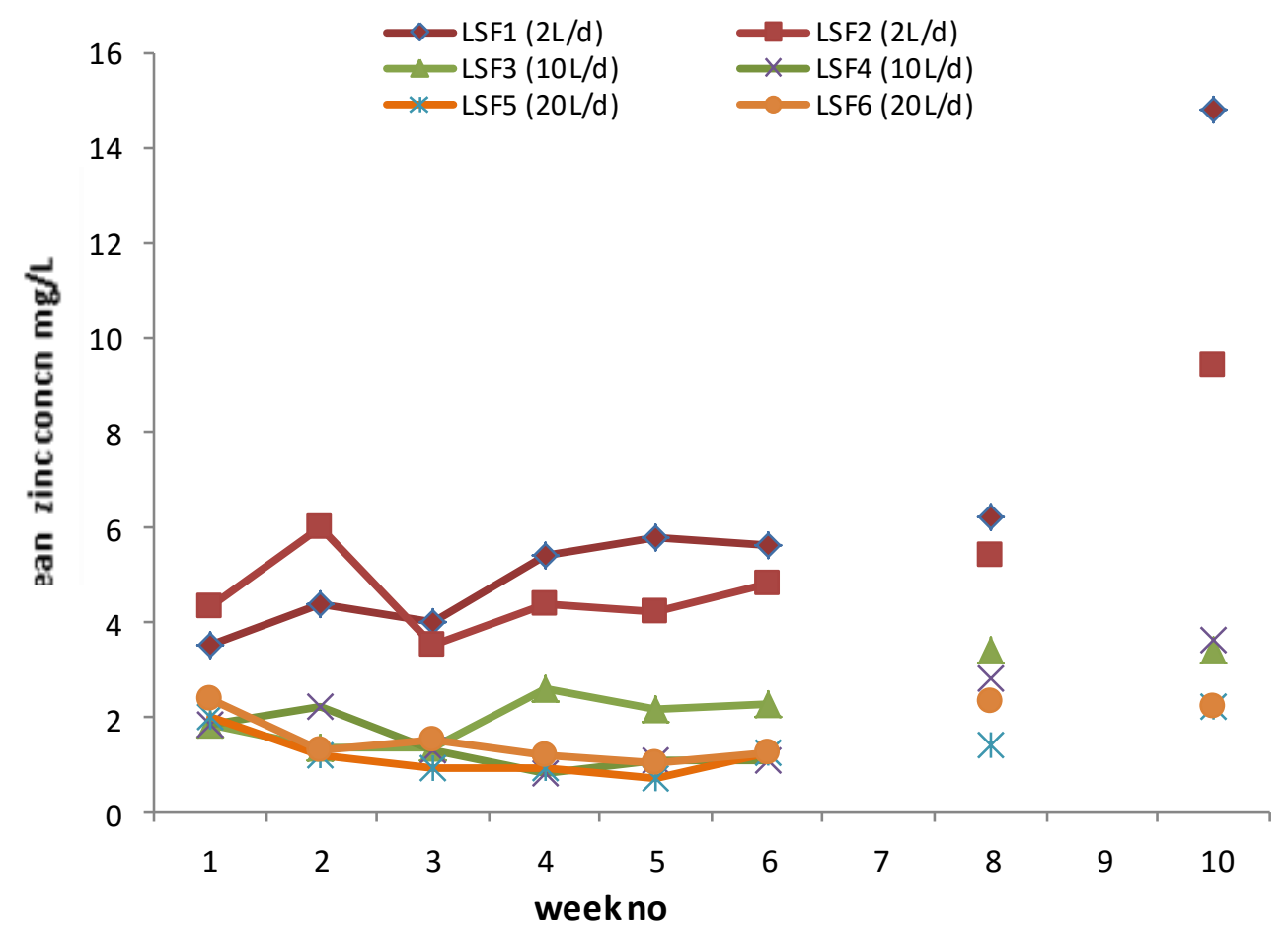

Figure 4: Eluted weekly mean zinc concentrations of the LSF devices over the study period

\section{Expected physiologic requirements covered}

It can be estimated that with the medium usage pattern $(10 \mathrm{~L} / \mathrm{d})$ and a median water intake of $477 \mathrm{ml} / \mathrm{d}$ [27] the fortified water can potentially cover 100 and $64 \%$ or 64 and 55\% of IZINCG or WHO physiological requirements in children aged between 2-3 year and 4-6 years respectively. For a high usage pattern (20L/d) the fortified water can cover 77 and $49 \%$ of IZiNCG or 49 and $42 \%$ of WHO set physiological requirements for children aged between 2-3years and 4-6 years 
respectively. With regards to safety, an enrichment level of $1.3 \mathrm{mg} / \mathrm{L}$ (high usage pattern) and the median water are expected to provide $0.62 \mathrm{mg} / \mathrm{d}$ for children aged 2-6 years. An enrichment level of $1.7 \mathrm{mg} / \mathrm{L}$ is expected to provide $0.81 \mathrm{mg} / \mathrm{d}$ for the same age group. This will not reach the IZiNCG upper limit (UL) which is $8 \mathrm{mg} / \mathrm{d}$ and $14 \mathrm{mg} / \mathrm{d}$ for children aged 2-3 and 4-6 years respectively (Table 4).

\section{DISCUSSION}

This study shows that the Lifestraw family device is capable of delivering reproducible, nutritionally relevant zinc concentrations of high bioavailability when used regularly (at least 10L/day).

The 7 fold higher bioavailability achieved with fortified water compared to zinc fortification of foods indicates this approach to have the potential to impact zinc nutrition in vulnerable populations by providing 30-120\% of the physiological requirements of children aged 2-6 years depending on the usage pattern used and water consumption. Our data highlight the potential advantages of using water as a fortification vehicle: with no inhibition of $\mathrm{Zn}$ absorption from phytic acid and other food components, even a low $\mathrm{Zn}$ fortification concentration can achieve high levels of absorbed Zn [28-30]. Previous measurements of Zn absorption from aqueous solutions found similarly high FAZs: $90 \%$ and $62 \%$ for a Zn dose of 1.0 and $5.0 \mathrm{mg}$ [13], 69\% and $63 \%$ of a $\mathrm{ZnCl}_{2}$ solution delivering 0.5 and $4.0 \mathrm{mg}$ [15], 73-74\% from a water solution delivering $2.6 \mathrm{mg} \mathrm{Zn}$ as $\mathrm{ZnSO}_{4}$ [16], 73\% for a $\mathrm{Zn}$ dose of $2.6 \mathrm{mg}$ [17], 73\% for an intake of $2.0 \mathrm{mg}$ aqueous $\mathrm{Zn}$ as $\mathrm{ZnSO}_{4}$ [14], and 61\%, 61\%, and 50\% from a $\mathrm{Zn}$ dose of $10 \mathrm{mg}$ as $\mathrm{Zn}$ citrate, $\mathrm{Zn}$ gluconate and $\mathrm{ZnO}$, respectively [18]. We therefore confirmed that $\mathrm{FAZ}$ of zinc from LSF water is comparable to values in literature.

When the Zn-fortified water was consumed with a maize meal, its FAZ was sharply lower and comparable to that of the $\mathrm{Zn}$-fortified maize. This finding is likely due to the chelating action of PA found in maize which, when consumed together, prevent absorption of $\mathrm{Zn}$ ions present in the fortified water. Previous studies have consistently shown that PA decreases $\mathrm{Zn}$ absorption. Sian and colleagues [13] showed FAZ decreased by a factor of 4.1 when $1 \mathrm{mg} \mathrm{Zn}$ was delivered in a high PA liquid meal (PA:Zn ratio of 240:1) compared to the same dose delivered in water. Fractional absorption decreased 2.5 folds when $2.6 \mathrm{mg} \mathrm{Zn}$ was delivered in a test meal consisting of rice and meat sauce compared to a $\mathrm{ZnCl}_{2}$ solution [16]. Our subjects absorbed $9.8 \%$ of $\mathrm{Zn}$ when delivered via LSF water consumed with a maize meal and 9.1\% when $\mathrm{Zn}$ was delivered with a fortified maize meal (PA:Zn molar ratio 16.4:1). Several tracer studies reported similar FAZ from medium to highly inhibitory meals, such as maize tortillas or porridge [31-34].

Despite these promises the delivery of zinc by the Lifestraw device was affected by high variability (Table 3). The high zinc concentrations in the low usage pattern during regular usage could be attributed to the dilution effect of low quantities of water passing through the nutrient chamber. With a low water turnover in the zinc nutrient chamber the concentration of zinc in eluted water is expected to be increased. For the same reason, storage had a negative effect on zinc elution. After the first week of storage there was a marked increase in zinc concentration across all filters. Percentage increase ranged from 23.4\%-82.4\%. Even though the percent increase was highest in the medium and high usage pattern group, the overall zinc concentrations for these two patterns remained within acceptable levels with regards to taste threshold [19]. Storage for another week led to even higher zinc concentrations across all usage 
patterns. The highest percentage increase was in the low usage $(2 \mathrm{~L} / \mathrm{d})$ pattern $(56.9 \%)$. The increase was less marked in the other 2 patterns studied $12.9 \%(10 \mathrm{~L} / \mathrm{d})$ and $7.5 \%(20 \mathrm{~L} / \mathrm{d})$. Only the increase in zinc elution in the $2 \mathrm{~L} / \mathrm{d}$ pattern due to storage was of concern with regards to safety as the levels $(9 \mathrm{mg} / \mathrm{L}$ ) began to exceed and approach the upper tolerable limit $8 \mathrm{mg} / \mathrm{d}$ and $14 \mathrm{mg} / \mathrm{d}$ for children 2-3 and 4-6years respectively.

The decrease in the upward trend observed in the medium and high usage pattern after storage may mean that with higher quantities of water and prolonged storage, zinc elution starts to decrease or to approach a plateau. However more data points would be required to prove if prolonged storage alternating with usage will reach either of the effects.

Our results indicate that in-frequent use of the filters increases zinc elution more markedly in a low usage pattern than in a higher usage pattern. The device when used with larger quantities of water seems to be more resilient to storage effects than when used with reduced quantities of water. This may mean that more regular use of the device with higher quantities of water should form part of the education message for future roll out programmes. Higher concentrations of zinc in filtered water may affect compliance and yet maximal compliance may be important to reduce inter filter variability. Changes in filter design for example a bigger upper bucket (capacity $\geq 10 \mathrm{~L}$ ) from the current $2.5 \mathrm{~L}$ may encourage households to filter at once the desirable higher volumes leading to acceptable zinc elution rates.

Even though we tried to simulate a range of usage patterns similar to real life settings based on baseline unpublished data, the limitations of the elution trial are that they were conducted using tap water with fixed physico-chemical properties. Water properties like turbidity, hardness, temperature and conductivity for rural household domestic use are expected to vary from season to season and source to source $[35,36]$. This variation may influence the elution rate. Unpublished data shows that elution is increased in water with decreased hardness and turbidity, and with higher temperatures. Another limitation is that the zinc content in the native water was not measured and used in correcting the final concentration as we assumed the levels to be negligible [19].However even if the zinc content was high in native water this would not have affected the trend, but it would have affected the mean level of zinc eluted across all filtering patterns. This may in the real setting present a safety hazard from over exposure of zinc coming from combined native water and enriched water.

Although we measured with a rapid assessment method we however validated the test kit against FAAS and we used the kit with water samples prepared for its most sensitive range in the field. We can therefore say that the zinc levels obtained are comparable to those obtained by FAAS. The use of the rapid zinc test method is however useful in resource limited settings because the test kits are portable, fast, and easy to use. Local personnel can be trained to selfmonitor the zinc levels in effluent water periodically.

The zinc enriched water can potentially provide coverage, for between $\approx 40 \%$ and $100 \%$ of the physiologic Zn requirement in children aged between 1 and 6 years. This is of great importance in vulnerable populations as we expect background dietary zinc intakes to be low [37] as confirmed in our dietary study (chapter 5). Even if the diet provides $50 \%$ or $100 \%$ RNI of zinc requirement (which is unlikely), the upper limit will not be reached with combined dietary intake and filtered water intake. 
Table 4: Expected fortification levels and estimated zinc intakes from fortified water

\begin{tabular}{|c|c|c|c|c|c|c|c|c|c|c|c|}
\hline & & & & WHO & & & & IZiNCG & & & \\
\hline $\begin{array}{l}\text { Enrichment } \\
\text { level }^{1}\end{array}$ & $\begin{array}{l}\text { Water } \\
\text { consumption } \\
(\mathrm{L})^{2}\end{array}$ & $\begin{array}{l}\text { Zinc intake } \\
\text { from } \\
\text { filtered } \\
\text { water }\end{array}$ & $\begin{array}{l}\text { TAZ3 }^{3} \\
(\mathrm{mg})\end{array}$ & $\begin{array}{l}\text { Age } \\
\text { group }\end{array}$ & $\begin{array}{l}\text { Zn physiologic } \\
\text { requirements } \\
\text { (mg/day) }\end{array}$ & $\begin{array}{l}\% \text { physiologic } \\
\text { requirements } \\
\text { covered }\end{array}$ & $\begin{array}{l}\mathrm{UL}^{5} \\
(\mathrm{mg} / \mathrm{d})\end{array}$ & $\begin{array}{l}\text { Age } \\
\text { group }\end{array}$ & $\begin{array}{l}\text { Zn physiologic } \\
\text { requirements } \\
\text { (mg/day) }\end{array}$ & $\begin{array}{l}\% \text { physiologic } \\
\text { requirements } \\
\text { covered }\end{array}$ & $\begin{array}{l}\text { NOAEL }^{5} \\
(\mathrm{mg} / \mathrm{d})\end{array}$ \\
\hline \multirow[t]{6}{*}{$1.3 \mathrm{mg} / \mathrm{L}$} & 378 & 0.49 & 0.32 & $1-3 y$ & 0.83 & 39.02 & 23.00 & $2-3 y$ & 0.53 & 61.10 & 8.00 \\
\hline & & 0.49 & 0.32 & $3-6 y$ & 0.97 & 33.38 & 23.00 & $4-8 y$ & 0.83 & 39.02 & 14.00 \\
\hline & 477 & 0.62 & 0.41 & $1-3 y$ & 0.83 & 49.23 & 23.00 & $2-3 y$ & 0.53 & 77.10 & 8.00 \\
\hline & & 0.62 & 0.41 & $3-6 y$ & 0.97 & 42.12 & 23.00 & $4-8 y$ & 0.83 & 49.23 & 14.00 \\
\hline & 600 & 0.78 & 0.51 & $1-3 y$ & 0.83 & 61.93 & 23.00 & $2-3 y$ & 0.53 & 96.98 & 8.00 \\
\hline & & 0.78 & 0.51 & $3-6 y$ & 0.97 & 52.99 & 23.00 & $4-8 y$ & 0.83 & 61.93 & 14.00 \\
\hline \multirow[t]{5}{*}{$1.7 \mathrm{mg} / \mathrm{L}$} & 378 & 0.64 & 0.42 & $1-3 y$ & 0.83 & 51.02 & 23.00 & $2-3 y$ & 0.53 & 79.90 & 8.00 \\
\hline & & 0.64 & 0.42 & $3-6 y$ & 0.97 & 43.48 & 23.00 & $4-8 y$ & 0.83 & 51.02 & 14.00 \\
\hline & 477 & 0.81 & 0.53 & $1-3 y$ & 0.83 & 64.38 & 23.00 & $2-3 y$ & 0.53 & 100.83 & 8.00 \\
\hline & & 0.81 & 0.53 & $3-6 y$ & 0.97 & 55.03 & 23.00 & $4-8 y$ & 0.83 & 64.38 & 14.00 \\
\hline & & 1.02 & 0.67 & $3-6 y$ & 0.97 & 69.30 & 23.00 & $4-8 y$ & 0.83 & 80.99 & 14.00 \\
\hline \multirow[t]{6}{*}{$4.7 \mathrm{mg} / \mathrm{L}$} & 378 & 1.78 & 1.17 & $1-3 y$ & 0.83 & 141.06 & 23.00 & $2-3 y$ & 0.53 & 220.90 & 8.00 \\
\hline & & 1.78 & 1.17 & $3-6 y$ & 0.97 & 120.93 & 23.00 & $4-8 y$ & 0.83 & 141.33 & 14.00 \\
\hline & 477 & 2.24 & 1.48 & $1-3 y$ & 0.83 & 178.00 & 23.00 & $2-3 y$ & 0.53 & 278.76 & 8.00 \\
\hline & & 2.24 & 1.48 & $3-6 y$ & 0.97 & 152.18 & 23.00 & $4-8 y$ & 0.83 & 177.85 & 14.00 \\
\hline & 600 & 2.82 & 1.86 & $1-3 y$ & 0.83 & 223.90 & 23.00 & $2-3 y$ & 0.53 & 350.64 & 8.00 \\
\hline & & 2.82 & 1.86 & $3-6 y$ & 0.97 & 191.59 & 23.00 & $4-8 y$ & 0.83 & 223.90 & 14.00 \\
\hline
\end{tabular}

${ }^{1}$ As per high, medium and low usage pattern respectively

2Filtered water consumption by children in rural Kisumu per quartile [27]

3TAZ-total absorbed zinc assuming FAZ of $65,9 \%$

${ }^{4}$ the amount of zinc that must be absorbed to offset the amount of endogenous zinc lost from both intestinal and non-intestinal sites[1]

5UL-upper limit, NOAEL-No observed adverse effect level [1] 


\section{Conclusion}

Regular filter usage with quantities above $10 \mathrm{~L}$ of water leads to decreased but adequate and safe zinc concentrations in drinking water. The device is more resilient to storage at high usage patterns. Highest bioavailability was obtained when zinc fortified water was consumed without meals and hence zinc fortified water should be consumed away from meals for high bioavailability.

Further research is needed to determine if regular use of the device can improve zinc nutrition in target populations and if so, what impact this would have on rates of growth and morbidity due to diarrhea and acute respiratory infections (ARI), particularly among infants and young children. 


\section{REFERENCES}

1. Brown KH, Rivera JA, Bhutta Z, Gibson RS, King JC, Lonnerdal B, Ruel MT, Sandtrom B, Wasantwisut E, Hotz C: International Zinc Nutrition Consultative Group (IZiNCG) technical document \#1. Assessment of the risk of zinc deficiency in populations and options for its control. Food Nutr Bull 2004, 25(1 Suppl 2):S99-203.

2. King J, Cousins R: Modern Nutrition in Health and Disease. 10th edition. Baltimore: Lippincott Williams \& Wilkins; 2006.

3. Bwibo NO, Neumann CG: The need for animal source foods by Kenyan children. $J$ Nutr 2003, 133(11 Suppl 2):3936S-3940S.

4. Prasad AS: Zinc in human health: An update. J Trace Elem Exp Med 1998, 11:63-87.

5. Lonnerdal B: Dietary Factors Influencing Zinc Absorption. J Nutr 2000, 130:1378S-1383.

6. Fairweather-Tait S, Hurrell RF: Bioavailability of minerals and trace elements. Nutr Res Rev 1996, 9:295-324.

7. Hunt JR, Beiseigel JM, Johnson LK: Adaptation in human zinc absorption as influenced by dietary zinc and bioavailability. Am J Clin Nutr 2008, 87:1336-1345.

8. Miller L V, Krebs NF, Hambidge KM: Mathematical model of zinc absorption: effects of dietary calcium, protein and iron on zinc absorption. Br J Nutr 2013, 109:695-700.

9. Miller L V., Krebs NF, Hambidge KM: A Mathematical Model of Zinc Absorption in Humans As a Function of Dietary Zinc and Phytate. J Nutr 2007, 137:135-141.

10. Clasen T, Naranjo J, Frauchiger D, Gerba C: Laboratory Assessment of a Gravity-Fed Ultrafiltration Water Treatment Device Designed for Household Use in Low-Income Settings. Am J Trop Med Hyg 2009, 80:819-823.

11. Peletz R, Simunyama M, Sarenje K, Baisley K, Filteau S, Kelly P, Clasen T: Assessing water filtration and safe storage in households with young chidren of HIV-positive mothers:a randomized, controlled trial in Zambia. PLoS One 2012, 7:e46548.

12. Walson J, Sangare L, Singa B, Naulikha J, Piper B, Yuhas K, Onchiri F, Otieno P, Mermin J, Zeh C, Richardson B, John-Stewart G: Evaluation of impact of long-lasting insecticide-treated bed nets and point-of-use water filters on HIV-1 disease progression in Kenya. AIDS 2013, 27:1493-1501.

13. Sian L, Hambidge K, Westcott J, Miller L, Fennessey P: Influence of a meal and incremental doses of zinc on changes in zinc absorption. Am J Clin Nutr 1993, 58:533-536.

14. Tran CD, Miller L V, Krebs NF, Lei S, Hambidge KM: Zinc absorption as a function of the dose of zinc sulfate in aqueous solution. Am J Clin Nutr 2004, 80:1570-1573.

15. Valberg L, Flanagan P, Chamberlain M: Effects of iron, tin, and copper on zinc absorption in humans. Am J Clin Nutr 1984, 40:536-541.

16. Sandstrom B, Davidsson L, Cederblad A, Lonnerdal B: Oral Iron, Dietary Ligands and Zinc Absorption. J Nutr 1985, 115:411-414.

17. Sandström B, Cederblad A: Effect of ascorbic acid on the absorption of zinc and calcium in man. Int J Vitam Nutr Res 1987, 115:411-414.

18. Wegmüller R, Tay F, Zeder C, Brnic M, Hurrell RF: Zinc absorption by young adults from supplemental zinc citrate is comparable with that from zinc gluconate and higher than from zinc oxide. J Nutr 2014, 144:132-6.

19. WHO: Guidelines for Drinking-Water Quality, 2nd Ed. Vol. 2. Health Criteria and Other Supporting Information. Geneva; 1996.

20. Friel J, Naake VJ, Miller L, Fennessey $\mathrm{P}$, Hambidge K: The analysis of stable isotopes in urine to determine the fractional absorption of zinc. Am J Clin Nutr 1992, 55:473-477.

21. Shames DM, Woodhouse LR, Lowe NM, King JC: Accuracy of Simple Techniques for Estimating Fractional Zinc Absorption in Humans. J Nutr 2001, 131:1854-1861.

22. Sheng X, Hambidge K, Miller L, Westcott J, Lei S, Krebs NF: Measurement of zinc absorption from meals: comparison of extrinsic zinc labelling and independent measurements of dietary zinc absorption. 2009, Int J Vita:230-237.

23. Hess SY, Peerson JM, King JC, Brown KH: Use of serum zinc concentration as an indicator of population zinc status. Food Nutr Bull 2007, 28:S403-429. 
24. Biasucci LM: CDC/AHA Workshop on Markers of Inflammation and Cardiovascular Disease: Application to Clinical and Public Health Practice: clinical use of inflammatory markers in patients with cardiovascular diseases: a background paper. Circulation 2004, 110:e560-7.

25. Burri J: Laboratory assessment of the effect of water hardness on zinc elution by the LSF device and validation of a rapid test kit. ETH Zurich; 2013.

26. R: A language and environment for statistical computing. R Foundation for Statistical Computing, Vienna, Austria [http://www.r-project.org/]

27. Ten Hove H: Zinc intake in young children.Simulation of the efficacy of adding zinc fortified drinking water to the diet on achieving zinc intake requirements of young children. Wageningen University; 2015.

28. Chung CS, Stookey J, Dare D, Welch R, Nguyen TQ, Roehl R, Peerson JM, King JC, Brown KH: Current dietary zinc intake has a greater effect on fractional zinc absorption than does longer term zinc consumption in healthy adult men. Am J Clin Nutr 2008, 87:12241229.

29. Lonnerdal B: Dietary Factors Influencing Zinc Absorption. J Nutr 2000, 130:1378S-1383.

30. King JC: Does zinc absorption reflect zinc status. Int J Vitam Nutr Res 2010, 80:300-6.

31. Hotz C, DeHaene J, Woodhouse LR, Villalpando S, Rivera JA, King JC: Zinc Absorption from Zinc Oxide, Zinc Sulfate, Zinc Oxide + EDTA, or Sodium-Zinc EDTA Does Not Differ When Added as Fortificants to Maize Tortillas. J Nutr 2005, 135:1102-1105.

32. Hambidge KM, Huffer JW, Raboy V, Grunwald GK, Westcott JL, Sian L, Miller L V, Dorsch JA, Krebs NF: Zinc absorption from low-phytate hybrids of maize and their wild-type isohybrids. Am J Clin Nutr 2004, 79:1053-1059.

33. Mazariegos M, Hambidge KM, Krebs NF, Westcott JE, Lei S, Grunwald GK, Campos R, Barahona B, Raboy V, Solomons NW: Zinc absorption in Guatemalan schoolchildren fed normal or low-phytate maize. Am J Clin Nutr 2006, 83:59-64.

34. Brnic M, Wegmüller R, Zeder C, Senti G, Hurrell RF: Influence of Phytase, EDTA, and Polyphenols on Zinc absorption in Adults from Porridges Fortified with Zinc Sulphate or Zinc Oxide. J Nutr 2014, 144:1467-73.

35. Hems D: Study and Interpretation of the Chemical Characteristics of Natural Water Vol 2254. 3rd edition. University of Virginia: Department of the Interior, U.S. Geological Survey; 1985.

36. Ouyang Y, Nkedi-Kizza P, Wu QT, Shinde D, Huang CH: Assessment of seasonal variations in surface water quality. Water Res 2006, 40:3800-10.

37. Gibson RS: Zinc nutrition in developing countries. Nutr Res Rev 1994, 7:151-73. 


\section{Chapter 4}

Daily consumption of zinc fortified water increases daily zinc intake and improves overall morbidity from common childhood infections in rural Kenyan children: a randomized, controlled effectiveness trial

Prosper Kujinga, Valeria Galetti, Elizabeth Opiyo Anyango, Viktor Jakab, Simone Heeb, Pauline Andang'o, Inge D. Brouwer, Michael B. Zimmerman, Diego Moretti 


\section{ABSTRACT}

Introduction: Zinc deficiency and diarrhea are highly prevalent and coexist in children from developing countries. A promising novel option for delivering zinc in diarrhea endemic, zinc deficient communities is through microbiologically treated, zinc fortified water provided with a household based fortification and filtration device.

Objectives: Our objective was to assess the effectiveness of zinc fortified filtered water to improve zinc intake and status, and reduce morbidity in children aged 2-6 years from rural Western Kenya

Methods: We randomly allocated 184 children (2-6 years) to receive either zinc fortified filtered water or filtered water with no zinc daily for 6 months. The main outcome measure was dietary zinc intake. Secondary outcomes were plasma zinc concentration (PZn), morbidity and growth. Dietary zinc intake was assessed using a quantitative multi-pass $24 \mathrm{hr}$ recall. Secondary outcomes were measured at baseline, midpoint and endpoint except morbidity which was assessed weekly by means of a questionnaire.

Results: Zinc fortified water contributed $42 \%$ and $36 \%$ of daily requirements for absorbable zinc in children 2-3 and 4-6 years respectively. A time treatment interaction effect was obtained on overall morbidity $(\mathrm{p}<0.001)$; RR $(95 \% \mathrm{CI})=0.91(0.87,0.96)$ morbidity due to cold $(\mathrm{p}=0.034)$ $\mathrm{RR}(95 \% \mathrm{CI})=0.91(0.83,0.99)$ and stomach pain $(\mathrm{p}=0.003) \mathrm{RR}(95 \% \mathrm{CI})=0.70(0.56,0.89)$. There was no treatment effect on plasma zinc concentration.

Conclusion: Daily consumption of zinc fortified, microbiologically treated water could have significant public heath impact in improving dietary zinc intake and preventing general childhood infections in preschool children in rural Africa. 


\section{INTRODUCTION}

Globally $17 \%$ of the world's population is estimated to be at risk of zinc deficiency [1]. Prevalence of zinc deficiency is estimated to be highest in Sub Saharan Africa, particularly among children [2-4]. Zinc deficiency causes growth deficits, compromised immunity and can lead to increased risk of infections such as diarrhea and respiratory tract infections (RTI) [5]. The most common cause of zinc deficiency is the habitual consumption of foods low in bioavailable zinc [6]. An important contributing factor may also be excessive zinc loss as experienced during frequent diarrhea episodes [7]. In settings where diarrhea is endemic, zinc deficiency can be a coexisting major nutritional deficiency $[8,9]$.

One way to reduce zinc deficiency and improve zinc status is through preventive zinc supplementation. Reviews and meta-analysis conducted in the recent past provide evidence on improved plasma zinc status and decreased morbidity due to diarrhea [10-13]. However, published evidence on effectiveness of zinc fortification and supplementation on growth and morbidity in children is limited [14] and has been attributed to many factors including choice of fortificant, food vehicle $[15,16]$ and excessive zinc losses due to diarrhea $[17,18]$. A promising and potentially novel option for delivering zinc in diarrhea endemic, zinc deficient communities is through fortified water. Provision of microbiologically clean drinking water combined with strategies that reduce zinc deficiency may improve zinc status and provide enhanced protection against diarrhea in such communities. Zinc from drinking water consumed away from meals has been shown to be well absorbed because of absence of absorption-inhibitory dietary components such as phytate $[19,20]$.

A novel approach of treating water by simultaneously removing microbiological contamination and adding zinc at a concentration of between $1-4 \mathrm{mg} / \mathrm{L}$ has been reported recently [19]. This approach was field tested in a controlled, primary school based efficacy trial in rural Benin, where daily consumption of $2.8 \mathrm{mg} \mathrm{Zn}$ in water was effective in maintaining plasma zinc over the 4 months intervention period [19], resulting in a better zinc status in the intervention group compared to control. While school based strategies may be effective in school aged children [21, 22], preschool children will benefit more from home based interventions [23]. To test impact on zinc intake, zinc status and morbidity in real life conditions, we conducted a 6 month-long effectiveness trial in a free living population in areas of low socioeconomic status exposed to unsafe water in rural Kenya.

\section{METHODS}

\section{Study setting design and randomization}

This study was a 6 month double-blind randomized effectiveness trial conducted between February 2014 and August 2014 in Western Kenya, Kisumu West District. The study area consisted of 15 villages in the sublocation Kajulu Koker which lies along the shores of Lake Victoria and about $25 \mathrm{Km}$ from Kisumu city. This rural population lacks access to many basic healthcare services and poverty is prevalent. The study population relies on water from Lake Victoria or rain water for domestic purposes with main economic activities being small scale farming and fishing restricted to parts bordering Lake Victoria. Western Kenya has a tropical climate which is warm and humid throughout the year, with 2 rainy seasons, typically taking place as long rains from March to May and as short rains from October to December. 
Eligible study households were randomly assigned to 2 groups using a block randomization procedure that guaranteed the same numbers of randomized participating households per study group. One child per eligible household was enrolled and when there was more than 1 child between 2-5 years old one of them was randomly selected to participate. The control group received a normal filter which did not deliver zinc but only purified water, while the LSF Zn intervention group received a filter containing zinc delivery glass plates. Randomization was performed by a member of the investigating team who was not present at screening and enrolment in Kenya, nor was involved in data analysis. Participants were randomized into 4 pseudo treatment arms. All study personnel and participants were blinded to treatment assignment for the duration of the study. Control and intervention filters were identical in presentation and were matched weight to weight so that subjects would not notice the presence or absence of zinc glass plates based on weight. Treatment assignment was revealed at the end of primary analysis.

\section{Study population and sample size}

Children were enrolled into the study if they were aged between 2-6 years, residing in Kajulu Koker, apparently healthy with hemoglobin $(\mathrm{Hb})>70 \mathrm{~g} / \mathrm{L}$. Subjects were excluded if they were chronically ill or were participating in other clinical trials in the area. Sample size was based on the outcome plasma zinc. A sample size of 180 was determined sufficient to detect a difference in PZn of $5 \mu \mathrm{g} / \mathrm{dl}$ assuming a SD of $9 \mu \mathrm{g} / \mathrm{dl}$ at a $5 \%$ significance level with $80 \%$ power assuming an attrition rate of $20 \%$.

The study protocol was approved by the Ethical Review Committees of Kenyatta National Hospital/Nairobi University (KNH-ERC/A/335), and ETH Zurich Ethical committee (EK 2013-N31). The study was presented to local leaders and they gave their approval for its conduction. Written informed consent was obtained from the head of household and caregiver on behalf of their children before the study commenced. The trial was registered at www.clinical trials.gov (NCT02162238).

A baseline questionnaire was administered to each enrolled household to collect information on socio economic status, demographics, drinking water sources, hygiene practices and sanitation conditions.

\section{Blood collection and biochemical analysis}

Blood samples were collected between 8 am and 13:00 pm from fasting and non-fasting subjects for PZn analysis according to the International Zinc Nutrition Consultative Group (IZINCG) protocol [24] at baseline, midpoint and endpoint. Blood was drawn from subject's vein into trace element free monovette (Sarstedt system tubes, Numbrecht, Germany). To obtain plasma, blood was centrifuged at 3000 revolutions per minute (rpm) for 10 minutes using a field centrifuge within 40 minutes from collection. The aliquots were kept in a cooler box before transporting on the same day to Maseno University for storage at $-20^{\circ} \mathrm{C}$. All samples were then sent to ETH Zurich, Switzerland on dry ice for analysis of PZn concentration. Hemoglobin (Hb) was analyzed in the field on the spot using a Hemocue photometer (Hemocue HB 201, Angelholm, Sweden).

\section{Plasma analysis}

In Zurich, we measured PZn by atomic absorption spectrometry (AAS) (AA240FS, Varian Inc., Australia) using standard addition technique to minimize matrix effects, a commercial aqueous standard (Titrisol 1.009953.0001, Merck, Germany) for external calibration and Seronorm ${ }^{\mathrm{TM}}$ 
Trace Elements Serum L-2 (Sero AS, Norway) as reference material, which delivered values within acceptable ranges as specified by the manufacturer. Instrumental parameters were set at $213.9 \mathrm{~nm}$ for wavelength, $1 \mathrm{~cm}$ for slit width and no background correction. Inter-assay mean coefficient of variation was $1.7 \%$ for PZn. To avoid exogenous or endogenous zinc contamination during sample collection, handling and analysis, IZiNCG standardized protocols were followed $[24,25]$. CRP and AGP were analysed using a sandwich ELISA [26]. Liquicheck Trilevel (Bio-Rad Laboratories Inc., Hercules, United States) were used as control materials with each run of analysis, and measured values were within acceptable ranges as specified by the manufacturer. We coded specimens from all time points and analysed them without knowledge of study arm and in a random order. All values represent the mean of an independent duplicate measurement; we re-ran analysis if coefficient of variation exceeded $5 \%$ and removed obvious outliers. We calculated prevalence of low PZn by using sex and age-specific lower cut-offs by IZiNCG [2]. Subclinical inflammation was defined as CRP $>5 \mathrm{mg} / \mathrm{l}$ and/or AGP $>1 \mathrm{~g} / \mathrm{l}$. Applied cutoff for $\mathrm{Hb}$ was $<110 \mathrm{~g} / \mathrm{L}$ in children aged 0.5 to 4.99 years and $115 \mathrm{~g} / \mathrm{L}$ in children 5 years and older [27].

\section{Anthropometry}

At baseline, midpoint and endpoint weight and height were measured according to WHO guidelines to the nearest $0.1 \mathrm{~kg}$ and $0.1 \mathrm{~cm}$ respectively using an electronic scale (Ashton Meyers, England, United Kingdom), and a UNICEF wooden three piece measuring board with a sliding foot or head piece. The accuracy of the weighing scale was checked daily with a known weight. The same research assistant took the measurements at the 3 time points. Age was calculated using verifiable records (birth certificate, health record), or estimated based on a traditional calendar). Z-scores, for height-for-age (HAZ), and weight-for-age (WAZ) were determined, for each child using WHO ANHTRO PLUS (version 1.0.4). Children were classified as stunted, or under-weight if their HAZ, or WAZ respectively, were less than -2 SD.

\section{Dietary intake}

Dietary intake in a subsample of the children $(n=110)$ was assessed using a quantitative multipass $24 \mathrm{hr}$ recall method [28, 29], with all days evenly distributed throughout the week. A second recall was carried out for each child on a non-consecutive day to permit adjustment for day-to-day variation. The interviews were carried out by local, trained interviewers speaking fluent Dholuo language. Children were randomly allocated to day of the week, interviewers were randomly allocated to households and repeated household visits by the same interviewer were avoided. Caregivers were first asked to list all the foods and drinks the child had consumed at home and away in the previous 24 hours from waking up the day before the interview till waking up the day of interview. Then they were requested to mention all the ingredients and cooking methods for each food/dish. Duplicate amounts of all foods, beverages and ingredients were weighed to the nearest 1 gram using a digital precision balance scale (Kern EMB, Germany, max 5200g). If duplicate amounts were not available in the household during the interview, amounts were estimated using household units, in volume, size (small medium large) or as monetary equivalents. Conversion factors were determined by the supervisors and these were used to determine the amount consumed by the child. Caregivers were systematically probed for any food, beverage or snack omitted during the interview. Standard recipes were generated to estimate the grams of ingredients consumed from mixed dishes purchased or eaten outside the home by averaging 3 recipes of different caregivers or vendors in the local area. For foods 
consumed at school, recipes were collected from the school cook. In all cases proportion given to child was calculated as the total volume given to the child minus any leftovers divided by the total volume of food cooked by the caregiver/vendor/school. This proportion was multiplied by the total amount of ingredients used in preparing the dish to determine amount consumed by the child.

\section{Drinking water consumption}

Consumption of both unfiltered and filtered water was assessed for each child during the 25 weeks of the intervention. All study children were provided with cups of standard volume $300 \mathrm{ml}$ graduated at 75, 150 and $300 \mathrm{ml}$. A personal diary was filled out by each caregiver every day to record the participating child's water intake by placing a tally mark under the image corresponding to the day of week, type of water consumed and administered volume whenever the index child consumed water.

\section{Morbidity}

Prevalence of diarrhea and the following symptoms, cold, rapid breathing, cough, stomach pain, fever and headache in the study children were assessed weekly by field assistants who completed a forced-choice questionnaire by interviewing the caregivers. The recall period for symptoms was one week, only for diarrhea a recall period of $48 \mathrm{hrs}$ was applied as it has been shown that diarrhea morbidity is often underreported if recall period is longer than 2-3 days [30-32]. Diarrhea was defined using the WHO definition of three or more loose stools passed in 24hrs [33]. Clinic visit records when available were asked for proof to verify symptoms reported.

\section{Monitoring device usage}

All households were provided with a tally counter to record the number of times they filtered water. The caregivers were instructed to push the tally counter each time they refilled one jerry can $(10 \mathrm{~L})$ with filtered water. The counter was stored near the filter, out of reach from small children. During the weekly visit from the field assistant, the number on the tally counter was recorded and set back to zero. One count was assumed to be equal to one filtering event of $10 \mathrm{~L}$.

\section{Monitoring of device effectiveness}

Device effectiveness was assessed by measuring zinc content, total coliforms (TCC) and E. coli in influent and effluent water samples from 35 randomly selected households representing 19\% of the study households (18=LSF Zn group, 17=control group). Water was sampled for zinc analysis at 4 random time points and for microbiology at 3 random time points over the intervention period the following way: water samples were collected from each filled jerry can during a household visit into (acidified) $50 \mathrm{ml}$ polypropylene bottles and transported to Kisumu in cooler boxes for zinc analysis by a rapid zinc assessment method (Aquaquant, Merck 1.14412.0001 Darmstadt, Germany). A duplicate sample was stored for zinc analysis by AAS. Influent and effluent (from jerry can) water samples were collected aseptically into previously autoclaved PEP bottles for assessment of microbiological quality. The samples were stored immediately in cooler boxes and transported to Government Analyst Laboratories in Kisumu town for analysis of coliforms and $E$. coli by the membrane filtration method. 


\section{Data Analysis}

\section{Dietary zinc intake}

Compl-eat(C) (version 1.0, Wageningen University, the Netherlands) was used to calculate nutrient intakes from the $24 \mathrm{hr}$ recalls. Nutrient intake calculations were based on a food composition table (FCT) developed specifically for this study using the Kenya national FCT as primary source [34] complemented with data from FCTs from South Africa [35], Mali [36], East Africa [37], International Minilist [38] and the United States Department of Agriculture database (USDA) [39]. USDA retention factors [40] were applied to raw ingredients and foods to account for nutrient losses during food preparation. Nutrient intake analysis was done using IBM SPSS (v21). Normality of distributions was tested visually using QQ plots. Non normal nutrient intake data was log transformed then adjusted for day-to-day variation according to the method developed by the National Research Council [41,42] and then back transformed to facilitate interpretation. The percentage of children below the WHO EAR for zinc intake was determined, assuming 15\% zinc bioavailability from food [2].

\section{Device effectiveness}

To compute percent reduction in microbial load after filtering the following formular was used: percent reduction $=((A-B) * 100) / A$ where $A$ is the number of viable microorganisms before treatment and $B$ is the number of viable microorganisms after treatment.

\section{Statistical analysis}

Data was analysed using IBM SPSS (v21). Normality of distributions was tested visually using QQ plots. We excluded outliers defined as more than 3SD from the overall mean at baseline, midpoint and endpoint. One outlier was identified at baseline for PZn $(22.4 \mu \mathrm{g} . \mathrm{dL}), 1$ at midpoint $(173.4 \mu \mathrm{g} / \mathrm{dL})$ and 1 at endpoint $(28.0 \mu \mathrm{g} / \mathrm{dL})$. We tested group wise differences using independent samples $\mathrm{T}$ test for normally distributed data, Mann Whitney $\mathrm{U}$ test when the data was non normal and Sign test for paired non normal data. Chi square was used to test difference between proportions. We tested intervention effects for continuous outcomes and binary outcomes using linear mixed effect models (MEM) and Generalised estimating equations (GEE) [43] respectively with unstructured covariance matrix. Subjects were entered as random components, time and treatment as fixed effects. For linear MEM we selected best fit model by Akaike Information Criterion (AIC) and Bayesian Information Criterion (BIC). Risk ratios (RR) and $95 \%$ confidence intervals (CI) for disease incidence were calculated by means of contingency tables. The significance level was set at $p<0.05$. Compliance to treatment was defined by the median amount of filtered water consumed per day over the intervention $(500 \mathrm{ml})$. The primary analysis was intention to treat and included all children enrolled at baseline. Per protocol analysis was restricted to children who completed 25 weeks of the trial.

\section{RESULTS}

In total 235 children and their caregivers initially consented to the study. 192 came for screening after 43 refusals between consenting and baseline for unknown reasons. Of these 6 had a low $\mathrm{Hb}$ and for 2 phlebotomy was unsuccessful. A total of 184 subjects were included in the study and randomized to 4 pseudo treatment arms, corresponding to the intervention and control group. 167 completed the study representing a dropout rate of 9.2\% (Figure 1) with no 
difference in withdrawals between LSF Zn group (8.0\%) and control group (10.6\%). The main reason for non-completion of the trial was migration from the study area.

Stunting was high in this population (17.7\%) with a negative overall mean HAZ scores at baseline (Table 1). The most common source of domestic water use in the wet season was rain water (91\% LSF Zn group, 89\% control group) and for the dry season it was mostly surface water from Lake Victoria (53\% LSF Zn group, 53\% control group). Zinc deficiency was high at baseline (LSF Zn group: 42.9\%, control group, 52.7\%). More than half of all children in both treatment arms were anemic at baseline (LSF Zn group: 60\%, control group: 51\%). An equally high number had elevated CRP concentration (39\% both groups) with $53.7 \%$ and $52.4 \%$ in the LSF Zn group and control group, respectively, having elevated AGP concentration.

At baseline the children in the two intervention groups were not significantly different from each other in terms of demographic and socio-economic characteristics, anthropometry, prevalence of anemia and inflammation (Table 1 and 2).

\section{Dietary zinc, energy and water intake}

Zinc intake from the diet was $6 \pm 1.7 \mathrm{mg} / \mathrm{d}$ in the LSF Zn group and $5.7 \pm 1.6 \mathrm{mg} / \mathrm{d}$ in the control group, with no difference between the groups ( $\mathrm{p}=0.368)$. Similarly, we did not find differences in energy intakes between the LSF Zn group $(1496 \pm 306 \mathrm{kcal} / \mathrm{d})$ and the control group (1496 $\pm 315 \mathrm{kcal} / \mathrm{d}$ ). The proportion below the WHO derived EAR for habitual zinc intake was $81.1 \%$ and $87.3 \%$ in the LSF Zn group and control group respectively [2]. There was no significant difference in these proportions $(\mathrm{p}=0.405)$ and $15.6 \%$ in both groups had energy intakes below the age and sex specific cutoffs [46] .

A significantly higher zinc concentration was measured in the LSF Zn-group water samples $(\mathrm{N}=74)$ compared to the Control-Group $(\mathrm{N}=76)(\mathrm{p}<0.01)$, with the overall median zinc concentration in the LSF Zn-group of $1.15 \mathrm{mg}$ zinc/L (range=0.04-18.7), compared to an overall median concentration of $0.30 \mathrm{mg}$ zinc/L (range=0.02-2.2) in control water (Figure 2).

Median and $\left[25^{\text {th }}, 75^{\text {th }}\right.$ percentile] filtered water intake for LSF Zn and Control group was 450 $[289,675] \mathrm{ml} / \mathrm{d}$ and $471[300,718] \mathrm{ml} / \mathrm{d}$ respectively over the intervention period with no significant difference between the 2 groups $(\mathrm{p}=0.168)$. Median zinc intake from LSF Zn group filtered water was therefore $0.52[0.37,0.74] \mathrm{mg} / \mathrm{d}$ with mean $0.59 \pm 0.32 \mathrm{mg} / \mathrm{d}$. Median zinc intake from control group filtered water was $0.14[0.10,0.20] \mathrm{mg} / \mathrm{d}$ with mean $0.15 \pm 0.07 \mathrm{mg} / \mathrm{d}$ respectively. Compliance was 39\% and $42 \%$ for LSF Zn and Control group respectively, with no significant difference between the two groups $(\mathrm{p}=0.626)$.

There was a slight increase in filtered water consumption in both groups in the first 3 weeks followed by a decrease which did not reach baseline levels through the study (Figure 3). There was an overall decrease in unfiltered water consumption in both groups. Median unfiltered water intake was $0 \mathrm{ml} / \mathrm{d}$ for both groups. Device usage as assessed with a tally counter (median with $25^{\text {th }}, 75^{\text {th }}$ percentile) was $3[2,5]$ filtration events per week for households of both groups. There was an overall slight decrease of filtration events over time. Notable peaks of increase in filter usage were observed at start of intervention, midpoint and endpoint. 


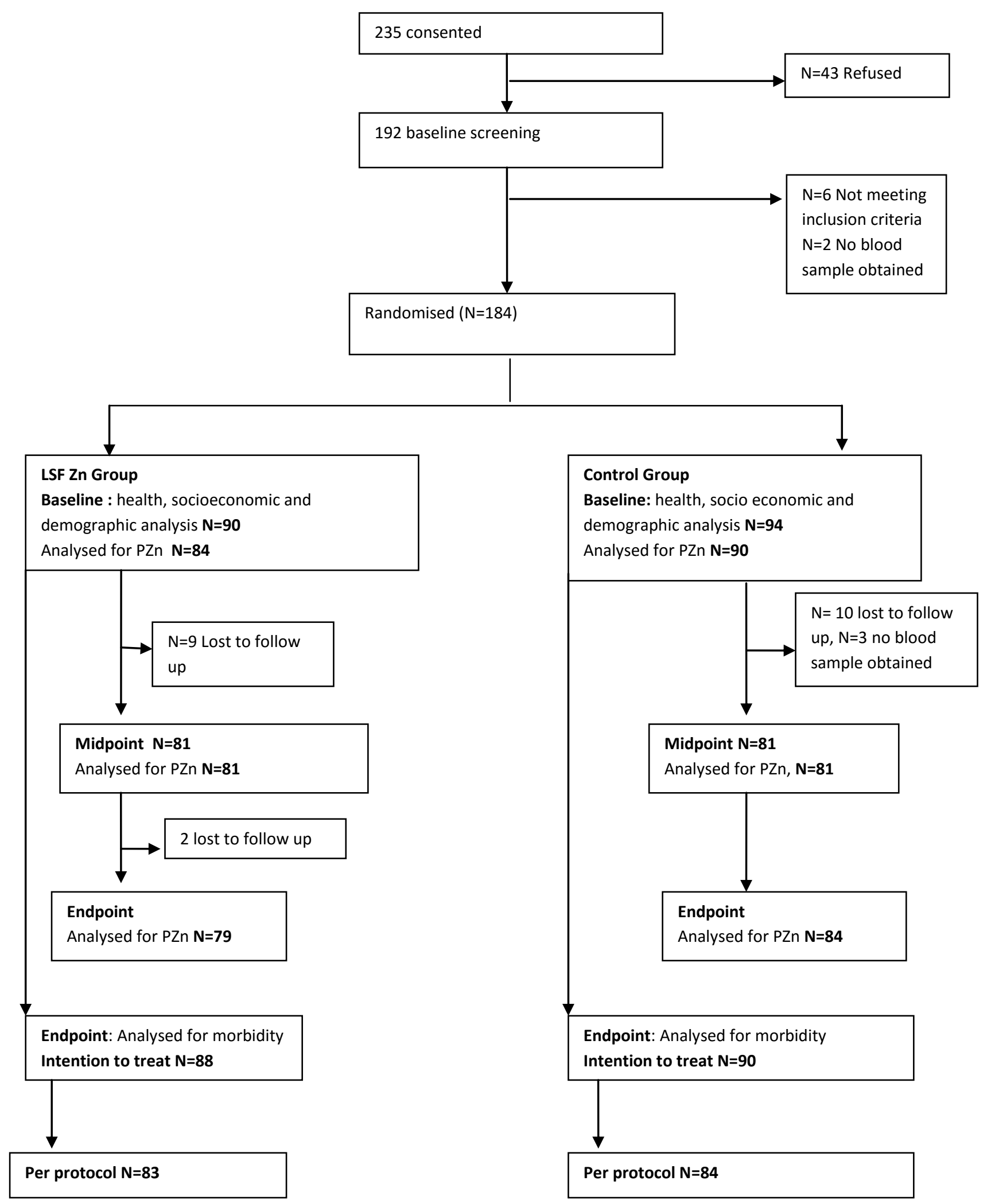

Figure 1: Trial Profile 
Table1: Demographic, socioeconomic and nutrition status profile of study children (2-6yrs) from rural Western Kenya*

\begin{tabular}{|c|c|c|c|}
\hline Variables assessed & $\begin{array}{l}\text { LSF Zn } \\
\text { group }\end{array}$ & $\begin{array}{l}\text { Control } \\
\text { group }\end{array}$ & p value ${ }^{1}$ \\
\hline $\mathrm{N}$ & 90 & 94 & \\
\hline Age (months) & $47[37,57]$ & $46[36,59]$ & 0.94 \\
\hline Sex male & 43 (39) & $48(45)$ & 0.48 \\
\hline \multicolumn{4}{|l|}{ Nutritional status ${ }^{2}$} \\
\hline Height for age $\mathrm{z}$ score & $-0.87 \pm 1.5$ & $-0.78 \pm 1.8$ & 0.72 \\
\hline Stunted 2 & $15.9(13.0)$ & $19.5(16.0)$ & 0.54 \\
\hline Weight for age z score & $-0.1 \pm 0.9$ & $-0.1 \pm 0.9$ & 0.84 \\
\hline Underweight ${ }^{2}(\%)$ & $7.3(6.0)$ & $12.2(10.0)$ & 0.29 \\
\hline \multicolumn{4}{|c|}{$\begin{array}{l}\text { Socioeconomic characteristics of } \\
\text { households }\end{array}$} \\
\hline Household size & $6.0[4.0,7.0]$ & $6.0[5.0,7.0]$ & 0.79 \\
\hline \multicolumn{4}{|l|}{ Main source of income ${ }^{3}$} \\
\hline casual labour & $51.7(46.0)$ & $56.7(55.0)$ & \\
\hline fishing & $25.8(23.0)$ & $15.5(15.0)$ & \\
\hline Other & $23.3(21.0)$ & $27.8(27.0)$ & \\
\hline \multicolumn{4}{|c|}{ Drinking water source (wet season) } \\
\hline Rain harvesting & $91.0(81.0)$ & $89.4(84.0)$ & \\
\hline Lake Victoria & $7.9(7.0)$ & $7.4(7.0)$ & \\
\hline Other & $1.1(1.0)$ & $3.2(3.0)$ & \\
\hline \multicolumn{4}{|c|}{ Drinking water source (dry season) } \\
\hline Lake Victoria & $53.3(48.0)$ & $53.2(50.0)$ & \\
\hline Public tap & $17.8(16.0)$ & $18.1(17.0)$ & \\
\hline private well protected & $14.4(13.0)$ & $14.9(14.0)$ & \\
\hline Other & $14.4(13.0)$ & $13.8(13.0)$ & \\
\hline \multicolumn{4}{|l|}{ Toilet facility } \\
\hline Not shared & $85.6(77.0)$ & $80.9(76.0)$ & \\
\hline No toilet & $7.8(7.0)$ & $14.9(14.0)$ & \\
\hline Shared & $5.6(5.0)$ & $2.1(2.0)$ & \\
\hline Other & $1.1(1.0)$ & $2.1(2.0)$ & \\
\hline \multicolumn{4}{|l|}{ Type of toilet } \\
\hline Pit latrine without slab & $60.0(54.0)$ & $62.8(59.0)$ & \\
\hline Pit latrine with slab & $31.1(28.0)$ & $22.3(21.0)$ & \\
\hline Bush toilet & $7.8(7.0)$ & $12.8(12.0)$ & \\
\hline Other & $1.1(1.0)$ & $2.1(2.0)$ & \\
\hline \multicolumn{4}{|l|}{ Transport type } \\
\hline None & $62.0(56.0)$ & $42.5(54.0)$ & \\
\hline Bicycle & $33.3(30.0)$ & $33.0(31.0)$ & \\
\hline Motorbike & $4.4(4.0)$ & $9.6(9.0)$ & \\
\hline \multicolumn{4}{|l|}{ Fuel source } \\
\hline Wood & $98.8(89)$ & $100.0(94.0)$ & \\
\hline Other & $1.1(1.0)$ & $0.0(0.0)$ & \\
\hline
\end{tabular}

*Values represent mean \pm SD or median $\left[25^{\text {th }}, 75^{\text {th }}\right.$ percentile $]$ or $\%(n)$ unless stated otherwise, ${ }^{1}$ Group wise differences analyzed by Independent samples T test and Mann Whitney $\mathrm{U}$ test for normal and non-normal data respectively, ${ }^{2} \mathrm{n}=82$ for $\mathrm{LSF} \mathrm{Zn}$ and placebo group for HAZ only due to missing date of birth, children with $\mathrm{Z}$ scores $<-2 \mathrm{SD}$ were considered as stunted and underweight according to WHO growth standards for children ( $<59 \mathrm{mths})$ and WHO 2007 reference population $(>60 \mathrm{mths}){ }^{3}$ multiple responses were possible 
Table 2: Baseline biochemical characteristics of study children (2-6yrs) in rural Western Kenya*

\begin{tabular}{llll}
\hline Variables assessed & LSF Zn group & Control group & P value $^{\mathbf{1}}$ \\
\hline Uncorrected PZn $(\mu \mathrm{g} / \mathrm{dl})$ & $65.9 \pm 10.6$ & $63.5 \pm 12.9$ & 0.169 \\
Zinc deficient $^{2}$ & $42.9(36 / 84)$ & $52.7(48 / 90)$ & 0.315 \\
Corrected $^{3} \mathrm{PZn} \mathrm{ug/dl}$ & $68.2 \pm 10.3$ & $64.8 \pm 13.3$ & 0.078 \\
Zinc deficient $^{2}$ & $32(28 / 82)$ & $46.2(42 / 84)$ & 0.083 \\
Hemoglobin concentration g/L & $109 \pm 1.4$ & $107 \pm 1.2$ & 0.377 \\
(Anemia) Low Hb & $51(46 / 90)$ & $60(56 / 94)$ & 0.248 \\
CRPmg/L & $2.4[0.7,15]$ & $2.4[0.9,15]$ & 0.768 \\
High CRP5 & $39(32 / 82)$ & $39.3(33 / 84)$ & 0.704 \\
AGPg/L & $1.1[0.7,1.9]$ & $1.0[0.8,1.6]$ & 0.946 \\
High AGP5 & $53.7(44 / 82)$ & $52.4(44 / 84)$ & 0.695 \\
\hline
\end{tabular}

*Values represent mean \pm SD or median $\left[25^{\text {th }} / 7^{\text {th }}\right.$ percentile $]$ and percent $(\mathrm{n} / \mathrm{N})$

${ }^{1}$ Group wise differences analysed by Independent samples T test (normal data), Mann Whitney U test (non-normal data) and Chi Square (proportions)

${ }^{2}$ Zinc deficiency: plasma zinc concentration $<65 \mu \mathrm{g} / \mathrm{dl}$ for AM and PZN $<57 \mu \mathrm{g} / \mathrm{dl}$ for PM samples [2]

${ }^{3}$ Corrected using the four level inflammation correction factor approach. Subjects were allocated to reference group unless plasma CRP concentration was $>5 \mathrm{mg} / \mathrm{L}$ and or plasma AGP was $>1.0 \mathrm{~g} / \mathrm{l}$ when subjects were allocated to the incubation (only CRP elevated), early convalescence (both CRP and AGP elevated) or late convalescence (AGP only) groups [44]

${ }^{4}$ Anaemia is defined as $\mathrm{Hb}<110 \mathrm{~g} / \mathrm{L}$ for children below the age of 59 months and $\mathrm{Hb}<115 \mathrm{~g} / \mathrm{L}$ for children 5-11 years [45]

${ }^{5}$ Defined by plasma concentrations of C-reactive protein $>5 \mathrm{mg} / \mathrm{L}$ or $\alpha 1$-acid glycoprotein $>1 \mathrm{~g} / \mathrm{l}$ [44]

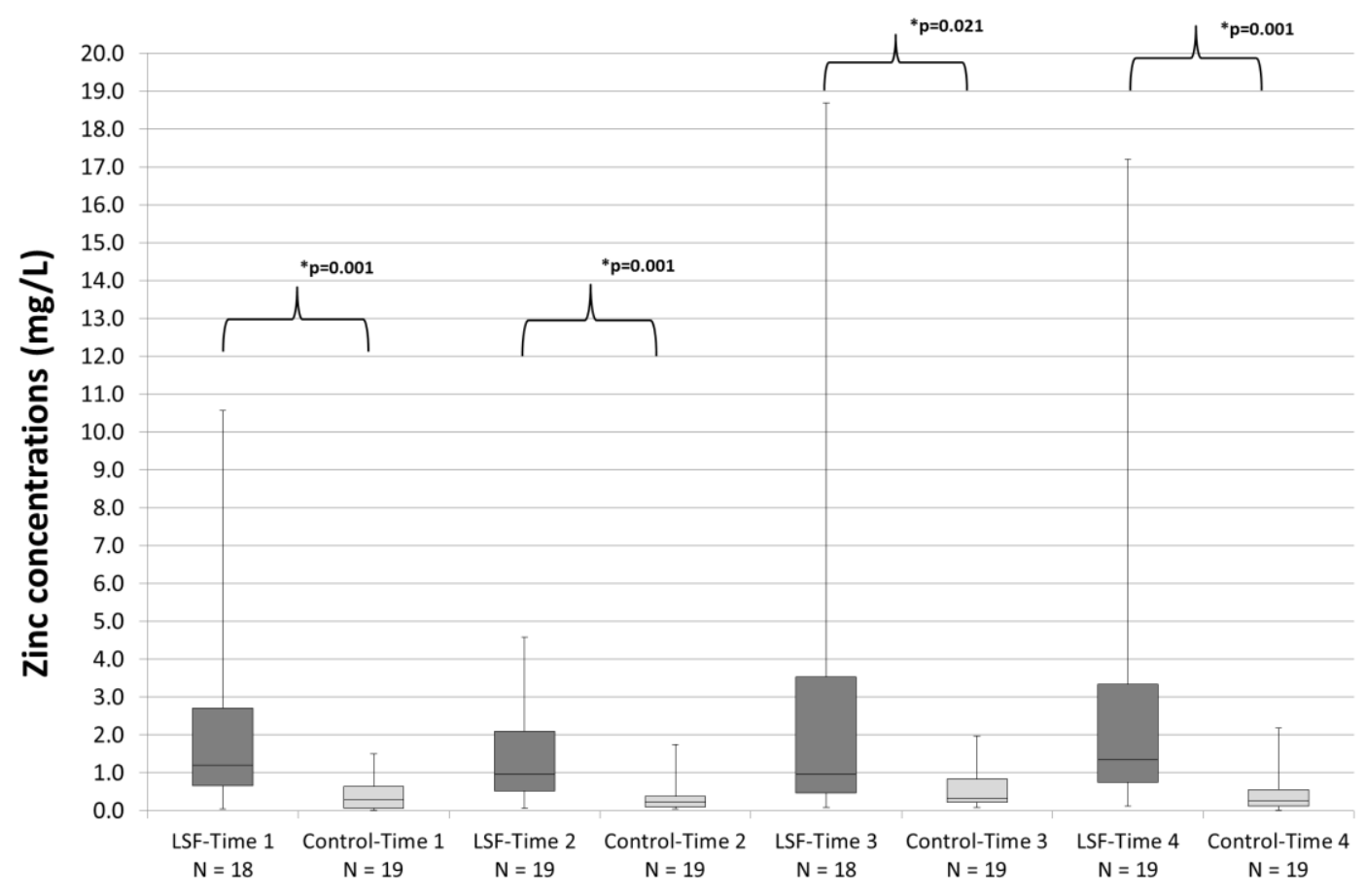

Figure 2: Zinc concentrations of random water samples collected in the households of the two treatment groups $\left(\mathrm{N}_{\text {total }}=150\right)$ LSF-Lifestraw family filter 


\section{Water quality}

The overall median colony forming units (cfu/100ml) TCC in influent and effluent water was $631[302,1743.75]$ and $22.5[0,136]$ respectively representing a percent reduction in TCC of $96 \%$ for both groups combined. Median Ecoli cfu/100ml before and after filtration was 12.5 [6.4, $50.6]$ and $0[0,1.5]$ representing a percent reduction in Ecoli of $100 \%$ for both groups combined. This reduction in TCC and Ecoli after filtration was significant $(\mathrm{p}<0.001)$. When the samples were analysed by group: LSF Zn group had a significant 95\% reduction in TCC and Control group a reduction of $99 \%$ in TCC counts. For Ecoli both groups had a significant reduction of $100 \%$.

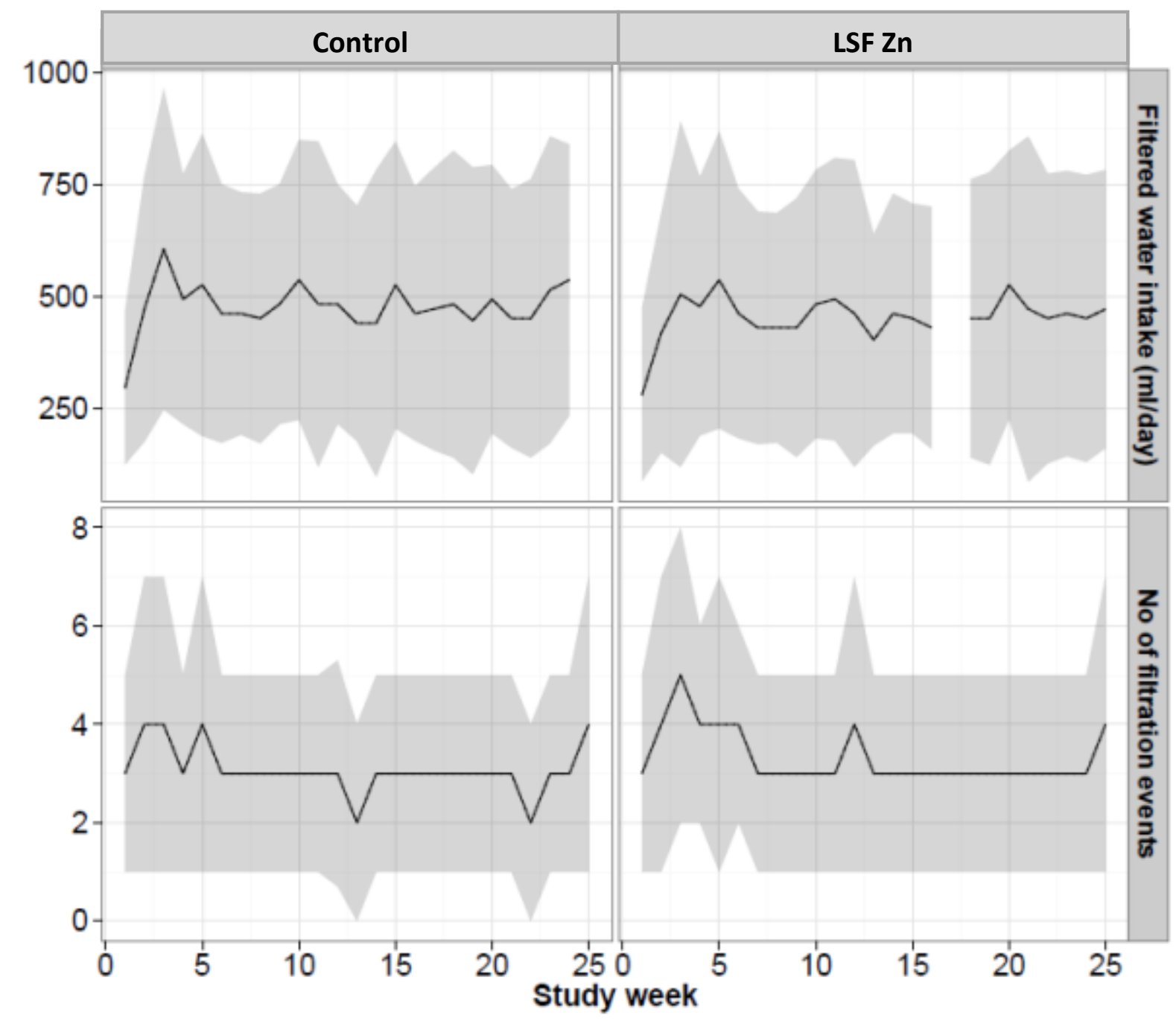

Figure 3: Graphs showing filtered water intake and filter usage by treatment group over study period. Solid line represents median with [25th, 75th] percentile (shaded area) for children 2-6 years old, rural Western Kenya

\section{Effect of intervention on serum zinc and stunting}

There was no significant time by treatment effect on plasma zinc $(\mathrm{p}=0.106)$ (Table 3). Zinc deficiency prevalence increased in LSF Zn group from $42 \%$ to $50 \%$ but decreased in the control from initial high of $53 \%$ to $52 \%$ however no significant time by treatment effect was observed $(p=0.506)$. There was a significant time effect on prevalence of zinc deficiency $(p=0.042)$. When change in plasma zinc was plotted against baseline plasma zinc levels, children with a higher initial corrected plasma zinc concentration had a minor change in PZn concentration and vice versa $(-0.72 \mu \mathrm{g} / \mathrm{dl}$ less increase in PZn for each $\mu \mathrm{g} / \mathrm{dl}$ greater baseline PZn concentration) (Figure 
4). This phenomenon occurred regardless of treatment group ( $\mathrm{p}=0.15)$ and also for uncorrected PZn (Figure 5). The strongest predictor of change in plasma zinc was baseline plasma zinc status $(\mathrm{p}=<0.001)$ and endpoint CRP $(\mathrm{p}<0.001)$.

At baseline overall median with IQR for CRP and AGP was $2.3[0.8,13.3]$ and $1.05[0.7,1.6]$ respectively indicating inflammation in 39\% (65/166) and 53\% (88/166) of the study population. There was a trend towards a time effect $(\mathrm{p}=0.067)$ and significant time by treatment interaction effect on the prevalence of elevated AGP $(p=0.019)$, while the difference in prevalence between the groups at endpoint was not significant $(p=0.937)$. There was no significant time effect or time by treatment effect on stunting $(\mathrm{p}=0.966)$ and prevalence of stunting $(\mathrm{p}=0.879)$.

\section{Morbidity}

Table 4 shows the effect of zinc fortified water and non-zinc fortified water on the occurrence of common infectious morbidities as reported by caregivers during the weekly field assistant visits. Overall, in the intention to treat analysis, percentage visits with reported illness were lower in LSF Zn (15.9\%) than Control group (17.4\%) for all conditions assessed ( $\mathrm{p}<0.001)$; RR (95\%CI) $=0.91(0.87,0.96)$. Analyzing symptoms separately, there were significantly higher percentage visits with reported for cold runny nose $(\mathrm{p}=0.034)$ and stomach pain $(\mathrm{p}=0.003)$ and a trend for a difference in the percentage of visits during which diarrhea $(\mathrm{p}=0.09)$ was reported, but no effect on other conditions assessed (Table 4). Per protocol analysis showed similar results, with the exception of reported diarrhea which was significantly lower in the LSF Zn group than the control group ( $\mathrm{p}=0.03)$. There were 34 total clinic visits for diarrhea with 11 occasions when zinc tablets were given (LSF Zn group) and 47 total visits for diarrhea with 12 occasions when zinc tablets were given as part of treatment (control group). Clinic visits did not significantly differ between the 2 groups $(\mathrm{p}=0.129)$

\section{DISCUSSION}

We investigated the effect of zinc fortified water on improving zinc intake, zinc status and morbidity of young rural Kenyan children. The results indicate that the consumption of fortified water (1.15 mg zinc/L; range=0.04-18.7) over a 25 weeks intervention period had a substantial addition to the daily zinc intake. This led to less reported overall morbidity and lower specific morbidity such as stomach pain and cold with runny nose, and to a trend towards less reported diarrhea, which was significant in the per protocol analysis. In contrast, we did not detect an increase in plasma zinc concentration and an effect on the prevalence of zinc deficiency. Similarly to our findings, daily zinc supplementation ( $5 \mathrm{mg}$ per day in $5 \mathrm{ml}$ sterile water) reduced incidence of diarrhea and upper respiratory tract infections in Tanzanian infants [48], and comparable benefits of zinc supplementation on diarrhea and acute respiratory infections have been observed in a systematic review [13]. PZn may not be a highly sensitive marker of zinc status [49] and a marker reflecting body zinc pools is yet to be identified [50]. A previous zinc supplementation study in zinc deficient children has shown improvement in clinical features of zinc deficiency such as linear growth and immune function with no change in PZn [51], whilst several studies have shown improvements in growth indices in zinc supplemented children with decrease in serum zinc [52-55]. 


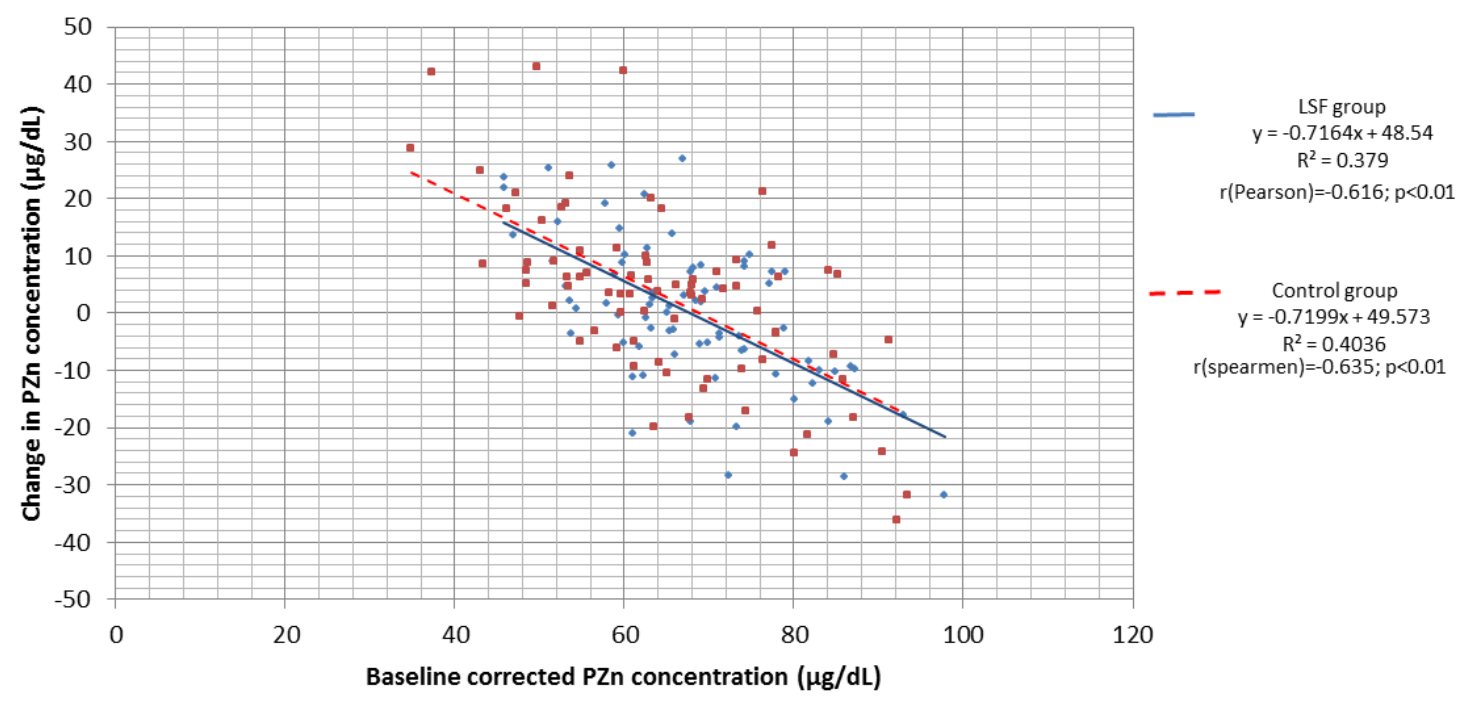

Figure 4: The magnitude of change in corrected plasma zinc concentration dependent $(\mathrm{p}<0.01)$ on baseline corrected PZn concentration, by LSF Zn-Group ( $N=75)$ and Control group $(\mathrm{N}=78)$ for the children 2-6 years old rural Western Kenya. PZn-plasma zinc. LSF-Lifestraw family filter. PZn was corrected using the four level inflammation correction factor approach. Subjects were allocated to reference group unless plasma CRP concentration was $>5 \mathrm{mg} / \mathrm{L}$ and or plasma AGP was $>1.0 \mathrm{~g} / \mathrm{l}$ when subjects were allocated to the incubation (only CRP elevated), early convalescence (both CRP and AGP elevated) or late convalescence (AGP only) groups [44]

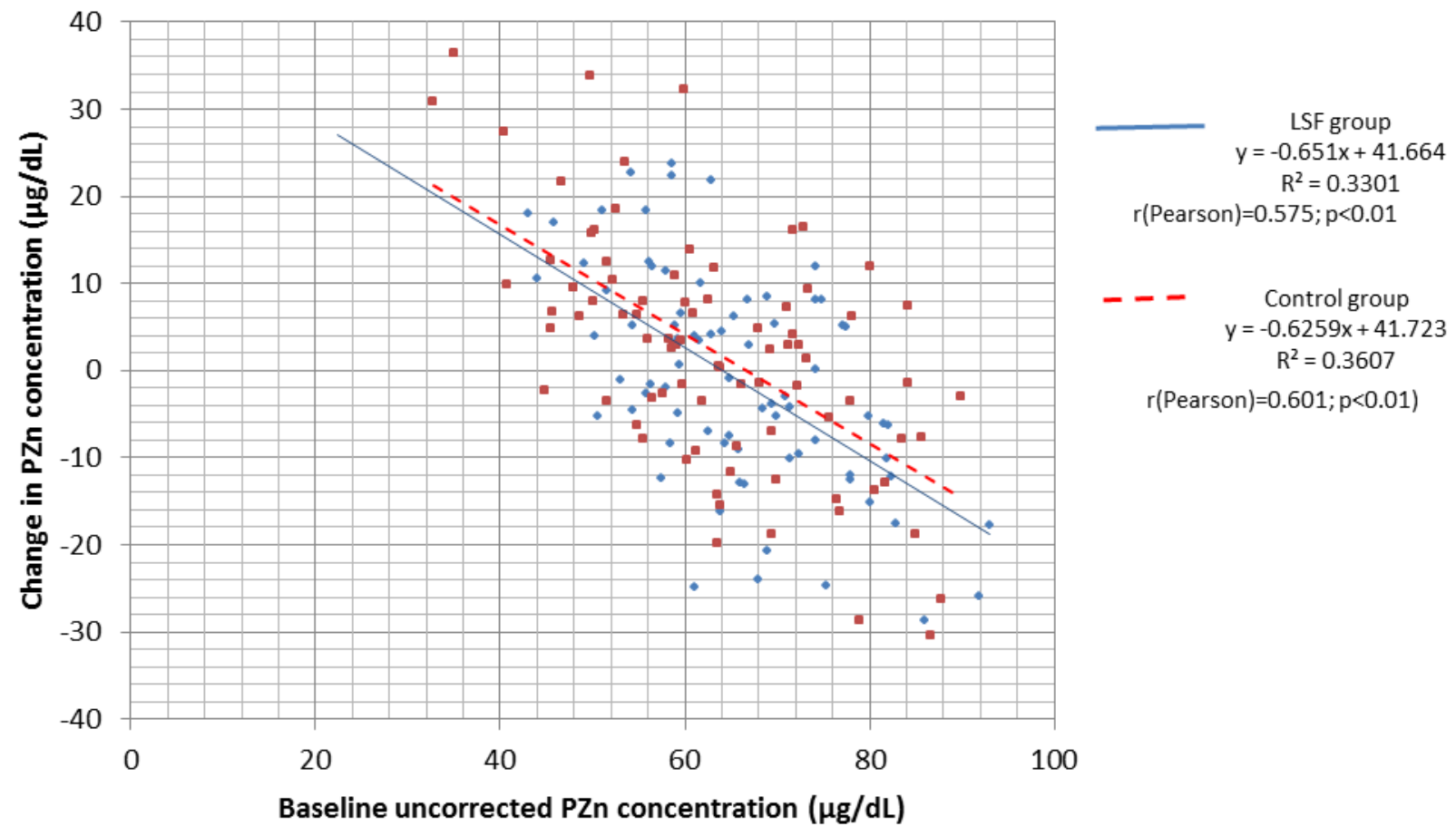

Figure 5: The magnitude of change in uncorrected plasma zinc concentration dependent $(\mathrm{p}<0.01)$ on baseline uncorrected PZn concentration, by LSF Zn-Group ( $\mathrm{N}=77$ ) and Control group ( $\mathrm{N}=83$ ) for the children 2-6 years old rural Western Kenya. PZn-plasma zinc, LSF-Lifestraw family filter

These children were either small for gestational age, stunted or malnourished at baseline. It could be that in nutritionally deficient children, functional response is higher due to higher sequestration rate of zinc by tissues in need of zinc, however this remains to be proven. ZIP4 is 
known to increase in times zinc deficiency [56], and zinc from plasma is taken up in the tissues by ZIP transporters [57]. Furthermore in a review to assess the therapeutic value of zinc supplementation in acute and persistent diarrhea, the efficacy of zinc therapy on acute diarrhea was not predicted by plasma zinc concentrations [58].

Table 4: Effect of daily consumption of zinc fortified (LSF Zn) or non-fortified (Control) water on the occurrence of common infectious morbidities in 2-6 year old children, rural Western Kenya

\begin{tabular}{|c|c|c|c|c|}
\hline & LSF Zn group $n=88$ & Control group $n=90$ & & \\
\hline & \multicolumn{2}{|c|}{$\%(n$ event $/ \mathbf{n}$ visit) } & $\operatorname{RR}(95 \% \mathrm{CI})$ & $P$ value \\
\hline Overall morbidity & $15.9(2623 / 16489)$ & $17.4(2916 / 16714)$ & $0.91(0.87,0.96)$ & 0.000 \\
\hline \multicolumn{5}{|c|}{ Morbidity per condition* } \\
\hline Diarrhea & $3.9(80 / 2063)$ & $5.0(103 / 2088)$ & $0.78(0.59,1.04)$ & 0.090 \\
\hline Cold runny nose & $29.8(615 / 2060)$ & $32.9(687 / 2088)$ & $0.91(0.83,0.99)$ & 0.034 \\
\hline Rapid breathing & $8.1(168 / 2062)$ & $9.0(188 / 2087)$ & $0.90(0.74,1.10)$ & 0.322 \\
\hline Cough & $27.0(562 / 2062)$ & $29.0(610 / 2089)$ & $0.93(0.85,1.03)$ & 0.164 \\
\hline Stomach pain & $5.6(116 / 2060)$ & $7.9(167 / 2091)$ & $0.70(0.56,0.89)$ & 0.003 \\
\hline Fever & $25.0(520 / 2063)$ & $26.0(550 / 2091)$ & $0.96(0.86,1.06$ & 0.419 \\
\hline Headache & $22.0(455 / 2058)$ & $23.4(489 / 2090)$ & $0.94(0.84,1.06)$ & 0.322 \\
\hline Sore throat & $5.2(107 / 2061)$ & $5.8(122 / 2090)$ & $0.89(0.69,1.14)$ & 0.362 \\
\hline
\end{tabular}

Our findings build upon a previous study assessing the efficacy of zinc fortified water to improve zinc status in young children [19]. In a school based trial conducted in Benin, zinc fortified drinking water was able to maintain higher plasma zinc concentration and reduce prevalence of zinc deficiency, but with no effect on morbidity levels in the study children. The difference in outcomes between the two studies can be partly explained by the study design, target group and duration of trial: our current study was designed as an effectiveness household based trial, as such we set out to investigate the effect of zinc fortified water in conditions similar to real life, where filtering devices would be distributed to the households, such as in a donor driven initiative. The target group comprised younger children (aged 2-6 years) generally more vulnerable to critical water quality and sanitary issues than school-aged children. By the nature of the effectiveness intervention, water consumption was less strictly controlled compared to the Benin study resulting in lower than expected water consumption (only $40 \%$ of the participants consumed in average $500 \mathrm{ml}$ treated water per day while the Benin study reported a compliance of about $80 \%$ ). The zinc level in the consumed water was limited to an average level of $1.15 \mathrm{mg} / \mathrm{l}$ (compared to about $4.6 \mathrm{mg} / \mathrm{l}$ in the Benin study), due to variability in water consumption and zinc elution rates from the device, which can vary when usage patterns fluctuate.

This study was conducted in rural Kisumu in villages along Lake Victoria. The households are daily exposed to unclean water and the risk of zinc deficiency and infections was expected to be high [59-62]. This was confirmed by the high prevalence of inflammation, zinc deficiency as well as anemia at baseline in the study population. Background dietary zinc intake was high in this group as compared to other studies that found low dietary zinc intakes in Kenyan children such as $2.8 \mathrm{mg} / \mathrm{d} \pm 1.5$ [63] and $3.7 \pm 0.88 \mathrm{mg} / \mathrm{d}$ [64] however a high proportion $81.1 \%$ and $87.3 \%$ (LSF $\mathrm{Zn}$ and control group respectively) of the children were below the WHO EAR [65] for zinc intake (without contribution of zinc fortified water) suggesting elevated risk of zinc deficiency. At a 
fortification level of $1.15 \mathrm{mg} / \mathrm{L}$ the fortified water contributed about $0.52[0.37,0.74] \mathrm{mg} / \mathrm{d}$ additional zinc per day. This amount though seemingly low is highly bioavailable [19] and can contribute up to 42 and $36 \%$ of the WHO set physiologic requirements for absorbed zinc of children aged 2-3 years and 4-6 years respectively [2].

\section{Intervention effect on serum zinc}

While we found no overall effect of the intervention on PZn level, in the control group the plasma zinc concentration at endpoint was higher than the baseline, whilst for the LSF Zn group it was lower. This trend can be partially explained by the levels of acute phase proteins in the children. Whilst in general there was a high prevalence of inflammation at baseline, inflammation levels remain elevated in the LSF Zn group with higher prevalence at endpoint than in the control group. Elevated acute phase proteins are known to decrease plasma zinc concentration [66]. The study was conducted from February to August, a period encompassing peak (April to July) malaria and influenza transmission [67]. Thus seasonal increase in infection could have blunted the effect of the intervention. Conducting the analysis with corrected PZn still gave no significant time by treatment effect $(p=0.137)$ (Table 3$)$.

The lack of an overall positive effect on plasma zinc concentration and stunting could also have been due to the low dosage delivered by the fortification device $(1.15 \mathrm{mg} / \mathrm{L})$. Comparison with other studies is limited as there have not been studies testing the effect of zinc fortified water on zinc status in literature. Trials on zinc fortification of foods that have used fortification levels below $5 \mathrm{mg} /$ day have shown mixed results. A recent review on effect of zinc fortified cereals and/or formula feed on zinc status in children showed a significant impact on serum zinc concentration but a non-significant change in height growth velocity. Fortification levels ranged from $3.2 \mathrm{mg} / \mathrm{L}$ to $15 \mathrm{mg} / \mathrm{L}$ [14].

\section{Intervention effect on diarrhea and other morbidities.}

This study shows a significant reduction in reported stomach pain, cold with runny nose and a trend towards reduced diarrhea events in the LSF Zn group compared to control group. In contrast we observed an opposite effect in the infection and inflammation marker AGP, which was more elevated in the LSF Zn group experiencing less reported morbidity. While we cannot fully explain this finding, a possible reason for this observation may be related to the failure of children in the control group to mount an effective immune response (detected by elevated AGP), which may have contributed to the increased observed morbidity from cold, stomach pain and diarrhea. Supplementation with zinc has been previously shown to amplify the acute phase response as shown by increased body temperature, cytokine concentrations, the acute phase protein ceruloplasmin, and IL-6 in human and animal studies [68, 69]. Adequate zinc levels are necessary for effective immunomodulation, as detected by the increased AGP levels [70]. Mechanistically, AGP may inhibit polymorphonuclear neutrophil activation [71], increase the secretion of an IL-1 inhibitor by murine macrophages, most probably the IL-1 receptor antagonist, and modulate LPS-induced cytokine secretion by monocytes-macrophages[71].

Participants in the LSF Zn group had less clinic visits for diarrhea $(n=34)$ than the control group $(\mathrm{n}=47)$, but this difference was not significant $(\mathrm{p}=0.129)$. A general effect modifier in our study could have been the dispensing of zinc tablets by the local clinic to study children. The Kenya government adopted into national policy the WHO recommendation of including zinc supplements as first line treatment for diarrhea [72]. However, the LSF Zn and control group 
reported to have received zinc tablets on a comparable number of occasions (11 and 12 respectively) as part of diarrhea treatment. Furthermore plasma zinc concentrations are known to decline rapidly after supplementation is withdrawn [73] and therefore it is unlikely that this treatment from the clinic had a lasting effect on the plasma zinc concentration of the study children. A further possible confounder could have been total filtered water consumed. When comparing diarrhea events with total filtered water consumed, total filtered water consumed was higher in children who never experienced diarrhea $(n=96,8074 \mathrm{~L})$ as compared to children who had one or more diarrhea event $(\mathrm{s})(\mathrm{n}=82,6544.5 \mathrm{~L})$. This translated to a difference of $4.3 \mathrm{~L}$ /per person over the intervention period. This difference though not significant $(p=0.486)$ may reflect the beneficial effect of filter usage irrespective of zinc dosage. Although the study was not directly powered to detect treatment effect on morbidity as a larger sample size would have been required, these results are important for future large scale studies that aim to test the preventative effect of low dose zinc fortification. The study reveals that when households are left alone to use the current LSF filter, a donated household water treatment device, compliance is likely to decrease in the absence of external reinforcement. This trend was especially observed at periods close to baseline, midpoint and endpoint (Figure 2). Although this specific study did not set out to investigate determinants of compliance to filter usage, a previous study has recommended a change in design of the filter to encourage and increase compliance [74].

Several strengths of our study deserve mention. The study was 6 month long prospective, randomized trial, with weekly surveillance from trained field assistants. The study population was divided into 4 pseudo arms to increase the level of blinding, and we experienced a low dropout rate of $9.2 \%$. The study was conducted in young, preschool children, the population likely to be vulnerable to both poor sanitary conditions and zinc deficiency and at the same time to benefit the most from a household based intervention. However, the study also had some limitations. Conducting the study during peak infection season may have led to lack of a net positive effect on PZn concentration. Although the field assistants that conducted morbidity surveillance were trained, they were not health personnel and this could have led to misclassification of symptoms. Morbidity data was based on recall from the mother, a method that relies on memory which may have introduced some errors. Recall bias is best minimized by blinding subjects sufficiently and standardizing data collection protocols and this was conducted to best ability.

In conclusion our results show that zinc fortified water contributes to dietary zinc intake and results in an improvement in reported childhood infections. Though we did not detect an improvement in plasma zinc status and reduction in prevalence of zinc deficiency, it led to a reduction in overall morbidity as well as morbidity due to cold, stomach pain and diarrhea, suggesting the high public health potential of zinc fortification of water through household water treatment systems. This novel approach should be further optimized with regard to device design and zinc elution, but our data suggest that the approach could have significant public heath impact in preventing general childhood infections in preschool children in rural Africa. 


\section{REFERENCES}

1. Wessels RK, Singh MG, Brown KH: Estimating the Global Prevalence of Inadequate Zinc Intake from national Food Balance Sheets: Effects of Methodological Assumptions. PLoS One 2012.

2. Brown KH, Rivera JA, Bhutta Z, Gibson RS, King JC, Lonnerdal B, Ruel MT, Sandtrom B, Wasantwisut E, Hotz C: International Zinc Nutrition Consultative Group (IZiNCG) technical document \#1. Assessment of the risk of zinc deficiency in populations and options for its control. Food Nutr Bull 2004, 25(1 Suppl 2):S99-203.

3. King J, Cousins R: Modern Nutrition in Health and Disease. 10th edition. Baltimore: Lippincott Williams \& Wilkins; 2006.

4. Black RE, Allen LH, Bhutta ZA, Caulfield LE, de Onis M, Ezzati M, Mathers C, Rivera J: Maternal and child undernutrition: global and regional exposures and health consequences. Lancet 2008, 371:243-60.

5. Shrimpton R, Shankar A: Zinc Deficiency. New Jersey, USA: Humana Press; 2008.

6. Hambidge M: Human Zinc Deficiency. J Nutr 2000, 130:1344S-1349.

7. Ghishan F: Transport of electrolytes, water, and glucose in zinc deficiency. J Pediatr Gastroenterol Nutr 1984, 3:608-12.

8. SA.Sarker, MM.Rahman, A.Ali, S.Hossain AA: Prolonged depression of serum zinc concentration in children following post measles diarrhea. Hum Nutr Clin Nutr 1985, 39:411-7.

9. KM. Hambidge: Zinc and diarrhea. Acta Paediatr Suppl 1992, 381:82-6.

10. Imdad A, Bhutta ZA: Effect of preventive zinc supplementation on linear growth in children under 5 years of age in developing countries: a meta-analysis of studies for input to the lives saved tool. BMC Public Health 2011, 11 Suppl 3(Suppl 3):S22.

11. Ramakrishnan $U$, Nguyen $P$, Martorell R: Effects of micronutrients on growth of children under 5 y of age: meta-analyses of single and multiple nutrient interventions. Am J Clin Nutr 2009, 89:191-203.

12. Brown KH, Peerson JM, Baker SK, Hess SY: Preventive zinc supplementation among infants, preschoolers, and older prepubertal children. Food \& Nutrition Bulletin 2009:12S-40S.

13. Mayo-Wilson E, Junior JA, Imdad A, Dean S, Chan XHS, Chan ES, Jaswal A, Bhutta ZA: Zinc supplementation for preventing mortality, morbidity, and growth failure in children aged 6 months to 12 years of age. Cochrane database Syst Rev 2014, 5:CD009384.

14. Das J, Kumar R, Bhutta Z, Salam R: Systematic Review of Zinc Fortification Trials. Ann Nutr Metab 2013, 62(suppl 1):44-56.

15. Brown K, Hambidge $M$, Ranum $P$, Zinc Fortification working group: Zinc fortification of cereal flours: Current recommendations and research needs. Food Nutr Bull 2010, 31(1 (Supplement)).

16. Hess SY, Brown KH: Impact of zinc fortification on zinc nutrition. Food Nutr Bull 2009, 30(1 Suppl):S79-107.

17. Wapnir RA: Zinc Deficiency, Malnutrition and the Gastrointestinal Tract. J Nutr 2000, 130:1388S-1392S.

18. Castillo-Duran C, Vial P, Uauy R: Trace mineral balance during acute diarrhea in infants. J Pediatr 2015, 113:452-457.

19. Galetti V, Kujinga $P$, Mitchikpè CES, Zeder C, Tay F, Tossou F, Hounhouigan JD, Zimmermann MB, Moretti D: Efficacy of highly bioavailable zinc from fortified water: a randomized controlled trial in rural Beninese children. Am J Clin Nutr 2015 Nov;102(5):1238-48

20. Sandstrom B, Davidsson L, Cederblad A, Lonnerdal B: Oral Iron, Dietary Ligands and Zinc Absorption. J Nutr 1985, 115:411-414.

21. Nutrition of the school-aged child...3. SCN News 1998.

22. Bundy D: School health and nutrition: policy and programs. Food Nutr Bull 2005, 26(2 Suppl 2):S186-92.

23. Bryce J, Coitinho D, Darnton-Hill I, Pelletier D, Pinstrup-Andersen P: Maternal and child undernutrition: effective action at national level. Lancet (London, England) 2008, 371:510-26. 
24. IZINCG: Collecting Blood in the Field for Assessment of Plasma Zinc Concentration. Practical Tips. 2012.

25. IZINCG: Assessing Population Zinc Status with Serum Zinc Concentration. Technical Brief No. 2. 2007.

26. Erhardt JG, Estes JE, Pfeiffer CM, Biesalski HK, Craft NE: Combined Measurement of Ferritin, Soluble Transferrin Receptor, Retinol Binding Protein, and C-Reactive Protein by an Inexpensive, Sensitive, and Simple Sandwich Enzyme-Linked Immunosorbent Assay Technique. J Nutr 2004, 134 (11):3127-3132.

27. McLean E, Cogswell M, Egli I, Wojdyla D, de Benoist B: Worldwide prevalence of anaemia, WHO Vitamin and Mineral Nutrition Information System, 1993-2005. Public Health Nutr 2009, 12:444-54.

28. Gibson R, Fergurson E: An Interactive 24-Hour Recall for Assessing the Adequacy of Iron and Zinc Intakes in Developing Countries. Washington DC: International Life Sciences Institute; 1999.

29. Blanton CA, Moshfegh AJ, Baer DJ, Kretsch MJ: The USDA Automated Multiple-Pass Method accurately estimates group total energy and nutrient intake. J Nutr 2006, 136:2594-9.

30. Boerma JT, Black RE, Sommerfelt AE, Rutstein SO, Bicego GT: Accuracy and Completeness of Mothers' Recall of Diarrhea Occurrence in Pre-School Children in Demographic and Health Surveys. Int J Epidemiol 1991, 20:1073-1080.

31. Alam N, Henry F, Rahaman M: Reporting errors in one-week diarrhea recall surveys : experience from a prospective study in rural Bangladesh. Int J Epidemiol 1989, 18:697-700.

32. Ramakrishnan R, Venkatarao $T$, Koya $P$, Kamaraj $P$ : Influence of recall period on estimates of diarrhea morbidity in infants in rural Tamilnadu. Indian J Public Heal 1999, 43:136-9.

33. WHO: Diarrheal disease. 2013.

34. Sehmi J: National Food Composition Tables and the Planning of Satisfactory Diets in Kenya. Nairobi Kenya: Government Press; 1993.

35. Wolmarans P, Danster N, Dalton A, Rossouw K, Schönfeldt H: Condensed Food Composition Tables for South Africa. Parrow valley Cape Town; 2001.

36. Barikmo I, Ouattara F, Oshaug A: Table de Composition D'aliments Du Mali. 12th Ed. Oslo: Oslo; 2004.

37. West C, Pepping F, Temalilwa C: The Composition of Foods Commonly Eaten in East Africa. Wageningen, the Netherlands; 1988.

38. World food dietary assessment system [www.fao.gov/infoods]

39. USDA: National Nutrient Database for Standard Reference, Release 27. Washington DC; 2007.

40. USDA Table of Nutrient Retention Factors, Release 6. Nutrient Data Laboratory home page [http://www.ars.usda.gov/ba/bhnrc/ndl]

41. National Research Council. Nutrient Adequacy: Assessment Using Food Consumption Surveys. Report of the Sub-Committee on Criteria for Dietary Evaluation, Food and Nutrition Board, Commission of Life Sciences. Washington DC: National Academy Press; 1986.

42. Nusser S, Carriquiry A, Fuller W: A Semiparametric Transformation Approach to Estimating Usual Daily Intake Distributions`. CARD Work Pap 1992.

43. Hanley JA: Statistical Analysis of Correlated Data Using Generalized Estimating Equations: An Orientation. Am J Epidemiol 2003, 157:364-375.

44. Thurnham DI, Mburu ASW, Mwaniki DL, Wagt A De: Micronutrients in childhood and the influence of subclinical inflammation. Proc Nutr Soc 2005, 64:502-509.

45. WHO/UNICEF/UNU: Iron Deficiency Anemia: Assessment, Prevention and Control. A Guide for Programme Managers. WHO/NHD/01.3. Geneva, Switzerland; 2001.

46. FAO: Human Energy Requirements, Report of a Joint FAO/WHO/UNU Expert Consultation. FAO Food and Nutrition Technical Report Series. FAO/WHO/UNU,Rome,Italy; 2004.

47. De Onis M, Blossner M: WHO Global Database on Child Growth and Malnutrition. Geneva, Switzerland; 1997.

48. McDonald CM, Manji KP, Kisenge R, Aboud S, Spiegelman D, Fawzi WW, Duggan CP: Daily Zinc but Not Multivitamin Supplementation Reduces Diarrhea and Upper Respiratory Infections in Tanzanian Infants: A Randomized, Double-Blind, Placebo-Controlled Clinical Trial. J Nutr 2015. 
49. Hess SY, Peerson JM, King JC, Brown KH: Use of serum zinc concentration as an indicator of population zinc status. Food Nutr Bull 2007, 28:S403-429.

50. King JC: Zinc: an essential but elusive nutrient. Am J Clin Nutr 2011, 94:679S-684S.

51. Schlesinger L, Arevalo M, Arredondo S, Diaz M, Lönnerdal B, Stekel A: Effect of a zinc-fortified formula on immunocompetence and growth of malnourished infants. Am J Clin Nutr 1992, 56 (3):491-498.

52. Friis $H$, Ndhlovu $P$, Mduluza T, Kaondera K, Sandström B, Michaelsen KF, Vennervald BJ, Christensen NO: The impact of zinc supplementation on growth and body composition: a randomized, controlled trial among rural Zimbabwean schoolchildren. Eur J Clin Nutr 1997, 51:38-45.

53. Ruz M, Castillo-Duran C, Lara X, Codoceo J, Rebolledo A, Atalah E: A 14-mo zinc-supplementation trial in apparently healthy Chilean preschool children. Am J Clin Nutr 1997, 66.

54. Sayeg Porto MA, Oliveira HP, Cunha AJ, Miranda G, Guimarães MM, Oliveira WA, dos Santos DM: Linear growth and zinc supplementation in children with short stature. J Pediatr Endocrinol Metab , 13:1121-8.

55. Castillo-Durán C, Rodríguez A, Venegas G, Alvarez P, Icaza G: Zinc supplementation and growth of infants born small for gestational age. J Pediatr 1995, 127:206-11.

56. Dufner-Beattie J, Kuo Y-M, Gitschier J, Andrews GK: The adaptive response to dietary zinc in mice involves the differential cellular localization and zinc regulation of the zinc transporters ZIP4 and ZIP5. J Biol Chem 2004, 279:49082-90.

57. Hess SY, Lönnerdal B, Hotz C, Rivera JA, Brown KH: Recent advances in knowledge of zinc nutrition and human health. Food Nutr Bull 2009, 30(1 Suppl):S5-11.

58. Patel A, Mamtani M, Dibley MJ, Badhoniya $N$, Kulkarni $H$ : Therapeutic value of zinc supplementation in acute and persistent diarrhea: a systematic review. PLoS One 2010, 5:e10386.

59. Siekmann JH, Allen LH, Bwibo NO, Demment MW, Murphy SP, Neumann CG: Kenyan School Children Have Multiple Micronutrient Deficiencies, but Increased Plasma Vitamin B-12 Is the Only Detectable Micronutrient Response to Meat or Milk Supplementation. J Nutr 2003, 133 (11):3972S-3980S.

60. Bwibo NO, Neumann CG: The need for animal source foods by Kenyan children. $J$ Nutr 2003, 133(11 Suppl 2):3936S-3940S.

61. Tornheim JA: The epidemiology of hospitalisation with diarrhea in rural Kenya: the utility of existing health facility data in developing countries. International Journal of infectious diseases. Int J Infect Dis 2010, 14:e499-e505.

62. Adazu K: Health and demographic surveillance in rural western Kenya: a platform for evaluating interventions to reduce morbidity and mortality from infectious diseases. Am J Trop Med Hyg 2005, 73:1151-1158.

63. Gegios A, Amthor R, Maziya-Dixon B, Egesi C, Mallowa S, Nungo R, Gichuki S, Mbanaso A, Manary $\mathrm{MJ}$ : Children consuming cassava as a staple food are at risk for inadequate zinc, iron, and vitamin A intake. Plant Foods Hum Nutr 2010, 65:64-70.

64. Murphy SP, Beaton GH, Calloway DH: Estimated mineral intakes of toddlers: predicted prevalence of inadequacy in village populations in Egypt, Kenya, and Mexico. Am J Clin Nutr 1992, 56 (3):565-572.

65. Allen L, de Benoist B, Dary O, Hurrell RF (Eds): WHO / Guidelines on Food Fortification with Micronutrients. World Health Organization; 2006.

66. Brown KH: Effect of infections on plasma zinc concentration and implications for zinc status assessment in low-income countries. Am J Clin Nutr 1998, 68 (2):425S-429S.

67. Waitumbi JN, Kuypers J, Anyona SB, Koros JN, Polhemus ME, Gerlach J, Steele M, Englund JA, Neuzil KM, Domingo GJ: Outpatient Upper Respiratory Tract Viral Infections in Children with Malaria Symptoms in Western Kenya. Am J Trop Med Hyg 2010, 83:1010-1013.

68. Krones C, Klosterhalfen B, Fackeldey V, Junge K, Rosch R, Schwab R, Stumpf M, Klinge U, Schumpelick V: Deleterious effect of zinc in a pig model of acute endotoxemia. J Invest Surg, 17:249-56. 
69. Braunschweig $\mathrm{CL}$, Sowers $\mathrm{M}$, Kovacevich DS, Hill GM, August DA: Parenteral zinc supplementation in adult humans during the acute phase response increases the febrile response. J Nutr 1997, 127:70-4.

70. Aydemir TB, Blanchard RK, Cousins RJ: Zinc supplementation of young men alters metallothionein, zinc transporter, and cytokine gene expression in leukocyte populations. Proc Natl Acad Sci U S A 2006, 103:1699-704.

71. Fournier T, Medjoubi-N N, Porquet D: Alpha-1-acid glycoprotein. Biochim Biophys Acta - Protein Struct Mol Enzymol 2000, 1482:157-171.

72. Sanitation M of PH and: Policy Guidelines on Control and Management of Diarrheal Diseases in Children below Five Years in Kenya. Nairobi Kenya; 2010.

73. Wessells KR, Jorgensen JM, Hess SY, Woodhouse LR, Peerson JM, Brown KH: Plasma Zinc Concentration Responds Rapidly to the Initiation and Discontinuation of Short-Term Zinc Supplementation in Healthy Men. J Nutr 2010, 140 (12 ):2128-2133.

74. Galetti V: Combining water treatment and zinc fortification against zinc deficiency and diarrhea in low-income settings. Ph.D. thesis. ETH Zurich; 2014. 


\section{Chapter 5}

Daily food-based dietary recommendations combined with zinc fortified drinking water ensure nutrient adequacy among 4-6 year old Kenyan children

Prosper Kujinga, Karin J. Borgonjen-van den Berg, Cecilia Superchi, Hermine J. ten Hove, Elizabeth Opiyo Onyango, Pauline Andang'o, Valeria Galetti, Michael B. Zimmerman, Diego Moretti, Inge D. Brouwer 


\section{ABSTRACT}

Introduction: Children in developing countries often face multiple micronutrient deficiencies. Introduction of zinc fortified water can increase zinc intake but additional recommendations are required to address overall diet nutrient adequacy.

Objective: We developed and tested food based recommendations (FBRs) that included zinc fortified water for children aged between 4 and 6 years from rural Kenya to achieve the best possible nutrient adequacy.

Methods: Dietary intakes of 60 children aged 4-6 years, from Kisumu district, Western Kenya, were assessed using a quantitative multi-pass 24-hour recall. Linear programming model parameters were derived, including a list of foods consumed, median serving sizes and distribution of frequency of consumption. By using the Optifood linear programming tool, food based recommendations for diets including zinc fortified water were developed. Food subgroups from nutrient dense foods were added to achieve an optimized nutritionally adequate diet. Food based recommendations with nutrient levels achieving $\geq 70 \%$ RNI of the WHO/FAO recommended nutrient intake (RNI) for most of the 12 considered nutrients were selected as the final recommendations for the children.

Results: With no FBRs and no zinc fortified water percent RNI coverage range was between 40 and $76 \%$ for zinc, improving to $66-101 \%$ after introduction of zinc fortified water. The final set of FBRs achieved nutrient adequacy for all nutrients except for vitamin A (25\%RNI) and folate (68\%RNI).

Conclusions: Introduction of zinc fortified water combined with FBRs will likely improve the nutrient adequacy of diets consumed by children in Kenya, but need to be complemented with alternative interventions to ensure dietary adequacy. Optifood is a useful tool to assess the extent to which introduction of a water fortification intervention plus additional FBRs can contribute to nutrient adequacy of the diet. 


\section{INTRODUCTION}

Zinc (Zn) deficiency is common in children in developing countries leading to poor growth and decreased immune competence [1]. Twenty-six percent of children under 5 years old in Kenya are estimated to be at risk of zinc deficiency [2]. An important cause of zinc deficiency is inadequate dietary zinc intake or low zinc bioavailability in plant based foods, due to the presence of absorption inhibitors such as phytic acid [3].

Food fortification with zinc is currently recommended as a strategy to address zinc deficiency [4]. As cereal foods contain phytic acid, the zinc absorption inhibition may persist in fortified cereals affecting bioavailability of native and fortificant zinc [4]. Fortification of drinking water promises to overcome this as the zinc from an aqueous solution has been reported to be highly bioavailable in particular, if consumed away from meals [5]. An additional benefit of consuming microbiological clean drinking water might be a reduction of diarrhea, both a cause and consequence of zinc deficiency [6]. In a recent isotopic study zinc from fortified water was found to be 9 times more bioavailable than zinc from fortified cereal and in an efficacy trial in rural Beninese children it sustained significantly higher plasma zinc levels [7].

Resource poor populations often face multiple micronutrient deficiencies concurrently due to inadequate intakes, low bioavailability, and frequent infections [8-10]. Zinc is one of the critical nutrients in addition to iron, iodine $[10,11]$, as well as vitamin $A$ and $B$ vitamins $[10,12]$. In low and middle income countries it is estimated that more than $25 \%$ of the population is at risk of inadequate zinc intake [13]. Kenya is estimated to have a high prevalence of hidden hunger and is ranked second out of 149 countries using the hidden hunger index developed in 2013 by Muthayya et al [10]. Food based recommendations (FBRs) for young children and adults in multi micronutrient deficiency settings developed through mathematical programming [14-16] can assist in defining a strategy to achieve nutrient adequacy in a well-defined, local setting. However, in most situations, adequacy cannot be reached by any combination of local foods and alternative strategies such as fortification or supplementation may be needed [17]. Especially for zinc it has been repeatedly demonstrated that nutrient adequacy cannot be reached through local food based dietary recommendations in different settings [15, 18-20]. Combining a recommendation to consume zinc fortified drinking water with FBRs could provide such an alternative to improve zinc intake specifically, but also overall nutrient adequacy.

Optifood uses linear modelling to develop FBRs based on local dietary patterns to achieve nutrient adequacy [14]. This mathematical modeling approach provides an objective method to predict, for example, whether fortification, supplementation or special complementary food products are needed to ensure dietary adequacy for high risk populations, and the extent to which they might contribute to its achievement $[21,22]$. No studies to date have combined FBRs with introduction of zinc fortified water. Based on dietary data collected in rural Western Kenya we developed and tested food based recommendations that include zinc fortified water for children aged between 4 and 6 years to achieve the best possible nutrient adequacy. 


\section{SUBJECTS AND METHODS}

\section{Study area and Design}

This study was carried out in the context of a larger research assessing the effectiveness of zinc fortified drinking water in improving zinc intake and status of non-breastfed children aged between 24-60 months $(n=184)$ at baseline. The larger research was designed as a randomized double blind effectiveness trial where households were divided into two treatment arms. One arm received a water ultrafiltration device capable of purifying water and fortifying it with zinc at a concentration between $1-4 \mathrm{mg} / \mathrm{L}$ and the control arm received the same water purification device that did not fortify the water. This larger research was conducted between February 2014 and August 2014 for 25 weeks in Kisumu West District, Western Kenya. This district has a population of about 123,447 people drawn from 29,043 households, being mainly rural and lacking access to many basic healthcare services. The main economic activities are small scale farming and fishing restricted to parts bordering Lake Victoria. This research site was chosen due to high prevalence of zinc deficiency [23], diarrheal disease [24, 25] and high surface water usage $[23,26]$.

The research protocol was approved by the Ethical Review Committee of Kenyatta National Hospital/Nairobi University (KNH-ERC/A/335) and ETH Zurich Ethical review committee (EK 2013-N-31). It was presented to local leaders who gave their approval for its conduction. Written informed consent was obtained from the household head and caregiver on behalf of their child before the research commenced. The trial was registered at www.clinicaltrials.gov (NCT0216223).

\section{Subjects}

As part of the larger research, a dietary assessment was carried out among a subsample of 112 randomly selected children during week 22 and 23 of the intervention in August 2014 to quantify the daily dietary and water intake during the pre-harvest season. The sample size was estimated to be adequate to determine a mean daily zinc intake deviating less than $0.3 \mathrm{mg}$ from the true intake with $80 \%$ power and $95 \%$ confidence, assuming an expected mean intake of $2.8 \mathrm{mg} / \mathrm{d}$ with an anticipated standard deviation of $1.5 \mathrm{mg} / \mathrm{d}[27,28]$ and a $10 \%$ non-response rate. Children between 4-6yrs $(n=62)$ constituted the largest age group in the dietary study subsample and therefore were considered the target group for the Optifood analysis.

\section{Survey data collection}

\section{Dietary assessment}

Dietary intake of the children was assessed using a quantitative multipass $24 \mathrm{hr}$ recall method [28-30], with all recalls evenly distributed throughout the week. A second recall was carried out for each child on a non-consecutive day to permit adjustment for day-to-day variation. The interviews were carried out by well-trained interviewers speaking fluent Dholuo language. Children were randomly allocated to day of the week, interviewers were randomly allocated to households and repeated household visits by the same interviewer were avoided. Caregivers were first asked to list all the foods and drinks the child had consumed at home and away in the previous $24 \mathrm{hrs}$ from waking up the day before the interview till waking up the day of interview. Then they were requested to mention all the ingredients and cooking methods for each food/dish. Duplicate amounts of all foods, beverages and ingredients were weighed to the 
nearest 1 gram using a digital balance scale (Kern EMB, Germany, max 5200g). If duplicate amounts were not available in the household during the interview, amounts were estimated using household units, in volume, size (small, medium, large) or as monetary equivalents. Caregivers were systematically probed for any food, beverage or snack consumed outside the home or omitted during the interview. Standard recipes were generated to estimate the grams of ingredients consumed from mixed dishes purchased or eaten outside the home by averaging 3 recipes of different caregivers or vendors in the local area. For foods consumed at school, recipes were collected from the school cook. In all cases proportion given to child was calculated as the total volume given to the child minus any leftovers divided by the total volume of food cooked by the caregiver/vendor/school. This proportion was multiplied by the total amount of ingredients used in preparing the dish to determine amount consumed by the child.

\section{Drinking water intake assessment}

Consumption of both unfiltered and filtered (both fortified and unfortified) drinking water was assessed for each child during the 25 weeks of the intervention. All study children were provided with cups of standard volume $300 \mathrm{ml}$ graduated at 75,150 and $125 \mathrm{ml}$. A personal diary was filled out by each caregiver every day to record the participating child's water intake by placing a tally mark under the image corresponding to the day of week; type of water consumed (filtered or unfiltered) and administered volume whenever the index child consumed water. For each child the median daily drinking water amount over the intervention period was determined.

\section{Drinking water zinc content}

Water was sampled from 35 households (representing 19\% of the households in the larger research) weekly during the first three weeks of the larger research as follows: samples were collected from the filters during a household visit into $10 \mathrm{ml}$ polypropylene bottles prefilled with $0.5 \mathrm{ml}$ of $2 \mathrm{M} \mathrm{HNO}_{3}$ for zinc stabilisation and transported to Kisumu in cooler boxes for zinc analysis by a rapid zinc assessment method (Aquaquant, Merck 1.14412.0001 Darmstadt, Germany).

\section{Weight and height}

Weight and height were measured in duplicate according to WHO guidelines [31] to the nearest $0.1 \mathrm{~kg}$ and $0.1 \mathrm{~cm}$ respectively using an electronic scale (Ashton Meyers, England, United Kingdom), and a UNICEF wooden three piece measuring board with a sliding foot or head piece. The weighing scale was calibrated daily.

\section{Blood sampling}

Blood samples were collected between 8 am and 13:00 pm from fasting and non-fasting subjects for plasma zinc (PZn) analysis according to IZINCG protocol [32] at baseline of the larger research. Blood was drawn from subject's vein into trace element free monovette sarsted system tubes. To obtain plasma, blood was centrifuged at 3000 revolutions per minute (rpm) for 10 minutes in the field within 40 minutes of collection. Plasma samples were aliquoted into acidwashed Eppendorf containers $(500 \mu \mathrm{l})$ in duplicate for zinc analysis and in triplicate into regular tubes (150ul) for analysis of C-reactive protein, alpha 1 acid glycoprotein, plasma ferritin, soluble transferrin receptor and retinol binding protein. The aliquotes were kept in a cooler box before transporting on the same day to Maseno University for storage at $-20^{\circ} \mathrm{C}$. All samples were then sent to ETH Zurich, Switzerland on dry ice for analysis of PZn concentration and to Germany for analysis of the proteins using a sandwich ELISA technique [33]. Hemoglobin (Hb) 
was analyzed in the field on the spot on a separate venous blood sample using a Hemocue photometer (Hemocue HB 201, Angelholm, Sweden).

\section{Data analysis}

\section{Nutrition status}

Z-scores, for height-for-age (HAZ), and BMI for age (BAZ) were calculated for each child using WHO ANTHRO PLUS (WHOv1.0.4), (www.who.int/childgrowth/software/en/). Children were classified as stunted or thin if their HAZ and BAZ, were less than -2 SD respectively [31]. We measured nutritional and inflammation status of the population by measuring the following biomarkers: PZn (flame atomic absorption spectrometry,FAAS) (AA240FS, Varian Inc., Australia), and the following proteins : ferritin (FER), transferrin receptor (sTFR), retinol binding protein (RBP), C reactive protein (CRP) and $\alpha 1$ acid glycoprotein (AGP) by a procedure that combines analytes using a sandwich ELISA technique [33]. We calculated prevalence of low PZn by using sex and age-specific lower cut-offs by IZINCG [34]: PZn $<65 \mu \mathrm{g} / \mathrm{dl}$ for blood samples collected during the morning, (AM) and PZn $<57 \mu \mathrm{g} / \mathrm{dl}$ for the afternoon (PM) samples irrespective of fasting status. Subclinical inflammation was defined as CRP $>5 \mathrm{mg} / \mathrm{l}$ and/or AGP $>1 \mathrm{~g} / \mathrm{l}$. Applied cut-off for $\mathrm{Hb}$ was $<110 \mathrm{~g} / \mathrm{L}$ in children below 59 months and $115 \mathrm{~g} / \mathrm{L}$ for children $\geq 60$ months [35]. The thresholds for defining iron deficiency were FER $<12 \mu \mathrm{g} / \mathrm{L}$ or sTfR $>8.3 \mathrm{mg} / \mathrm{L}$. Vitamin A deficiency was defined by RBP $<0.75 \mu \mathrm{mol} / \mathrm{L}$. PZn, FER and RBP were corrected for inflammation using the Thurnham method [36].

\section{Habitual nutrient intakes}

Compl-eat $\subset$ (version 1.0, Wageningen University, the Netherlands) was used to calculate energy and nutrient intakes from the $24 \mathrm{hr}$ recalls. The following nutrients were considered: protein, fat, calcium, vitamin $\mathrm{C}$, thiamin, riboflavin, niacin, vitamin B6, folate, vitamin B12, vitamin A, iron and zinc. Energy and nutrient intake calculations were based on a food composition table (FCT) developed specifically for this study using the Kenya national FCT as primary source [37] complemented with data from FCTs from South Africa [38], Mali [39], East Africa [40], International Minilist [41] and the United States Department of Agriculture database (USDA) [42]. USDA retention factors [43] were applied to raw ingredients and foods to account for nutrient losses during food preparation. $\beta$-carotene and retinol were converted into retinol activity equivalent (RAE) using the International Vitamin A Consultative Group recommended conversion factors $[44,45]$. Energy and nutrient intake analysis was done using IBM SPSS (v21). Outliers were identified per nutrient according to the outlier labelling rule [46] and excluded from habitual intake analysis of that nutrient. Normality of distributions was tested visually using QQ plots. Non normal nutrient intake data was log transformed. All nutrient intakes were adjusted for day-to-day variation according to the method developed by the National Research Council $[47,48]$. The percentage of children below the EAR and the percent coverage of RNI for each nutrient was determined.

\section{Preparation of model parameters}

The 24hr recall data were used to generate model parameters using Excel 2010 (Microsoft Corporation) and Access 2010 (Microsoft Corporation). These parameters were: a list of noncondiment foods consumed by $\geq 5 \%$ of the target children, and per food the median serving size for those children that had consumed it, the minimum and maximum number of servings/week for the single foods, and (sub) food groups they belonged to. These were based on the $10^{\text {th }}$ and $90^{\text {th }}$ percentile distribution of serve counts. For fortified water the minimum and maximum 
number of servings per week was set at seven, assuming this water would be provided every day to the child. The median daily drinking water consumed used in the modelling process was $477 \mathrm{ml} / \mathrm{d}$ based on the drinking water intake assessment and the zinc concentration for zinc fortified water was $1.15 \mathrm{mg} / \mathrm{L}$.

An energy constraint was used to ensure all modelled diets provided the average energy requirement for the target group, estimated using reference mean body weight and the FAO/WHO/UNU algorithm for estimating energy requirements [49]. The FAO/WHO [50] RNI were used for the following nutrients: calcium, vitamin C, thiamin, riboflavin, niacin, vitamin B6, folate, vitamin B12, and vitamin A with $12.6 \mathrm{mg} / \mathrm{d}$ as RNI for iron (assuming $5 \%$ bioavailability) and $9.6 \mathrm{mg} / \mathrm{d}$ for zinc (assuming 15\% bioavailability). Only for zinc fortified water the bioavailability of $65.9 \%$ was used, based on isotope studies conducted when fortified water was consumed between meals [7].

\section{Optifood analysis}

Analysis was carried out using Optifood (v4.0.9), a linear modelling approach to design population-specific FBRs [51]. Two scenarios were modelled: 1) diet with no zinc fortified water-model parameters were entered without zinc fortified water 2) diet with zinc fortified water-model parameters are entered including zinc fortified water.

Optifood modules 1 and 2 were run for both scenarios. Module 1 was used to check feasibility of diets. This analysis step checks if: (a) the model parameters can run correctly, (b) realistic diets can be generated for the target population and (c) the possible range in the energy contents of diets is wide enough for modelling. Module 2 analysis was run to generate two best (optimized) diets. One average food pattern diet, optimized close to the average food pattern and one best food pattern diet, optimized within the upper and lower food pattern limits but deviating more from the average food pattern. Module 2 best food pattern was used to identify nutrient dense foods and their (sub) food group if their contribution to nutrient intake was $\geq 5 \%$ for any of the nutrients considered.

Module 3 was run in 3 phases. In phase I the module was run without recommendations. In this phase the model minimizes each nutrient by including the low nutrient dense foods per food group (worst case scenario) and maximizes each nutrient by selecting the high nutrient dense foods (best case scenario) within each food group. As the \%RNI coverage in the no-fortified drinking water diet was the same as for the fortified drinking water diet (except for zinc), phase II was run only for the latter. In phase II food subgroups belonging to the nutrient dense foods identified in Module 2 were separately and in combination (phase III) added in the model. The FBRs with nutrient levels achieving $\geq 70 \%$ RNI in the worst-case scenario for most nutrients were selected as the final FBRs for the children.

\section{RESULTS}

\section{Study characteristics}

Dietary data from 60 out of 62 children was used in the analysis as one child dropped out of the study and the second child turned 7 just at the time of the start of the study. The children had an average age of 62 months (Table 1). The percentage prevalence of stunting and thinness was $16 \%$ and $3 \%$ respectively. Zinc deficiency was high in this population with $52 \%$ of the children having low serum zinc $(<65 \mu \mathrm{g} / \mathrm{dl})$. Twenty seven percent of the children suffered from vitamin 
A deficiency. The prevalence of anemia, iron deficiency and iron deficiency anemia was $52 \%$, $63 \%$ and $38 \%$ respectively. Inflammation affected $53 \%$ of the children. Thirty five out of the 60 children had more than one micronutrient deficiency.

Table 1: Nutritional status of the children aged 4-6 years old Kisumu, Western Kenya, Kenya*

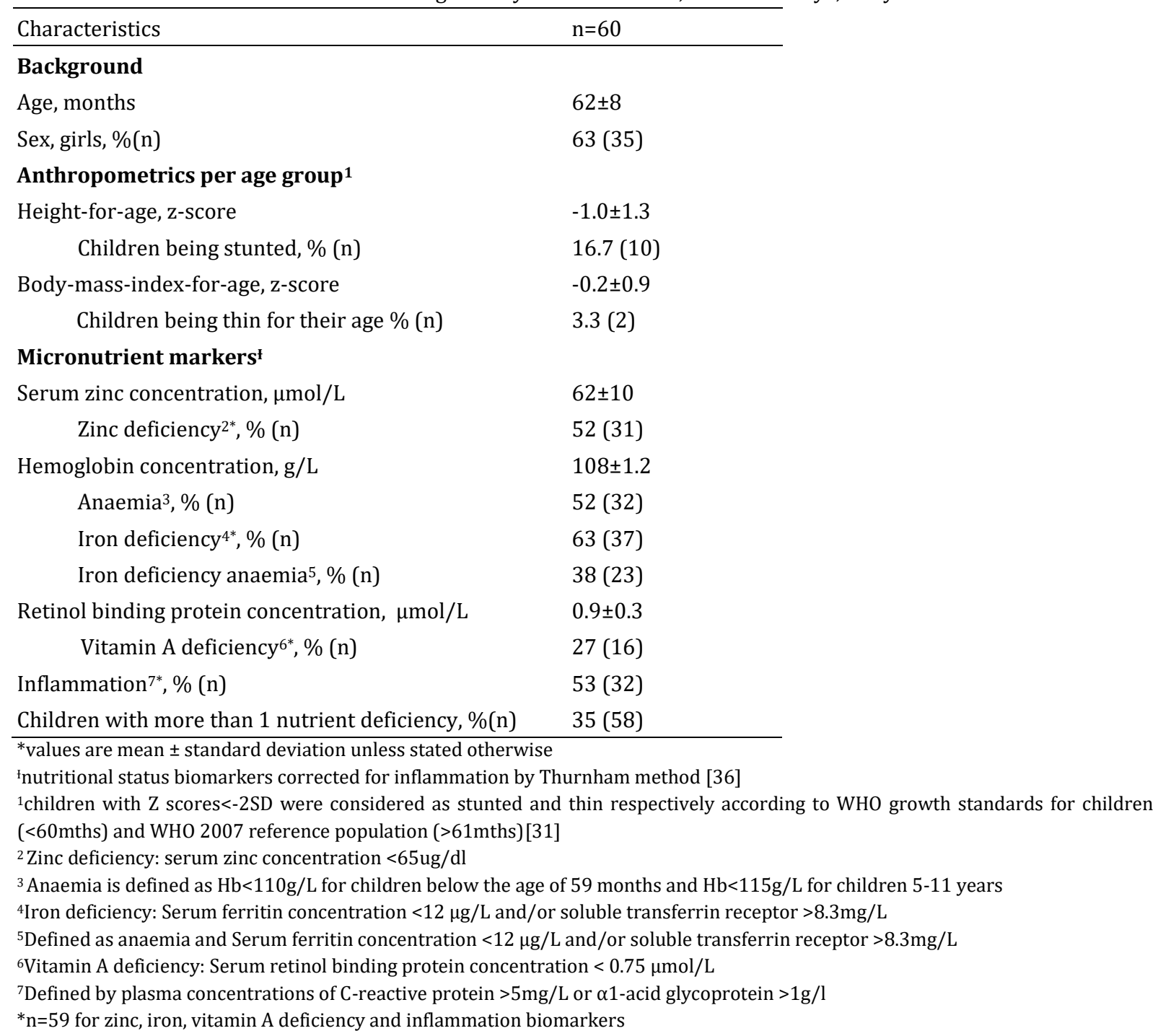

\section{Food and nutrient Intake}

Data analysis included 120 dietary recalls (first and second recalls). Overall, 69 non condiment food items were reported in the dietary recalls over the two days. From this list, 45 foods were consumed by more than $5 \%$ of the children and were included in the modelling (Table 2). Excluded condiments were baking soda and soup powder. Three foods (brookside milk, okoko fish, and lemon) were excluded for having a maximum frequency consumption per week below one. Foods consumed by over $90 \%$ of the children were spring onion (96\%), maize white flour (96\%), brown sugar (96\%), and tomato (90\%). On average children consumed these foods every day. Median serving sizes varied from $3.7 \mathrm{~g} / \mathrm{d}$ for onion to $237 \mathrm{~g} / \mathrm{d}$ for sour cow milk. Most foods (42 out of 45 foods) had serving sizes of more than $10 \mathrm{~g} / \mathrm{d}$. All children had iron and thiamin intake above the EAR. Respectively $36 \%$ and $2 \%$ of the children had energy and protein intake below their daily requirements [49]. More than 50\% of children had intake below EAR for calcium, riboflavin, vitamin B12, vitamin C, folate, and vitamin A. Respectively 19 and 49\% of children had a low intake for vitamin B6 and niacin (Table 3). Eighty five percent of the children 
had a zinc intake below the EAR. The median percent coverage of RNI without zinc fortified water was $61 \%$.

Food pattern and nutrients of optimized diets

In Module 1 twenty realistic diets were generated for both possible diets (diet with and without zinc fortified water). The best food pattern resulting from Module 2 covered the RNI for most nutrients except vitamin A and zinc for both diets, although \%RNI coverage for zinc was higher in the diet including zinc fortified (95.7\%) compared to without fortified drinking water (70.8\%). Based on this pattern, the foods (and their respective subfood groups) that contributed $\geq 5 \%$ to the intake of at least 5 or more nutrients were selected to be included in the modelling exercise in Module 3 (Table 4).

With no recommendation or zinc fortification, \%RNI coverage range was between $40 \%$ (worst case scenario) and $76 \%$ (best case scenario) for zinc. This improved to $66 \%$ (worst case scenario) and 101\% (best-case scenario), suggesting that zinc nutritional adequacy can be reached by including zinc fortified water in the recommendations (Table 5, Module III Phase I no recommendation).

Subsequently, recommendations for the sub food groups belonging to the selected nutrient dense foods identified in module 2 (Table 4), were added individually (Table 5) and in combination (Table 6) to the diet with zinc fortified water and for each combination a new set of FBR was developed and tested. The final set of FBRs selected covered $87 \%$ of zinc RNI and contained whole grain products, unfortified (14 serves per week), fluid or powdered milk unfortified ( 7 serves per week), nuts and seeds ( 4 serves per week), vitamin A rich vegetables ( 7 serves per week), other starchy plants ( 7 serves per week), vitamin $C$ rich vegetables $(7$ serves per week) and small whole fish with bones (7 serves per week). Nutrient adequacy did not reach $70 \%$ for vitamin A (25\%RNI) and folate (68\%RNI) in the worst case scenario. The increased nutrient adequacy as \%RNI coverage in the final FBR compared to the children's actual median intakes is shown in Figure 1. The \%RNI coverage improved to over $100 \%$ for most nutrients (calcium, vitamin C, riboflavin, niacin and vitamin B12). Only for iron (98\%) and zinc (87\%) intake remains below $100 \%$ RNI but above $70 \%$ RNI in the worst case scenario.

\section{DISCUSSION}

The objective of this study was to develop FBRs that included zinc fortified water to improve nutrient adequacy for children between 4 and 6 years in rural Kisumu, Kenya. We found that inclusion of zinc fortified water with careful combination of local foods in realistic servings can substantially improve the nutritional quality of the diet. Addition of zinc fortified water could improve the actual RNI coverage of $61 \%$ to a theoretical coverage of $87 \%$ even when low nutrient dense foods are consumed. Addition of fortified drinking water to FBRs can therefore substantially contribute to an adequate zinc intake. Calcium, vitamin C, riboflavin, niacin, vitamin B12, iron and zinc achieved $>70 \%$ RNI in the final food based recommendation. However, adequate intake of vitamin $\mathrm{A}$ and folate could not be ensured even when high nutrient dense foods were included. 
Table 2: Foods consumed by children (4-6 years), median serving sizes and minimum and maximum servings per week in Kisumu, Western Kenya ${ }^{1}$

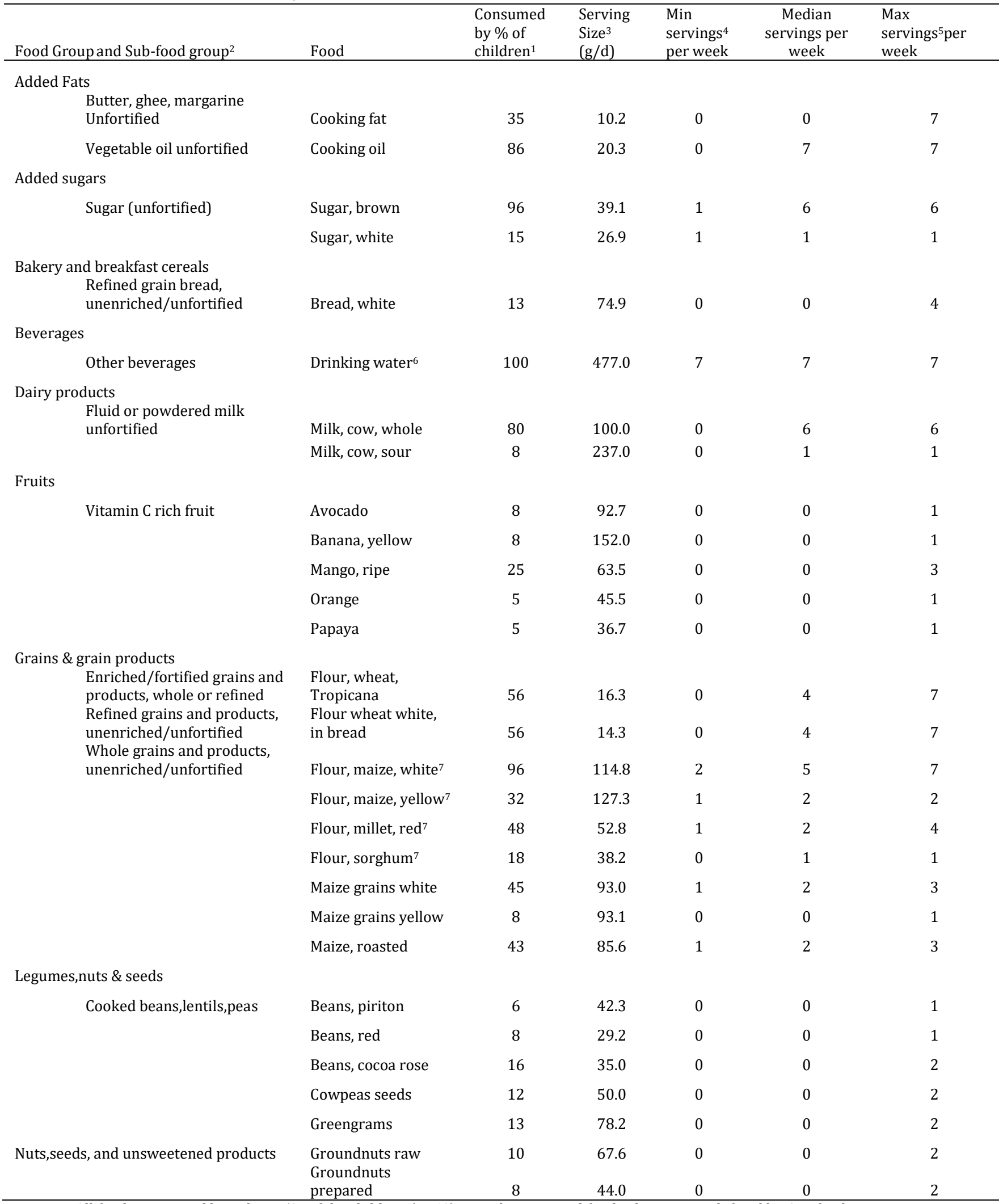

${ }^{1}$ All foods consumed by at least $5 \%$ of the children $(n=60),{ }^{2}$ Food groups and food subgroups as defined by Optifood programme, ${ }^{3}$ Values are median serving sizes of the raw edible portions when consumed based on 24-h recalls, ${ }^{4}$ Minimum frequencies were calculated based on the $10^{\text {th }}$ percentile of distribution of the serve counts with consideration of proportion consuming each food within each food sub-group

${ }^{5}$ Maximum frequencies were calculated based on the $90^{\text {th }}$ percentile of distribution of the serve counts with consideration of proportion consuming each food within each food sub-group, ${ }^{6}$ as assessed during the course of the study using personal diaries, ${ }^{7}$ Unrefined cereal flour 
Table 3: Nutrient intake of the children aged 4-6 yrs and percent below EAR without zinc fortified water ${ }^{1}$

\begin{tabular}{|c|c|c|c|c|}
\hline Nutrient & Intake $^{2}$ & \%below EAR ${ }^{3}$ & \%of RNI ${ }^{4}$ & \\
\hline Energy (Kcal/d) & $1464[1328,1653]$ & \multicolumn{2}{|l|}{$36^{5}$} & \\
\hline Protein (g) & $36[30,41]$ & $2^{6}$ & \multicolumn{2}{|l|}{$192[158,216]$} \\
\hline Calcium (mg/d) & $456[352,600]$ & 60 & \multicolumn{2}{|l|}{$76[59,100]$} \\
\hline Iron $(\mathrm{mg} / \mathrm{d})$ & $10[9,12]$ & 0 & \multicolumn{2}{|l|}{$82[73,99]$} \\
\hline Thiamin (mg/d) & $0.7[0.6,0.8]$ & 0 & \multicolumn{2}{|l|}{$134[114,154]$} \\
\hline Riboflavin (mg/d) & $0.4[0.4,0.6]$ & 52 & \multicolumn{2}{|l|}{$82[67,103]$} \\
\hline VitaminB6 (mg/d) & $0.8[0.6,1.2]$ & 19 & \multicolumn{2}{|l|}{$150[96,211]$} \\
\hline $\operatorname{VitaminB} 12(\mu \mathrm{g} / \mathrm{d})$ & $0.8[0.4,1.2]$ & 58 & \multicolumn{2}{|l|}{$73[41,104]$} \\
\hline Vitamin C (mg/d) & $23[13,28]$ & 55 & \multicolumn{2}{|l|}{$77[50,99]$} \\
\hline Folate $(\mu \mathrm{gDFE} / \mathrm{d})$ & $99[94,106]$ & 100 & \multicolumn{2}{|l|}{$50[47,54]$} \\
\hline Niacin $(\mathrm{mg} / \mathrm{d})$ & $6[4,8]$ & 49 & \multicolumn{2}{|l|}{$75[58,99]$} \\
\hline Vitamin A ( $\mu \mathrm{gRAE} / \mathrm{d})$ & $86[54,116]$ & 55 & \multicolumn{2}{|l|}{$18[12,24]$} \\
\hline $\operatorname{Zinc}(\mathrm{mg} / \mathrm{d})$ & $5.8[4,6.6]$ & 85 & \multicolumn{2}{|l|}{$61[46,73]$} \\
\hline \multicolumn{5}{|c|}{$\begin{array}{l}{ }^{1} \text { excluson of outlier nutrient intakes using outlier la } \\
\mathrm{n}=57 \text {, Vitamin } \mathrm{B} 6 \mathrm{n}=58 \text {, Vitamin } \mathrm{B} 12 \mathrm{n}=50 \text {, iron } \mathrm{n}=5 \\
{ }^{2} \text { median }\left[25^{\text {th }}, 75^{\text {th }} \text { percentile] of the distribution of }\right. \\
{ }^{3} \text { EARs were calculated from RNIs (FAO/WHO), usin } \\
{ }^{4} \text { percent coverage of the RNI of the intakes of the ch } \\
{ }^{5} \text { daily energy requirements were used [49] } \\
{ }^{6} \text { recommended dietary allowance of the IOM used } \\
\text { DFE-dietary folate equivalents } \\
\text { RAE-retinol activity equivalents }\end{array}$} \\
\hline Sub food group & 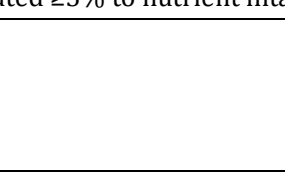 & $\mathrm{Fo}$ & 年 & $\begin{array}{l}\text { Count of nutrients } \\
\text { with } \\
\text { contribution } \geq 5 \% \\
\text { to intake }\end{array}$ \\
\hline Whole grains and prod & unenriched/unfortified & & red & 9 \\
\hline Nuts, seeds and unswe & d products & & raw & 9 \\
\hline Whole grains and prod & unenriched/unfortified & & white & 8 \\
\hline Whole grains and prod & unenriched/unfortified & & ,yellow & 8 \\
\hline Vitamin C rich vegetabl & & & aves & 7 \\
\hline Fluid or powdered milk & rtified & & hole & 7 \\
\hline Small whole fish with $b$ & & & & 6 \\
\hline Vitamin A rich vegetabl & & & & 5 \\
\hline Other starchy plants & & & & 5 \\
\hline
\end{tabular}

The nutritional status indicators of the children confirmed existence of multiple micronutrient deficiencies. Fifty eight percent of the children had more than one nutrient deficiency. Forty-four out of the 60 children studied had intakes below the EAR of 4 or more nutrients. These low intakes may indicate the key role of low dietary intake as main cause of deficiencies. On the contrary even though prevalence of anemia and iron deficiency was high, there were no children with iron intakes below the EAR. Although the actual iron bioavailability might have been lower than assumed [53,54], it is most likely that the presence of parasitic infections and chronic inflammation may play a large role in iron deficiency in this population. This was also confirmed by the fact that $53 \%$ of the children were suffering from inflammation. Western Kenya is classified as a malaria endemic area [55] and has high prevalence of helminth diseases such as hookworm and bilharzia [56-58]. Parasitic infections will lead to iron deficiency through mechanisms that include extra corporeal blood loss, haemolysis and inflammation [59, 60]. 
Furthermore it is also well established that deficiencies of other nutrients such as vitamin B12, and folate can lead to anemia through ineffective erythropoiesis [61]. All our children had intakes below the EAR for folate and 58\% for vitamin B12 and were at high risk of deficiency from these nutrients further exacerbating their risk for anemia.

Consistent with our results other studies also found high prevalence of vitamin A deficiency in Western Kenya [62, 63], and zinc deficiency [64, 65] as well as multiple micronutrient deficiencies in primary school children from Eastern Kenya [8]. The diet of the children was characterised by low variation in food intake. Only 45 foods were consumed by $\geq 5 \%$ of the population. Cereals and legumes were consumed in larger quantities and higher frequency than nutrient dense foods such as animal source foods (ASF). Other studies also confirm that in Kenyan children consumption of ASFs is limited and consumption of plant based foods is high [8, 66].

The modelled final FBRs clearly suggest that using local foods in combination with zinc enriched water can ensure nutrient adequacy except that of vitamin A and folate. With exclusion of zinc fortified water, intakes of zinc, vitamin A and folate remain inadequate. The zinc nutrient gap can be covered by daily consumption of zinc fortified water however this should be complemented with additional FBRs that address the multiple micronutrient deficiencies. For vitamin A alternative interventions and approaches beyond the foods that are already consumed by the children and approaches such as supplementation, food fortification and biofortification have to be explored in order to improve intake. Though the Government of Kenya has universal vitamin A supplementation programmes for all under five year old children, national coverage has been shown to be low as 19\% [67]. Biofortification of plant foods with pro vitamin A such as yellow sweet potato and yellow cassava is a promising approach that has been proven to improve vitamin A status in vulnerable groups $[68,69]$, and recently in an efficacy trial in central Kenya [70] The challenge will be to improve coverage of vitamin A supplementation, enforce and monitor vitamin A fortification of other foods and scaling up of biofortification efforts. 


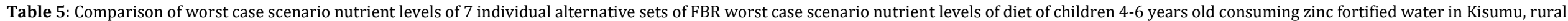
western Kenya, Kenya ${ }^{1}$

\begin{tabular}{|c|c|c|c|c|c|c|c|c|c|c|c|c|c|c|}
\hline Analysis $^{2}$ & \% \% & Fat \% & $\begin{array}{l}\text { Calcium } \\
\%\end{array}$ & $\begin{array}{l}\text { Vitamin } \\
\text { C \% }\end{array}$ & $\begin{array}{l}\text { Thiamin } \\
\%\end{array}$ & $\begin{array}{l}\text { Riboflavin } \\
\%\end{array}$ & $\begin{array}{l}\text { Niacin } \\
\% \\
\end{array}$ & $\begin{array}{l}\text { Vitamin } \\
\text { B-6 \% }\end{array}$ & $\begin{array}{l}\text { Folate } \\
\%\end{array}$ & $\begin{array}{l}\text { Vitamin } \\
\text { B-12\% }\end{array}$ & $\begin{array}{l}\text { Vitamin } \\
\text { A \% }\end{array}$ & $\begin{array}{l}\text { Iron } \\
\%\end{array}$ & $\begin{array}{l}\text { Zinc } \\
\%\end{array}$ & $\begin{array}{l}\text { Count } \\
\geq 70 \% \mathrm{RNI}\end{array}$ \\
\hline \multicolumn{15}{|c|}{ Module III Phase I (no recommendation) } \\
\hline $\begin{array}{l}\text { Best case scenario with zinc } \\
\text { fortified water }\end{array}$ & 318 & 132 & 158 & 274 & 238 & 154 & 132 & 194 & 110 & 211 & 52 & 135 & 101 & 12 \\
\hline $\begin{array}{l}\text { Best case scenario No zinc } \\
\text { fortified water }\end{array}$ & 318 & 132 & 158 & 274 & 238 & 154 & 132 & 194 & 110 & 211 & 52 & 135 & 76 & 12 \\
\hline $\begin{array}{l}\text { worst case scenario with zinc } \\
\text { fortified water }\end{array}$ & 144 & 41 & 13 & 7 & 105 & 38 & 39 & 82 & 28 & 15 & 2 & 56 & 66 & 3 \\
\hline $\begin{array}{l}\text { Worst case scenario No zinc } \\
\text { fortified water }\end{array}$ & 144 & 41 & 13 & 7 & 105 & 38 & 39 & 82 & 28 & 15 & 2 & 56 & 40 & 2 \\
\hline \multicolumn{15}{|c|}{ Module III Phase II worst case scenario nutrient levels for 8 single alternative sets of recommendations ${ }^{2}$} \\
\hline $\begin{array}{l}\text { Small whole fish } 7 \text { serves } \\
\text { /week }\end{array}$ & 180 & 45 & 71 & 8 & 107 & 43 & 52 & 86 & 28 & 133 & 2 & 61 & 71 & 6 \\
\hline $\begin{array}{l}\text { VitC rich vegetables } 7 \text { serves } \\
\text { per week }\end{array}$ & 151 & 41 & 31 & 105 & 111 & 53 & 46 & 92 & 41 & 15 & 5 & 74 & 66 & 5 \\
\hline $\begin{array}{l}\text { Nuts, seeds unsweetened } \\
\text { products } 4 \text { serves per week }\end{array}$ & 144 & 72 & 13 & 7 & 107 & 64 & 39 & 83 & 40 & 15 & 2 & 56 & 68 & 4 \\
\hline $\begin{array}{l}\text { Fluid milk unfortified } 7 \text { serves } \\
\text { per week }\end{array}$ & 157 & 49 & 40 & 11 & 105 & 73 & 39 & 82 & 28 & 49 & 12 & 56 & 67 & 4 \\
\hline $\begin{array}{l}\text { Vit A rich vegetables } 7 \text { serves } \\
\text { per week }\end{array}$ & 147 & 41 & 21 & 58 & 112 & 38 & 47 & 90 & 28 & 15 & 12 & 59 & 66 & 3 \\
\hline $\begin{array}{l}\text { Other starchy plants } 7 \text { serves } \\
\text { per week }\end{array}$ & 144 & 41 & 17 & 34 & 131 & 38 & 69 & 93 & 35 & 15 & 2 & 58 & 66 & 3 \\
\hline
\end{tabular}

per week

${ }^{1}$ Values are expressed as percentage of recommended nutrient intakes (RNI)

${ }^{2}$ Module three was run with the fortified zinc water group

"serves/ week" refers to the number of averaged sized portions consumed per week

alternative sets of recommendations selected at subfood group level 


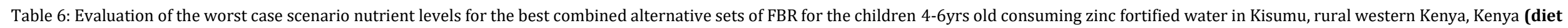
with zinc fortified water)

\begin{tabular}{|c|c|c|c|c|c|c|c|c|c|c|c|c|c|c|}
\hline Analysis & $\begin{array}{l}\text { Protein } \\
\%\end{array}$ & $\begin{array}{l}\text { Fat } \\
\%\end{array}$ & Calcium & Vit. C & Thiamin & Riboflavin & Niacin & $\begin{array}{l}\text { Vit. } \\
\text { B6 }\end{array}$ & Folate & $\begin{array}{l}\text { Vit. } \\
\text { B12 }\end{array}$ & Vit A & $\mathrm{Fe}$ & $\mathrm{Zn}$ & $\begin{array}{l}\text { Count of } \\
\text { nutrients } \\
\geq 70 \% \text { RNI }^{4}\end{array}$ \\
\hline No recommendations_best case & 318 & 132 & 158 & 274 & 238 & 154 & 132 & 194 & 110 & 211 & 52 & 135 & 101 & 12 \\
\hline No recommendations_worst case & 144 & 41 & 13 & 7 & 105 & 38 & 39 & 82 & 28 & 15 & 2 & 56 & 66 & 3 \\
\hline \multicolumn{15}{|c|}{ Module III Phase III worst case scenario nutrient levels for best combined single alternative sets. } \\
\hline $\mathrm{N} 4+\mathrm{WG} 14+\mathrm{VC} 7+\mathrm{VA7}+\mathrm{F} 7$ & 193 & 78 & 97 & 156 & 136 & 90 & 75 & 130 & 56 & 134 & 15 & 90 & 80 & 11 \\
\hline N4+WG14+VA7+F7+S7 & 186 & 77 & 83 & 85 & 159 & 75 & 99 & 133 & 50 & 134 & 12 & 78 & 80 & 11 \\
\hline $\mathrm{N} 4+\mathrm{VC} 7+\mathrm{VA} 7+\mathrm{F} 7+\mathrm{S} 7$ & 191 & 77 & 101 & 182 & 149 & 86 & 96 & 126 & 62 & 134 & 15 & 84 & 74 & 11 \\
\hline $\mathrm{N} 4+\mathrm{VC} 7+\mathrm{M} 7+\mathrm{F} 7+\mathrm{S} 7$ & 201 & 86 & 121 & 135 & 142 & 123 & 88 & 121 & 64 & 168 & 15 & 81 & 76 & 11 \\
\hline $\mathrm{N} 4+\mathrm{WG} 14+\mathrm{VC} 7+\mathrm{VA} 7+\mathrm{M} 7+\mathrm{F} 7$ & 208 & 88 & 125 & 160 & 141 & 128 & 76 & 136 & 59 & 168 & 25 & 91 & 84 & 11 \\
\hline $\mathrm{N} 4+\mathrm{WG} 14+\mathrm{VC} 7+\mathrm{VA} 7+\mathrm{F} 7+\mathrm{S} 7$ & 195 & 78 & 102 & 183 & 168 & 91 & 106 & 147 & 65 & 134 & 15 & 97 & 82 & 11 \\
\hline $\mathrm{N} 4+\mathrm{WG} 14+\mathrm{VC} 7+\mathrm{M} 7+\mathrm{F} 7+\mathrm{S} 7$ & 211 & 88 & 121 & 136 & 165 & 130 & 99 & 143 & 68 & 168 & 15 & 95 & 86 & 11 \\
\hline $\mathrm{N} 4+\mathrm{WG} 14+\mathrm{VA} 7+\mathrm{M} 7+\mathrm{F} 7+\mathrm{S} 7$ & 205 & 87 & 111 & 90 & 165 & 113 & 100 & 139 & 54 & 168 & 22 & 79 & 85 & 11 \\
\hline $\mathrm{N} 4+\mathrm{VC} 7+\mathrm{VA} 7+\mathrm{M} 7+\mathrm{F} 7+\mathrm{S} 7$ & 205 & 86 & 129 & 186 & 149 & 123 & 96 & 131 & 64 & 168 & 25 & 84 & 77 & 11 \\
\hline $\mathrm{N} 4+\mathrm{WG} 14+\mathrm{VC} 7+\mathrm{VA} 7+\mathrm{M} 7+\mathrm{F} 7+\mathrm{S} 7^{2}$ & 217 & 88 & 130 & 188 & 174 & 130 & 108 & 153 & $68^{3}$ & 169 & $25^{3}$ & 98 & 87 & 11 \\
\hline
\end{tabular}

${ }^{1}$ Values are expressed as percentage of recommended nutrient intakes (RNI)

Recommendations include zinc fortified water

$\mathrm{WG}=$ Whole grain products unenriched unfortified 14 serves per week, $\mathrm{M}=$ Fluid or powdered milk unfortified 7 serves per week, N= Nuts, seeds and unsweetened products 4 serves per week, $\mathrm{S}=\mathrm{O}$ ther Starchy plants 7 serves per week, $\mathrm{VC}=$ Vitamin $\mathrm{C}$ rich vegetables 10 serves per week, $\mathrm{VA}=\mathrm{Vitamin} \mathrm{A}$ rich vegetables 7 serves per week, $\mathrm{F}=$ Small whole fish with bones 7 serves per week

2best optimized diet worst case scenario

3remained below $70 \%$ in final food based recommendations (FBR)

${ }^{4}$ total number of nutrients $>70 \%$ RNI 


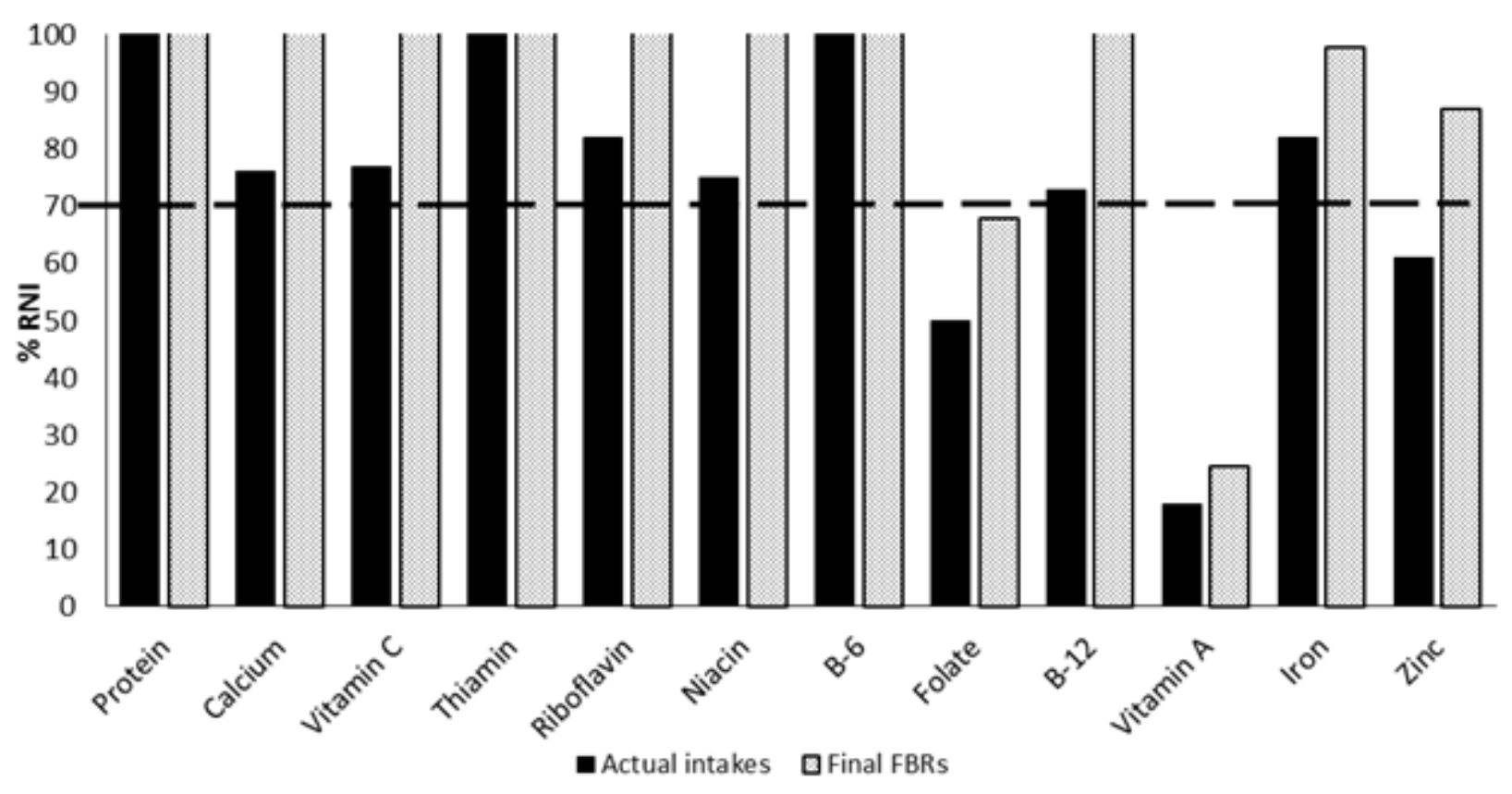

Figure 1: A comparison between the actual median nutrient intake levels of the Kenyan children aged 4-6 years with the final modelled diet

The Optifood approach is a useful tool for analysing nutrient gaps in diet patterns and developing FBRs for improving nutrient adequacy in the diet. However, the process is dependent on the quality of the dietary recall data, the food composition table used, assumed bioavailability of nutrients and proposed RNIs. Although our analysis is based on the best available information at this time, the results are sensitive to the decisions made concerning the model parameters [71]. Therefore, the decision process for input parameters should be clearly outlined for concluding and reproducibility purposes. We used the actual median daily drinking water intake derived from a more extensive surveillance of fortified drinking water quantity consumed. This ensured that a realistic quantity was modelled into the Optifood analysis. Also, the zinc content of the drinking water was regularly determined by own chemical analysis. The simulation of the contribution of zinc intake through water is thus close to a realistic setting. The bioavailability of zinc from fortified water was assumed to be $65.9 \%$, a result of absorption studies conducted using stable isotopic zinc labels with the fortified water [72]. Although caregivers and children were strongly advised to consume the water away from meals, it is not known whether this was actually done. When consumed with a meal, zinc bioavailability from water is drastically lower and will be dependent on the phytic acid level in the diet [7]. Using the lower bioavailability level when modelling the same final FBRs, the percentage RNI coverage of zinc was reduced from $87 \%$ to $66 \%$ in the worst case scenario. Depending on the bioavailability level chosen, our zinc adequacy might therefore be overestimated.

We selected for the modelling process foods consumed by $5 \%$ or more children as we assumed that these were the commonly consumed foods. This resulted in total 45 foods for input into the model. When modelling foods consumed by more than $10 \%$ of the children the food list contained less foods (38 foods) and resulted in the identification of an additional problem nutrient (fat) in addition to folate, and vitamin A. Including less foods into the modelling may limit the options Optifood analysis has for selection of foods and as a result more problem nutrients might be expected. Including foods consumed by $<5 \%$ of the children might have 
increased the options, but may decrease the feasibility of implementing recommendations as these foods are not commonly consumed. The choice of cut off for frequently consumed foods therefore influenced the results and the effect of such decisions on final recommendations should be further studied. We used the WHO/FAO RNI for zinc of $9.6 \mathrm{mg} / \mathrm{d}$. An option would have been to use the IZINCG RDA's which is set at $5 \mathrm{mg} / \mathrm{d}$ [34]. Using the latter cut off would have made the diet sufficient and zinc would not have been a problem nutrient. However this sufficiency was not reflected by the high level of zinc deficiency in the study population. This may indicate that in our population zinc requirements are elevated, may be due to frequent diarrheal infections. Diarrhea is known to deplete zinc stores in children $[6,73,74]$ and is a common infection in Western Kenya [24, 25]. Therefore, the use of the WHO/FAO RNI for zinc was considered to be more appropriate for our study population.

Data collection took place during the pre- harvest season, and results cannot necessarily be extrapolated to other seasons. The households mainly relied on own food production dependent on rain fed agriculture and seasonal variations in food availability and intake are expected [7577]. In general there are fewer vegetables available in the pre harvest season than post-harvest and this, in our study area, is reflected by limited availability of vegetables like pumpkin leaves (Cucurbita sp ), cowpeas (Vigna unguiculata) and sunnhemp (Crotalaria brevidens) but high availability of sukuma wiki (Brassica sp), spider plant (Gynandropsis gynandra), amaranth (Amaranthus sp) and nightshade (Solanum nigrum) [78]. Sukuma wiki was the most consumed vegetable in our study population and is in the subfood group of vitamin A rich vegetables. However, even in the season of abundance, its consumption at the mentioned serving sizes did not ensure adequate vitamin A intake. A study conducted in rural Kenya found a deficit in vitamin A, riboflavin and thiamin but no difference in energy, fat, protein and niacin intake when pre harvest intake was compared to postharvest [79]. Conducting this study during the postharvest season would probably have resulted in selecting more vegetables and plant foods with higher serving sizes most likely yielding higher \%RNI coverage for vitamin A and folate. Comparative analysis using dietary intake data from different seasons would be required to understand how food-based recommendations might change. In addition, it is important to emphasize that the data used to set the model parameters in Optifood originated from a limited area in the western part of Kenya and the agro-ecological zone in which the study area is located, is not representative for the whole of Kenya. Therefore, the extent to which the developed recommendations also apply to other areas in Kenya needs to be further assessed.

Optifood is a useful tool to show objectively the contribution that zinc fortified water can make when introduced in food based recommendations to meeting, or come as close as possible to meeting, the nutrient needs of rural Kenyan children. Our study also showed that introduction of zinc fortified water should be accompanied by FBRs to improve nutrient adequacy of the whole diet in order to address multiple micronutrient deficiencies. However, the extent to which the developed food-based recommendations are acceptable to implement by the target population remains to be determined. As the recommendations are based on local dietary patterns, they may be considered as realistic and achievable by some, but may ask for substantial changes for others. Consultation with local stakeholders is essential to identify barriers and supporting factors that could encourage the adoption of the recommendations, and might lead to adaptation of the suggested recommendations to facilitate their adoption. 


\section{REFERENCES}

1. Hambidge M: Human Zinc Deficiency. J Nutr 2000, 130:1344S-1349.

2. Kenya National Bureau of Statistics (KNBS): Kenya Demographic and Health Survey 2014: Key Indicators. 2015.

3. Lonnerdal B: Dietary Factors Influencing Zinc Absorption. J Nutr 2000, 130:1378S-1383.

4. Brown K, Hambidge M, Ranum P, Zinc Fortification working group: Zinc fortification of cereal flours: Current recommendations and research needs. Food Nutr Bull 2010, 31(1 (Supplement)).

5. Sandstrom B, Davidsson L, Cederblad A, Lonnerdal B: Oral Iron, Dietary Ligands and Zinc Absorption. J Nutr 1985, 115:411-414.

6. Wapnir RA: Zinc Deficiency, Malnutrition and the Gastrointestinal Tract. $J$ Nutr 2000, 130:1388S-1392S.

7. Galetti V, Kujinga $P$, Mitchikpè CES, Zeder C, Tay F, Tossou F, Hounhouigan JD, Zimmermann $\mathrm{MB}$, Moretti D: Efficacy of highly bioavailable zinc from fortified water: a randomized controlled trial in rural Beninese children. Am J Clin Nutr 2015. Nov;102(5):1238-48

8. Siekmann JH, Allen LH, Bwibo NO, Demment MW, Murphy SP, Neumann CG: Kenyan School Children Have Multiple Micronutrient Deficiencies, but Increased Plasma Vitamin B12 Is the Only Detectable Micronutrient Response to Meat or Milk Supplementation. J Nutr 2003, 133 (11):3972S-3980S.

9. Torheim LE, Ferguson EL, Penrose K, Arimond M: Women in resource-poor settings are at risk of inadequate intakes of multiple micronutrients. J Nutr 2010, 140:2051S-8S.

10. Muthayya S, Rah JH, Sugimoto JD, Roos FF, Kraemer K, Black RE: The global hidden hunger indices and maps: an advocacy tool for action. PLoS One 2013, 8:e67860.

11. Joy EJM, Ander EL, Young SD, Black CR, Watts MJ, Chilimba ADC, Chilima B, Siyame EWP, Kalimbira AA, Hurst R, Fairweather-Tait SJ, Stein AJ, Gibson RS, White PJ, Broadley MR: Dietary mineral supplies in Africa. Physiol Plant 2014, 151:208-229.

12. Ramakrishnan U: Prevalence of Micronutrient Malnutrition Worldwide. Nutr Rev 2002, 60:S46-S52.

13. Wessels RK, Singh MG, Brown KH: Estimating the Global Prevalence of Inadequate Zinc Intake from national Food Balance Sheets: Effects of Methodological Assumptions. PLoS One 2012.

14. Briend A, Darmon N, Ferguson E, JG E: Linear programming: a mathematical tool for analyzing and optimizing children's diets during the complementary feeding period. $J$ Pediatr Gastroenterol Nutr 2003, 36:12-22.

15. Ferguson EL, Darmon N, Fahmida U, Fitriyanti S, Harper TB, Premachandra IM: Design of Optimal Food-Based Complementary Feeding Recommendations and Identification of Key “Problem Nutrients” Using Goal Programming. J Nutr 2006, 136:2399-2404.

16. Maillot M, Vieux F, Ferguson EF, Volatier J-L, Amiot MJ, Darmon N: To meet nutrient recommendations, most French adults need to expand their habitual food repertoire. J Nutr 2009, 139:1721-7.

17. Allen L, de Benoist B, Dary O, Hurrell RF (Eds): WHO / Guidelines on Food Fortification with Micronutrients. World Health Organization; 2006.

18. Santika O, Fahmida U, Ferguson EL: Development of Food-Based Complementary Feeding Recommendations for 9- to 11-Month-Old Peri-Urban Indonesian Infants Using Linear Programming. J Nutr 2009, 139 (1):135-141.

19. Levesque S, Delisle H, Agueh V: Contribution to the development of a food guide in Benin: linear programming for the optimization of local diets. Public Health Nutr 2015, 18:622-631.

20. Fahmida U, Kolopaking R, Santika O, Sriani S, Umar J, Htet MK, Ferguson E: Effectiveness in improving knowledge, practices, and intakes of "key problem nutrients" of a complementary feeding intervention developed by using linear programming: experience in Lombok, Indonesia. Am J Clin Nutr 2015, 101 (3 ):455-461.

21. Skau J, Bunthang T, Chamnan C, Wieringa F, Dijkhuizen M, Roos N, Ferguson EL: The use of linear programming to determine whether a formulated complementary food 
product can ensure adequate nutrients for 6- to 11-month-old Cambodian infants. $\mathrm{Am}$ J Clin Nutr 2014, 99:130-8.

22. FANTA: Summary Report: Development of Evidence Based Dietary Recommendations for Children, Pregnant Women and Lactating Women Living in the Western Highlands in Guatemala. Washington DC, USA; 2013.

23. Kenya National Bureau of Statistics (KNBS) and ICF Macro: Kenya Demographic Health Survey 2008-2009. Calverton, Maryland; 2010.

24. Tornheim JA: The epidemiology of hospitalisation with diarrhea in rural Kenya: the utility of existing health facility data in developing countries. International Journal of infectious diseases. Int J Infect Dis 2010, 14:e499-e505.

25. Adazu K: Health and demographic surveillance in rural western Kenya: a platform for evaluating interventions to reduce morbidity and mortality from infectious diseases. Am J Trop Med Hyg 2005, 73:1151-1158.

26. Bennett SD, Otieno R, Ayers TL, Odhiambo A, Faith SH, Quick R: Acceptability and use of portable drinking water and hand washing stations in health care facilities and their impact on patient hygiene practices, Western kenya. PLoS One 2015, 10:e126916.

27. Gegios A, Amthor R, Maziya-Dixon B, Egesi C, Mallowa S, Nungo R, Gichuki S, Mbanaso A, Manary MJ: Children consuming cassava as a staple food are at risk for inadequate zinc, iron, and vitamin A intake. Plant Foods Hum Nutr 2010, 65:64-70.

28. Gibson R, Fergurson E: An Interactive 24-Hour Recall for Assessing the Adequacy of Iron and Zinc Intakes in Developing Countries. Washington DC: International Life Sciences Institute; 1999.

29. Blanton CA, Moshfegh AJ, Baer DJ, Kretsch MJ: The USDA Automated Multiple-Pass Method accurately estimates group total energy and nutrient intake. J Nutr 2006, 136:2594-9.

30. Conway JM, Ingwersen LA, Vinyard BT, Moshfegh AJ: Effectiveness of the US Department of Agriculture 5-step multiple-pass method in assessing food intake in obese and nonobese women. Am J Clin Nutr 2003, 77 (5):1171-1178.

31. WHO: World Health Organization. Training Course on Child Growth Assessment. Geneva; 2008.

32. IZINCG: Collecting Blood in the Field for Assessment of Plasma Zinc Concentration. Practical Tips. 2012.

33. Erhardt JG, Estes JE, Pfeiffer CM, Biesalski HK, Craft NE: Combined Measurement of Ferritin, Soluble Transferrin Receptor, Retinol Binding Protein, and C-Reactive Protein by an Inexpensive, Sensitive, and Simple Sandwich Enzyme-Linked Immunosorbent Assay Technique. J Nutr 2004, 134 (11 ):3127-3132.

34. Brown KH, Rivera JA, Bhutta Z, Gibson RS, King JC, Lonnerdal B, Ruel MT, Sandtrom B, Wasantwisut E, Hotz C: International Zinc Nutrition Consultative Group (IZiNCG) technical document \#1. Assessment of the risk of zinc deficiency in populations and options for its control. Food Nutr Bull 2004, 25(1 Suppl 2):S99-203.

35. McLean E, Cogswell M, Egli I, Wojdyla D, de Benoist B: Worldwide prevalence of anaemia, WHO Vitamin and Mineral Nutrition Information System, 1993-2005. Public Health Nutr 2009, 12:444-54.

36. Thurnham DI, Mburu ASW, Mwaniki DL, Wagt A De: Micronutrients in childhood and the influence of subclinical inflammation. Proc Nutr Soc 2005, 64:502-509.

37. Sehmi J: National Food Composition Tables and the Planning of Satisfactory Diets in Kenya. Nairobi Kenya: Government Press; 1993.

38. Wolmarans P, Danster N, Dalton A, Rossouw K, Schönfeldt H: Condensed Food Composition Tables for South Africa. Parrow valley Cape Town; 2001.

39. Barikmo I, Ouattara F, Oshaug A: Table de Composition D'aliments Du Mali. 12th Ed. Oslo: Oslo; 2004.

40. West C, Pepping F, Temalilwa C: The Composition of Foods Commonly Eaten in East Africa. Wageningen,the Netherlands; 1988.

41. World food dietary assessment system [www.fao.gov/infoods]

42. USDA: National Nutrient Database for Standard Reference, Release 27. Washington DC; 2007. 
43. USDA Table of Nutrient Retention Factors, Release 6. Nutrient Data Laboratory home page [http://www.ars.usda.gov/ba/bhnrc/ndl]

44. IVACG: (International Vitamin A Consultative Group). Conversion Factors for Vitamin A and Carotenoids in: Vitamin and Mineral Requirements in Human Nutrition 2ed. Bangkok,Thailand; 2002.

45. IOM, FNB: Dietary Reference Intakes for Vitamin A, Vitamin K, Arsenic, Boron, Chromium, Copper, Iodine, Iron, Manganese, Molybdenum, Nickel, Silicon, Vanadium, and Zinc. 2nd edition. Washington D C, USA: National Academy Press; 2001.

46. Hoaglin D, Iglewicz B, Tukey J: Performance of some resistant rules for outlier labelling. $J$ Am Stat Assoc 1986, 81:991-9.

47. National Research Council. Nutrient Adequacy: Assessment Using Food Consumption Surveys. Report of the Sub-Committee on Criteria for Dietary Evaluation, Food and Nutrition Board, Commission of Life Sciences. Washington DC: National Academy Press; 1986.

48. Nusser S, Carriquiry A, Fuller W: A Semiparametric Transformation Approach to Estimating Usual Daily Intake Distributions`. CARD Work Pap 1992.

49. FAO: Human Energy Requirements, Report of a Joint FAO/WHO/UNU Expert Consultation. FAO Food and Nutrition Technical Report Series. FAO/WHO/UNU,Rome,Italy; 2004.

50. WHO, FAO: Vitamin and Mineral Requirements in Human Nutrition 2nd Ed. Bangkok,Thailand; 2004.

51. Ferguson EL, Darmon N, Briend A, Premachandra IM: Food-Based Dietary Guidelines Can Be Developed and Tested Using Linear Programming Analysis. J Nutr 2004, 134:951957.

52. Dietary Reference Intakes: Applications in Dietary Assessment. Washington, DC: The National Academies Press; 2000.

53. Hallberg L: Bioavailability of Dietary Iron in Man. Annu Rev Nutr 1981, 1:123-147.

54. Zimmermann MB, Chaouki N, Hurrell RF: Iron deficiency due to consumption of a habitual diet low in bioavailable iron: a longitudinal cohort study in Moroccan children. Am J Clin Nutr 2005, 81:115-121.

55. World Malaria Report

[http://www.rollbackmalaria.org/files/files/about/9789241564830_eng.pdf]

56. Brooker S, Miguel E, Moulin S, Luoba A, Bundy D, Kremer M: Epidemiology of single and multiple species helminth infections among schoolchildren in Busia district, Kenya. East Afr Med J 2000:279-282.

57. Thiong'o F, Luoba A, Ouma J: Intestinal helminths and schistosomiasis among school children in a rural district in Kenya. East Afr Med J 2001, 78:279-282.

58. Koukounari A, Estambale BBA, Njagi JK, Cundill B, Ajanga A, Crudder C, Otido J, Jukes MCH, Clarke SE, Brooker S: Relationships between anaemia and parasitic infections in Kenyan schoolchildren: a Bayesian hierarchical modelling approach. Int J Parasitol 2008, 38:1663-71.

59. Haldar K, Mohandas N: Malaria, erythrocytic infection, and anemia. ASH Educ Progr $B$ 2009, 2009 (1):87-93.

60. Friedman JF, Kanzaria HK, McGarvey ST: Human schistosomiasis and anemia: the relationship and potential mechanisms. Trends Parasitol 2005, 21:386-392.

61. Koury MJ, Ponka P: New insights into Erythropoiesis: The Roles of Folate, Vitamin B12, and Iron. Annu Rev Nutr 2004, 24:105-131.

62. Friis H, Mwaniki D, Omondi B, Muniu E, Magnussen P, Geissler W, Thiong'o F, Michaelsen KF: Serum retinol concentrations and Schistosoma mansoni, intestinal helminths, and malarial parasitemia: a cross-sectional study in Kenyan preschool and primary school children. Am J Clin Nutr 1997, 66:665-671.

63. Ngare D, Muttunga J, Njonge E: Vitamin A deficiency in pre-school children in Kenya. East Afr Med J 2000, 77:421-4.

64. Feikin DR, Bigogo G, Audi A, Pals SL, Aol G, Mbakaya C, Williamson J, Breiman RF, Larson CP: Village-randomized clinical trial of home distribution of zinc for treatment of childhood diarrhea in rural Western kenya. PLoS One 2014, 9:e94436. 
65. GOK\&UNICEF: Anaemia and the Status of Iron, Vitamin A and Zinc in Kenya. The 1999 Micronutrient Survey Report. Nairobi; 2002.

66. Bwibo NO, Neumann CG: The need for animal source foods by Kenyan children. $J$ Nutr 2003, 133(11 Suppl 2):3936S-3940S.

67. Vitamin A supplementation coverage rate (\% of children ages 6-59 months) | Data | Table

[http://data.worldbank.org/indicator/SN.ITK.VITA.ZS?order=wbapi_data_value_2013+wba pi_data_value+wbapi_data_value-last\&sort=asc]

68. De Moura FF, Palmer AC, Finkelstein JL, Haas JD, Murray-Kolb LE, Wenger MJ, Birol E, Boy E, Pena-Rosas JP: Are Biofortified Staple Food Crops Improving Vitamin A and Iron Status in Women and Children? New Evidence from Efficacy Trials. Adv Nutr An Int Rev J 2014, 5:568-570.

69. Brauw A De, Eozenou P, Gilligan D, Hotz C, Kumar N, Meenakshi J V: Biofortification, crop adoption and health information: Impact pathways in Mozambique and Uganda. 2013.

70. Talsma EF, Brouwer ID, Verhoef H, Mbera GN, Mwangi AM, Demir AY, Maziya-Dixon B, Boy E, Zimmermann MB, Melse-Boonstra A: Biofortified yellow cassava and vitamin A status of Kenyan children: a randomized controlled trial. Am J Clin Nutr .

71. Daelmans B, Ferguson E, Lutter CK, Singh N, Pachón H, Creed-Kanashiro H, Woldt M, Mangasaryan N, Cheung E, Mir R, Pareja R, Briend A: Designing appropriate complementary feeding recommendations: tools for programmatic action. Matern Child Nutr 2013, 9 Suppl 2:116-30.

72. Galetti V: Combining water treatment and zinc fortification against zinc deficiency and diarrhea in low-income settings. Ph.D. thesis. ETH Zurich; 2014.

73. UNICEF/WHO: Diarrhea: why children are still dying and what can be done. 2009.

74. Castillo-Duran C, Vial P, Uauy R: Trace mineral balance during acute diarrhea in infants. $J$ Pediatr 2015, 113:452-457.

75. Nyambose J, Koski KG, Tucker KL: High Intra/Interindividual Variance Ratios for Energy and Nutrient Intakes of Pregnant Women in Rural Malawi Show That Many Days Are Required to Estimate Usual Intake. J Nutr 2002, 132 (6 ):1313-1318.

76. Brown KH, Black RE, Becker S: Seasonal changes in nutritional status and the prevalence of malnutrition in a longitudinal study of young children in rural Bangladesh. Am J Clin Nutr 1982, 36:303-313.

77. Willet W: Nutritional Epidemiology. 2nd ed. Oxford, UK: Oxford University Press; 1998.

78. Guarini $L(E d)$ : Traditional African vegetables Promoting the conservation and use of underutilized and neglected crops. 16. In Proceedings of the IPGRI International Workshop on Genetic Resources of Traditional Vegetables in Africa: Conservation and Use 2931 August 1995, ICRAF-HQ, Nairobi, Kenya.Institute of Plant Genetics and Crop Plant Research, Gatersleben/International Plant. Rome, Italy; 1997.

79. Kigutha HN, van Staveren WA, Veerman W, Hautvast JG: Child malnutrition in poor smallholder households in rural Kenya: an in-depth situation analysis. Eur J Clin Nutr 1995, 49:691-702. 


\section{Chapter 6}

General Discussion 


\section{GENERAL DISCUSSION}

The overall aim of this thesis was to investigate whether zinc fortified water when provided daily through a household based water treatment system (LSF) to households can increase dietary zinc intake and improve zinc status and morbidity in children living in areas exposed to unsafe water sources. To achieve this aim four related studies were conducted in rural Kisumu, Western Kenya. This chapter will summarize the main findings of the research, internal and external validity, public health and policy implications of the findings as well as suggestions for future research. The main findings are displayed in Table 1 below.

In summary the background investigations found that 3 out of 4 children suffered from zinc deficiency (74.4\% low plasma zinc status), 34\% suffered from vitamin A deficiency and 61\% from iron deficiency. Half of the children (53\%) were affected by inflammation. Correcting PZn and RBP for inflammation by all applicable methods reduced prevalence of zinc and vitamin A deficiency by $2-10 \%$ (excluding published CF approach) and $43-78 \%$ respectively. Correcting PF for inflammation changed the prevalence of iron deficiency from $0.6-10 \%$ depending on the method used (Chapter 2). We show that the LSF strategy provided zinc through fortified water which was more bioavailable (7 times higher) compared to zinc provided in fortified maize. Frequent usage of the LSF filter with high volumes (10 and 20L/d) of water delivered adequately fortified water (1.7 and $1.3 \mathrm{mg} / \mathrm{L}$ respectively) (Chapter 3 ). Daily consumption of zinc fortified water at the study participant consumption rates $(\approx 500 \mathrm{ml} / \mathrm{d})$ and fortification level $(1.15 \mathrm{mg} / \mathrm{L})$ contributed a significant amount (42\% and 36\%) to the daily absorbable zinc requirements for children 2-3 and 4-6 years old respectively. We showed that daily intake of zinc fortified water reduced overall morbidity prevalence and morbidity due to specific conditions (cold runny nose, stomach pain and diarrhea), however we did not detect an effect on PZn (Chapter 4). Lastly using linear modelling we found that combining the introduction of zinc fortified water with local food-based dietary recommendations achieved nutrient adequacy for all nutrients except for vitamin $\mathrm{A}$ and folate. For the latter nutrients additional interventions are recommended. 
Table 1: Summary of the main findings of each trial carried out in the framework of the thesis

\section{Background investigation}

\begin{tabular}{|c|c|c|}
\hline Design & Objective & Main results \\
\hline $\begin{array}{l}\text { Chapter } 2 \\
\text { Cross sectional } \\
\text { Population: 2-6 year olds } \\
\text { from rural Kisumu }\end{array}$ & $\begin{array}{l}\text { To estimate prevalence of } \mathrm{Zn} \text {, } \\
\text { vitamin A and Fe deficiency. } \\
\text { To compare inflammation } \\
\text { corrected prevalence } \\
\text { estimates using various } \\
\text { approaches from literature. }\end{array}$ & $\begin{array}{l}\text { - Zinc deficiency prevalence: } 74 \% \text {, Vitamin } \mathrm{A} \\
\text { deficiency: } 34 \% \text { and iron deficiency } 61 \% \text {. } \\
\text { - Inflammation affected } 53 \% \text { of the children. } \\
\text { - Prevalence estimates varied for all nutrient } \\
\text { biomarkers depending on method used to } \\
\text { correct for inflammation: percent change range } \\
\text { Zn } 2 \%-10 \% \text {; Fe } 0.6 \%-10.3 \% \text { and Vitamin } \mathrm{A} \\
43 \%-78 \%\end{array}$ \\
\hline $\begin{array}{l}\text { Chapter } 3 \\
\text { Elution trial } \\
\text { Laboratory based } \\
\text { experiment } \\
\text { Absorption trial } \\
\text { Single blind cross over trial } \\
\text { Population 18-45y Swiss } \\
\text { healthy adults }\end{array}$ & $\begin{array}{l}\text { To assess the effect of } \\
\text { different usage patterns }(2,10 \\
\text { and 20L/d) and storage on } \\
\text { zinc elution } \\
\text { To measure fractional } \\
\text { absorption of Zn from } \\
\text { following } 3 \text { meals: i) LSF Zn } \\
\text { fortified water, ii) a Zn } \\
\text { fortified inhibitory maize } \\
\text { porridge, and iii) Zn fortified } \\
\text { water consumed with maize } \\
\text { porridge }\end{array}$ & $\begin{array}{l}\text { - Zinc elution was higher in filters used to treat } \\
2 \mathrm{~L} / \mathrm{day}(4.7 \pm 1.6 \mathrm{mg} / \mathrm{L}) \text { than } 10 \mathrm{~L} / \mathrm{d}(1.7 \pm 0.9) \\
\text { and } 20 \mathrm{~L} / \mathrm{d}(1.3 \pm 0.7 \mathrm{mg} / \mathrm{L}) \text {. } \\
\text { - Storage for } 1 \text { week increased zinc elution by } \\
23.4 \%(2 \mathrm{~L} / \mathrm{d}), 82.4 \%(10 \mathrm{~L} / \mathrm{d}) \text { and } 43.1 \% \\
(20 \mathrm{~L} / \mathrm{d}) \text {. After second week of storage zinc } \\
\text { elution further increased by } 56.9 \%(2 \mathrm{~L} / \mathrm{d}) \text {, } \\
12.9 \%(10 \mathrm{~L} / \mathrm{d}) \text { and } 7.5 \%(20 \mathrm{~L} / \mathrm{d}) \\
\text { - Fractional absorption from } \mathrm{LSF}-\mathrm{Zn} \text { fortified } \\
\text { water was } 65.9 \%, 7 \text { times higher than from a } \\
\text { fortified maize porridge }(9.1 \%) \text { and zinc } \\
\text { fortified water consumed with maize porridge } \\
(9.8 \%)\end{array}$ \\
\hline \multicolumn{3}{|c|}{ Effectiveness of zinc fortified water } \\
\hline $\begin{array}{l}\text { Chapter 4: } \\
\text { Effectiveness trial } \\
\text { Home based, Double blind } \\
\text { RCT } \\
\text { Population: 2-6 year old } \\
\text { Rural Kisumu }\end{array}$ & $\begin{array}{l}\text { To assess effectiveness of zinc } \\
\text { fortified water on zinc intake, } \\
\text { status and morbidity }\end{array}$ & $\begin{array}{l}\text { - Zinc fortified water contributed } 42 \% \text { and } 36 \% \\
\text { of daily requirements for absorbable zinc in } \\
\text { children 2-3 and 4-6 years respectively } \\
\text { - Treatment effect on overall morbidity and } \\
\text { morbidity due to cold, stomach pain and } \\
\text { diarrhea. No treatment effect on plasma zinc } \\
\text { concentration }\end{array}$ \\
\hline \multicolumn{3}{|c|}{ Development of food based dietary recommendations } \\
\hline $\begin{array}{l}\text { Chapter } 5 \\
\text { Linear Modelling (Optifood) } \\
\text { using cross sectional dietary } \\
\text { intake data } \\
\text { Population: 4-6 year old } \\
\text { children } \\
\text { Rural Kisumu }\end{array}$ & $\begin{array}{l}\text { To develop local food based } \\
\text { dietary recommendations in } \\
\text { combination with Zn fortified } \\
\text { water to ensure nutrient } \\
\text { adequacy }\end{array}$ & 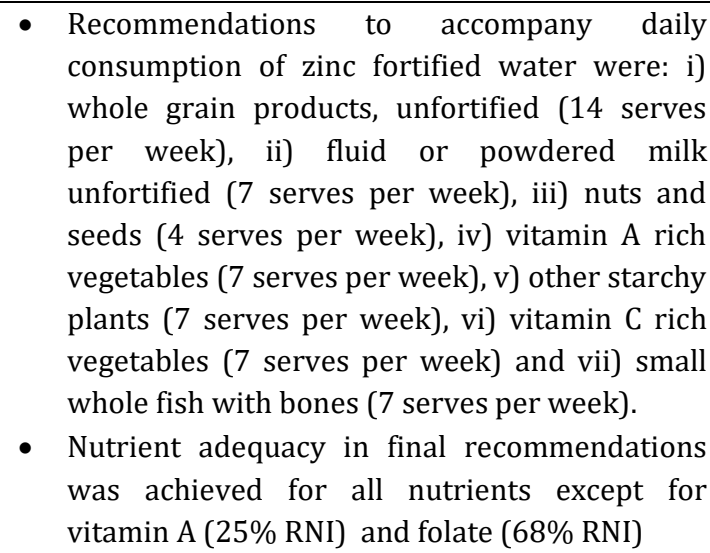 \\
\hline
\end{tabular}




\section{INTERNAL VALIDITY}

This section of the chapter discusses the main methodological issues not addressed in chapters 2-5 that may affect the conclusion of this thesis, related to selection bias, measurement bias and confounding.

\section{Selection bias}

Selection bias occurs when the selected sample does not represent the population intended to be analyzed [1]. For the baseline study which was conducted in 2011 (chapter 2), households with under five year old children were identified from a health and demographic surveillance system (HDSS) established by United States Army Medical Research Unit-Kenya (USAMRU-K) and the Kenya Medical Research Institute (KEMRI) [2].The HDSS established in 2007 collects key demographic and health indicators through bi-annual household surveys in rural Kisumu County. It covers an area $369 \mathrm{~km}^{2}$ wide along the north eastern shores of Lake Victoria [2]. All households identified from the HDSS as having an under five year old in the sub-locality of Kajulu Koker, a small area compared to the overall HDSS system were invited for information sessions and then recruited after consenting. The most recent census of the villages was done prior by the HDSS in January 2011 and our baseline study was conducted in September 2011. By using the HDSS we may have missed out on new households that arrived in the area between January 2011 and the recruitment for our study. Out migration by the 15-35 year old age group is considered to be high in rural Kisumu as the youth and young adults search for better educational and employment opportunities in neighboring towns. Immigration is mainly in the 50-55 year age group due to retirements [2]. However we do not expect these new households to be many as the HDSS and our study intricately involved all administrative hierarchies in the village system consisting of individuals who were knowledgeable of new/old inhabitants. Each village was under a village elder who knew if there was a new family that had been offered land to build with the chief overseeing all the activities. In this regard care was taken to include all new households that were not yet enlisted by the HDSS. This related selection bias can be considered to be negligible.

Even though effectiveness trials are known to have less stringent eligibility criteria [3], we had to restrict our recruitment to children who were not participating in any other trial in the study site carried out by other research groups (chapter 2 and 4). There was a malaria vaccine trial and a malaria transmission intensity study implemented during our recruitment phase, and children involved in these studies were excluded from our study. There is some evidence that individuals of low socio economic status may volunteer more to participate in studies due to perceived benefit than individuals of higher socio economic standing $[4,5]$. We therefore may have recruited children who were from better of households by virtue of recruiting after other trials in the study site, possibly introducing a selection bias. However this was not reflected by the children's nutritional status as stunting, zinc, iron and vitamin A deficiency were high and comparable to averages known from the area.

A potential source of bias is refusal to participate in a study. Refusals may lead to over generalization of results if reasons of refusal are related to the exposure. There were 43 refusals between consenting and baseline for the effectiveness trial (chapter 4). Studies conducted to determine the difference between responders and non-responders have found differences in some variables e.g. demographic or health related [6]. Considering the fact that the non- 
responders constituted $18 \%$ of total consented, this may have introduced a non-response bias. However with no information about the characteristics of these non-responders available except that they 'changed their minds', we are unsure how this may have affected the conclusions of the study.

If in the trial, participants who do not perceive benefit drop out more frequently due to adverse events, their exclusion from analysis can lead investigators to exaggerating the benefits of the intervention. The total dropout rate was relatively low (9.2\%) with no difference between the two treatment arms, just as there was also no difference in compliance between the two treatment arms, hence a systematic bias was unlikely. One strategy to eliminate this form of bias is by conducting "intention to treat" analysis. This way all participants are included in the analysis as part of the groups to which they were randomized to regardless of whether they completed the study or not. We conducted both "intention to treat" and "per protocol" analyses as a way to take into account this potential bias.

Bioavailability of zinc from fortified water was measured in Swiss adults (chapter 3) whilst the intervention was conducted in young African children (chapter 4). The higher bioavailability assumed may not have been the case due to age and physiological differences between the participants of the isotope study (chapter 3) and participants of the effectiveness study. There is evidence that age significantly affects absorptive capacity with younger age being associated with lower zinc absorption possibly due to intestinal length [7]. This reduced absorptive capacity may be further exacerbated by environmental enteropathy believed to be highly prevalent in developing countries $[8,9]$. This condition is known to impair zinc absorption and or increase zinc losses due to mechanisms such as reduced gut barrier function and increased permeability $[10,11]$. More studies to determine absorptive capacity of children from such areas may be needed to answer these questions.

Subgroup analysis may lead to selection bias especially if randomization of the study population is not stratified according to factors defining the subgroup [12]. A proportion of the study households (19\%) were monitored for water zinc content. Samples for atomic absorption spectrophotometry were collected up to midpoint whilst samples for rapid zinc analysis were collected throughout the intervention period. Monitoring a proportion of the households for a proportion of the time may not reflect the zinc water concentration of all study households throughout the study, especially when zinc concentrations in water show a high variation as in our study. Even though the households were selected randomly, this subgroup analysis may have distorted the balance achieved by randomization. Results should therefore be interpreted with caution.

\section{Information bias}

Interviewer bias refers to "a systematic difference between interviewers in how interview data is collected, recorded or interpreted" [13] and can occur especially when interviewers are aware of objectives of the study. Knowledge about the study of zinc intake and health outcomes may have increased attention to morbidity. Diarrhea morbidity especially may have been affected, possibly increasing prevalence estimates. The health surveillance in chapter 4 assessed other health problems in the study child reducing the attention on diarrhea. This may have reduced interviewer bias. 
Allocation concealment is said to protect randomization sequence before and up to the time when the intervention is allocated to participants. Treatment allocation was done by a member of the research team who was not directly involved with data collection and it was concealed to the research team as well as all participants. Biochemical analysis was conducted by researchers unaware of treatment allocation. The treatment code was only revealed after primary analysis of the data. In this regard information bias was greatly reduced. The RCT was double blind meaning neither the subjects nor the researchers knew in which treatment arm the subjects were. Blinding helps protect randomization sequence after allocation. Control filters and intervention filters were matched weight to weight to avoid households identifying the filters that contained the zinc glass plates. Furthermore intervention arms were randomized into 4 pseudo treatment arms identified by color code to further enhance the blinding. Hence information bias due to prior knowledge of treatment by participants, interviewers and analysts is considered to be minimal. One possibility of quantifying success of blinding weakness would have been to ask participants and the study team to identify the identity of the treatment arms prior deblinding.

\section{Respondent bias}

Respondent bias is a form of bias caused by participants not giving accurate or truthful responses [14]. This bias is highly prevalent in studies that involve self-reports and interviews. Data collection methods that rely on memory may bring about respondent bias. The morbidity survey as well as the dietary assessment (24hr recall) relied on the caregivers' ability to recall symptoms present or foods consumed in the past week or 24 hours respectively. The request for clinic visit cards could have reduced this form of bias in the morbidity survey. The intervention group and control group had a total of only 34 and 47 clinic visits respectively throughout the intervention specifically for diarrhea related infections. The proportion of clinic visits was low and did not differ statistically between the groups, suggesting that this was a population with low treatment seeking behavior and clinic records could not be entirely relied upon.

Social desirability is a type of response bias in which participants answer in a way that may be favorable to the experimenter [14]. They may over report perceived good behavior and/ or under report perceived bad behavior. This type of bias may also have occurred in the effectiveness trial. Knowledge of the hypothesis of the study may have led participants to under report morbidity, and over report filtered drinking water consumption. The distortions in response could have had an effect on validity of data collected. This phenomenon is closely related to the Hawthorne effect which describes a situation where study participants behave in a certain way because of the awareness that they are under observation $[15,16]$. Filter usage was recorded by tally counter. Households were left to move the tally counter one count forward after a filtering event. The constant presence of field workers collecting data in the field may have 'motivated' filter usage artificially. This and the fact that we recorded increased filter usage at baseline, midpoint and endpoint assessments may have been caused by higher than usual presence of researchers in the field during the crucial time points. We therefore may have unintentionally influenced the performance of the participants. In this regard higher compliance in future roll out programs should not be assumed. However due to allocation concealment and blinding we may have made the bias equal for both intervention groups.

\section{Dietary Assessment}

In chapter 4 we aimed to estimate the habitual dietary intake of the study population. We conducted a $24 \mathrm{hr}$ recall with duplicate recall on a non-consecutive day. Measuring dietary intake 
by the $24 \mathrm{hr}$ recall method presents many challenges such as recall error, interviewer bias and measurement error [17]. These errors could have affected the estimated nutrient intake (chapter 4) as well as the quality of data imputed into the modelling process (chapter 5). For this reason we took many precautions. Interviewers underwent an extensive training on collecting dietary intake data. Research instruments and methods were pretested before actual data collection. The multipass method used ensures that forgotten foods are captured by the process of using several 'passes' [17]. Dietary scales were calibrated before use each day. The recall days were randomly assigned to the interviewers and no interviewer visited the same household twice. Spot visits during data collection were made on the research assistants and each team had a supervisor who screened the questionnaires for inconsistencies and omissions at the end of every day, scheduling re-visits to correct the mistakes. Actual weights of duplicate portions were weighed, and when these were not available estimates were made based on household units, volume, size (small medium large) or as monetary equivalents. Conversion factors were determined by the supervisors and these were used to determine the amount consumed by the child. The mothers were able to use their own utensils during the interview and this aided the recall process. Finally to permit for day to day variation the $24 \mathrm{hr}$ recall was repeated on a nonconsecutive day in each house. The use of food composition tables can also be a source of error in nutrient intakes due to variation in values estimated from different conversion factors [18]. We primarily used the Kenya FCT [19] and this was complemented by data from other FCTs compiled using recognized international standards for food database compilation [20]. Measurement error was therefore reduced to a minimum.

\section{Measurement bias}

We found no effect of the intervention on plasma zinc status of the children. This could have been due to the choice of indicator for zinc status. PZn is the recommended biomarker to indicate a populations risk of zinc deficiency due to its ability to respond to zinc supplementation [21]. However while plasma zinc is often used, it is not a sensitive and reliable marker of zinc status because zinc levels in the blood are known to be re distributed as a result of infection /inflammation and fasting status amongst many factors [22, 23]. As such a suitable biomarker of zinc status is yet to be found [24].

To determine proportion at risk of inadequate zinc intake for children 4-6 years old (chapter 5) we used EARs derived from RNIs set by FAO/WHO $(8 \mathrm{mg} / \mathrm{d})$ [25]. These gave a prevalence of inadequacy of $85 \%$. Using the EARs set by IZINCG $(4 \mathrm{mg} / \mathrm{d})$ [21] would have given a prevalence of inadequate zinc intake of $10 \%$. However, this did not correspond with the high level of zinc deficiency found in our population based on serum zinc concentration (74\%). It is possible that our children have higher zinc requirements due to high prevalence of diarrheal infections [10, 26] and therefore the EARs set by IZINCG would have underestimated the prevalence of those at risk of inadequate zinc intake. This large discrepancy in estimating prevalence of population at risk of deficiency when using EARs set by IZINCG and WHO has also been observed in a recent cross sectional study in Benin [27]. Low plasma zinc status was elevated in the 5-8 year olds in the Benin study (65.3\%) however 0\% were below the IZiNCG EAR and hence it could be that the cutoffs set by IZINCG do not support the elevated requirements in such populations.

Higher disease incidence has been observed with higher frequency of surveillance, i.e. surveillance of twice per week and above [28]. We therefore conducted household visits once per week for morbidity surveillance. With diarrhea only, the recall period was $48 \mathrm{hrs}$ as it has been shown that diarrhea morbidity can be under reported when the recall period exceeds 3 
days [29-31]. We made use of trained field assistants from the local village area, due to their closeness to and trust from the community. In the absence of health workers, another alternative would have been to use health diaries however field worker data has been shown to be more reliable and complete in a morbidity survey comparing field worker interviews and health diaries in recording morbidity data [32].

We made use of pictorial diaries throughout the intervention period to record amount of water consumed (filtered and unfiltered). This method is useful in resource poor settings and has been used before to measure food consumption and record health related conditions [33].The use of illustrations ensured that also an illiterate caregiver could fill it in. The disadvantage of using diaries over a long period of time is the issue of fatigue. As the diary keeping period lengthens participants may become less thorough in their record keeping [34, 35]. However the diaries were collected once a week and there was opportunity to stress on completeness of the diary at every household visit hence the rate of completeness was high and equal in both intervention groups.

\section{Confounding}

Confounding occurs when the effect of exposure is mixed together with the effect of another variable leading to results that do not reflect the actual relationship between exposure and outcome [36]. Confounding is best controlled at the design stage by procedures such as randomization. In chapter 4 study participants were assigned to 4 pseudo treatment arms using a block randomization procedure that guaranteed the same numbers of randomized participating households per arm and balance in terms of $\mathrm{Hb}$ status, age and sex. Randomization was done successfully as a check in data analysis revealed that participants were balanced at baseline in terms of demographic characteristics as well as, prevalence of anemia and inflammation. In this case, it can be expected that both unknown and known confounders may be evenly distributed during randomization. Confounding can also be controlled at the data analysis stage. A major confounder in analyzing the effect of intervention on plasma zinc is level of inflammation. The effectiveness study was conducted during a season known to have high influenza and malaria transmission therefore infection was expected to be high in the study population [37]. This was reflected in high prevalence of elevated CRP and AGP in the study participants. However even after correcting plasma zinc for inflammation there was no significant time by treatment effect. Correcting for inflammation proved to be suboptimal as in chapter 2 , the change in zinc deficiency prevalence ranged from $2 \%$ to $10 \%$ by all applicable methods of correcting except when using the published CF approach (19.2\% change).

\section{EXTERNAL VALIDITY}

Under this section the results from this thesis will be discussed in relation to other studies as well as how generalizable to different settings the results are:

\section{Prevalence of zinc, iron and vitamin A deficiency in preschool children in the presence of inflammation}

The findings of chapter 2 indicate that there is high prevalence of zinc, iron and vitamin A deficiency among preschool children in rural western Kenya. This to a large extent reflects 
inadequate dietary intake or poor quality diets at household level. This was also reflected in chapter 5 when 44 out of 60 children had intakes below the EAR in 4 or more of the 11 nutrients studied. The diets of the children were characterized by low variation in foods consumed and other studies have confirmed this low variation in foods consumed and presence of multimicronutrient deficiencies in Kenyan children [38,39]. The prevalence of zinc deficiency reported in this chapter $(74.4 \%)$ is higher than values reported among children from western Kenya (32\%) [40], and 50.8\% [41]. The causes of this discrepancy is unclear however, and even after correcting for inflammation the level of deficiency was still above the set global threshold $(20 \%)$ indicating that zinc deficiency is a significant public health problem in Western Kenya. Our comparison of methods used to correct for inflammation led to varying estimates. The magnitude of difference, for iron and zinc deficiency was small and produced a change in estimated prevalence of $\approx 10 \%$ for both nutrients. Zinc deficiency prevalence varied from $66.8 \%$ to $74 \%$ (excluding use of published CFs), iron deficiency prevalence from $57 \%-66 \%$ and vitamin A deficiency from $8 \%$ to $37 \%$ depending on the approach used. Limited studies have described or compared the effect of different approaches of correcting for inflammation on prevalence estimates $[42,43]$, in addition the absence of a reference approach is a constraint. Nevertheless it is evident from all the studies that a context specific consensus is required on approaches to account for inflammation.

\section{Zinc elution and bioavailability}

The elution trials showed that the LSF strategy was capable of delivering nutritionally relevant zinc concentrations when used regularly. Concentrations of zinc in eluted water increased when filters were stored for periods of time ( 1 week) and when low amounts of water were filtered $(<10 \mathrm{~L} / \mathrm{d})$. We could not compare our results due to lack of data from published similar studies however it has been shown before that irregular filter usage with low amounts of water can affect zinc elution adversely [44]. The absorption trial in chapter 2 showed that when zinc fortified water was consumed away from meals, absorption was $65.9 \%$ whilst it was approximately 7 times lower with no significant difference when zinc fortified maize cereal was consumed or zinc fortified water was consumed with an inhibitory maize porridge. The amount of zinc absorbed proved to be similar to results obtained from previous absorption studies of zinc in aqueous solution; $90 \%$ and $62 \%$ for a Zn dose of 1.0 and $5.0 \mathrm{mg}$ [45], 69\% and $63 \%$ of a $\mathrm{ZnCl}_{2}$ solution delivering 0.5 and $4.0 \mathrm{mg}$ [46], 73-74\% from a water solution delivering $2.6 \mathrm{mg}$ $\mathrm{Zn}$ as $\mathrm{ZnSO}_{4}$ [47], 73\% for a $\mathrm{Zn}$ dose of $2.6 \mathrm{mg}$ [48], 73\% for an intake of $2.0 \mathrm{mg}$ aqueous $\mathrm{Zn}$ as $\mathrm{ZnSO}_{4}$ [49], and 61\%, 61\%, and 50\% from a $\mathrm{Zn}$ dose of $10 \mathrm{mg}$ as $\mathrm{Zn}$ citrate, $\mathrm{Zn}$ gluconate and $\mathrm{ZnO}$, respectively [50]. This high absorption reflects the absence of inhibitory factors in an aqueous medium such as the food matrix or phytic acid $[21,47]$. 


\section{Effectiveness of zinc fortified water}

Drinking water fortified with zinc at the level of $1.15 \mathrm{mg} / \mathrm{L}(\approx 0.6 \mathrm{mg} / \mathrm{d})$ made a substantial addition to dietary zinc intake ( $42 \%$ and $36 \%$ of daily requirements of absorbable zinc intake of children 1-3 and 4-6 years respectively). This led to a decrease in overall morbidity rates and morbidity due to cold, stomach pain and diarrhea; however we did not find an effect on plasma zinc and prevalence of zinc deficiency. To our knowledge no study has reported on the effectiveness of zinc fortified water on zinc status and morbidity of children, however similarly to our findings on morbidity, daily zinc supplementation (5mg per day $\mathrm{Zn}$ in $5 \mathrm{ml}$ sterile water) reduced incidence of diarrhea and upper respiratory tract infections in Tanzanian infants [51]. Plasma zinc is known to respond to supplementation [24,52] however it is also not a highly sensitive and reliable biomarker [24]. This and the fact that the dose was much lower than that used in supplementation could be the reason we did not observe an effect on PZn.

A previous study on the effect of zinc fortified formula $(3.2 \mathrm{mg} / \mathrm{L})$ in infants showed a change in functional outcomes (growth and improved immune competence) but no change in plasma zinc [53]. Several other zinc intervention studies have also demonstrated a functional effect with no effect on plasma or serum zinc [54-57]. These studies mostly conducted in malnourished children may indicate that a functional response is higher due to sequestration of zinc by tissues or biochemical processes (such as immune response) in need of zinc. ZIP4 is known to increase in times zinc deficiency [58], and zinc from plasma is taken up in the tissues by ZIP transporters [59]. This is what may have occurred in the current study. Furthermore a review on the effect of zinc supplementation on acute and persistent diarrhea did not find plasma zinc to be a significant predictor of response to zinc supplementation in acute diarrhea [60].

In the absence of studies on effectiveness of zinc fortified water, our study can be cautiously compared to a recent efficacy trial on the effect of zinc fortified water on zinc status in children conducted in rural Benin [61]. In this school based trial, zinc fortified drinking water (overall daily intake of $2.8 \mathrm{mg} / \mathrm{d}$ ) was able to uphold higher plasma zinc concentration and reduce prevalence of zinc deficiency, but no effect was detected on morbidity levels in the study children. Several differences between the two studies deserve mention. The population of the current effectiveness trial was much younger (2-6 vs 6-10years old) and possibly more vulnerable to infections (prevalence of elevated CRP and AGP at baseline was higher for the Kenya study than the Benin study) hence an intervention effect was observed on morbidity. The average daily amount of zinc consumed from fortified water $(0.6 \mathrm{mg} / \mathrm{d}$ vs $2.8 \mathrm{mg} / \mathrm{d})$, average water consumed per day $(500 \mathrm{ml} / \mathrm{d}$ vs $600 \mathrm{ml} / \mathrm{d})$ and compliance $(40 \%$ vs $87 \%)$ were all higher in the efficacy trial compared to the effectiveness trial. The prevalence of malnutrition as indicated by anemia, iron, zinc and vitamin A deficiency was higher in Kenya compared to Benin. These contrasts in addition to study design (effectiveness vs efficacy) may have led to differences in outcomes between the 2 studies. 


\section{Dietary recommendations}

In chapter 5 in the final modelled diet, the problem nutrients in the subsample of 4-6 year olds were identified as folic acid and vitamin A. Vitamin A especially is a nutrient often found to be limiting in most diets of individuals from low income countries [62] and this is also demonstrated in other modelling studies [63-66]. Surprisingly no children were below the EAR for iron intake and iron was not identified as a problem nutrient in the children's diets in the modelling process. This is despite the prevalence of anemia and iron deficiency being high in this population (52 and 63\% respectively). It has been observed from other studies that iron is often inadequate from diets of individuals of poor regions $[67,68]$. This discrepancy of high prevalence of anemia and iron deficiency with no children at risk of inadequate iron intake may indicate the presence of anemia and iron deficiency of non-nutrition origin such as that caused by malaria and other parasites eg helminthes. These parasitic infections can lead to iron deficiency through mechanisms that include extra corporeal blood loss, haemolysis and inflammation $[69,70]$. Parasitic infections are highly prevalent in western Kenya as observed in some studies [71-74] with co infection known to lead to greater risk of anemia [75] and this could also be the situation in western Kenya.

The results of linear modelling indicated that the addition of zinc fortified water can improve zinc RNI coverage from an actual $61 \%$ to a theoretical $87 \%$. Combining this intervention with additional food based recommendations led to nutrient adequacy in all nutrients except for vitamin A (25\%) and folic acid (68\%). The modelled final FBRs clearly suggest that using local foods alone cannot provide adequate vitamin A and folic acid. Alternative methods have to be explored in order to improve their intake particularly for vitamin A whose coverage was far below the cutoff of 70\%. Routine vitamin A supplementation conducted in all health centres in Kenya can be adequate to fill the nutrient gap provided the coverage is extensive however national coverage has been shown to be low as 19\% [76]. Biofortification of plant foods with pre vitamin $A$ is a novel approach that has been proven to improve vitamin A status in vulnerable groups [77, 78]. Examples of biofortified plants that have been tested with positive outcomes include yellow maize [79] and orange flesh sweet potato [80]. It remains a challenge however to scale up this approach for implementation on a larger scale. In chapter 5 we conclude that a single nutrient intervention such as LSF strategy must be accompanied by food based recommendations to ensure nutrient adequacy.

Until the recommendations are implemented and tested in practice the results of such modelling exercises should be interpreted with caution as they may be under or over estimation of the effects of the intervention. The recommendations may be acceptable or may require modification in order to make them feasible and acceptable in a real setting.

\section{GENERALIZABILITY}

Effectiveness trials are designed to measure the beneficial effect of an intervention in a real life setting [81] and therefore should be conducted on participants who represent the full spectrum of the population to which the intervention might be applied. The research reported in this thesis was conducted in pre-school children living in areas with unimproved water supply. These children had an elevated risk of zinc deficiency due to increased requirements and exposure to contaminated water sources which made them susceptible to diarrheal infections [82]. Children between the ages of 2-6 years were particularly selected because it was assumed that they were non breastfed, spent most of their time at home and could therefore drink from 
the LSF device an unlimited number of times as compared to school going children. Our results of the efficacy trial therefore may not be extrapolated to older children for the following reasons. They are expected to spend a greater proportion of the day away from the households and may not be able to drink exclusively from the device reducing exposure to intervention unless measures are put in place for them such as provision of zinc fortified water in schools. Older children have higher zinc requirements [21] and possibly lower disease prevalence.

The most important reason for selecting Kajulu Koker in Western Kenya was because it is situated along the shores of Lake Victoria with limited supply of improved water sources. Households relied mainly on the lake for domestic water purposes especially during the dry season. A preliminary survey of water sources in the area revealed high levels of contamination from this large water body (unpublished data). Diarrhea prevalence was expected to be high in this area as well as zinc deficiency and this was confirmed in our study. We expected the intervention effect to be higher in these zinc deficient children with documented high rates of diarrhea $[83,84]$. In this regard, our results may be applicable to children living in areas with unimproved water sources and not just Western Kenya and may not be extrapolated to populations with access to improved water sources and or with normal zinc status.

Generalizability of results is not only influenced by respondent (or subject) characteristics but by adherence to protocol [85]. The current study designed as an effectiveness study reflects better the true effect of the Lifestraw in a non-study setting compared to the efficacy trial. The distinction between effectiveness and efficacy has been described before and includes the employment of more stringent controls in efficacy trials for all variables concerned maximizing internal validity more than external validity $[3,81]$. In this regard participant compliance was higher in the school based Benin efficacy trial as the study participants were served with ready to drink zinc fortified water than the household based effectiveness study where the participants prepared and consumed the zinc fortified water independently from the investigators. Compliance to such interventions in real world setting is expected to more closely resemble an implemented hypothetical fortification program.

In chapter 5 we made use of intake data from a particular season (pre harvest season) to develop the food based recommendations. Seasonal variation in food availability is expected as the household food production relied on rain fed agriculture. Other studies conducted in developing countries have observed seasonal variations in dietary intake [86-88]. For this reason the results obtained cannot be generalized to the whole year. Further studies that take into consideration seasonal variation would be necessary. 


\section{CONCLUSIONS}

- Zinc deficiency is a problem of significance in rural African pre-school children living in diarrhea endemic areas exposed to unsafe water sources and interventions are necessary.

- With elevated uncorrected prevalence (above the respective threshold), the choice of approach may not be important to decide if a problem is of public health significance or not.

- The Lifestraw Family filter with zinc is one such intervention capable of fortifying water with highly bioavailable zinc at adequate and safe levels when used regularly in sufficient quantities.

- Zinc fortified water is effective in improving dietary zinc intake, reducing childhood morbidity but had no effect on plasma zinc in preschool children from rural Western Kenya.

- Zinc fortified water together with food based recommendations has the potential to ensure nutrient adequacy for all nutrients except folic acid and vitamin A in children 4-6 years old from rural Western Kenya. Additional interventions will be required to ensure dietary adequacy for these nutrients.

\section{IMPLICATIONS FOR PUBLIC HEALTH}

The concept of water fortification with zinc has great potential and should be considered for introduction in communities that subsist on cereal based diets due to numerous advantages of water as a vehicle for fortification. Water is devoid of inhibitors and reduces prevalence of water borne infections such as diarrheal infections also contributing to improved zinc status. However it is the concept of water fortification with LSF device that would require more attention, especially concerning technical considerations, compliance and practical challenges.

\section{Technical considerations}

Before implementation future studies should focus on reducing the inter and intra filter variability in terms of zinc elution. This could entail the development of a homogenously soluble zinc phosphate glass plate with a dissolution constant that is unaffected by usage pattern or storage. The zinc phosphate glass plates designed for the effectiveness trial were slow dissolving plates but gave a range of zinc concentration from as low as 0.04 to as high as $18.7 \mathrm{mg} / \mathrm{L}$. Since results of the elution trial showed that zinc elution was very much dependent on usage pattern, to reduce variability in elution due to different usage patterns, there should be consideration of using this concept in bulk water supply systems such as tanks, boreholes and wells. This will have an added advantage of making elution rate independent of compliance.

\section{Compliance}

Research is required on how compliance can be further increased at household level as compliance will affect efficacy or effectiveness of any intervention. This study did not set out to investigate causes of compliance however a change in filter design to reduce user burden has been suggested before [44]. This should be coupled with behavior change interventions as suggested in other literature [89] as a change in filter design alone may not guarantee increased 
compliance. Compliance may have been affected by factors we experienced in the field explained further below:

\section{Field experiences with LSF filter}

The filters often suffered some degree of blockage especially during the dry season when available ground water was more turbid than usual. A more porous pre-filter supplied with the device or technique to reduce turbidity before filtering could reduce episodes of blockage. We often advised the households to first remove turbidity using a disused clean cloth however even though we did not check, this could have been burdensome for some of the households. Households often gave reference to how small the upper bucket was $(2.5 \mathrm{~L})$. This meant that they had to refill it several times each time in between household chores and on farm activities in order to fill the 10L jerrican. Failure to refill would create an airlock in the column and the filter would have to be backwashed to re-ensure a continuous stream of filtered water flowing into the jerrican. Increasing the size of the upper bucket may eliminate this need to constantly re fill which may have affected compliance.

Field workers on some occasions spent time unblocking and replacing parts of the filter during routine household visits. This may indicate that such an intervention may not be able to run independently in the community without adequate support personnel. Until the filter is designed to function with minimal attention from support personnel, this type of intervention can only be scaled up when there are adequate financial resources to support additional staff required.

\section{FUTURE RESEARCH}

- Our study was not powered to investigate effect of zinc fortified water on stunting as an indicator of zinc status [90]. We recommend further effectiveness studies with adequate sample sizes powered to investigate the effect of zinc fortified water on child growth.

- Considering the presence of multiple micronutrient deficiencies in areas of low socio economic status further studies should investigate the efficacy of this concept with other nutrients and/or more than one nutrient on nutrition status of vulnerable groups such as pre school children. This could ensure that the RNI for vulnerable groups is covered to the greatest extent possible through water fortification.

- Considering the adverse effects of zinc deficiency on birth outcomes such as pre term birth and low birthweight, inconsistent results from zinc supplementation interventions [91, 92], and limited results from effect of zinc cereal fortification on pregnancy and birth outcomes [93], It is worthwhile to investigate efficacy of zinc fortified water on pregnancy and birth outcomes. Efficacy trials are therefore required.

- We show that combining water fortification with food based recommendations improves nutrient adequacy in children 4-6 years old. Further studies should investigate nutrient adequacy achieved by linear modelling in older children or other target groups such as pregnant and lactating women. The feasibility and acceptability of food based recommendations achieved from linear modelling must be investigated in the communities intended for their use.

- Considering that plasma zinc was unresponsive to intervention, future research should focus on finding novel zinc biomarkers more sensitive to small changes in dietary zinc intake and reflecting long term zinc status. 
- The role of zinc at higher supplementation rates as an immune-modulator is well established. Future studies designed as dose response studies should aim to test our hypothesis that the low amount of zinc in the fortified water may have amplified the immune response as shown by high prevalence of the acute phase protein AGP in the intervention group

- Future research should aim at achieving a consensus on approaches for correcting nutritional biomarkers for the presence of inflammation. 


\section{REFERENCES}

1. Margetts BM, Vorster HH, Venter CS: Evidence-based nutrition: the impact of information and selection bias on the interpretation of individual studies. South African J Clin Nutr , 16:79-87.

2. Sifuna P, Oyugi M, Ogutu B, Andagalu B, Otieno A, Owira V, Otsyula N, Oyieko J, Cowden J, Otieno L, Otieno W: Health \& Demographic Surveillance System Profile: The Kombewa Health and Demographic Surveillance System (Kombewa HDSS). Int J Epidemiol 2014, 43:1097-1104.

3. Gartlehner G, Hansen RA, Nissman D, Lohr KN, Carey TS: A simple and valid tool distinguished efficacy from effectiveness studies. J Clin Epidemiol 2006, 59:1040-8.

4. Grady C: Payment of clinical research subjects. J Clin Invest 2005, 115:1681-1687.

5. Grant RW, Sugarman J: Ethics in Human Subjects Research: Do Incentives Matter? J Med Philos 2004, 29 (6):717-738.

6. Mazor KM, Clauser BE, Field T, Yood RA, Gurwitz JH: A demonstration of the impact of response bias on the results of patient satisfaction surveys. Health Serv Res 2002, 37:1403-17.

7. Hambidge KM, Krebs NF, Westcott JE, Miller L V.: Changes in zinc absorption during development. J Pediatr 2006, 149:S64-S68.

8. Guerrant RL, DeBoer MD, Moore SR, Scharf RJ, Lima AAM: The impoverished gut--a triple burden of diarrhea, stunting and chronic disease. Nat Rev Gastroenterol Hepatol 2013, 10:220-9.

9. Prendergast A, Kelly P: Enteropathies in the developing world: neglected effects on global health. Am J Trop Med Hyg 2012, 86:756-63.

10. Manary MJ, Abrams SA, Griffin IJ, Quimper MM, Shulman RJ, Hamzo MG, Chen Z, Maleta K, Manary MJ: Perturbed Zinc Homeostasis in Rural 3-5-y-Old Malawian Children Is Associated With Abnormalities in Intestinal Permeability Attributed to Tropical Enteropathy. Pediatr Res 2010, 67:671-675.

11. Lindenmayer GW, Stoltzfus RJ, Prendergast AJ: Interactions between Zinc Deficiency and Environmental Enteropathy in Developing Countries. Adv Nutr An Int Rev J 2014, 5 (1 ):1-6.

12. Cui L, Hung JHM, Wang SJ, Tsong Y: Issues Related to Subgroup Analysis. In Proceedings of the Annual Meeting of the American Statistical Association,; 2001.

13. Davis RE, Couper MP, Janz NK, Caldwell $\mathrm{CH}$, Resnicow K: Interviewer effects in public health surveys. Health Educ Res 2010, 25:14-26.

14. Paulhus DL: Measurement and control of response bias. In Measures of Personality and Social Psychological Attitudes. Volume 1. Edited by Robinson J, Shaver P, Wrightsman LS. Elsevier; 1991.

15. Franke RH, Kaul JD: The Hawthorne Experiments: First Statistical Interpretation. $A m$ Sociol Rev 1978, 43:623-643.

16. McCarney R, Warner J, Iliffe S, van Haselen R, Griffin M, Fisher P: The Hawthorne Effect: a randomised, controlled trial. BMC Med Res Methodol 2007, 7:30.

17. Thompson F, Subar A: Dietary assessment methodology. In Nutrition in the Prevention and Treatment of Disease. 2nd edition. Edited by Coulston A, Boushe Cj. Burlington, MA; 2008.

18. Gibson R, Fergurson E: An Interactive 24-Hour Recall for Assessing the Adequacy of Iron and Zinc Intakes in Developing Countries. Washington DC: International Life Sciences Institute; 1999.

19. Sehmi J: National Food Composition Tables and the Planning of Satisfactory Diets in Kenya. Nairobi Kenya: Government Press; 1993.

20. Greenfield H, Southgate DAT: Food Composition Data: Production, Management, and Use. Food \& Agriculture Org.; 2003.

21. Brown KH, Rivera JA, Bhutta Z, Gibson RS, King JC, Lonnerdal B, Ruel MT, Sandtrom B, Wasantwisut E, Hotz C: International Zinc Nutrition Consultative Group (IZiNCG) technical document \#1. Assessment of the risk of zinc deficiency in populations and options for its control. Food Nutr Bull 2004, 25(1 Suppl 2):S99-203. 
22. Golden M: Zinc in Human Biology. London: Springer London; 1989. [ILSI Human Nutrition Reviews]

23. Wallock LM, King JC, Hambidge KM, English-Westcott JE, Pritts J: Meal-induced changes in plasma, erythrocyte, and urinary zinc concentrations in adult women. Am J Clin Nutr 1993, 58:695-701.

24. Hess SY, Peerson JM, King JC, Brown KH: Use of serum zinc concentration as an indicator of population zinc status. Food Nutr Bull 2007, 28:S403-429.

25. Allen L, de Benoist B, Dary O, Hurrell RF (Eds): WHO / Guidelines on Food Fortification with Micronutrients. World Health Organization; 2006.

26. Young GP, Mortimer EK, Gopalsamy GL, Alpers DH, Binder HJ, Manary MJ, Ramakrishna BS, Brown IL, Brewer TG: Zinc deficiency in children with environmental enteropathydevelopment of new strategies: report from an expert workshop. Am J Clin Nutr 2014, 100:1198-1207.

27. Galetti V, Mitchikpè CES, Kujinga $P$, Tossou F, Hounhouigan DJ, Zimmermann MB, Moretti D: Rural Beninese Children Are at Risk of Zinc Deficiency According to Stunting Prevalence and Plasma Zinc Concentration but Not Dietary Zinc Intakes. J Nutr, 2016 Jan 1;146 (1):114-23.

28. Bern C, Martines J, de Zoysa I, Glass RI: The magnitude of the global problem of diarrheal disease: a ten-year update. Bull World Health Organ 1992, 70:705-14.

29. Ramakrishnan R, Venkatarao T, Koya P, Kamaraj P: Influence of recall period on estimates of diarrhea morbidity in infants in rural Tamilnadu. Indian J Public Heal 1999, 43:1369.

30. Alam N, Henry F, Rahaman M: Reporting errors in one-week diarrhea recall surveys : experience from a prospective study in rural Bangladesh. Int J Epidemiol 1989, 18:697700.

31. Boerma JT, Black RE, Sommerfelt AE, Rutstein SO, Bicego GT: Accuracy and Completeness of Mothers' Recall of Diarrhea Occurrence in Pre-School Children in Demographic and Health Surveys. Int J Epidemiol 1991, 20:1073-1080.

32. Thomas RJ, Ramanujam K, Velusamy V, Puthupalayam Kaliappan S, Kattula D, Muliyil J, Kang G: Comparison of fieldworker interview and a pictorial diary method for recording morbidity of infants in semi-urban slums. BMC Public Health 2015, 15:43.

33. Wiseman V, Conteh L, Matovu F: Using diaries to collect data in resource-poor settings: questions on design and implementation. Heal Policy Plan 2005, 20 (6):394-404.

34. Verbrugge LM: Health diaries. Med Care 1980, 18:73-95.

35. Wheeler L, Reis HT: Self-Recording of Everyday Life Events: Origins, Types, and Uses. J Pers 1991, 59:339-354.

36. Rothman K: Epidemiology.An Introduction. Oxford, UK: Oxford University Press; 2002.

37. Waitumbi JN, Kuypers J, Anyona SB, Koros JN, Polhemus ME, Gerlach J, Steele M, Englund JA, Neuzil KM, Domingo GJ: Outpatient Upper Respiratory Tract Viral Infections in Children with Malaria Symptoms in Western Kenya. Am J Trop Med Hyg 2010, 83:10101013.

38. Siekmann JH, Allen LH, Bwibo NO, Demment MW, Murphy SP, Neumann CG: Kenyan School Children Have Multiple Micronutrient Deficiencies, but Increased Plasma Vitamin B12 Is the Only Detectable Micronutrient Response to Meat or Milk Supplementation.J Nutr 2003, 133 (11):3972S-3980S.

39. Bwibo NO, Neumann CG: The need for animal source foods by Kenyan children. $J$ Nutr 2003, 133(11 Suppl 2):3936S-3940S.

40. Feikin DR, Bigogo G, Audi A, Pals SL, Aol G, Mbakaya C, Williamson J, Breiman RF, Larson CP: Village-randomized clinical trial of home distribution of zinc for treatment of childhood diarrhea in rural Western kenya. PLoS One 2014, 9:e94436.

41. GOK\&UNICEF: Anaemia and the Status of Iron, Vitamin A and Zinc in Kenya. The 1999 Micronutrient Survey Report. Nairobi; 2002.

42. Larson L, Addo OY, Sandalinas F, Baawo K, Faigao K, Kupka R, Flores-Ayala R, Suchdev P: Accounting for the Influence of Inflammation on Retinol Binding Protein in a 
Population Survey of Liberian Preschool-Aged Children. FASEB J 2015, 29 (1 Supplement ).

43. Raiten DJ, Ashour FAS, Ross AC, Meydani SN, Dawson HD, Stephensen CB, Brabin BJ, Suchdev PS, van Ommen B: Inflammation and Nutritional Science for Programs/Policies and Interpretation of Research Evidence (INSPIRE). J Nutr 2015, 145:1039S-108S.

44. Galetti V: Combining water treatment and zinc fortification against zinc deficiency and diarrhea in low-income settings. Ph.D. thesis. ETH Zurich; 2014.

45. Sian L, Hambidge K, Westcott J, Miller L, Fennessey P: Influence of a meal and incremental doses of zinc on changes in zinc absorption. Am J Clin Nutr 1993, 58:533-536.

46. Valberg L, Flanagan P, Chamberlain M: Effects of iron, tin, and copper on zinc absorption in humans. Am J Clin Nutr 1984, 40:536-541.

47. Sandstrom B, Davidsson L, Cederblad A, Lonnerdal B: Oral Iron, Dietary Ligands and Zinc Absorption. J Nutr 1985, 115:411-414.

48. Sandström B, Cederblad A: Effect of ascorbic acid on the absorption of zinc and calcium in man. Int J Vitam Nutr Res 1987, 115:411-414.

49. Tran CD, Miller L V, Krebs NF, Lei S, Hambidge KM: Zinc absorption as a function of the dose of zinc sulfate in aqueous solution. Am J Clin Nutr 2004, 80:1570-1573.

50. Wegmüller R, Tay F, Zeder C, Brnic M, Hurrell RF: Zinc absorption by young adults from supplemental zinc citrate is comparable with that from zinc gluconate and higher than from zinc oxide. J Nutr 2014, 144:132-6.

51. McDonald CM, Manji KP, Kisenge R, Aboud S, Spiegelman D, Fawzi WW, Duggan CP: Daily Zinc but Not Multivitamin Supplementation Reduces Diarrhea and Upper Respiratory Infections in Tanzanian Infants: A Randomized, Double-Blind, Placebo-Controlled Clinical Trial. J Nutr 2015.

52. Wessells KR, Jorgensen JM, Hess SY, Woodhouse LR, Peerson JM, Brown KH: Plasma Zinc Concentration Responds Rapidly to the Initiation and Discontinuation of Short-Term Zinc Supplementation in Healthy Men. J Nutr 2010, 140 (12 ):2128-2133.

53. Schlesinger L, Arevalo M, Arredondo S, Diaz M, Lönnerdal B, Stekel A: Effect of a zincfortified formula on immunocompetence and growth of malnourished infants. $\mathrm{Am} J$ Clin Nutr 1992, 56 (3 ):491-498.

54. Friis H, Ndhlovu P, Mduluza T, Kaondera K, Sandström B, Michaelsen KF, Vennervald BJ, Christensen NO: The impact of zinc supplementation on growth and body composition: a randomized, controlled trial among rural Zimbabwean schoolchildren. Eur J Clin Nutr 1997, 51:38-45.

55. Ruz M, Castillo-Duran C, Lara X, Codoceo J, Rebolledo A, Atalah E: A 14-mo zincsupplementation trial in apparently healthy Chilean preschool children. Am J Clin Nutr 1997, 66.

56. Sayeg Porto MA, Oliveira HP, Cunha AJ, Miranda G, Guimarães MM, Oliveira WA, dos Santos DM: Linear growth and zinc supplementation in children with short stature. J Pediatr Endocrinol Metab , 13:1121-8.

57. Castillo-Durán C, Rodríguez A, Venegas G, Alvarez P, Icaza G: Zinc supplementation and growth of infants born small for gestational age. J Pediatr 1995, 127:206-11.

58. Dufner-Beattie J, Kuo Y-M, Gitschier J, Andrews GK: The adaptive response to dietary zinc in mice involves the differential cellular localization and zinc regulation of the zinc transporters ZIP4 and ZIP5. J Biol Chem 2004, 279:49082-90.

59. Hess SY, Lönnerdal B, Hotz C, Rivera JA, Brown KH: Recent advances in knowledge of zinc nutrition and human health. Food Nutr Bull 2009, 30(1 Suppl):S5-11.

60. Patel A, Mamtani M, Dibley MJ, Badhoniya $N$, Kulkarni $H$ : Therapeutic value of zinc supplementation in acute and persistent diarrhea: a systematic review. PLoS One 2010, 5:e10386.

61. Galetti V, Kujinga P, Mitchikpè CES, Zeder C, Tay F, Tossou F, Hounhouigan JD, Zimmermann MB, Moretti D: Efficacy of highly bioavailable zinc from fortified water: a randomized controlled trial in rural Beninese children. Am J Clin Nutr 2015, Nov;102(5):1238-48 
62. Joy EJM, Ander EL, Young SD, Black CR, Watts MJ, Chilimba ADC, Chilima B, Siyame EWP, Kalimbira AA, Hurst R, Fairweather-Tait SJ, Stein AJ, Gibson RS, White PJ, Broadley MR: Dietary mineral supplies in Africa. Physiol Plant 2014, 151:208-229.

63. Ferguson EL, Darmon N, Fahmida U, Fitriyanti S, Harper TB, Premachandra IM: Design of Optimal Food-Based Complementary Feeding Recommendations and Identification of Key “Problem Nutrients” Using Goal Programming. J Nutr 2006, 136:2399-2404.

64. Santika O, Fahmida U, Ferguson EL: Development of Food-Based Complementary Feeding Recommendations for 9- to 11-Month-Old Peri-Urban Indonesian Infants Using Linear Programming. J Nutr 2009, 139 (1):135-141.

65. Levesque $\mathrm{S}$, Delisle $\mathrm{H}$, Agueh $\mathrm{V}$ : Contribution to the development of a food guide in Benin: linear programming for the optimization of local diets. Public Health Nutr 2015, 18:622-631.

66. Fahmida U, Kolopaking R, Santika O, Sriani S, Umar J, Htet MK, Ferguson E: Effectiveness in improving knowledge, practices, and intakes of "key problem nutrients" of a complementary feeding intervention developed by using linear programming: experience in Lombok, Indonesia. Am J Clin Nutr 2015, 101 (3 ):455-461.

67. Ramakrishnan U: Prevalence of Micronutrient Malnutrition Worldwide. Nutr Rev 2002, 60:S46-S52.

68. Muthayya S, Rah JH, Sugimoto JD, Roos FF, Kraemer K, Black RE: The global hidden hunger indices and maps: an advocacy tool for action. PLoS One 2013, 8:e67860.

69. Haldar K, Mohandas N: Malaria, erythrocytic infection, and anemia. ASH Educ Progr B 2009, 2009 (1):87-93.

70. Friedman JF, Kanzaria HK, McGarvey ST: Human schistosomiasis and anemia: the relationship and potential mechanisms. Trends Parasitol 2005, 21:386-392.

71. World Malaria Report [http://www.rollbackmalaria.org/files/files/about/9789241564830_eng.pdf]

72. Brooker S, Miguel E, Moulin S, Luoba A, Bundy D, Kremer M: Epidemiology of single and multiple species helminth infections among schoolchildren in Busia district, Kenya. East Afr Med J 2000:279-282.

73. Thiong'o F, Luoba A, Ouma J: Intestinal helminths and schistosomiasis among school children in a rural district in Kenya. East Afr Med J 2001, 78:279-282.

74. Koukounari A, Estambale BBA, Njagi JK, Cundill B, Ajanga A, Crudder C, Otido J, Jukes MCH, Clarke SE, Brooker S: Relationships between anaemia and parasitic infections in Kenyan schoolchildren: a Bayesian hierarchical modelling approach. Int J Parasitol 2008, 38:1663-71.

75. Brooker S, Akhwale W, Pullan R, Estambale B, Clarke SE, Snow RW, Hotez PJ: Epidemiology of Plasmodium-Helminth Co-Infection in Africa: Populations at Risk, Potential Impact on Anemia, and Prospects for Combining Control. Am J Trop Med Hyg 2007, 77 (6 Suppl ):88-98.

76. Vitamin A supplementation coverage rate (\% of children ages 6-59 months) | Data | Table

[http://data.worldbank.org/indicator/SN.ITK.VITA.ZS?order=wbapi_data_value_2013+wba pi_data_value+wbapi_data_value-last\&sort=asc]

77. De Moura FF, Palmer AC, Finkelstein JL, Haas JD, Murray-Kolb LE, Wenger MJ, Birol E, Boy E, Pena-Rosas JP: Are Biofortified Staple Food Crops Improving Vitamin A and Iron Status in Women and Children? New Evidence from Efficacy Trials. Adv Nutr An Int Rev J 2014, 5:568-570.

78. Talsma EF, Brouwer ID, Verhoef H, Mbera GN, Mwangi AM, Demir AY, Maziya-Dixon B, Boy E, Zimmermann MB, Melse-Boonstra A: Biofortified yellow cassava and vitamin A status of Kenyan children: a randomized controlled trial. Am J Clin Nutr .

79. Gannon B, Kaliwile C, Arscott SA, Schmaelzle S, Chileshe J, Kalungwana N, Mosonda M, Pixley $\mathrm{K}$, Masi $\mathrm{C}$, Tanumihardjo SA: Biofortified orange maize is as efficacious as a vitamin $\mathrm{A}$ supplement in Zambian children even in the presence of high liver reserves of vitamin A: a community-based, randomized placebo-controlled trial. Am J Clin Nutr 2014, 100:1541-1550. 
80. Hotz C, Loechl C, Lubowa A, Tumwine JK, Ndeezi G, Nandutu Masawi A, Baingana R, Carriquiry A, de Brauw A, Meenakshi J V, Gilligan DO: Introduction of $\boldsymbol{\beta}$-carotene-rich orange sweet potato in rural Uganda resulted in increased vitamin $A$ intakes among children and women and improved vitamin A status among children. $J$ Nutr 2012, 142:1871-80.

81. Godwin M, Ruhland L, Casson I, MacDonald S, Delva D, Birtwhistle R, Lam M, Seguin R: Pragmatic controlled clinical trials in primary care: the struggle between external and internal validity. BMC Med Res Methodol 2003, 3:1-7.

82. Hambidge KM: Zinc and diarrhea. Acta Paediatr Suppl 1992, 381:82-86.

83. Tornheim JA: The epidemiology of hospitalisation with diarrhea in rural Kenya: the utility of existing health facility data in developing countries. International Journal of infectious diseases. Int J Infect Dis 2010, 14:e499-e505.

84. Adazu K: Health and demographic surveillance in rural western Kenya: a platform for evaluating interventions to reduce morbidity and mortality from infectious diseases. Am J Trop Med Hyg 2005, 73:1151-1158.

85. Lovato LC, Hill K, Hertert S, Hunninghake DB, Probstfield JL: Recruitment for controlled clinical trials: Literature summary and annotated bibliography. Control Clin Trials 1997, 18:328-352.

86. Nyambose J, Koski KG, Tucker KL: High Intra/Interindividual Variance Ratios for Energy and Nutrient Intakes of Pregnant Women in Rural Malawi Show That Many Days Are Required to Estimate Usual Intake. J Nutr 2002, 132 (6 ):1313-1318.

87. Brown KH, Black RE, Becker S: Seasonal changes in nutritional status and the prevalence of malnutrition in a longitudinal study of young children in rural Bangladesh. Am J Clin Nutr 1982, 36:303-313.

88. Willet W: Nutritional Epidemiology. 2nd ed. Oxford, UK: Oxford University Press; 1998.

89. Boisson S, Kiyombo M, Sthreshley L, Tumba S, Makambo J, Clasen T: Field Assessment of a Novel Household-Based Water Filtration Device: A Randomised, Placebo-Controlled Trial in the Democratic Republic of Congo. PLoS One 2010, 5:e12613.

90. Gibson RS, Hess SY, Hotz C, Brown KH: Indicators of zinc status at the population level: a review of the evidence. Br J Nutr 2008, 99(Supplement S3):S14-S23.

91. Darnton-Hill I: WHO | Zinc supplementation during pregnancy. 2013.

92. Chaffee BW, King JC: Effect of zinc supplementation on pregnancy and infant outcomes: a systematic review. Paediatr Perinat Epidemiol 2012, 26 Suppl 1:118-37.

93. Das J, Kumar R, Bhutta Z, Salam R: Systematic Review of Zinc Fortification Trials. Ann Nutr Metab 2013, 62 (suppl 1):44-56. 


\section{Summary}

Zinc deficiency is likely highly prevalent in preschool children in rural Africa. These children mainly subsist on cereal based diets that are high in inhibitors of zinc absorption and suffer from repeated infections such as diarrheal infections that further deplete the body of zinc. It has been observed that in areas with high prevalence of diarrheal infections, zinc deficiency also coexists as a problem of public health significance. Interventions to reduce both diarrheal infections and zinc deficiency can be effective in improving zinc status in vulnerable groups living in these areas. Vestergaard Frandsen has developed a point of use household water filter that purifies water and concomitantly fortifies it with zinc at a range approximately $1-4 \mathrm{mg} / \mathrm{l}$. This household water filter is meant for areas of low socioeconomic status with limited access to improved water sources. Introduction of zinc fortified drink water through Lifestraw Family filter (LSF) strategy offers two benefits: purifying drinking water and secondly improving zinc intake and status, however direct evidence on the public health potential of this approach is lacking

The first chapter provides background information on zinc, functions and metabolism in the body, zinc deficiency, as well as the research questions and a description of the study area. The investigations in this thesis consists of a cross sectional study, an effectiveness study conducted in children 2-6 years old from rural Western Kenya, as well as a stable isotope study conducted in Swiss adults. The research was conducted in rural Western Kenya, Kisumu west district. The study site consisted of 15 villages that lie along Lake Victoria approximately $25 \mathrm{~km}$ from Kisumu town. This rural population lacks access to many basic health care services and poverty is prevalent. The research aimed to investigate the contribution that zinc fortified water would make to dietary zinc intake and effect of daily consumption on zinc status and morbidity in children aged 2-6 years.

In a baseline cross sectional study we first investigated the prevalence of zinc, iron and vitamin A deficiency in pre-school children from rural Western Kenya (Chapter 2). In order to quantify prevalence of deficiency in this population in the presence of inflammation, we compared effect on prevalence estimates of different approaches proposed in literature for correcting nutritional biomarker for the presence of inflammation. The results indicated that zinc and iron deficiency were severe public health problems among the pre-school children affecting $74 \%$ and $61 \%$ of the children respectively. The prevalence did not change substantially after correcting by all applicable approaches (Zn deficiency change range 2-10.2\% when excluding published CF approach), (iron deficiency change range $0.6-10.3 \%$, definition inclusive of sTfR). Vitamin A deficiency affected $34 \%$ of the children and different approaches changed the prevalence from high to moderate and to a problem of no public health significance. The percent decrease in prevalence ranged from 43-78\%. Regardless of approach used, iron and zinc deficiency was high in this population and of public health importance.

Chapter 3 describes the LSF filter device-with-zinc meant to provide zinc fortified water in areas at elevated risk of zinc deficiency exposed to limited improved water sources. We first conducted a single blind cross over trial in Swiss adults (18-45yrs) to compare zinc absorption from fortified water with zinc absorption from a fortified maize porridge. Absorption was 7 times higher $(65.9 \%)$ from zinc fortified water when consumed alone compared to when 
consumed with maize porridge $(9.8 \%)$ or from fortified maize porridge consumed with water (9.1\%). In order to instruct households on how to use the device, we conducted laboratory experiments to assess effect of volume filtered and idle time on zinc elution from the device. High volumes resulted in lower zinc elution $2 \mathrm{~L} /$ day $(4.7 \pm 1.6 \mathrm{mg} / \mathrm{L}), 10 \mathrm{~L} / \mathrm{d}(1.7 \pm 0.9)$ and $20 \mathrm{~L} / \mathrm{d}$ $(1.3 \pm 0.7 \mathrm{mg} / \mathrm{L})$ whilst increased idle time led to higher zinc elution. The percent increase in zinc eluted after 1 week storage was 23.4\% (2L/d), 82.4\% (10L/d) and 43.1\% (20L/d). After a second week of storage zinc elution further increased by $56.9 \%(2 \mathrm{~L} / \mathrm{d}), 12.9 \%(10 \mathrm{~L} / \mathrm{d})$ and $7.5 \%(20 \mathrm{~L} / \mathrm{d})$, compared to the last week of filtering. This led to the conclusion that zinc fortified water should be consumed away from meals for high bioavailability. The filter should be used regularly with higher quantities of water for adequate and safe zinc concentrations. The filter is more resilient to idle time when used with higher volumes of water.

Chapter 4 describes the effectiveness study conducted with children 2-6 years old from rural Western Kenya to investigate whether zinc fortified water when provided daily would contribute to dietary zinc intake and if this would translate to improved plasma zinc, growth and reduced morbidity. Eligible children $(n=184)$ were randomised to 2 intervention groups; LSF with zinc group and LSF without zinc group. We found that daily consumption of zinc fortified water at the median rate $\approx 461 \mathrm{ml} / \mathrm{d}$ per child contributed $42 \%$ and $36 \%$ of daily requirements for absorbable zinc in children 2-3 and 4-6 years respectively. A treatment effect was obtained on overall morbidity ( $\mathrm{RR}=0.91 ; 95 \% \mathrm{CI}$ : $0.87,0.96$ ), morbidity due to colds (RR=0.91; 95\%CI: $0.83,0.99)$ and stomach pain ( $R R=0.70 ; 95 \% \mathrm{CI}:=0.56,0.89)$ and a significant reduction for diarrhea in the per protocol analysis, $(\mathrm{RR}=0.72 ; 95 \% \mathrm{CI}$ : $=0.53,0.96)$. There was no treatment effect on plasma zinc concentration or on stunting.

In chapter $\mathbf{5}$ we designed food based recommendations that would be required to accompany introduction of zinc fortified water in children aged 4-6 years old to ensure nutrient adequacy. We formulated the following set of FBRs in the modelling exercise :1) whole grain products, unfortified (14 serves per week), 2) fluid or powdered milk unfortified (7 serves per week), 3) nuts and seeds (4 serves per week), 4) vitamin A rich vegetables (7 serves per week), 5) other starchy plants (7 serves per week), 6) vitamin C rich vegetables (7 serves per week) and 7) small whole fish with bones (7 serves per week). These FBRs achieved nutrient adequacy for all nutrients except for vitamin A $(25 \% \mathrm{RNI})$ and folate $(68 \% \mathrm{RNI})$. We concluded that additional interventions would be required to close the remaining nutrient gaps for vitamin $A$ and folate.

Finally chapter 6 discusses the main findings and conclusions of this thesis in a broader public health context and provides recommendations for further research. Overall, research from this thesis has shown that in pre-school children at elevated risk of zinc deficiency living in areas with limited access to improved water sources, zinc fortified water is capable of contributing to dietary zinc intake and reducing morbidity due to colds, stomach pain and diarrhea. Food based recommendations are required to accompany a single nutrient intervention such as this one in order to achieve overall nutrient adequacy. This thesis provides evidence on the effectiveness of this household based zinc fortified water intervention approach. Future research should focus on improving the zinc delivery method. Feasibility and acceptability of FBRs produced by linear programming must be tested in a real setting. We also show that with high prevalence of zinc and iron deficiency, the approach used to correct biomarker for inflammation does not lead to a substantial difference in prevalence. 


\section{Acknowledgements}

Better is the end of a matter than the beginning thereof Eccl 7 vs 8 . It is hard to believe I am writing this section of the thesis. It is with great pleasure that I take this opportunity to thank all the people and institutions who contributed to this project in one way or the other. Without your steadfast commitment this project would not have been possible.

In Kenya I would like to thank the community of East Seme, the caregivers and the children, the Chief, Assistant chief, village elders, pastors and school heads. You accepted me and embraced this project. This made the research possible. The Lab technicians namely Aurthur and Ben. You were so good with the children and were always on time. The drivers Bob, Geoffrey, Bonface, Ben and George. Thank you for safely taking us to and from the field. All field assistants: Florence, Joshua, Leah, Zadock, Wycliff, Christine, Emma, Nelson Mandela, Tobias, enumerators: Dedan, Maureen, Febronne, Mercy and Collins Asweto. I will never forget you. You walked long distances on foot in the sun, wind and rain, carried boxes and boxes of filters all this with a smile and maintained a good rapport with the community. You were my vital link with the households. I wish you success in all that you will do. To Philip Ndemwa our Nairobi link. Thank you for submitting our protocols to the ethical committee and checking now and again for the approvals.

To Prof Michael Zimmerman, It was a great honour working alongside such a revered scientist like you. I appreciate the direction you gave to the project. I admire your ability to create ideas. Your contribution was invaluable.

My deepest gratitude to Diego Moretti, you were there every step of the way. You sharpened my intellectual skills and were very patient with me. You are a solid scientist and I will always admire and respect that about you. Your constructive criticism and comments were valuable in shaping the researcher I am today. Thank you also for taking time to show me around Zurich the times I was in Switzerland. You made my stay comfortable and pleasant.

To Inge D Brouwer. You joined the project during the planning stage of the effectiveness trial and immediately assumed so many roles, supervisor, teacher, accountant etc. All the times you encouraged me and believed in me. You were available to me all the time without fail, heaped me with references, and posed more questions than answers and this taught me to think critically and deeply. I will always be grateful to you and for the necessary push when it seemed we would not meet our deadlines.

Conducting work in Kenya would not have been possible without the assistance of two remarkable women. Pauline, i remember our first meeting in Kisumu in a coffee shop where Diego and I presented the project to you. It was nice that you agreed to be part of the project. You bailed us out of many sticky situations in the field with your ability to 'talk' to the community. I really appreciate all you did from inception of the project right to the end.

To Elizabeth Opiyo, you were my vital link to the field workers and community. We spent so much time together and became friends more than workmates. You were the best research assistant any project could have and im so glad you have started on a $\mathrm{PhD}$ in Canada! I wish you success in your studies. 
Valeria, our journeys and experiences were similar. You assisted me during the critical times and sharpened my analytical skills. You were so easy to work with. I admire your personality moreso the scientist in you. Working with you was special and I will always treasure our experiences. I wish you success in all your future endevours. I also take this opportunity to appreciate members of the Human Nutrition lab, ETH Zurich especially Marica and Tanja. Not only did you offer valuable scientific input but you invited me into your homes. It meant a lot to me..

A special thank you to Karin Borgonjen-van den Berg. You brought out the fun in dietary assessment at the same time training me to collect and analyse high quality data. You made me very comfortable around you, it was nice working with you.

I want at this moment to appreciate Alida Melse-Boonstra because it was you who called me into your office one spring morning in 2010 and told me about the project for the first time. Even though you were not my supervisor you kept up to date with what was going on all the way. Thank you for that continued interest. I enjoyed the occasional chats but most important your great sense of humour.

The staff members of the University of Zimbabwe, Faculty of Science and Institute of Food Nutrition and Family Sciences. I really appreciate your unconditional support. Special mention goes to Prof Muchuweti. Thank you for the administrative support especially at inception of the project.

I would like to appreciate the administrative support I received from Human Nutrition Division especially from Jasmijn Maters. You prepared for my journeys, my stay in the Netherlands and for my permits and always with a pleasant nature and a dash of humour.

To all the MSc Students who conducted their thesis in the project namely-Emma Chimzukira, Britt Broersen, Simone Heeb, Hermine ten Hove, Cecilia Superchi and Viktor Jakab. You were all so enthusiastic and keen. Your contribution was invaluable. I also learnt a lot from you and I wish you well in all your future plans. Ilse my office mate and paranymph. We shared an office for several months. You made a great companion and was very resourceful. Thank you also for agreeing to be my paranymph. All former WUR Phd students- Ciku, Elise, Martin, Laura, your tips and hints assisted me in my journey. I thank you.

In order to survive the Phd journey I heavily relied upon special social structures. Pastor Farai and Busi you lifted me up when I was down. You always had something positive and pleasant to say. Everything made sense because of your preaching. Edna and Elton- always available and so accommodating. You made Wageningen feel like a home away from home. The Amazing grace parish family-It is because of you, that i felt renewed every Sunday. You were a vital part of my life abroad and kept me grounded spiritually.

The Zimbabwe community in Netherlands. All students who came and went, who I conversed with even for just a minute. I cannot list you all but know that I thank you.

To the following Zimbabwean Phd students starting with Juliet Mubaiwa, thanks for the 6am power walk or power talk as you called it. The therapy was worth it. Ruth Ngadze and your unending antidotes I benefited from, still benefit from and will continue to benefit from. Lesley Macheka our journeys were similar, sharing our academic experiences made part of the journey lighter. Thank you for assisting with the initial cover design and ideas. Faith Manditsera now and 
again our little chats proved useful to me. The Kenya community in the Netherlands you made me feel like a Kenyan and made sure I was part of all your celebrations and festivities.

I am greatly indebted to my family. To Tatenda. I would need a separate chapter just to express my gratitude. You waited patiently for me all the times I was away. I cherish your honesty, transparency and accountability. You became all in one to Michy in my absence; dad, mum, nurse, doctor, pharmacist, teacher, playmate, disciplinarian.......the list is endless. You were there every step of the way urging me on. You made/always make my life so comfortable. I know this section would not be complete if I don't thank our pets, that kept you company all these years; Paddy and all the bullogs, tyson and all the pitbulls, the jack russels; george (RIP), sister, terminator and last but not least new addition Ruby the boerbul. To Michy, You always said to me on my way to the airport "don't worry mum I'll be fine'. You were mature beyond your years and knew if mom worried she would not work well. Intelligent and beautiful you are the best daughter anyone could ever have.

My siblings-my young sister and personal nurse Tendai, my prayer warriors: Karen and Sabina. You gave me enormous strength because you believed in me. My brothers Kenny, Harris, Victor Keith and Terry-I could see you cheering me on by the sidelines. I know you wished me well every step of the way and so I thank you and I appreciate you. To my parents in law, you took over from where my parents left off and continued to mould me into who I am today. I have learnt a lot from you. To My mum in law. This is the part where words fail me. You played role of a mother to a baby in diapers (Michy) all over again and yet your last born was married and long gone from home. But you did this so that I could pursue my education. In short you gave me wings to fly. Both you and dad took care of Michy in my absence. I feel very priviledged and spoilt because of you. My sisters in law, Tariro Kunaka, Vimbai Fambisai and Ropafadzo Sibanda. You are a blessing to me and you continue to be a blessing to my life. I love you all so much from the bottom of my heart. My brother in law Dr Dennis Chopera. You inspire me and it's because of you that I felt I could do it. To all Choperas, Nyakakwetos and Kaches. You are so so special to me. I have received nothing from you than first class treatment. You were my perfect wedding present a decade ago.

I thank you all

Makaita basa

Ngiyalibonga lonke! 


\section{About the author}

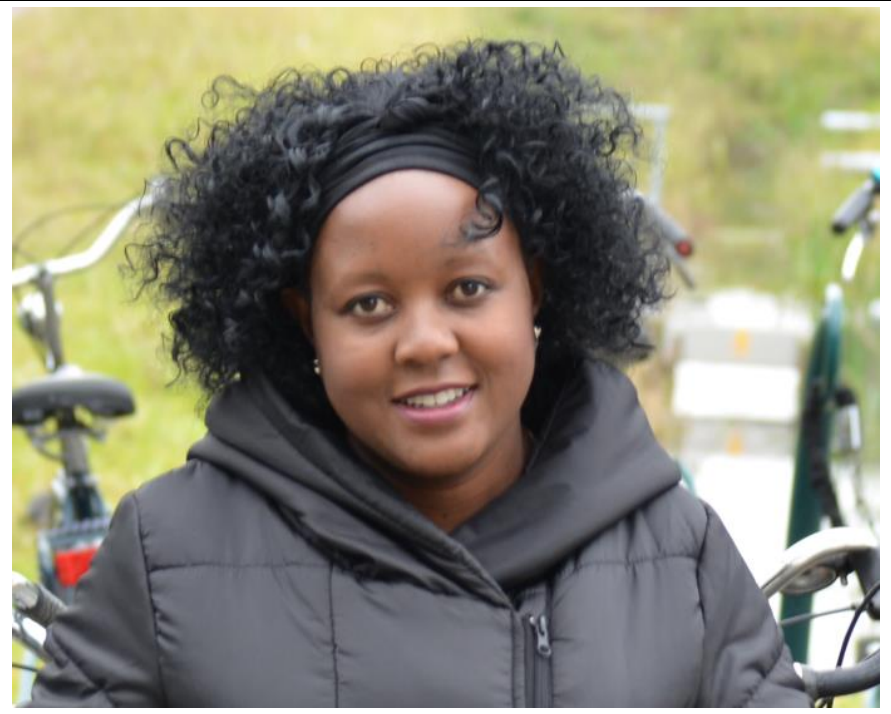

Prosper Kujinga was born on 1 September 1980 in Bulawayo, Zimbabwe. After completing secondary and high school education in Bulawayo, she joined the University of Zimbabwe in August 2000 to pursue a degree in BSc Nutrition. She graduated in 2003 and proceeded to do humanitarian work for 2 years in a food aid Non-Governmental Organization; Help From Germany. Due to her passion for academia, Prosper rejoined the University of Zimbabwe as a teaching assistant from 2005 to 2008. In August 2008 she was granted a NUFFIC fellowship by The Netherlands Government to study for a MSc degree in Nutrition and Health at Wageningen University in The Netherlands. For her MSc thesis, Prosper tested and developed standardized protocols for community level flour fortification with NaFeEDTA. It was during her MSc thesiswork that an opportunity arose in the Division of Human Nutrition for PhD research in the area of water fortification with zinc. Prosper took up the opportunity enthusiastically, and in 2011 she was granted a NUFFIC scholarship to pursue the PhD. For PhD, Prosper studied whether daily consumption of zinc fortified water could improve zinc status and reduce morbidity due to common infections in pre-school children. Additional research she undertook during her $\mathrm{PhD}$ include the development of food based recommendations that would be required to improve overall nutrient adequacy of the diet of the study population. During her PhD programme Prosper was also a Lecturer at the University of Zimbabwe, Faculty of Science, Institute of Food and Nutrition. She taught courses that include: Public Health Nutrition, Nutrition Education and Communication, Clinical Nutrition and Dietetics, Micronutrients and Macronutrients. Prosper in the future intends to combine research and humanitarian work to improve the quality of life for vulnerable population groups of the world. 


\section{List of Publications}

Peer reviewed articles

Galetti V, Mitchikpè CES, Kujinga $\mathbf{P}$, Tossou F, Hounhouigan DJ, Zimmermann MB, Moretti D. Rural Beninese Children Are at Risk of Zinc Deficiency According to Stunting Prevalence and Plasma Zinc Concentration but Not Dietary Zinc Intakes. J Nutr 2016 Jan 1;146 (1 ):114-23.

Galetti V, Kujinga P, Mitchikpè CES, Zeder C, Tay F, Tossou F, Hounhouigan JD, Zimmermann MB, Moretti D. Efficacy of highly bioavailable zinc from fortified water: a randomized controlled trial in rural Beninese children. Am J Clin Nutr 2015 Nov;102(5):1238-48

Kujinga P, Chagwena DT, Mushonga NGT. Food label reading and understanding in parts of rural and urban Zimbabwe, African Health Sciences vol 14 (3) 2014.

Mushonga NGT, Kujinga P, Chagwena DT, Chituwu R, Nyabanga G. A retrospective study of nutritional status of primary school children in Harare. African Journal of Food, Agriculture Nutrition and Development, Vol 14 (3),2014

\section{Abstracts}

Kujinga P, Moretti D, Opiyo E, Andang'o P, Galetti V, Sifuna P, Brouwer I, Zimmerman M. Correcting for inflammation in assessment of childhood nutritional status using correction factors. Abstract presented at Wollongong University, Australia, PhD Tour October 2012

Galetti V, Moretti D, Mitchikpè E, Kujinga P,Tossou F, Hounhouigan J and Zimmermann M. Assessment of zinc Fortification of a Household-Based Water Filtration Device: Zn Absorption Using Stable Isotopes and Efficacy in a Controlled Trial in Beninese School Children. European Journal of Nutrition \& Food Safety, 5(5): 928-929, 2015 


\section{Training activities}

\section{Discipline specific Courses}

Regression Analysis

Logistic Regression

Zinc Stable Isotope analysis

Serum zinc analysis by AAS

CRP analysis by Immulite 2000

Master class-Writing for Scientific Publishing

Dietary Surveys (24hr recall)

Optifood Analysis

NutriScience

Production and use of Food Composition Tables

\section{Conferences and Workshops}

Micronutrient Deficiencies: First 1000 days

Nutrition Congress South Africa

Hidden Hunger Congress

General Courses and Workshops

Sustainable Nutrition Research Africa in years

to come (SUNRAY)

Post-Harvest Management Technologies for

Reducing Aflatoxin Contamination in Maize

Grain and Exposure to Humans

$\begin{array}{ll}\text { Institute and location } & \text { Year } \\ \begin{array}{l}\text { Netherlands Institute for Health } \\ \text { Sciences, Rotterdam, The Netherlands }\end{array} & 2012 \\ \begin{array}{l}\text { Netherlands Institute for Health } \\ \text { Sciences, Rotterdam, The Netherlands }\end{array} & 2012 \\ \text { ETH Zurich, Switzerland } & 2012 \\ \text { ETH Zurich, Switzerland } & 2012 \\ \text { ETH Zurich, Switzerland } & 2012 \\ \text { Nutrition Congress (NCA), South Africa } & 2012 \\ \text { Wageningen UR, The Netherlands } & 2014 \\ \text { Wageningen UR, The Netherlands } & 2015 \\ \text { Wageningen UR, The Netherlands } & 2015 \\ \text { Wageningen UR, The Netherlands } & 2015\end{array}$

Nestle Nutrition Institute Africa (NNIA) 2014 Scientific meeting, Harare, Zimbabwe NCA, South Africa 2012

Hornheim, Germany 2015

SUNRAY, Johannesburg, South Africa 2012

IDRC,UZ and ACF, Harare, Zimbabwe 2014

\section{General Courses}

Philosophy and Ethics in Food Science and

Wageningen UR, THE Netherlands

2015

Nutrition Research

Information Literacy including introduction to

Wageningen UR, THE Netherlands

2015

Endnote

Scientific writing

Wageningen UR, THE Netherlands

2015

\section{Optional Courses and Activities}

Research Proposal development

PhD Excursion to Australia

ETH lab meetings

University of Zimbabwe Staff Seminar

$\mathrm{PhD}$ last stretch workshop

$\begin{array}{ll}\text { Wageningen UR, THE Netherlands } & 2011 \\ \text { Wageningen UR, THE Netherlands } & 2013 \\ \text { ETH Zurich, Switzerland } & 2012-13 \\ \text { UZ, Harare, Zimbabwe } & 2011-14 \\ \text { Wageningen UR, THE Netherlands } & 2015\end{array}$


The research described in this thesis was financially supported by grants/fellowships received from Vestergaard S.A. (Lausanne, Switzerland) and NUFFIC (Netherlands Organisation For International Cooperation in Higher Education)

Financial support from Dr Judith Zwartz Foundation for printing of this thesis is gratefully acknowledged.

Thesis layout by Prosper Kujinga-Chopera

Cover inspired by Prosper Kujinga and designed by GVO drukkers \& vormgevers B.V/Ponsen \& Looijen

Printed by GVO drukkers \& vormgevers B.V/Ponsen \& Looijen, Ede, The Netherlands

(C) Prosper Kujinga-Chopera, 2016 